\title{
The ubiquitin ligase G2E3 modulates cell proliferation, survival and the DNA damage response
}

\section{Dissertation}

\author{
for the award of the degree \\ "Doctor rerum naturalium" (Dr. rer. nat.) \\ in the "Molecular Biology of Cells" Program \\ at the Georg-August-Universität Göttingen, \\ Faculty of Biology
}

submitted by

Franziska Schmidt

born in

Dresden, Germany

Göttingen 2013 


\section{PhD Thesis Committee:}

Prof. Dr. Matthias Dobbelstein, Faculty of Medicine, University of Göttingen (Reviewer)

Prof. Dr. Holger Reichardt, Faculty of Medicine, University of Göttingen (Reviewer)

Prof. Dr. Felix Brembeck, Faculty of Medicine, University of Göttingen

Date of oral exam: August 30, 2013 


\section{Affidavit}

Herewith I declare that I prepared the PhD Thesis "The ubiquitin ligase G2E3 modulates cell proliferation, survival and the DNA damage response" on my own and with no other sources and aids than quoted.

Franziska Schmidt

Göttingen, 28.06.2013 


\section{Acknowledgments}

First of all, I would like to thank my dissertation supervisor Prof. Matthias Dobbelstein for the years of guidance, support and advice that he contributed to my development as a scientist. I am very grateful for his helpful and encouraging ideas and discussions.

I thank my thesis committee members Prof. Holger Reichardt and Prof. Felix Brembeck for their guidance throughout my doctoral training, for their helpful suggestions and discussions and their interest in my project. I thank Prof. Heidi Hahn, Prof. Andreas Wodarz and Prof. Ralph Kehlenbach to serve as my extended committee.

Furthermore, I would like to express my honest gratitude to the Göttingen Graduate School for Neurosciences, Biophysics, and Molecular Biosciences (GGNB) for their constant support and always helpful and friendly communication. Within GGNB, I enjoyed plenty of interesting workshops and excursions and got to know open-minded PhD students including the Wocanet team. Thank you!

I am grateful to those who provided financial support: The doctoral fellowship from the Dorothea Schlözer Program of the University of Göttingen, the Graduiertenkolleg 1034 and GGNB.

Within the Institute of Molecular Oncology, I would like to express my special thanks to all the members I have worked with, be it for years, months or weeks. Especially, I would like to thank Ann-Christine for her exceptionally good work and her contributions to this thesis.

For support concerning lab organization and administration, I would like to say thank you to Antje, Cathrin, Claudia, Kamila, Karola, Kathrin and Patricia.

I am very grateful to all lab members that encouraged me scientifically and personally, who discussed experiments and offered help when needed. Thank you for sharing experiences and thoughts, it was great to work with you! I am also very thankful for friendships that were built and the excellent and inspiring atmosphere in our lab. I especially appreciate

... my office mates Antje, Cathrin, Kamila, Magdalena and Veena for interesting conversations and spontaneous fits of laughter.

... Priyanka, Sai and Veena for giving me the opportunity to gain insight into the Indian culture, to try delicious food and to engage in philosophical conversations. 
... Anna, Daniela, Felix, Frederik, Hannes, Konstantina, Lena, Magali, Monika, Muriel, Ramona, Sonja, Uli and Xin for enjoyable, funny and sometimes controversial discussions in the lunch and coffee breaks.

I also want to thank my friends in- and outside Göttingen that encouraged and supported me. Thank you Benjamin, Benni, Daniel, Esther, Julia, Katrin, Kirstin and Sonja for always having an open ear and to successfully cheering me up in stressful times.

I would like to express my gratitude to my parents Gabriele and Ulrich and my sister Friederike. Thank you ever so much for your continuous support, understanding and encouragement. 


\section{Table of contents}

Table of contents

List of figures. viii

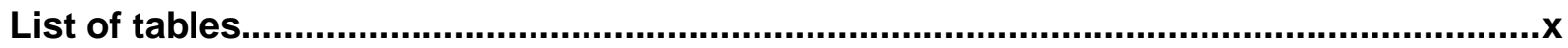

Abbreviations...................................................................................................... xii

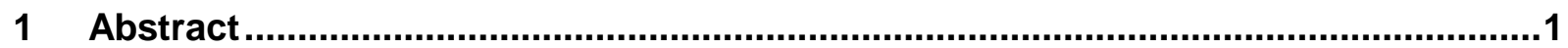

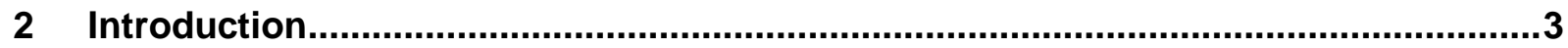

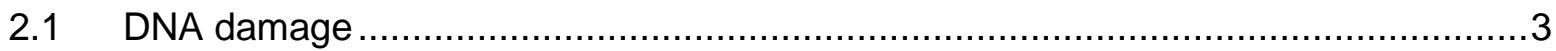

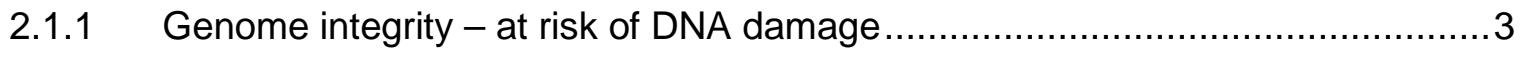

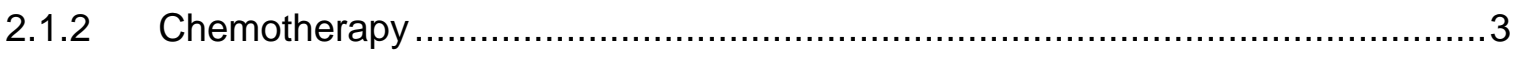

2.1.2.1 DNA-damaging chemotherapeutics..........................................

2.1.2.2 Selected chemotherapeutics: Cisplatin ........................................

2.1.2.3 Selected chemotherapeutics: Neocarzinostatin .................................. 5

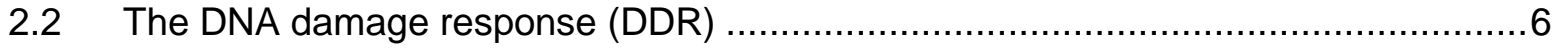

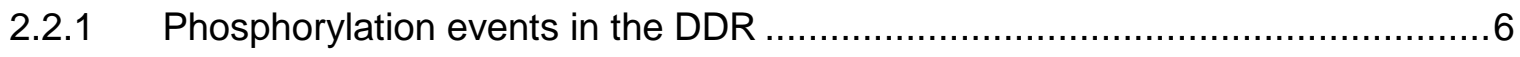

2.2.1.1 ATM-Chk2 pathway as response to DNA double-strand breaks ................. 6

2.2.1.2 ATR-Chk1 pathway as response to single-stranded DNA ....................... 7

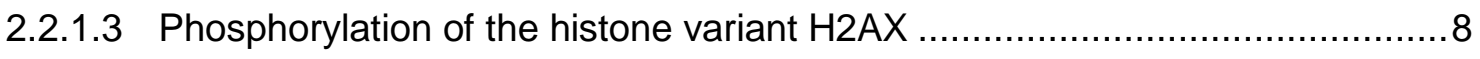

2.2.2 Ubiquitin ligases and deubiquitinating enzymes in the DDR ........................

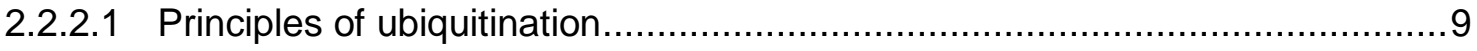

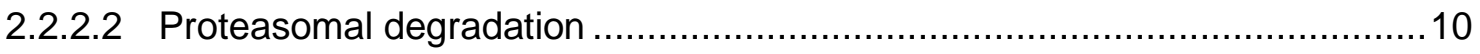

2.2.2.3 Ubiquitin ligases in the DDR to DNA DSBs ..................................... 11

2.2.2.4 The ubiquitin-dependent Fanconi anemia pathway .............................. 11

2.2.2.5 Examples of deubiquitinating enzymes in the DDR ........................... 12 
2.2.3 The DDR after cisplatin treatment.......................................................... 12

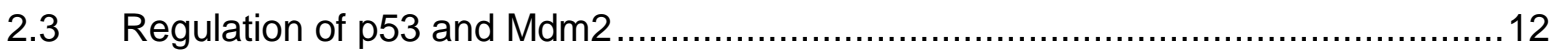

2.3.1 Regulation and post-translational modification of the tumor suppressor p53....12

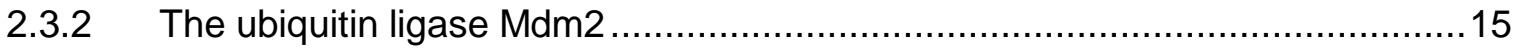

2.3.2.1 Regulation and post-translational modification of Mdm2 ........................ 15

2.3.2.2 Regulation of Mdm2 expression and Mdm2 isoforms ........................... 16

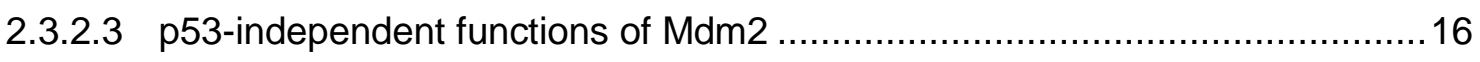

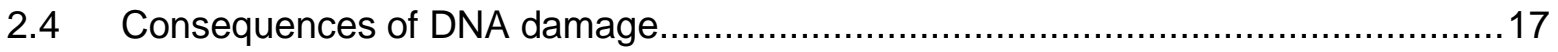

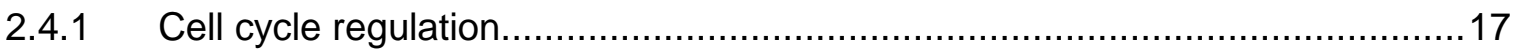

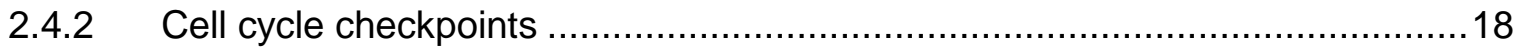

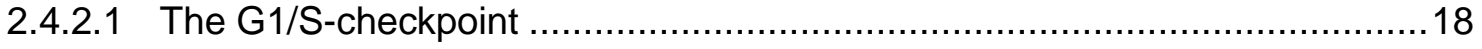

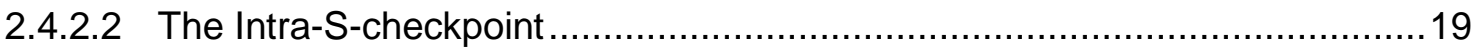

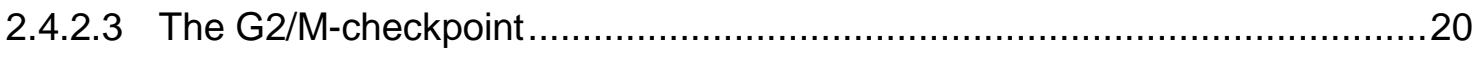

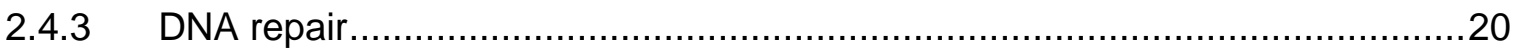

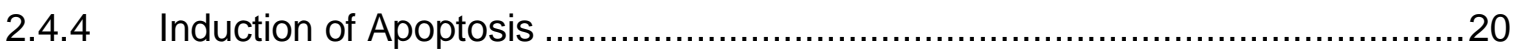

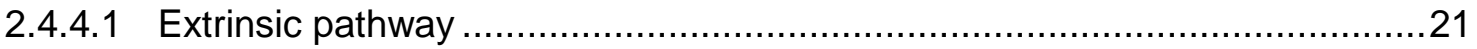

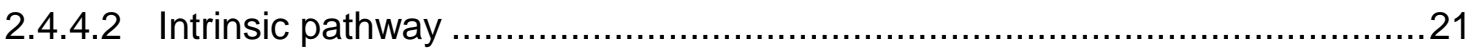

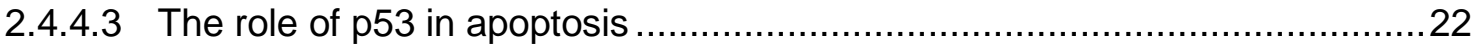

2.4.4.4 Ubiquitination in apoptotic pathways ........................................... 23

2.4.5 Feedback mechanisms between DDR, cell cycle regulation and apoptosis

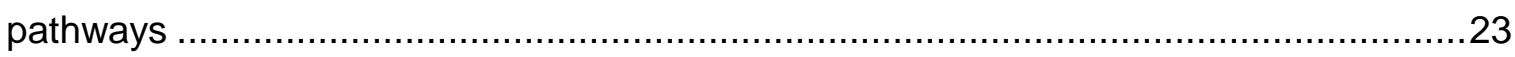

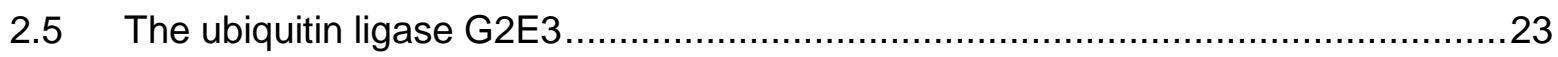

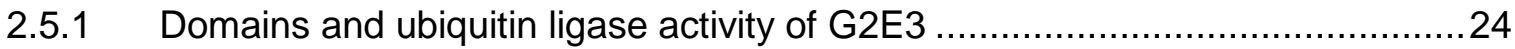

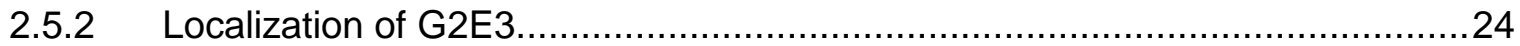

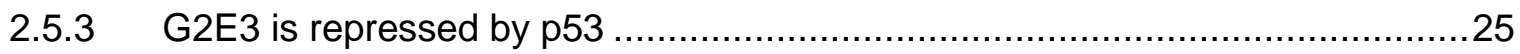

2.5.4 Inactivation of G2E3 in mice and of its ortholog pie in Drosophila ..................25

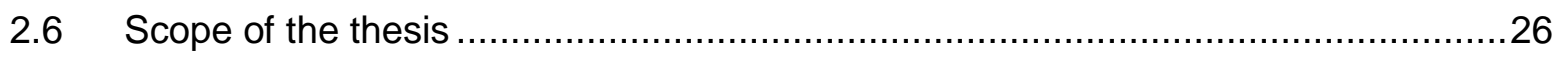




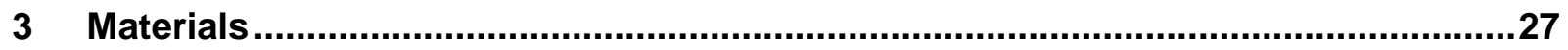

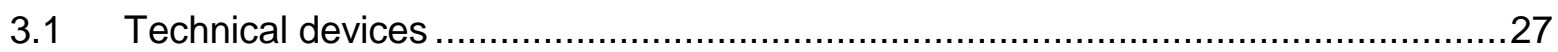

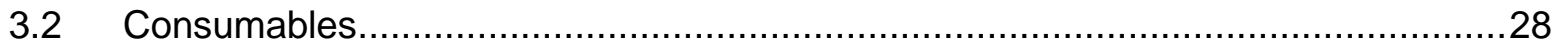

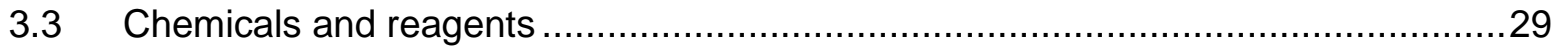

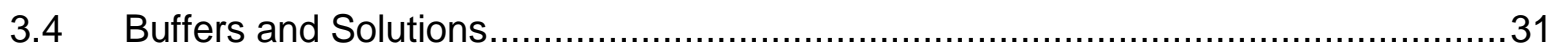

3.5 Chemotherapeutics and pharmacological inhibitors ................................... 32

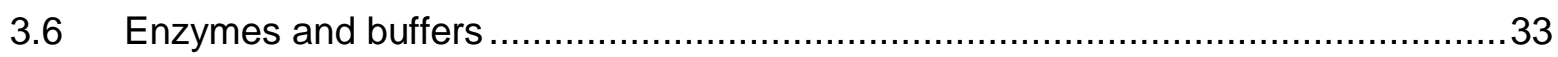

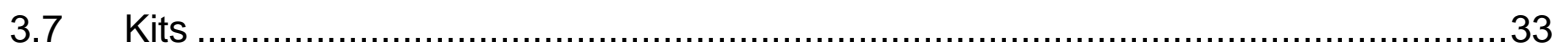

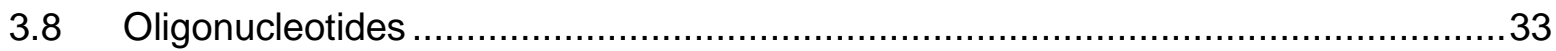

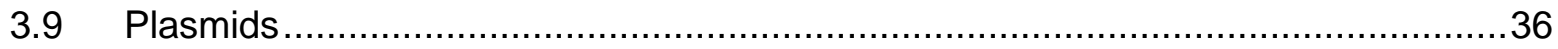

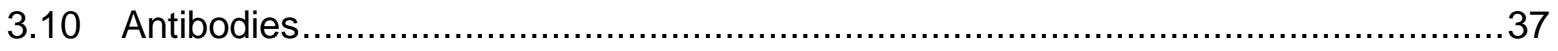

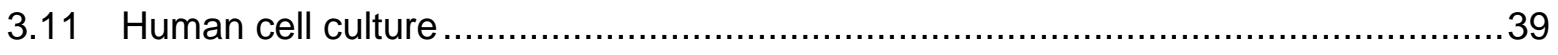

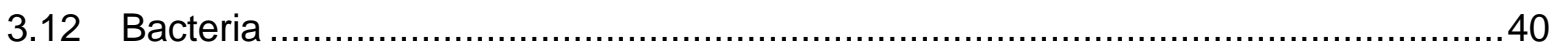

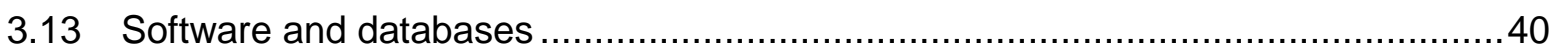

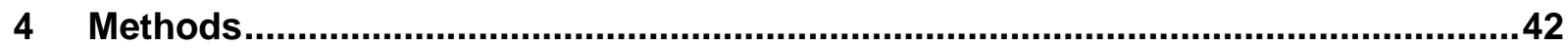

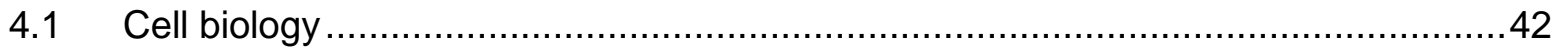

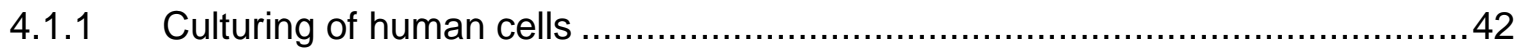

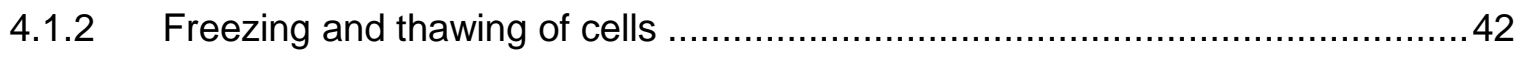

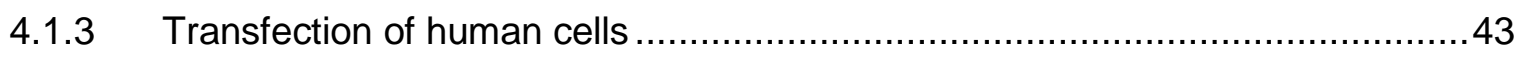

4.1.3.1 Transient transfection with expression vectors ................................ 43

4.1.3.2 Transient transfection with siRNAs................................................... 44

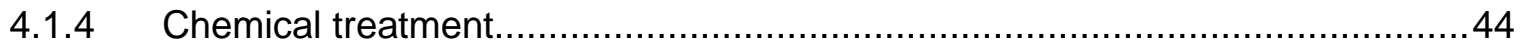

4.1.5 Generation of cell lysates for SDS-PAGE analysis............................... 45

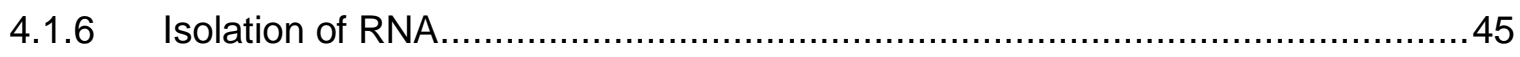

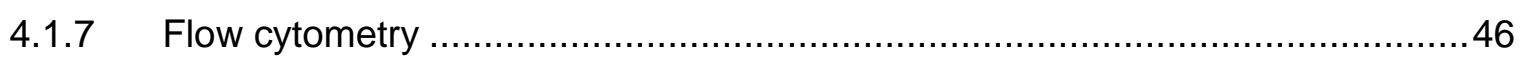

4.1.8 Cell synchronization by double thymidine block .................................4

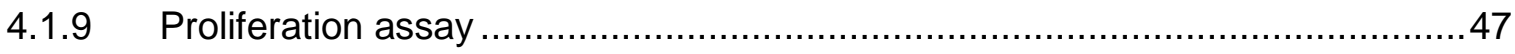




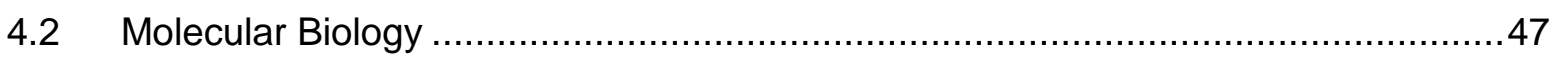

4.2.1 Polymerase chain reaction.............................................................. 47

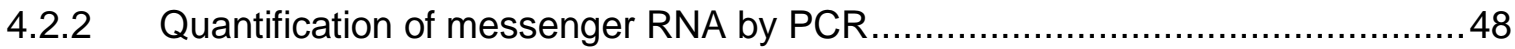

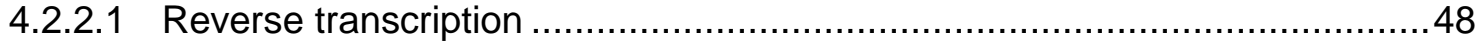

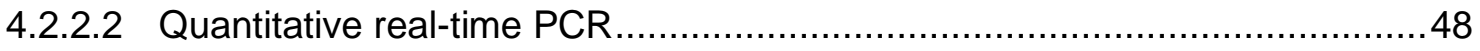

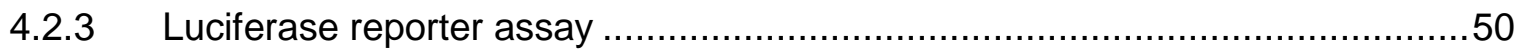

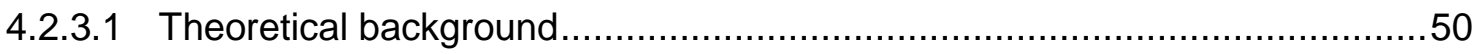

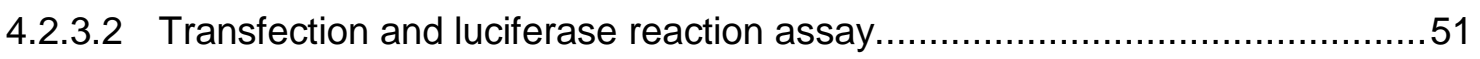

4.2.4 Heat-shock transformation of chemically competent bacteria ........................52

4.2.5 Transformation of electro-competent bacteria.......................................52

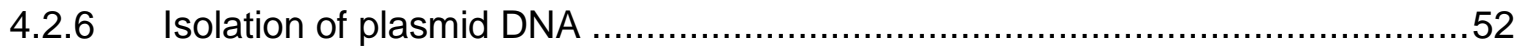

4.2.7 Determination of nucleic acid concentrations ..................................... 52

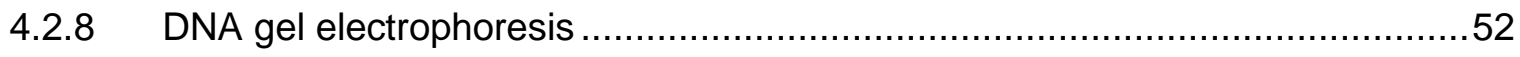

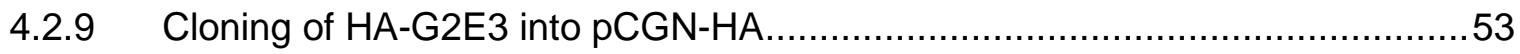

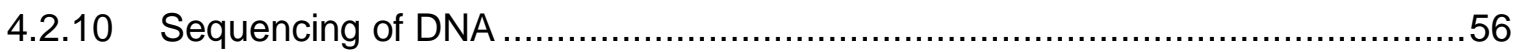

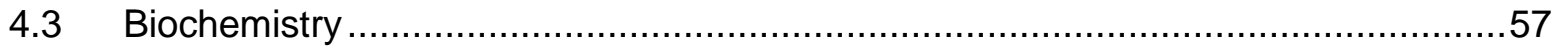

4.3.1 Separation of proteins by SDS-PAGE and Immunoblot analysis ....................57

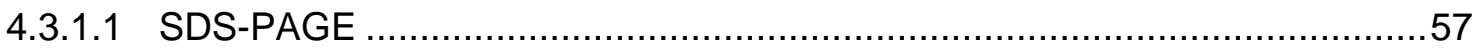

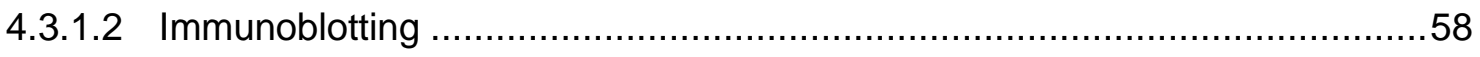

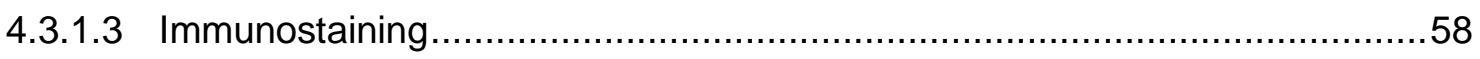

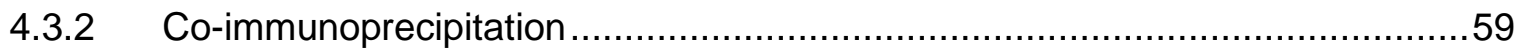

4.3.3 Immunofluorescence staining and microscopy..................................60

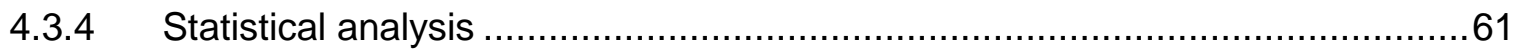

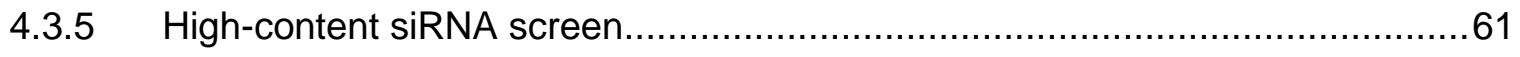

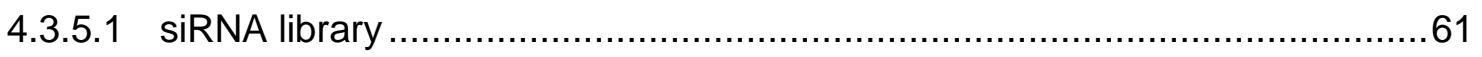

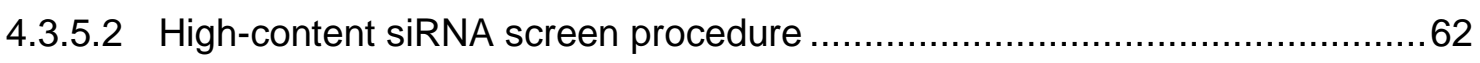

4.3.5.3 High-content siRNA screen data acquisition and analysis ....................... 62

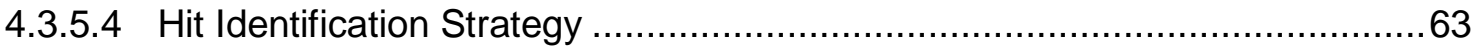


5 Results 64

5.1 A high-content siRNA screen identifies new regulators in the DDR to cisplatin .......64

5.1.1 High-content siRNA screen procedure ................................................. 64

5.1.2 Candidates identified by high-content siRNA screening ............................68

5.2 Investigation of the ubiquitin ligase G2E3 as a regulator of the DDR to cisplatin treatment

5.2.1 Knockdown of G2E3 decreases phosphorylation of H2AX in U2OS cells ........68

5.2.2 G2E3 does not influence pChk1 and pChk2 levels in the DDR to cisplatin ......69

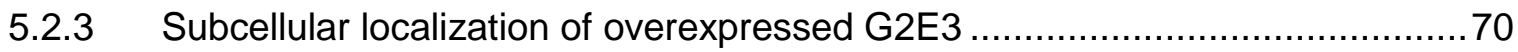

5.3 G2E3 as a regulator of apoptosis and cell cycle ........................................ 72

5.3.1 Knockdown of G2E3 results in p53-independent apoptosis in colon carcinoma and osteosarcoma cell lines. 72

5.3.2 Proliferation rate of cancer cells is decreased following depletion of G2E3 $\ldots . . .74$

5.3.3 Knockdown of G2E3 results in G1-arrest and decreased percentage of cells in S-phase in untreated as well as cisplatin treated U2OS cells.................................. 75

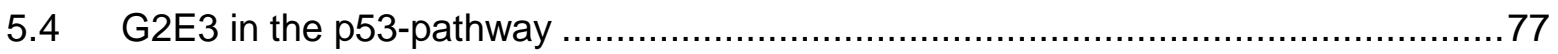

5.4.1 Knockdown of G2E3 results in p53-dependent p21 induction in U2OS cells ....77

5.4.2 Depletion of the p53-pathway regulators RBBP6 and STUB1 results in decreased $\mathrm{yH} 2 \mathrm{AX}$ levels similar to G2E3 knockdown 79

5.4.3 Overexpressed Mdm2 and G2E3 co-localize and relocalize to subnuclear structures in untreated and cisplatin treated cells. 80

5.4.4 Overexpressed G2E3 and Mdm2 are found in a complex..... 83

5.4.5 Mdm2 and p53 interact independently of co-expressed HA-G2E3

5.4.6 An endogenous interaction of G2E3 and Mdm2 is not detectable independent of p53-status.

5.4.7 Overexpressed G2E3 has no impact on p53 transcriptional activity and on Mdm2-dependent inhibition of p53 transactivation 
5.4.8 Co-expression of Mdm2 and HA-G2E3 does not affect their protein levels ......90

5.4.9 Overexpressed HA-G2E3 does not affect Mdm2 and p53 levels in cisplatin treated cells, but HA-G2E3 levels are down-regulated by cisplatin treatment.

5.4.10 Loss of G2E3 results in decreased Mdm2 protein levels after cisplatin and neocarzinostatin treatment independent of p53-status

5.4.10.1 G2E3 knockdown does neither affect Mdm2 mRNA levels nor Mdm2 protein stability .96

5.4.10.2 Apoptosis induced by G2E3 knockdown results in decrease of Mdm2 protein levels in p53-proficient, but not in p53-deficient cells . ... .98

5.5 Regulation of G2E3 expression - G2E3 levels and cell cycle dependency ...........100

5.5.1 G2E3 levels are maximal in G2-phase. 100

5.5.2 Endogenous G2E3 mRNA and protein levels are decreased after DNA damage independent of p53-activation or -status 101

6 Discussion .103

6.1 G2E3 - a DNA damage-responsive, cell cycle-dependent survival factor 103

6.1.1 Summary and implications of our findings. 103

6.1.2 Interdependence of apoptosis and the DNA damage response 104

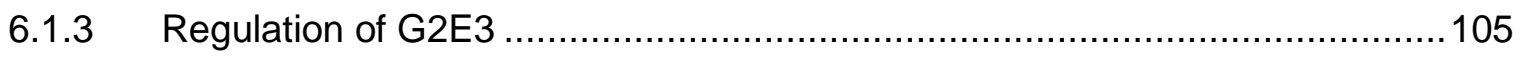

6.1.3.1 DNA damage-responsive regulation of G2E3 mRNA levels ....................105

6.1.3.2 DNA damage-responsive regulation of G2E3 protein levels .................. 106

6.1.3.3 Cell cycle-dependent regulation of G2E3 levels ................................ 107

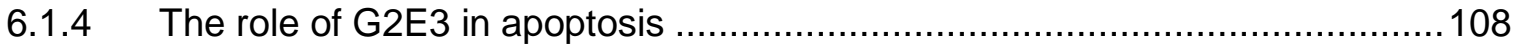

6.1.4.1 How could G2E3 be involved in p53-independent apoptosis? ................. 108

6.1.4.2 Could G2E3 inhibit apoptosis through checkpoint regulation? .................110

6.1.4.3 Does G2E3 protect Mdm2 against caspase cleavage? ........................ 112

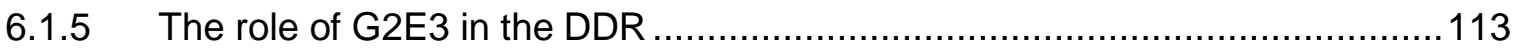

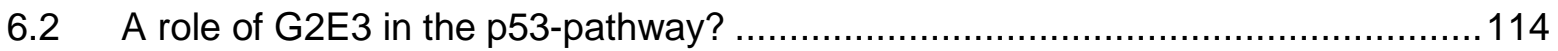

6.2.1 Is G2E3 a new regulator of the p53-pathway? ..................................... 114 
6.2.2 Do G2E3, Mdm2 and p53 interact? ..................................................... 114

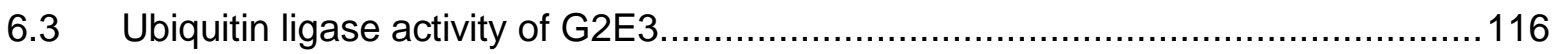

6.4 A high-content siRNA screen to identify new regulators in the DDR to cisplatin....117

6.5 Conclusions and future perspectives .................................................... 119

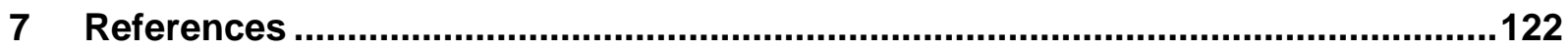




\section{List of figures}

Figure 2.1: Cisplatin mechanism of action .5

Figure 2.2: Kinase signaling in the DNA damage response ........................................

Figure 2.3: Enzymatic cascade of ubiquitination. .................................................... 9

Figure 2.4: The ubiquitin-proteasome pathway. ......................................................... 10

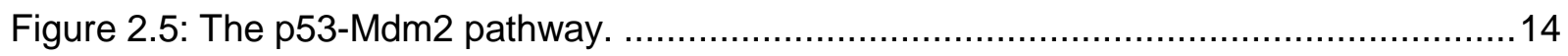

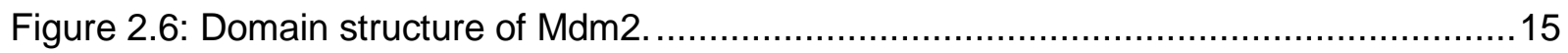

Figure 2.7: Scheme of the mammalian cell cycle................................................. 18

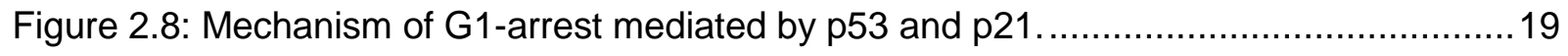

Figure 2.9: Simplified scheme of apoptosis pathways in the cell. ..................................22

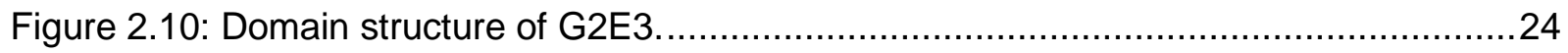

Figure 5.1: High-content siRNA screen procedure to identify new regulators in the DNA damage response to cisplatin.

Figure 5.2: High-content siRNA screen results: The influence of 327 human ubiquitin ligases and 92 DUBs on $\mathrm{H} 2 \mathrm{AX}$ phosphorylation.

Figure 5.3: Knockdown of G2E3 decreases phosphorylation of H2AX in U2OS cells after cisplatin treatment.

Figure 5.4: G2E3 in the DNA damage response after cisplatin treatment: G2E3 knockdown does not influence pChk1 and pChk2 levels.

Figure 5.5: Overexpressed HA-G2E3 localizes to nuclei and subnuclear structures in untreated cells and to nuclei with exclusion from some areas in cisplatin treated cells. 71 Figure 5.6: Knockdown of G2E3 results in apoptosis in colon carcinoma (HCT116) and osteosarcoma (U2OS, SJSA) cell lines. .73

Figure 5.7: Proliferation rate of cells is decreased following depletion of G2E3. .75 Figure 5.8: Knockdown of G2E3 results in G1-arrest and decreased percentage of cells in Sphase in untreated cells. .76 Figure 5.9: Knockdown of G2E3 results in G1-arrest and decreased percentage of cells in S-

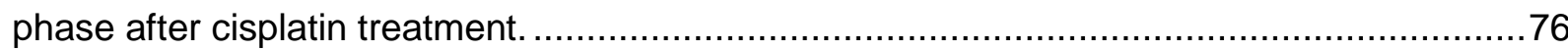
Figure 5.10: Knockdown of G2E3 results in p53-dependent p21 induction in U2OS cells. ....78 Figure 5.11: Knockdown of RBBP6 or STUB1/CHIP decreases phosphorylation of H2AX in U2OS cells. 
Figure 5.12: Overexpressed Mdm2 and G2E3 co-localize and relocalize to subnuclear structures in untreated cells. Co-localization is independent of Mdm2 ubiquitin ligase activity since Mdm2 RING mutant and G2E3 also co-localize.

Figure 5.13: Overexpressed Mdm2 and G2E3 co-localize and relocalize to subnuclear structures in cisplatin treated cells.

Figure 5.14: Overexpressed G2E3 and Mdm2 are found in a complex.

Figure 5.15: Mdm2 and p53 interact independently of co-expressed HA-G2E3. HA-G2E3-

Mdm2-interaction is independent of co-expressed p53. Overexpressed G2E3 and p53 are found in a complex.

Figure 5.16: An endogenous interaction of G2E3 and Mdm2 is not detectable in p53-proficient (U2OS, SJSA) and p53-deficient (H1299 and HCT116 p53 ${ }^{-t_{-}^{-}}$) cell lines.

Figure 5.17: Overexpressed G2E3 has no impact on p53 transcriptional activity and on

Mdm2-dependent inhibition of p53 transactivation. .90

Figure 5.18: Co-expression of Mdm2 and HA-G2E3 does not affect their protein levels.

Figure 5.19: Overexpressed HA-G2E3 does not affect Mdm2 and p53 levels in cisplatin treated U2OS cells. HA-G2E3 protein levels are down-regulated by cisplatin treatment.

Figure 5.20: Decrease in HA-G2E3 protein levels upon cisplatin treatment is not due to proteasome activity, but dependent on apoptosis.

Figure 5.21: Knockdown of G2E3 results in decreased Mdm2 protein levels after cisplatin and neocarzinostatin treatment independent of p53-status.

Figure 5.22: G2E3 knockdown does neither affect Mdm2 mRNA levels nor Mdm2 protein stability.

Figure 5.23: Apoptosis induced by G2E3 knockdown results in decrease of Mdm2 protein levels in p53-proficient, but not in p53-deficient cells.

Figure 5.24: G2E3 levels are maximal in G2-phase. 101

Figure 5.25: Endogenous G2E3 mRNA and protein levels are decreased after DNA damage independent of p53-activation or -status.

Figure 6.1: Model of G2E3 affecting cellular survival. 104 


\section{List of tables}

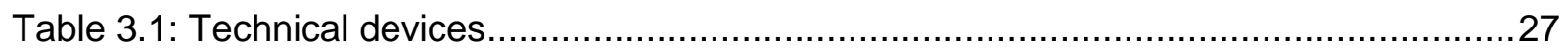

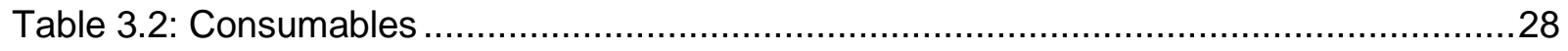

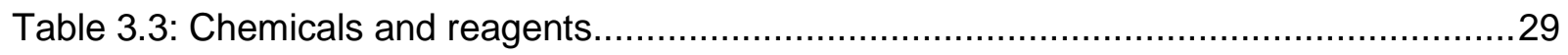

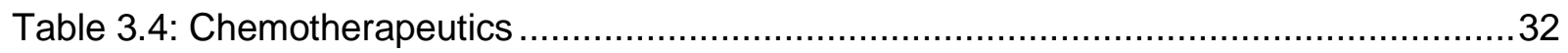

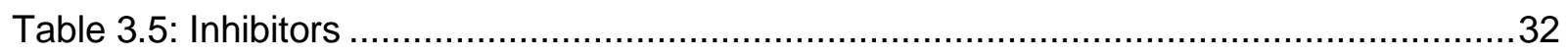

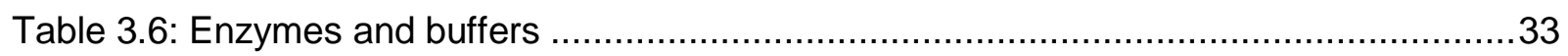

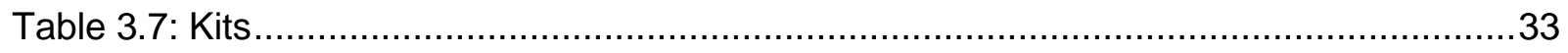

Table 3.8: Small interfering RNAs from Ambion/Life Technologies ...............................34

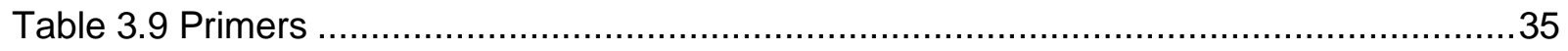

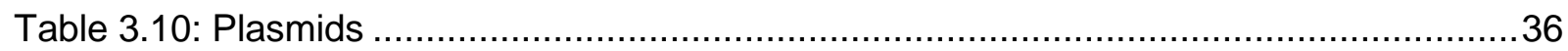

Table 3.11: Primary antibodies for Western blot and co-immunoprecipitation (CoIP) ...........37

Table 3.12: Primary antibodies for immunofluorescence .............................................. 38

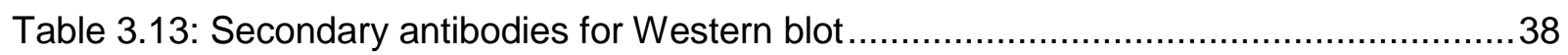

Table 3.14: Secondary antibodies for immunofluorescence ..................................... 38

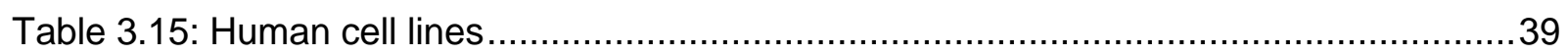

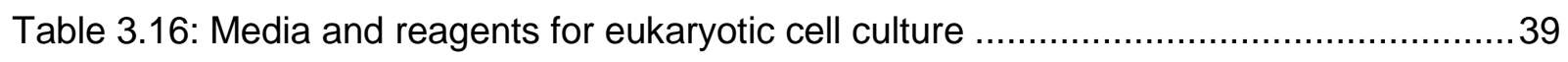

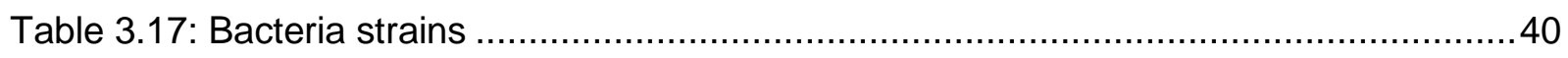

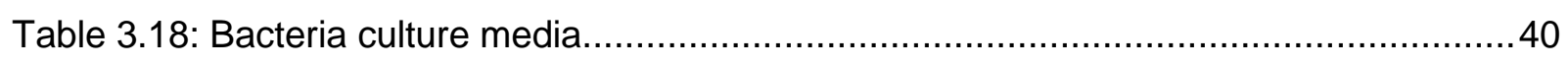

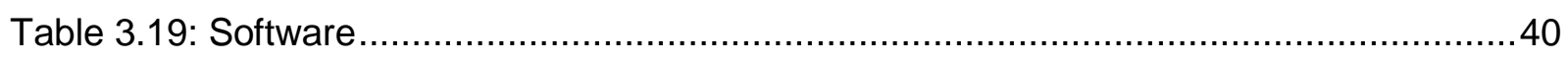

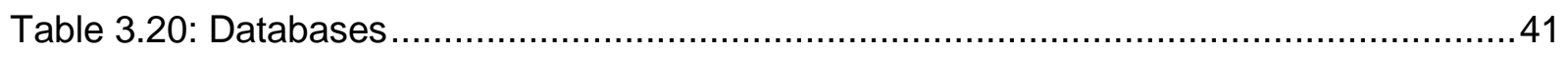

Table 4.1: Culture media for human cell lines .................................................... 42

Table 4.2: Amounts of culture medium without supplements, plasmid DNA and LF2000 for

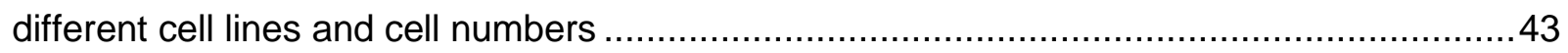

Table 4.3: Amounts of culture medium without supplements, siRNA and LF2000 for different cell lines and cell numbers ............................................................................ 44

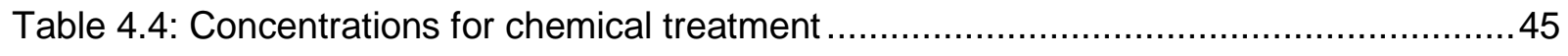

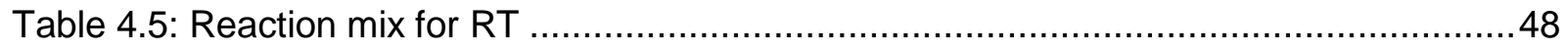

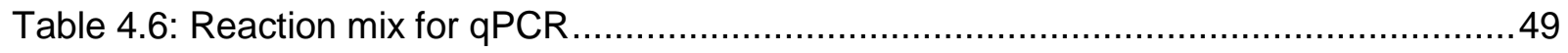

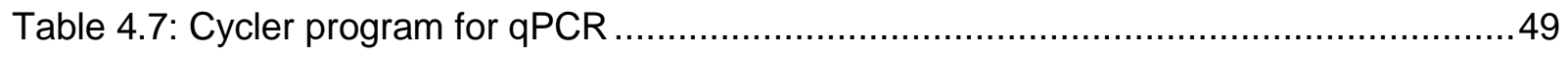

Table 4.8: Program for Dual Luciferase Assay .................................................... 51

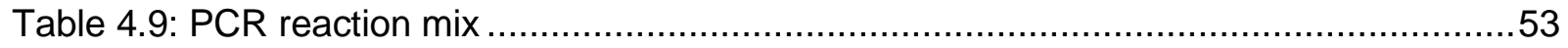

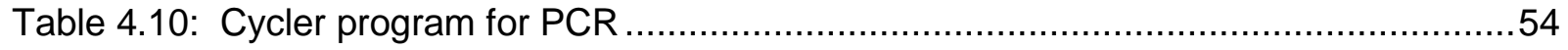


Table 4.11: Reaction mix for restriction digest....................................................... 54

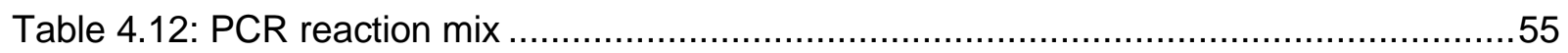

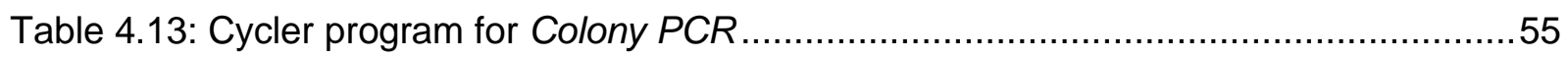

Table 4.14: Cycler program for sequencing PCR ….............................................. 56

Table 4.15: Composition of gels for SDS-PAGE ............................................... 57 


\section{Abbreviations}

\begin{tabular}{|c|c|}
\hline${ }^{\circ} \mathrm{C}$ & Degree Celcius \\
\hline$\mu \mathrm{g}$ & Microgram \\
\hline$\mu \mathrm{l}$ & Microliter \\
\hline$\mu \mathrm{M}$ & Micromolar \\
\hline A & Acrylamide \\
\hline APAF1 & Apoptotic protease activating factor 1 \\
\hline approx. & Approximately \\
\hline APS & Ammonium persulfate \\
\hline ATM & Ataxia telangiectasia mutated \\
\hline ATP & Adenosine triphosphate \\
\hline ATR & ATM- and Rad3-related \\
\hline ATRIP & ATR interacting protein \\
\hline BA & Bisacrylamide \\
\hline bp & Base pair \\
\hline BRCA1 & Breast cancer type 1 susceptibility protein \\
\hline BSA & Bovine serum albumin \\
\hline CARD & Caspase recruitment domains \\
\hline caspase & Cysteine-dependent aspartate-directed protease \\
\hline Cat. No. & Catalogue number \\
\hline CBP & CREB-binding protein \\
\hline CDK & Cyclin-dependent kinase \\
\hline cDNA & Complementary DNA \\
\hline Chk1 & Checkpoint kinase 1 \\
\hline Chk2 & Checkpoint kinase 2 \\
\hline CIAP & Calf Intestine Alkaline Phosphatase \\
\hline C-IAP & Cellular inhibitor of apoptosis \\
\hline CK1 & Casein kinase 1 \\
\hline $\mathrm{cm}$ & Centimeter \\
\hline ColP & Co-immunoprecipitation \\
\hline conc. & Concentration \\
\hline CREB & Cyclic AMP-responsive element-binding protein \\
\hline CRM1 & Chromosome region maintenance 1 protein \\
\hline $\mathrm{C}_{\mathrm{t}}$ & Cycle threshold \\
\hline C-terminus & Carboxy terminus \\
\hline ddNTP & Dideoxynucleotide triphosphate \\
\hline DDR & DNA damage response \\
\hline DISC & Death-inducing signaling complex \\
\hline DMEM & Dulbecco's Modified Eagle Medium \\
\hline DMEM(-) & Dulbecco's Modified Eagle Medium without supplements \\
\hline DMSO & Dimethylsulfoxide \\
\hline DNA & Deoxyribonucleic acid \\
\hline DNA-PK & DNA-dependent protein kinase \\
\hline dNTP & Deoxyribonucleotide triphosphate \\
\hline DSB & Double-strand break \\
\hline DTT & Dithiotreitol \\
\hline DUB & Deubiquitinating enzyme \\
\hline dUTP & Deoxyuridine triphosphate \\
\hline
\end{tabular}




\begin{tabular}{|c|c|}
\hline E6AP & E6-associated protein \\
\hline ECL & enhanced chemiluminescence \\
\hline E.coli & Escherichia coli \\
\hline EDTA & Ethylene diamine tetraacetic acid \\
\hline elF4E & Eukaryotic translation initiation factor $4 \mathrm{E}$ \\
\hline EGTA & Ethylene glycol tetraacetic acid \\
\hline EMT & Epithelial-to-mesenchymal transition \\
\hline ER & Endoplasmic reticulum \\
\hline $\mathrm{EtOH}$ & Ethanol \\
\hline FA & Fanconi anemia \\
\hline FADD & Fas-Associated protein with Death Domain \\
\hline FCS & Fetal calf serum \\
\hline g & Gravitational force \\
\hline G & Guanine \\
\hline G2E3 & G2-specific E3 ligase \\
\hline GFP & Green fluorescent protein \\
\hline GSC & Germline stem cells \\
\hline $\mathrm{h}$ & Hour \\
\hline $\mathrm{H} 2 \mathrm{AX}$ & Histone variant $2 \mathrm{AX}$ \\
\hline HA-tag & Hemagglutinin tag \\
\hline HAUSP & Herpesvirus-associated ubiquitin-specific protease \\
\hline HECT domain & Homologous to the E6AP carboxyl terminus domain \\
\hline HEPES & 4-(2-hydroxyethyl)-1-piperazineethanesulfonic acid \\
\hline hnRNP-K & Heterogeneous nuclear ribonucleoprotein $\mathrm{K}$ \\
\hline HPV & Human papillomavirus \\
\hline HR & Homologous recombination \\
\hline HRP & Horseradish peroxidase \\
\hline hTERT & Human telomerase reverse transcriptase \\
\hline IAP & Inhibitor of apoptosis \\
\hline ICL & Inter-strand crosslink \\
\hline IF & Immunofluorescence \\
\hline IGF-1R & Insulin-like growth factor 1 receptor \\
\hline $\lg G$ & Immunoglobulin G \\
\hline IR & Ionizing radiation \\
\hline kb & Kilobase \\
\hline $\mathrm{kDa}$ & Kilodalton \\
\hline KIU & Kallikrein inactivator unit \\
\hline LF2000 & Lipofectamine $^{\mathrm{TM}} 2000$ \\
\hline lincRNA & Large intergenic noncoding RNA \\
\hline Lys & Lysine \\
\hline M & Molar \\
\hline MAD & Median absolute deviation \\
\hline MAPK & Mitogen activated protein kinase \\
\hline Mbp & Mega base pairs \\
\hline Mdm2 & Mouse double minute 2 \\
\hline MetOH & Methanol \\
\hline $\mathrm{mg}$ & Milligram \\
\hline $\min$ & Minute \\
\hline MK2 & MAPK-activated protein kinase 2 \\
\hline $\mathrm{ml}$ & Milliliter \\
\hline $\mathrm{mM}$ & Millimolar \\
\hline MMR & Mismatch repair \\
\hline
\end{tabular}




\begin{tabular}{|c|c|}
\hline M-MuLV & moloney murine leukemia virus \\
\hline MOMP & Mitochondrial outer membrane permeabilization \\
\hline MRN complex & Mre11-Rad50-Nbs1 complex \\
\hline mRNA & Messenger RNA \\
\hline $\mathrm{n}$ & Sample size \\
\hline Nbs1 & Nijmegen breakage syndrome protein 1 \\
\hline NCS & Neocarzinostatin \\
\hline NES & Nuclear export signal \\
\hline ng & Nanogram \\
\hline NHEJ & Non-homologous end joining \\
\hline NLS & Nuclear localization signal \\
\hline $\mathrm{nM}$ & Nanomolar \\
\hline $\mathrm{nm}$ & Nanometer \\
\hline NP-40 & Nonidet P-40 substitute \\
\hline $\mathrm{n} / \mathrm{a}$ & Not applicable \\
\hline n.s. & Not significant \\
\hline $\mathrm{p}$ & Phospho \\
\hline PAS & Protein A sepharose \\
\hline PBS & Phosphate buffered saline \\
\hline PCAF & p300/CREB-binding protein-associated factor \\
\hline PCNA & Proliferating cell nuclear antigen \\
\hline PCR & Polymerase chain reaction \\
\hline PGS & Protein G sepharose \\
\hline PHD & Plant homeodomain \\
\hline PI & Propidium iodide \\
\hline pie & Pineapple eye \\
\hline PIKK & Phosphatidylinositol 3-kinase related kinase \\
\hline PLK1 & Polo-like kinase 1 \\
\hline PP2A & Protein phosphatase $2 \mathrm{~A}$ \\
\hline PRR & Postreplication repair \\
\hline PSMD & $26 S$ proteasome non-ATPase regulatory subunit \\
\hline PUMA & p53 upregulated modulator of apoptosis \\
\hline $\mathrm{Q}$ & Glutamine \\
\hline qPCR & Quantitative real-time PCR \\
\hline RB & Retinoblastoma protein \\
\hline RBBP6 & Retinoblastoma binding protein 6 \\
\hline RFWD & RING finger and WD repeat domain protein \\
\hline RING domain & Really interesting new gene domain \\
\hline RNA & Ribonucleic acid \\
\hline ROI & Region of interest \\
\hline ROS & Reactive oxygen species \\
\hline RPA & Replication protein A \\
\hline rpm & Rounds per minute \\
\hline RT & Reverse transcriptase \\
\hline SD & Standard deviation \\
\hline SDS & Sodium dodecyl sulfate \\
\hline SDS-PAGE & SDS-polyacrylamide gel electrophoresis \\
\hline sec & Second \\
\hline SEM & Standard error of the mean \\
\hline Ser & Serine \\
\hline SiRNA & Small interfering ribonucleic acid \\
\hline SSB & Single-strand break \\
\hline
\end{tabular}




$\begin{array}{ll}\text { SSDNA } & \text { Single-stranded DNA } \\ \text { tBid } & \text { Truncated Bid } \\ \text { TBST } & \text { Tris buffered saline + Tween } 20 \\ \text { TEMED } & \text { Tetramethylethylenediamine } \\ \text { Thr } & \text { Threonine } \\ \text { TLS } & \text { Translesion synthesis } \\ \text { TNF } & \text { Tumor necrosis factor } \\ \text { Tris } & \text { Trisamine } \\ \text { TUNEL } & \text { Terminal deoxynucleotidyl transferase dUTP nick end labeling } \\ \text { Tyr } & \text { Tyrosine } \\ \text { U } & \text { Unit } \\ \text { untr. } & \text { Untreated } \\ \text { UPS } & \text { Ubiquitin-proteasome system } \\ \text { USP } & \text { Ubiquitin-specific protease } \\ \text { UV } & \text { Ultraviolet } \\ \text { V } & \text { Volt } \\ \text { WB } & \text { Western Blotting } \\ \text { WT } & \text { Wild type } \\ \text { XIAP } & \text { X-chromosome-linked inhibitor of apoptosis protein } \\ \beta-G a l & \beta-G a l a c t o s i d a s e \\ \text { YH2AX } & \text { H2AX phosphorylated on S319 }\end{array}$




\section{Abstract}

The chemotherapeutic cisplatin is widely used to treat various tumors. By inducing crosslinking of DNA, signaling and repair pathways are activated which are referred to as the DNA damage response (DDR). However, the cellular and molecular mechanisms of cisplatin treatment are incompletely understood. We set up a study to find new regulators in the DDR to cisplatin. Since ubiquitination plays a major role in the DDR, we applied a high-content siRNA screen targeting 327 human ubiquitin ligases and 92 deubiquitinating enzymes in U2OS cells. We detected phosphorylation of the histone variant $\mathrm{H} 2 \mathrm{AX}$ (yielding $\mathrm{YH} 2 \mathrm{AX}$ ), a marker for DNA damage. Knockdown of one of the candidates, the ubiquitin ligase G2E3, led to decrease in $\mathrm{YH} 2 \mathrm{AX}$ levels. G2E3 had previously been proposed to play a role in the DDR and in cell survival. However, little was known about the underlying mechanisms. In the work presented here, we show that G2E3 is a DNA damage-responsive, cell cycle-dependent survival factor.

We found that G2E3 mRNA and protein levels are down-regulated upon DNA damage. Knockdown of G2E3 resulted in p53-independent apoptosis and decreased proliferation in colon carcinoma and osteosarcoma cell lines. Furthermore, we verified that G2E3 levels are maximal in G2-phase, suggesting a cell cycle-dependent regulation of G2E3. Hence, we propose that G2E3 acts as a pro-survival factor that protects normal cells against cell death. Upon DNA damage, G2E3 down-regulation contributes to apoptosis.

So far, we did not identify a direct role of G2E3 in the DDR explaining changes in $\mathrm{H} 2 \mathrm{AX}$ phosphorylation. However, we found that knockdown of G2E3 results in G1-arrest and decreased percentage of cells in S-phase in untreated and cisplatin treated U2OS cells. Correspondingly, we observed p53-dependent p21 induction in U2OS cells upon G2E3 depletion. The tumor suppressor p53 becomes activated upon DNA damage and is an important transcription factor for genes involved in apoptosis and cell cycle arrest (e.g. p21). Based on our findings, we propose that after G2E3 knockdown arrested U2OS cells do not continue replicating their DNA and are therefore less prone to DNA damage by cisplatin treatment. This hypothesis is supported by the fact that knockdown of Mdm2, the main negative regulator of $\mathrm{p} 53$, also leads to induction of G1-arrest and exhibits decreased $\mathrm{yH} 2 \mathrm{AX}$ levels upon cisplatin treatment. Interestingly, we found that depletion of the p53-pathway regulators RBBP6 and STUB1 results in decreased $\mathrm{YH} 2 \mathrm{AX}$ levels similar to G2E3 knockdown. This led us to further investigate the role of G2E3 in the p53-pathway. Overexpressed Mdm2 and G2E3 co-localized in subnuclear structures in untreated and cisplatin treated cells. Moreover, overexpressed G2E3 and Mdm2 were found in a complex as seen by co-immunoprecipitation. Mdm2 and p53 interacted independently of co-expressed HA-G2E3, and Mdm2 bound HA-G2E3 independently of co-expressed p53. Thus, G2E3, 
Mdm2 and p53 might form a heterotrimeric complex. In search for the functional role of this interaction, we did not observe an impact of overexpressed G2E3 on p53 transcriptional activity or on Mdm2-dependent inhibition of p53 transactivation. Also, co-expression of Mdm2 and HA-G2E3 did not affect their ubiquitination status or protein levels. However, siRNAmediated depletion of G2E3 resulted in decreased Mdm2 protein levels after cisplatin treatment independently of the p53-status. This result suggests that G2E3 regulates Mdm2 levels independently of p53, the principal transcription factor for Mdm2 expression.

In conclusion, our results suggest that G2E3 is required for cell proliferation and survival. DNA damage induces a strong down-regulation of G2E3 levels, possibly contributing to apoptosis. One of the mechanisms by that G2E3 ensures cell survival appears to consist in the maintenance of Mdm2 levels. 


\section{Introduction}

\subsection{DNA damage}

\subsubsection{Genome integrity - at risk of DNA damage}

The integrity of the genome is a prerequisite for organism development and survival. Additionally, genetic information has to be accurately transmitted from one cell to the daughter cells. This requires correct DNA replication and distribution of chromosomes, but also the capability to cope with DNA damage and to minimize the number of mutations. The cell harbors an efficient genome maintenance machinery to identify and eliminate defects in the DNA. Thus, spontaneous mutations are very rare.

Genome integrity is at risk due to endogenous and exogenous types of DNA damage. Endogenous damage originates from within the cell, e.g. from replication errors while unsuitable nucleotides are incorporated, or from exposure to reactive oxygen species (ROS) caused by metabolic side-products (reviewed in Marnett and Plastaras 2001; De Bont and van Larebeke 2004). On the other hand, exogenous damage is evoked externally by UV-and ionizing radiation (IR), or by cytotoxic agents like antimetabolites and replication inhibitors.

The cellular response to damaged DNA is a very important issue in cancer biology for three reasons (Kastan and Bartek 2004). First of all, DNA damage can cause cancer. This has been shown in different studies of humans and animal models. Furthermore, susceptibility to cancer is often accompanied by mutations in genes involved in the response to DNA damage. Secondly and importantly, DNA-damaging agents are used to treat cancer. As detailed below, chemotherapeutics and radiotherapy are besides surgery the main approaches to medicate cancer. Thirdly and regrettably, side effects of cancer therapy are caused by damaged DNA, too. Examples include accumulation of mutations or cell death of noncancerous cells and induction of leukemia or new tumors years after chemotherapy treatment (Kastan and Bartek 2004).

\subsubsection{Chemotherapy}

\subsubsection{DNA-damaging chemotherapeutics}

Cancer cells are more sensitive to genotoxic stress, leading to a higher rate of mutations. The reasons are defects in the genome maintenance system at various points, e.g. malfunctions in detecting or repairing DNA damage or in inactivating DNA-damaging molecules (reviewed in Jackson and Bartek 2009; Negrini, Gorgoulis et al. 2010). Proteins involved in DNA maintenance are called "caretakers" of the genome (Kinzler and Vogelstein 1997). During tumor progression, their function can get lost by inactivating mutations or gene repression, 
leading to cells sensitive to DNA damage. This fact is used by chemotherapy and also radiotherapy with the aim to kill cancer cells. DNA-damaging chemotherapeutics cause cell cycle arrest and cell death. This occurs either directly or after replication during S-phase. If cells try to replicate damaged DNA, even more cells die: stalled replication forks finally result in highly toxic DNA double-strand breaks (DSBs). In this regard, DNA-damaging agents are more toxic to replicating cells which is advantageous since cancer cells are often characterized by an increased proliferation rate.

Common DNA-damaging drugs include antimetabolites, alkylating agents, replication inhibitors and topoisomerase inhibitors (reviewed in Helleday, Petermann et al. 2008). Antimetabolites, e.g. nucleoside analogs like 5-fluorouracil, inhibit nucleotide metabolism and synthesis of DNA, hence interfere with replication and deplete cells of dNTPS. This leads to base damages and DNA single-strand breaks (SSB). Alkylating agents like mitomycin $\mathrm{C}$ and alkylating-like agents such as cisplatin induce different toxic lesions, i.e. DNA crosslinks, single-stranded DNA, DNA DSBs and bulky adducts. Inhibitors of replication, for example aphidicolin, inhibit DNA polymerases, impair replication fork progression and cause lesions in the DNA like DSBs (Saintigny, Delacote et al. 2001). Furthermore, inhibition of topoisomerases is a common strategy in cancer therapy. Inhibition of topoisomerase II (e.g. by etoposide) causes DNA DSBs. On the other hand, inhibition of topoisomerase I (e.g. by camptothecin) leads to supercoils upstream of replication forks and replication-associated DSBs (Helleday, Petermann et al. 2008).

Remarkably, although most DNA-damaging drugs have been used for years, their detailed mechanisms of actions are mostly not well understood.

Here, we introduce two DNA-damaging agents in more detail which are important for the results obtained.

\subsubsection{Selected chemotherapeutics: Cisplatin}

Platinating agents are used in the clinics since the 1970s to treat different types of cancer like testicular, ovarian, cervical, head and neck, lung and colorectal cancer. Cisplatin, together with oxaliplatin and carboplatin, is one of the most frequently prescribed chemotherapeutics for treating solid tumors. It was originally discovered in 1969 as a growth inhibitor of Escherichia coli (Rosenberg, VanCamp et al. 1969). The structure is depicted in Figure 2.1A. Cisplatin is given intravenously. After entering the cell, it becomes aquated by losing the chloride ions and exchanging them with two water molecules (Figure 2.1B). Now positively charged cisplatin can interact with nucleophilic molecules like DNA, RNA and proteins. It is believed that cisplatin preferentially binds DNA (favoring imidazole rings of guanosine and adenosine), leading to formation of mono-adducts and crosslinks (Yang and Wang 1999; Zorbas and Keppler 2005). More than $90 \%$ of mono-adducts further react to become crosslinks (Rabik and Dolan 2007). As visualized in Figure 2.1C, crosslinks between two DNA 
bases can be either within the same DNA strand (intra-strand crosslink) or between two DNA strands (inter-strand crosslink). The majority of crosslinks are intra-strand, mostly 1,2-d(GpG) crosslinks of adjacent guanine bases (Rabik and Dolan 2007). Crosslinking leads to torsion of the DNA by different angles and steric changes. It is still in debate whether inter- or intrastrand crosslinks are more toxic to the cells. Anyhow, the conformational changes induced are the basis for recognition and processing of cisplatin-DNA-adducts. The pathways induced upon cisplatin treatment are described below (2.2.3).

A

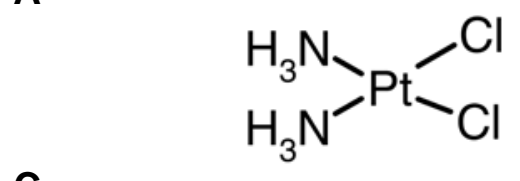

C

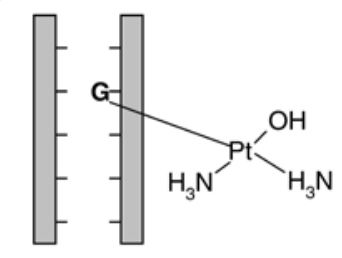

DNA Monoadduct

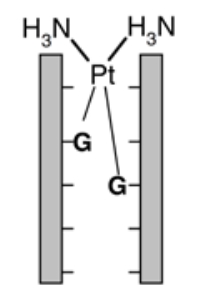

Interstrand Crosslink

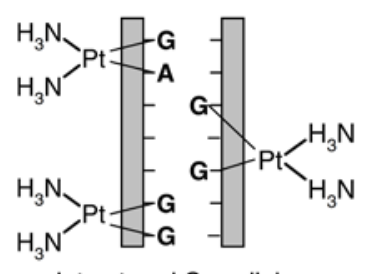

Intrastrand Crosslinks

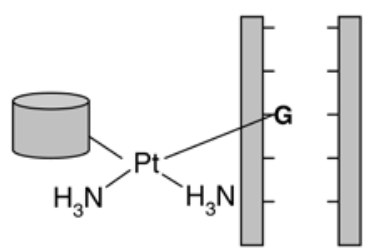

DNA-Protein Crosslink
B

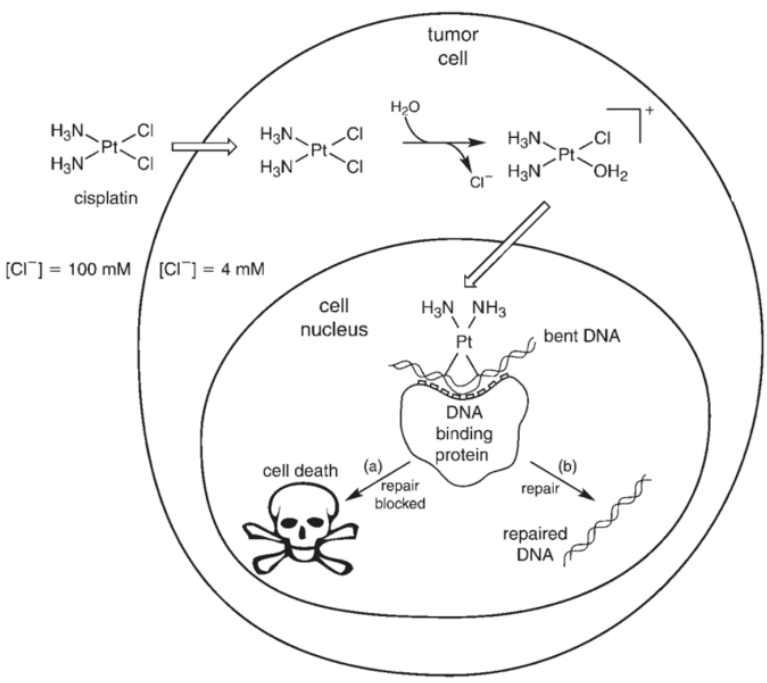

Figure 2.1: Cisplatin mechanism of action.

(A) Chemical structure of cisplatin (taken from Rabik and Dolan 2007). (B) Cytotoxic pathway of cisplatin. Cisplatin is aquated in the cell, leading to binding to the DNA. Outcomes are either cell cycle arrest to repair DNA or apoptosis if damage is irreparable (taken from Alderden, Hall et al. 2006). (C) Adducts formed by cisplatin and DNA can be either mono-adducts, intra-strand or interstrand crosslinks. Also, crosslinks between DNA and protein are possible (taken from Rabik and Dolan 2007).

\subsubsection{Selected chemotherapeutics: Neocarzinostatin}

Neocarzinostatin (NCS) is a radiomimetic. Like radiotherapy, it causes DNA DSBs which are replication-independent and thus also kill non-replicating cells. NCS is a macromolecule composed of a 113 amino acid protein bound to an enediyne chromophore. Enediynes are cyclic, natural products from bacteria (Nicolaou, Smith et al. 1993). NCS is secreted by Streptomyces macromomyceticus and has anti-proliferative and anti-tumoral activity (Smith and Nicolaou 1996). Whereas the protein has stabilizing properties, the chromophore mediates DNA cleavage. Under reductive conditions in the cell, the NCS-epoxide forms a 
highly reactive biradical intermediate which leads to DNA DSBs. NCS has been tested in clinical trials in Japan, for example for treatment of colorectal cancer and acute leukemia (Kimura 1978; Takahashi, Yamaguchi et al. 1993), but has only been used clinically in Japan against liver cancer. Still, it is a valuable agent in research as it can be used as a radiomimetic agent, thus rendering ionizing radiation unnecessary.

\subsection{The DNA damage response (DDR)}

Cells possess a highly developed system to recognize, signal and repair DNA when lesions occur. This is called the DNA damage response (DDR). Depending on the type of lesion, different mechanisms come into action, in a rapid and coordinated fashion. First, DNA damage is recognized by specific proteins, then mediators are recruited and signaling is amplified, so that transducer and effector proteins come into play (Jackson and Bartek 2009). During these processes, post-translational modifications play a major role, including phosphorylation and ubiquitination events. The cellular responses range amongst others from effects on the cell cycle and repair, on chromatin remodeling and transcription to effects on apoptosis and senescence (Jackson and Bartek 2009). The importance of these pathways becomes evident by the fact that defects have been related to higher risk of cancer and developmental and immunological diseases.

Here, we want to focus on the response to DNA DSBs, DNA SSBs and crosslinking of DNA. The mechanisms of detecting and signaling these damages are described in the following passages.

\subsubsection{Phosphorylation events in the DDR}

Phosphorylation cascades play a major role in the DDR. Damaged DNA is recognized by kinases of the PIKK (phosphatidylinositol 3-kinase-related kinase) family. These are ATM (ataxia telangiectasia mutated), ATR (ATM and Rad3-related) and DNA-PK (DNA-dependent protein kinase). Interestingly, more than 900 phosphorylation sites of over 700 proteins were reported to be regulated by ATM and ATR in a large-scale proteomic analysis (Matsuoka, Ballif et al. 2007), indicating the importance of these kinases. Depending on the kind of DNA lesion, different response pathways are induced. Here, we want to introduce the two main responses, i.e. the response to DNA DSBs and to single-stranded DNA.

\subsubsection{ATM-Chk2 pathway as response to DNA double-strand breaks}

In recent years, extensive research has been conducted on the response to DNA DSBS. Double-stranded DNA activates ATM which phosphorylates the checkpoint kinase Chk2 (Matsuoka, Huang et al. 1998; Matsuoka, Rotman et al. 2000). Both ATM and Chk2 lead to phosphorylation and thus activation of the transcription factor p53, an important target as detailed below. ATM has many more substrates in the DDR, for example Mdm2, BRCA1 and Nbs1 (Cortez, Wang et al. 1999; Khosravi, Maya et al. 1999; Gatei, Scott et al. 2000; Gatei, 
Young et al. 2000). Mdm2 is the main negative regulator of p53 and BRCA1 plays an important role in the response and repair of DNA DSBs. Both proteins will be introduced in more detail below. Nbs1 is a component of the MRN (Mre11-Rad50-Nbs1) complex which plays a role in processing and repair of DSBs. The repair of DSBS is conducted by homologous recombination (HR) and non-homologous end joining (NHEJ) which are both controlled by ATM. Just as ATM, Chk2 has different substrates, which are involved in cell cycle and apoptosis.

\subsubsection{ATR-Chk1 pathway as response to single-stranded DNA}

Single-stranded DNA (ssDNA) leads to the activation of the ATR-Chk1 pathway. It has been reported that replicative stress in S-phase leads to stalled replication forks. As a result, the polymerase stalls, whereas the helicase continues to unwind the DNA. This results in SSDNA which is bound by RPA (replication protein A). ATR is found in a complex with ATRIP (ATRinteracting protein) (Cortez, Guntuku et al. 2001). It is proposed that RPA binding to ssDNA facilitates the binding of ATRIP to this DNA region (Zou and Elledge 2003; Unsal-Kacmaz and Sancar 2004). ATR is then capable of phosphorylating substrates like the checkpoint kinase Chk1 (Liu, Guntuku et al. 2000; Zhao and Piwnica-Worms 2001), leading to activation of the cell cycle checkpoint. The ATR-Chk1 pathway also leads to phosphorylation and activation of p53. Many studies indicate that ATR plays a major role in the stress response to inhibited replication-fork progression.

It has been shown that the ATM-Chk2 and ATR-Chk1 pathway can activate each other, leading to considerable cross-talk at several points, including downstream events. For instance, stalled replication forks can collapse into DNA DSBs which activate ATM. And DSBs are repaired by HR which involves DNA end resection, resulting in SSDNA, activating ATR (Shiotani and Zou 2009). A scheme of the pathways is depicted in Figure 2.2.

It is of note that ATM and ATR can activate another stress response pathway via the mitogen activated protein kinase (MAPK) p38 and its substrate MK2 (MAPK activated protein kinase 2) (Reinhardt, Aslanian et al. 2007; Reinhardt and Yaffe 2009).

Naturally, also dephosphorylation events play a role in the DDR, but insights into the importance of phosphatases are not as extensive as of kinases. Phosphatases can control DDR events by dephosphorylating kinases or their substrates. A well-known example is WIP1 (or PPM1D) which dephosphorylates important proteins like Chk1, Chk2, ATM, p38 and p53 (Takekawa, Adachi et al. 2000; Lu, Nannenga et al. 2005; Fujimoto, Onishi et al. 2006; Shreeram, Demidov et al. 2006). 


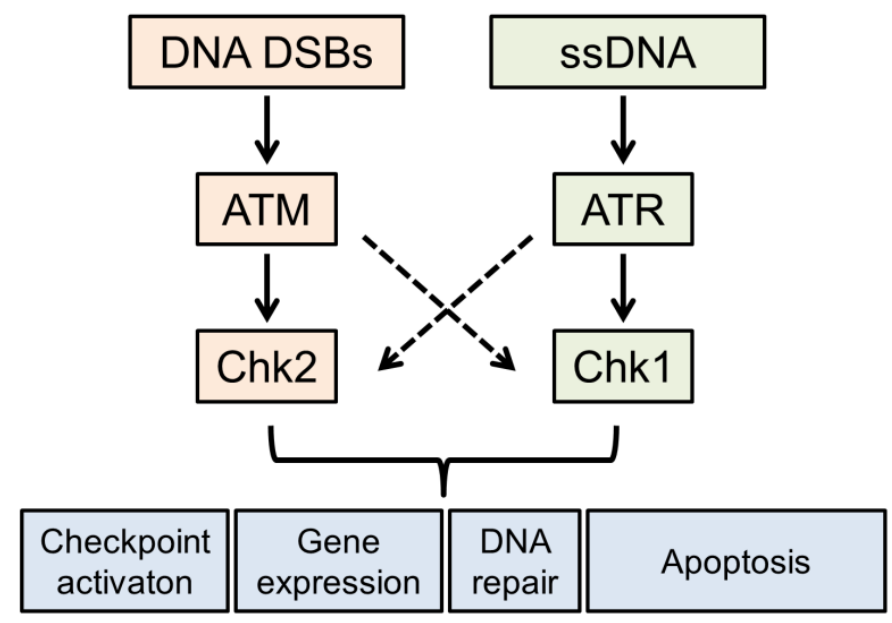

Figure 2.2: Kinase signaling in the DNA damage response.

ATM and ATR are sensor kinases for DNA double-strand breaks (DSBs) and single-stranded DNA (ssDNA). Amongst others, they phosphorylate and thus activate the transducer kinases Chk1 and Chk2. Considerable cross-talk exists between the ATM-Chk2 and ATR-Chk1 pathway. DDR signaling can impair checkpoint activation, regulation of gene expression and DNA repair or can lead to apoptosis if damage is irreparable.

\subsubsection{Phosphorylation of the histone variant $\mathrm{H} 2 \mathrm{AX}$}

In mammals, $2-25 \%$ of histones $\mathrm{H} 2 \mathrm{~A}$ are represented by the histone variant $\mathrm{H} 2 \mathrm{AX}$. Upon DNA damage, H2AX is specifically phosphorylated at Ser139 (Rogakou, Pilch et al. 1998; Fernandez-Capetillo, Lee et al. 2004). This is performed by kinases of the PIKK family, i.e. by ATM (Burma, Chen et al. 2001), by ATR (Ward and Chen 2001) and by DNA-PK (Stiff, O'Driscoll et al. 2004). The signal of phosho-H2AX (then called $\mathrm{YH} 2 \mathrm{AX}$ ) spreads on each side of the DNA lesion in a ca. 1-2 Mbp wide region (Rogakou, Boon et al. 1999; Bewersdorf, Bennett et al. 2006). It mostly occurs after formation of DNA DSBs (Rogakou, Pilch et al. 1998), but is also induced during replication stress (Ward, Minn et al. 2004). Furthermore, it has been used as an indicator for genome instability and as marker in early stages of tumor progression (Gorgoulis, Vassiliou et al. 2005). yH2AX plays an important role in amplifying and maintaining DNA damage-induced checkpoints, but also in recruiting repair factors. The mechanisms of $\mathrm{YH} 2 \mathrm{AX}$ function are not well understood. For instance, the response to DNA DSBs and involvement of $\mathrm{yH} 2 \mathrm{AX}$ has been investigated in detail, but the consequences, e.g. how DSB repair is connected to cellular proliferation and survival are still not completely understood. Dephosphorylation of $\mathrm{YH} 2 \mathrm{AX}$ has been reported to be mediated by different phosphatases, including PP2A (protein phosphatase 2A) (Chowdhury, Keogh et al. 2005), PP4 (Nakada, Chen et al. 2008) and WIP1 (Macurek, Lindqvist et al. 2010). 


\subsubsection{Ubiquitin ligases and deubiquitinating enzymes in the DDR}

\subsubsection{Principles of ubiquitination}

Ubiquitin is a 76 amino acid long protein which covalently attached to other proteins has a multitude of functions. It targets proteins for proteasomal degradation, regulates protein localization, activity and protein interactions (reviewed in Bergink and Jentsch 2009; Komander and Rape 2012). Attachment of ubiquitin is mediated by ubiquitin-activating enzymes (E1), ubiquitin-conjugating enzymes (E2) and ubiquitin ligases (E3) as depicted in Figure 2.3 (reviewed in Deshaies and Joazeiro 2009; Schulman and Harper 2009; Ye and Rape 2009). In mammals, two E1s have been described as well as $35 \mathrm{E} 2 \mathrm{~s}$ and more than 600 E3s to date (Jackson and Durocher 2013). During ubiquitination, an isopeptide bond is formed between the C-terminus of ubiquitin and the lysine of a substrate (or another ubiquitin molecule) in an ATP-dependent manner.

Two major E3 ubiquitin ligase families exist: the HECT (homologous to the E6AP carboxyl terminus) domain family (Rotin and Kumar 2009) and the group of RING (really interesting new gene) and RING-related E3s, including plant homeodomain (PHD) proteins and members of the U-box family (Deshaies and Joazeiro 2009). Since RING and PHD domains are so similar, it was in the past often difficult to assign proteins to one class or the other. PHD domains infrequently have E3 activity, but bind methylated histones and are involved in chromatin-mediated gene regulation (Musselman and Kutateladze 2011). HECT and RING ubiquitin ligases differ in their mechanism of action: HECT E3s contain a conserved catalytic cysteine which accepts ubiquitin from the E2 protein before it is transferred to a specific lysine of the substrate. In contrast, RING E3s work as scaffolds and facilitate the interaction between E2 and the substrate. The majority of ubiquitin ligases are RING E3s.
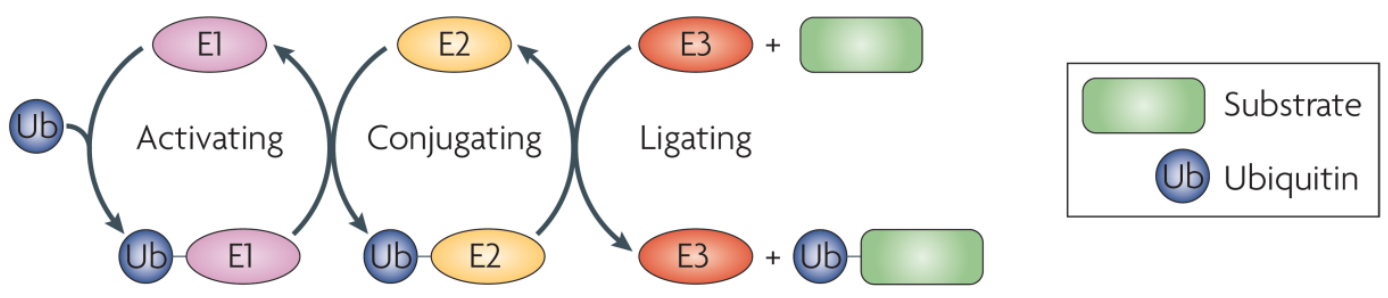

Figure 2.3: Enzymatic cascade of ubiquitination.

Ubiquitin attachment to a substrate is mediated by an ubiquitin-activating enzyme (E1), an ubiquitinconjugating enzyme (E2) and the ubiquitin ligase (E3). First, ubiquitin is transferred to $E 1$, then activated to E2 and finally covalently attached to the substrate with the help of E3 (taken from Dikic, Wakatsuki et al. 2009).

Ubiquitination is a reversible process like other post-translational modifications. Proteases that can cleave ubiquitin are called deubiquitinating enzymes (DUBs) of which ca. 100 are described to date. They are divided into five classes (four cysteine protease classes and one 
metallo-protease class) (Vucic, Dixit et al. 2011). It is not known whether all ubiquitinated substrates have a corresponding DUB.

The target protein can be linked to one ubiquitin molecule (mono-ubiquitination) or several lysines of the target are bound to ubiquitin (multi-ubiquitination). Mono-ubiquitination plays a role in processes like DNA repair, gene silencing and vesicle sorting. Beyond that, ubiquitin possesses seven lysine residues itself (Lys6, Lys11, Lys27, Lys29, Lys33, Lys48, Lys63) which can be used to link ubiquitin molecules to chains (Deshaies and Joazeiro 2009). Binding of ubiquitin chains to one or more lysine residues of a substrate is called polyubiquitination. These structures have different functions, e.g. Lys63 ubiquitin chains mediate protein interactions and linkage via Lys48 is a signal for proteasomal degradation. Current research also investigates ubiquitin chains using other lysines of ubiquitin, with more and new functions becoming evident.

\subsubsection{Proteasomal degradation}

The connection between ubiquitination and proteasomal degradation is called the ubiquitinproteasome system (UPS), depicted in Figure 2.4. The 26S proteasome consists of a $20 \mathrm{~S}$ core particle which is capped either at one end or both ends by a 19S regulatory particle. The regulatory particle contains ubiquitin receptors recognizing the ubiquitinated substrate and initiates degradation. The core particle comprises deubiquitinating enzymes and ATPases to cleave ubiquitin chains and to unfold the substrate, finally leading to proteolysis of the substrate. The "discovery of ubiquitin-mediated protein degradation" was rewarded with a Nobel Prize in Chemistry in 2004 (to Aaron Ciechanover, Avram Hershko and Irwin Rose).

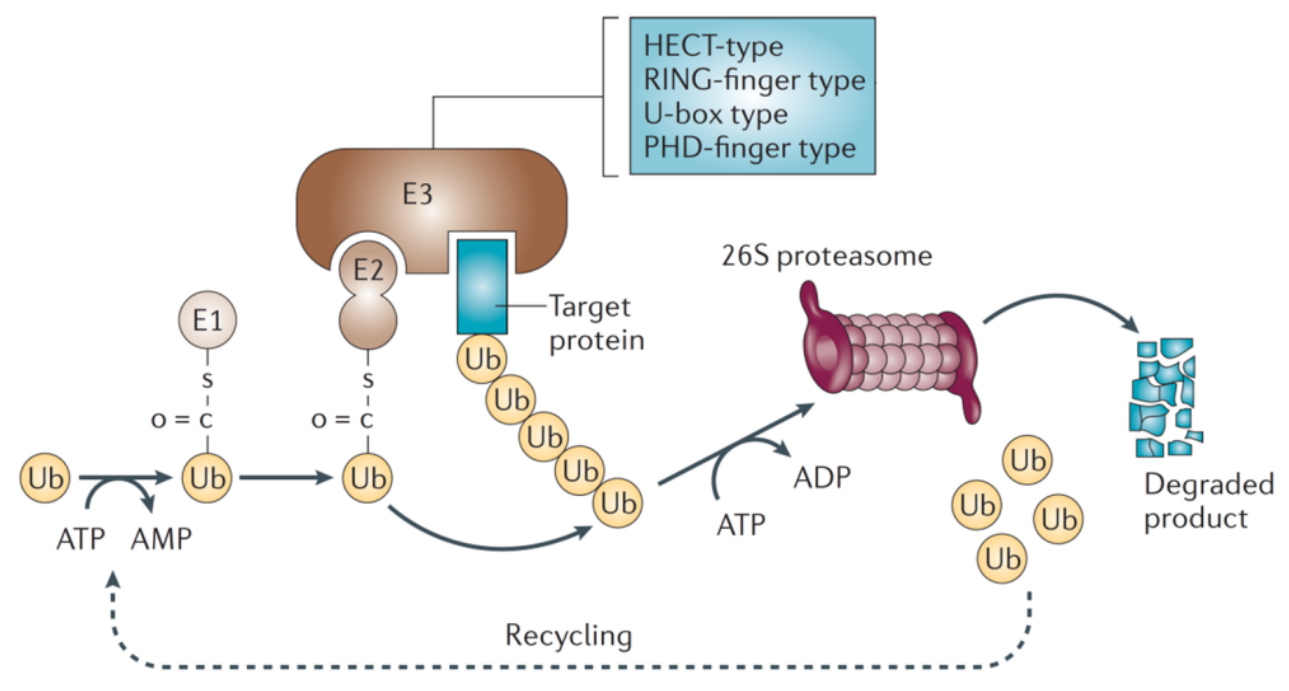

Figure 2.4: The ubiquitin-proteasome pathway.

Ubiquitin ( $\mathrm{Ub}$ ) is transferred to E1 in an ATP-dependent manner, from there to E2 and then by E3 to the substrate. A poly-ubiquitin chain marks substrates for ATP-dependent degradation in the $26 \mathrm{~S}$ proteasome (taken from Nakayama and Nakayama 2006). 
For research purposes, the proteasome can be blocked by inhibitors like MG132 (Lee and Goldberg 1998). This is a potent, reversible and cell-permeable proteasome inhibitor which reduces the degradation of ubiquitin-conjugated proteins. Treatment with MG132 has been shown to result in accumulation of ubiquitin chains linked by Lys6, Lys11, Lys27, Lys33, Lys48 and Lys63 in HeLa cells (Meierhofer, Wang et al. 2008).

\subsubsection{Ubiquitin ligases in the DDR to DNA DSBS}

Ubiquitination plays an essential role in DNA damage signaling. A prominent example is the DDR to DNA DSBs. After phosphorylation of H2AX, MDC1 binds to $\mathrm{YH} 2 \mathrm{AX}$ (Stucki, Clapperton et al. 2005) and becomes phosphorylated by ATM. This enables the RING ubiquitin ligase RNF8 to bind MDC1 and to ubiquitinate proteins at the site of damage (Huen, Grant et al. 2007; Kolas, Chapman et al. 2007; Mailand, Bekker-Jensen et al. 2007). The group of Mailand et al. has shown that RNF8 can ubiquitinate histones H2A and H2AX. Another RING ligase, RNF168, is recruited which interacts with ubiquitinated $\mathrm{H} 2 \mathrm{~A}$ and amplifies Lys63-linked ubiquitin chains (Doil, Mailand et al. 2009). Ubiquitination events by RNF8 and RNF168 are required so that further signaling proteins are recruited or retained at the DSB, like 53BP1, BRCA1 and RAD18 (Lukas, Lukas et al. 2011). BRCA1 (breast cancer type 1 susceptibility protein) is an ubiquitin ligase with important functions in the cell (Huen, Sy et al. 2010). It promotes the DSB repair pathway of homologous recombination (HR) and is necessary for resection of DSBs. Furthermore, it contributes to the G2/M-checkpoint and is recruited to sites of replication problems, e.g. in response to inter-strand crosslinks (ICLs) during S-phase.

\subsubsection{The ubiquitin-dependent Fanconi anemia pathway}

If the DNA is impaired by inter-strand crosslinks (ICLs), the Fanconi anemia (FA) pathway is induced. FA is a rare genetic disorder which is characterized by genomic instability, increased predisposition to cancer and a defect in repairing ICLs. Cells from FA patients are hypersensitive to crosslinking agents like cisplatin and mitomycin $\mathrm{C}$. Till today, 15 genes have been shown to result in FA if mutated (FANCA to FANCP). The proteins encoded by these genes participate in four different complexes. The key event of the FA pathway is yet again an ubiquitination event. At first, the recognition complex consisting of the helicase FANCM detects ICLs (Meetei, Medhurst et al. 2005; Ciccia, Ling et al. 2007). The core complex, composed of several FANC proteins including the RING E3 ligase FANCL, is responsible for the mono-ubiquitination of the FANCD2-FANCI-complex (Meetei, de Winter et al. 2003; Smogorzewska, Matsuoka et al. 2007). This complex interacts with BRCA2 (FANCD1) and other repair enzymes. In this way, ICLs are first recognized and excised by NER, followed by translesion synthesis and HR-mediated repair (Bergink and Jentsch 2009). 


\subsubsection{Examples of deubiquitinating enzymes in the DDR}

Besides ubiquitin ligases, several deubiquitinating enzymes (DUBs) play an essential role in DDR pathways. An important example is the ubiquitin-specific protease USP1 which deubiquitinates FANCD2 (Nijman, Huang et al. 2005). USP1 is also involved in translesion synthesis (TLS) since it deubiquitinates PCNA (Huang, Nijman et al. 2006). Further representatives of DUBs in the DDR include USP3, USP16, BRCC36 and POH1/PSMD14 that comprise negative regulators of the RNF8-dependent response to DNA DSBs described above (Dong, Hakimi et al. 2003; Doil, Mailand et al. 2009; Shao, Lilli et al. 2009; Shanbhag, Rafalska-Metcalf et al. 2010; Butler, Densham et al. 2012).

\subsubsection{The DDR after cisplatin treatment}

Cisplatin treatment leads to crosslinking of DNA. This prevents separation of DNA strands during transcription and replication and thus activates various signaling and repair pathways. The components and mechanisms involved are incompletely understood. It is known that DNA crosslinks activate the FA pathway as specified above. Furthermore, inter-strand crosslinks result in stalled replication forks, leading to DNA SSBs which activate the ATRChk1 pathway. During repair of these lesions, DNA DSBs are induced which activate the ATM-Chk2 pathway. Upon cisplatin treatment, H2AX phosphorylation is induced and well detectable. The repair pathways are again complex. Crosslinks are primarily repaired by nucleotide excision repair (NER) (Huang, Zamble et al. 1994; Zamble, Mu et al. 1996). Also, mismatch repair pathways (MMR) are involved which contribute to cisplatin-induced apoptosis (Fink, Nebel et al. 1996). Intra-strand and inter-strand crosslinks have been shown to be bypassed by translesion synthesis (TLS) polymerases. Repair of inter-strand crosslinks is conducted by a complex interplay of NER, followed by translesion synthesis and HRmediated repair (Bergink and Jentsch 2009; Ho and Scharer 2010; Vasquez 2010).

\subsection{Regulation of p53 and Mdm2}

\subsubsection{Regulation and post-translational modification of the tumor suppressor p53}

The tumor suppressor p53 is often dysregulated in cancer, either by genomic loss or point mutation or by changes in signaling pathways upstream of p53. Its function is abrogated in more than $50 \%$ of human tumors (Hollstein, Sidransky et al. 1991). Importantly, p53 decides on the cell's fate. Under unstressed conditions, the transcription factor is kept at low levels. Upon stress like damaged DNA, p53 becomes post-translationally modified which inhibits its degradation and promotes stabilization and thus transcriptional activity. This leads to induction of genes involved in processes like cell cycle arrest, DNA repair and apoptosis (reviewed in Vousden 2006; Menendez, Inga et al. 2009). Functions of p53 are highlighted in more detail below (see sections 2.4.2 and 2.4.4). 
P53 consists of a transactivation, SH3, DNA binding, tetramerisation and regulatory domain. Extensive research has revealed how p53 levels and function are controlled. Different regulators affect the stability and activity of p53 by means of post-translational modifications, protein-protein interactions and subcellular localization (reviewed in Lavin and Gueven 2006; Horn and Vousden 2007; Meek and Anderson 2009). Post-translational modifications of p53 include phosphorylation, acetylation, methylation, neddylation, sumoylation and ubiquitination. Here, we will focus on the ubiquitin-dependent regulation of p53, especially by the ubiquitin ligase Mdm2.

More than ten ubiquitin ligases are involved in p53 regulation. Both mono- and polyubiquitination of p53 occur. The main negative regulator of p53 function and stability is the RING E3 ligase Mdm2 (also called Hdm2). Mdm2 and p53 interact at the N-terminal domain of p53 which inhibits transactivation of genes by p53 (Momand, Zambetti et al. 1992; Kussie, Gorina et al. 1996). In addition, Mdm2 mediates the proteasomal degradation of p53 (Haupt, Maya et al. 1997; Kubbutat, Jones et al. 1997). Interestingly, low levels of Mdm2 lead to mono-ubiquitination of p53 which permits nuclear export of p53, whereas higher levels of Mdm2 result in poly-ubiquitination and hence degradation of p53 (Lohrum, Woods et al. 2001; $\mathrm{Li}$, Brooks et al. 2003). Since Mdm2 is a direct target gene of p53 (Barak, Juven et al. 1993; Juven, Barak et al. 1993; Wu, Bayle et al. 1993), a negative feedback loop exists which leads to inhibition of p53 activity in later stages of the DDR. The importance of the relationship between p53 and Mdm2 was shown by mdm2 null mice which are characterized by embryonic lethality. Remarkably, this lethality can be rescued by double-knockout of mdm2 and p53 (Jones, Roe et al. 1995; Montes de Oca Luna, Wagner et al. 1995).

Upon cellular stress, the interaction between p53 and Mdm2 is disrupted, so that p53 becomes stabilized. This is achieved by different mechanisms like phosphorylation of p53 at Ser15 and Ser20 by ATM, ATR, DNA-PK, Chk1 and Chk2 upon cellular stress and DNA damage (Chehab, Malikzay et al. 1999; Tibbetts, Brumbaugh et al. 1999; Chehab, Malikzay et al. 2000; Hirao, Kong et al. 2000; Saito, Goodarzi et al. 2002). Other ways are acetylation of p53 or indirect mechanisms like binding of p14-ARF to Mdm2 which frees p53 from Mdm2 (Honda and Yasuda 1999; Weber, Taylor et al. 1999). A summary of the p53-Mdm2 pathway is depicted in Figure 2.5. 


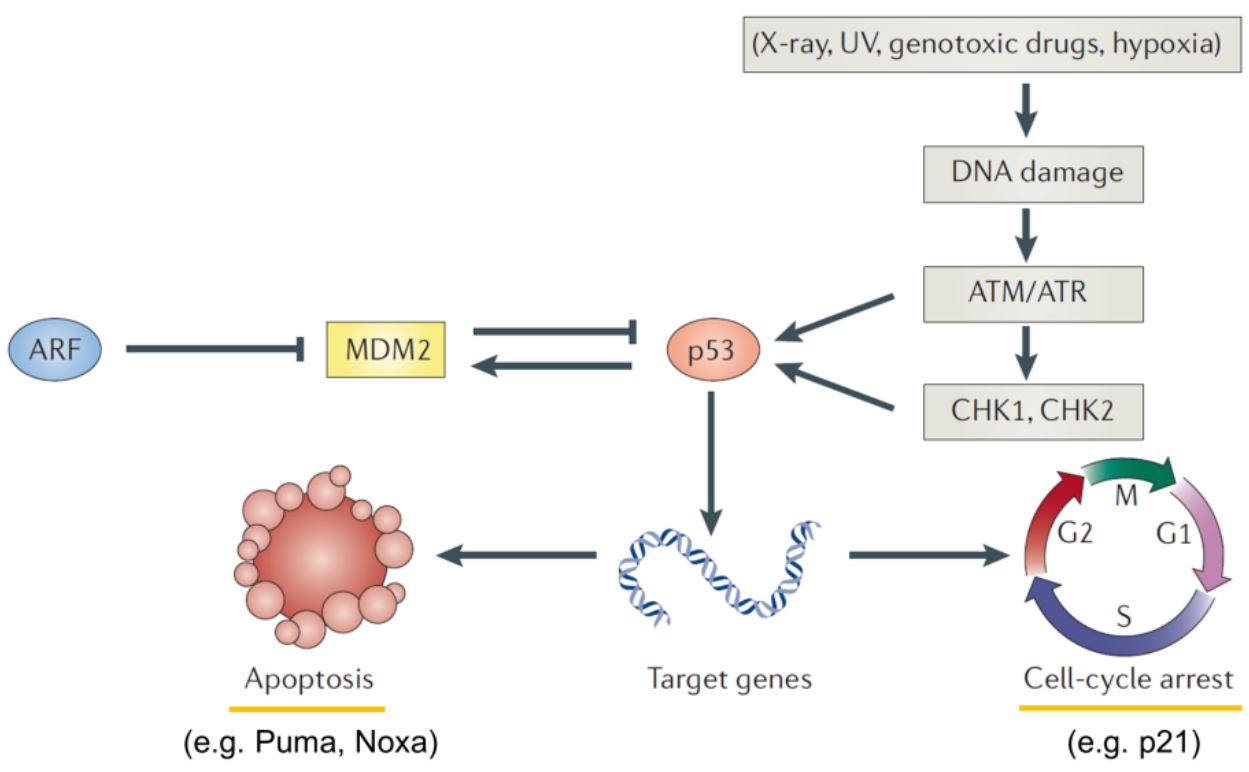

Figure 2.5: The p53-Mdm2 pathway.

Upon genotoxic stress, induction of the DDR activates kinase cascades of the ATR-Chk1 and ATMChk2 pathway which lead to phosphorylation of p53. Post-translational modification of p53 leads to disruption of the p53-Mdm2 interaction and leads to transcription of p53 target genes involved in cell cycle arrest (e.g. p21) and apoptosis (e.g. Puma and Noxa). The ubiquitin ligase Mdm2 is negatively regulating $\mathrm{p} 53$ transcription and promotes its degradation. Being a target gene of p53, it is part of a negative feedback loop. Mdm2 can be inhibited by p14-ARF (abbreviated to ARF), leading to p53 stabilization (modified from Sherr 2006).

It is well established that further ubiquitin ligases regulate p53 in a Mdm2-independent manner. This became obvious when it was shown that p53 is still degraded in mdm2-deficient mice (Ringshausen, O'Shea et al. 2006). Examples include the ubiquitin ligases Pirh2 and COP1 that have been shown to ubiquitinate $\mathrm{p53}$, leading to its proteasomal degradation (Leng, Lin et al. 2003; Dornan, Wertz et al. 2004). CHIP (or STUB1) is a chaperoneassociated ubiquitin ligase that leads to poly-ubiquitination and proteasomal degradation of p53 (Esser, Scheffner et al. 2005). Interestingly, regulation of p53 by ubiquitination does not only lead to its degradation. For example, Msl2 was reported to poly-ubiquitinate p53, resulting in nuclear export of p53 (Kruse and Gu 2009).

Besides ubiquitin ligases, also DUBs are regulating p53. The first to be identified was HAUSP (Herpesvirus-associated ubiquitin-specific protease or USP7) which deubiquitinates p53 and also regulates Mdm2 stability (Li, Chen et al. 2002; Li, Brooks et al. 2004). Further examples of DUBs that deubiquitinate p53 are USP42 and USP10 (Yuan, Luo et al. 2010; Hock, Vigneron et al. 2011). 


\subsubsection{The ubiquitin ligase $\mathrm{Mdm} 2$}

\subsubsection{Regulation and post-translational modification of Mdm2}

Mdm2 is the main negative regulator of p53, but also exhibits p53-independent functions. Its domain structure including the N-terminal p53-binding domain and the C-terminal RING domain is depicted in Figure 2.6. Mdm2 is found as a heterodimer with Mdmx (also called Mdm4) (Sharp, Kratowicz et al. 1999; Tanimura, Ohtsuka et al. 1999). Both proteins have sequence homology and a RING domain. Mdmx does not have ubiquitin ligase activity towards p53, but can repress p53 transactivation activity (Stad, Ramos et al. 2000). Further studies suggest that Mdm2 and Mdmx have different functions and thus different effects on p53 activity. Mdm2 has been shown to be regulated by diverse proteins. As mentioned above, the nucleolar protein p14-ARF can bind Mdm2 and thus prevent Mdm2 from degrading p53. Further nucleolar proteins including the ribosomal proteins RPL5, RPL11 and RPL23 interact with and hence inactivate Mdm2 in response to nucleolar stress, thus freeing p53 from Mdm2 and leading to its activation (Zhou, Liao et al. 2012).

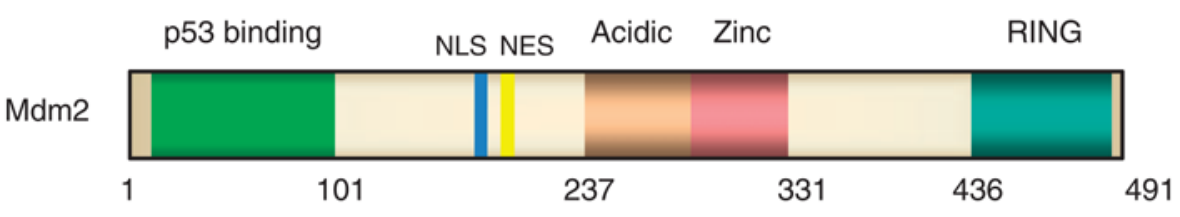

Figure 2.6: Domain structure of Mdm2.

Domains: p53 binding, acidic domain, zinc finger domain, RING finger domain, NLS = nuclear localization signal, NES = nuclear export signal (taken from Lee and Gu 2010).

Mdm2 is post-translationally modified by proteins including ubiquitin ligases and DUBs. Examples include the ubiquitin ligase RBBP6 (Retinoblastoma binding protein 6) which interacts with Mdm2 and enhances Mdm2-mediated ubiquitination and degradation of p53 due to increased p53-Mdm2-affinity ( $\mathrm{Li}$, Deng et al. 2007). Mdm2 was shown to be deubiquitinated by USP2a, which specifically binds and deubiquitinates Mdm2, but not p53 (Stevenson, Sparks et al. 2007). The deubiquitinating enzyme HAUSP not only deubiquitinates and stabilizes p53, but also stabilizes Mdm2 in a p53-independent manner (Cummins, Rago et al. 2004; Li, Brooks et al. 2004).

Like p53, Mdm2 is also regulated during the DDR. It was reported to be degraded upon DNA damage which leads to accumulation and thus activation of p53 (Stommel and Wahl 2004). There is some debate about the degradation of Mdm2. It was shown that Mdm2 can be degraded due to auto-ubiquitination (Stommel and Wahl 2004; Stommel and Wahl 2005), but it was also reported that auto-degradation is not the only mechanism. Using a mouse model with inactivated Mdm2 RING domain, it became evident that Mdm2 E3 ligase activity is not 
necessary for its destruction (Itahana, Mao et al. 2007). Furthermore, a recent study demonstrated that Mdm2 becomes phosphorylated at multiple sites by casein kinase 1 (CK1) in a cell-cycle and DNA damage-dependent manner which leads to ubiquitination and destruction of Mdm2 via SCF ${ }^{\beta-T R C P}$ (Inuzuka, Tseng et al. 2010). Additionally, it was reported that upon ionizing radiation or treatment with a radiomimetic, ATM is not only involved in phosphorylation of p53, but also phosphorylates Mdm2 (Khosravi, Maya et al. 1999).

\subsubsection{Regulation of $M d m 2$ expression and $M d m 2$ isoforms}

Expression of Mdm2 is regulated by two promoters, (P1) and (P2), both encoding full-length Mdm2 protein (Saucedo, Myers et al. 1999). Interestingly, p53 stimulates the internal mdm2 promoter (P2) leading to synthesis of RNA lacking the non-coding exon 1 (Juven, Barak et al. 1993; Barak, Gottlieb et al. 1994). This transcript is more efficiently translated than the one from the (P1) promoter (Landers, Cassel et al. 1997) which explains why activated p53 leads to strong increase in Mdm2 levels. The negative feedback loop model argues that this mechanism finally allows recovering of normal p53 levels (Wu, Bayle et al. 1993; Chen, Oliner et al. 1994).

When investigating Mdm2 protein expression, different isoforms can be detected. More than $40 \mathrm{Mdm} 2$ splice variants and various isoforms were identified in both normal tissues and tumors (Bartel, Taubert et al. 2002). Full-length Mdm2 at $97 \mathrm{kDa}$ is often seen as two bands in Western blot, arguing for the existence of two isoforms. Also, lower bands at $60 \mathrm{kDa}$ are often observed. The mechanisms and biological roles of Mdm2 isoforms are largely unknown. Additional Mdm2 proteins seem to exist due to differences in mRNA splicing and posttranslational modifications (Olson, Marechal et al. 1993). Also, initiation of translation has been reported from two separate internal AUG codons (Cheng and Cohen 2007). The same group showed that Mdm2 transcripts initiated from the p53-activated (P2) promoter are preferentially the $97 \mathrm{kDa}$ isoform. This isoform seems to be responsible for p53 degradation (Cheng and Cohen 2007).

\subsubsection{3 p53-independent functions of Mdm2}

The importance of Mdm2 is obvious since it is the main regulator of the p53 tumor suppressor pathway and important in tumor development. The mdm2 gene is amplified in ca. $10 \%$ of all human cancers (Momand, Jung et al. 1998). It is of note that besides its role in regulating p53, Mdm2 fulfills p53-independent tasks in the cell. Mdm2 was reported to interact with chromatin and chromatin-associated proteins and to affect gene expression and DNA repair. For example, it can promote genetic instability and transformation by induction of chromosomal breaks and a delay in repair of DNA DSBs by interaction with Nbs1, a component of the MRN complex (Bouska, Lushnikova et al. 2008). The MRN complex is involved in detection and processing of DSBs. Furthermore, Mdm2 affects proliferation, apoptosis and epithelial-to-mesenchymal transition (EMT). For instance, Mdm2 has been 
shown to target E-cadherin for proteasomal degradation (Yang, Zong et al. 2006). E-cadherin plays an important role in EMT, the process important in development of metastases when epithelial cells gain migratory and invasive properties and become mesenchymal cells.

These examples show that Mdm2 has broader influence on the cell beyond regulating the tumor suppressor p53.

\subsection{Consequences of DNA damage}

Whereas the previous sections have described DNA damage signaling pathways and the proteins involved, we now want to focus on the consequences for the cell. As already seen in Figure 2.2, damaged DNA signaling results in checkpoint activation and cell cycle regulation, finally leading to repair of the damage or cell death. These processes are mostly accompanied by changes in gene expression. Here, we want to introduce the processes of cell cycle regulation, DNA repair and apoptosis in more detail, but also point out that these mechanisms cannot be regarded as operating fully independently from each other.

\subsubsection{Cell cycle regulation}

Damaged DNA results in activation of cell cycle checkpoints via pathways like the ATM-Chk2 and ATR-Chk1 pathway described above. Signal transduction thereby aims at proteins involved in cell cycle progression. Cells progressing through the cell cycle are tightly regulated by complexes consisting of cyclins and cyclin-dependent kinases (CDKs) as depicted in Figure 2.7. In G1-phase where cells increase in size and prepare for DNA synthesis, cyclin D complexes with CDK4 and CDK6. Cyclin E and CDK2 are activated in late G1-phase and trigger progression into S-phase where DNA is replicated. During S-phase, the cyclin A-CDK2/CDK1 complex stimulates chromosome duplication and stays stable till entry into mitosis. The cyclin B-CDK1 complex is important at the G2/M-checkpoint for entry into mitosis. In this time period between DNA synthesis and mitosis (or M-phase), cells grow and ensure that they can progress to the final cell division phase which results in two daughter cells. Many genes show a cell-cycle specific expression, for example the transcription factor E2F1 which is expressed in G1/S-phase and induces transcription of genes like cyclin E, cyclin A and DNA-polymerase. Also, there are S-phase specific genes coding for histones and components required for DNA polymerase, for example the processivity factor PCNA (proliferating cell nuclear antigen) (Prelich, Tan et al. 1987). Genes specifically expressed in G2/M-phase include cyclin B1, Cdc25C and PLK1 (Polo-like kinase1) (Sadhu, Reed et al. 1990; Hamanaka, Smith et al. 1995; Lee, Yuan et al. 1995). 


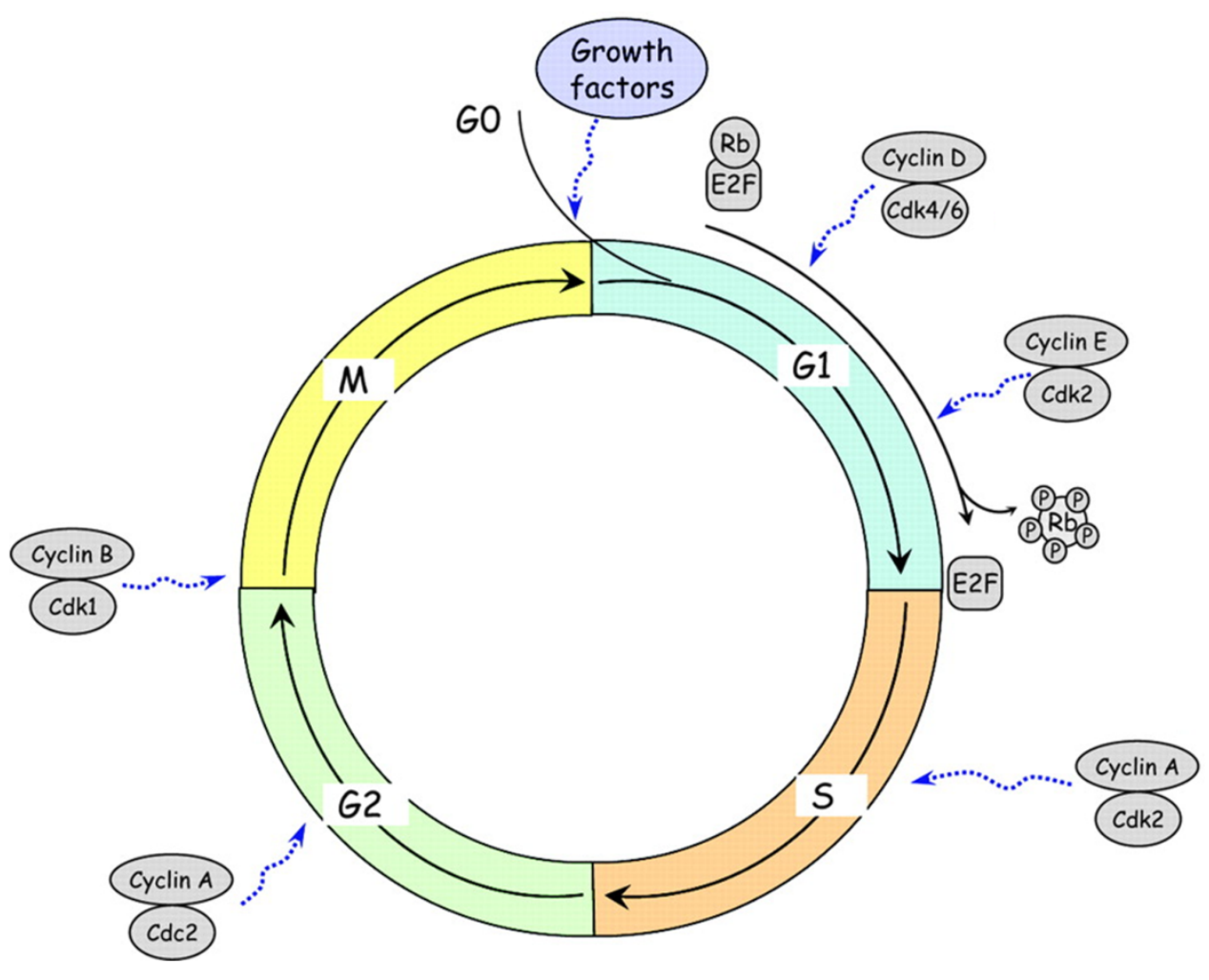

Figure 2.7: Scheme of the mammalian cell cycle.

In G1-phase, cyclin D complexes with CDK4 and CDK6. Cyclin E and CDK2 are activated in late G1-phase and trigger progression into S-phase. During S-phase, the cyclin A-CDK2/CDK1 complex forms and stays stable till entry into mitosis. The cyclin B-CDK1 complex is important at the G2/M-checkpoint for entry into mitosis. The cyclin D-CDK4/CDK6 and cyclin E-CDK2 complex phosphorylate retinoblastoma protein (RB), leading to release of the transcription factor E2F (modified from Abrous, Koehl et al. 2005).

If DNA damage occurs, cell cycle checkpoints are activated that delay progression through the cell cycle and give time to repair damaged DNA or to induce apoptosis if irreparable. Commonly, three cell cycle checkpoints can be distinguished: the G1/S-, the Intra-S- and the G2/M-checkpoint. These checkpoints are introduced in the next section.

\subsubsection{Cell cycle checkpoints}

\subsubsection{The G1/S-checkpoint}

The G1/S-checkpoint leads to cell cycle arrest prior to DNA synthesis in S-phase. The main regulator of this checkpoint is p53. It becomes stabilized upon DNA damage via the ATM-Chk2 and ATR-Chk1 pathway as described above, promoting transcriptional activation of target genes like p21 (el-Deiry, Tokino et al. 1993; Waldman, Kinzler et al. 1995). The cyclin-dependent kinase inhibitor p21 hinders the complexes cyclin D-CDK4 and cyclin ECDK2 which are necessary for entry into S-phase (Harper, Adami et al. 1993; Brugarolas, 
Chandrasekaran et al. 1995). Inhibition of CDKs influences the RB/E2F1-complex as depicted in Figure 2.8. The transcription factor E2F1 is inactive when bound to hypophosphorylated RB (retinoblastoma protein). If RB is phosphorylated by CDKs, binding to E2F1 is reduced and gene expression activated. Thus, the CDK-inhibitor p21 represses E2F1 activity which is important for maintenance of the checkpoint. Furthermore, p21 promotes G1-arrest by binding PCNA and thus inhibits its function during replication (Moldovan, Pfander et al. 2007). Progression to S-phase following G1-arrest is achieved by degradation of p21 (Gottifredi, McKinney et al. 2004).

Apart from that, also p53-independent mechanisms have been described to play a role at the G1/S-checkpoint (Agami and Bernards 2000).

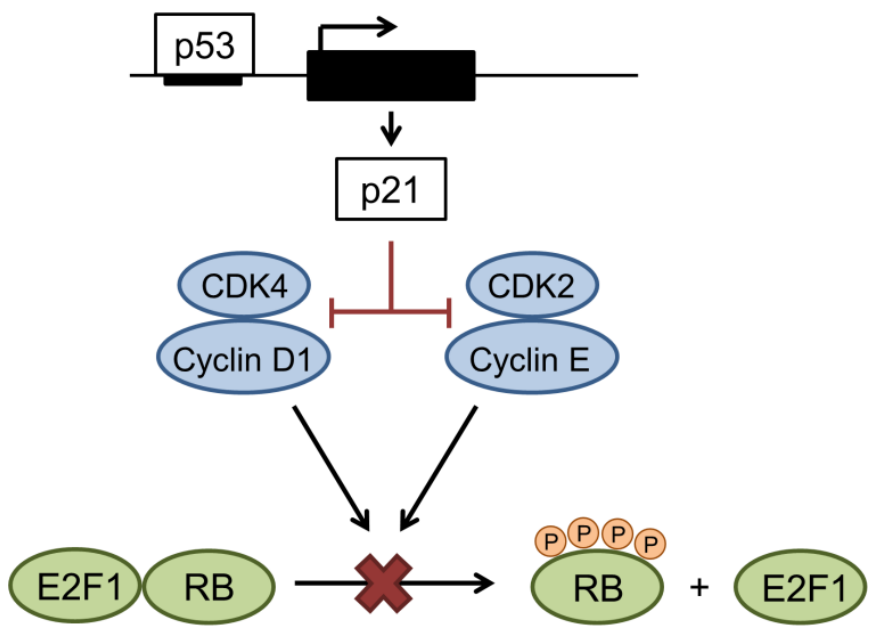

Figure 2.8: Mechanism of G1-arrest mediated by p53 and p21.

Activation of p53 induces p21 expression. The cyclin-dependent kinase inhibitor p21 prevents phosphorylation of RB by inhibiting CDK4 and CDK2. This prevents RB from de-repressing E2F1, inhibiting E2F1 transcriptional activity, causing a G1-arrest.

\subsubsection{The Intra-S-checkpoint}

The intra-S-checkpoint plays an important role in regulation of DNA replication. Upon genotoxic stress, it inhibits firing from origins of replication which have not been initiated (Kastan and Bartek 2004). Regulation is accomplished by ATM and ATR signaling and leads to inhibition of CDK1 and CDK2 (Bartek and Lukas 2003; Hochegger, Dejsuphong et al. 2007). One of the main mechanisms consists in the proteasomal degradation of the phosphatase Cdc25A which results in inhibition of the cyclin E/A-CDK2 complex since CDK2's inhibitory phosphorylation is not removed (Mailand, Falck et al. 2000; Falck, Mailand et al. 2001). 


\subsubsection{The G2/M-checkpoint}

If damage occurs prior to mitosis, cells are arrested at the G2/M-checkpoint. Remarkably, p53 and p21 are again required to maintain the G2-arrest (Bunz 1998; Taylor and Stark 2001). P53 is able to block CDK1 (also called Cdc2). The mechanism of CDK1 inhibition involves three transcriptional targets of p53, namely GADD45, p21 and 14-3-3-sigma (Chan, Hermeking et al. 1999; Wang, Zhan et al. 1999). Whereas p21 can inhibit CDK1 directly, 14-3-3-sigma leads to localization of CDK1 in the cytoplasm which prevents its role during mitosis (Taylor and Stark 2001). In addition, GADD45 causes dissociation of CDK1 from cyclin B (Zhan, Antinore et al. 1999). Furthermore, p53 represses the cyclin B1 and cdc2 gene. However, p53-independent mechanisms also exist. For example, activation of the ATM-Chk2 and ATR-Chk1 pathways results in inhibition of CDK1. This is conducted by Chk1 and Chk2 through phosphorylation and hence inactivation of the phosphatase Cdc25 that usually activates CDK1 (Furnari, Rhind et al. 1997; Sanchez, Wong et al. 1997; Chaturvedi, Eng et al. 1999).

It is generally accepted that multiple p53-dependent and p53-independent pathways regulate the G2/M-checkpoint in response to genotoxic stress.

Some scientists define a forth checkpoint in the middle of mitosis, called metaphase checkpoint. This checkpoint is necessary to guarantee that the cell is ready to complete cell division.

\subsubsection{DNA repair}

If cells encounter DNA lesions, a complex system of repair mechanisms is applied. Since we did not investigate repair processes in more detail, we only briefly summarize them here (Bergink and Jentsch 2009; Jackson and Durocher 2013): DNA DSBs are repaired by homologous recombination (HR) or non-homologous end joining (NHEJ). Repair of simple base lesions is conducted by base-excision repair (BER). Bulky DNA adducts or UV-induced DNA lesions are repaired by nucleotide excision repair (NER). DNA crosslinks are repaired by proteins of the Fanconi anemia (FA) pathway, by NER and by HR, while mismatch repair (MMR) corrects for DNA base mismatches. If replication continues despite present lesions, the DNA-damage-tolerance pathway of postreplication repair (PRR) is employed. PRR can be carried out either as translesion synthesis (TLS) or as a mechanism involving a templateswitch combined with HR.

\subsubsection{Induction of Apoptosis}

If cells exhibit irreparably damaged DNA, a form of programmed cell death called apoptosis is initiated (reviewed in Taylor, Cullen et al. 2008). During apoptosis, cells decrease in size, their cytoskeleton is destructed and chromatin condenses and becomes fragmented. Often, these cells are disrupted into apoptotic bodies, i.e. membrane-enclosed fragments. Induction of apoptosis leads to activation of caspases (cysteine-dependent aspartate-directed 
proteases). They exist as inactive precursor molecules (procaspases) and are activated by proteolytic cleavage of other (active) caspases. This proteolytic activation of caspases results in an irreversible cascade divided into initiator and executioner caspases. Initiator caspases start the proteolytic cascade and activate executioner caspases which cleave specific proteins in the cell like nuclear lamins, cell-cell adhesion molecules and proteins that lead to activation of endonucleases to break down DNA. Initiator caspases contain so-called caspase recruitment domains (CARD) which are needed to bind to adaptor proteins. Thus, procaspases are in close proximity and activate and cleave each other. The caspase cascade can be triggered in two ways as detailed below and depicted in Figure 2.9.

\subsubsection{Extrinsic pathway}

During the extrinsic apoptosis pathway, extracellular ligands bind death receptors, transmembrane proteins found on the cell surface (reviewed in Taylor, Cullen et al. 2008). Death receptors belong to the tumor necrosis factor (TNF) receptor family. Signal proteins that bind death receptors are for example TNF and Fas. Death receptors contain intracellular death domains which recruit further adaptor proteins to assemble initiator procaspases in a death-inducing signaling complex (DISC). In the case of the Fas ligand, procaspases 8, 10 or both are recruited. These initiator caspases then activate executioner procaspases, i.e. firstly caspase 3 which then cleaves and activates caspases 6 and 7. This caspase cascade finally results in cleavage of target proteins to promote the apoptotic process.

\subsubsection{Intrinsic pathway}

If cells encounter stress inside the cell, for instance DNA damage or lack of nutrients, they initiate the intrinsic apoptosis pathway (reviewed in Taylor, Cullen et al. 2008). This is characterized by release of mitochondrial proteins into the cytoplasm, some of which activate the caspase cascade. The intrinsic pathway is highly regulated by $\mathrm{Bcl}-2$ family proteins. Whereas some are pro-apoptotic (like Bax, Bak), some are anti-apoptotic (like Bcl-2, Bcl-XL). These pro- and anti-apoptotic Bcl-2 proteins can form different combinations of heterodimers resulting in their mutual inhibition. Upon apoptotic stimulation, this inhibition is abrogated, leading to activation and oligomerization of the proapoptotic proteins Bax and Bak. This results in mitochondrial outer membrane permeabilization (MOMP) (Letai, Bassik et al. 2002; Kuwana, Bouchier-Hayes et al. 2005). The process of pore formation at the outer mitochondrial membrane enables release of cytochrome $\mathrm{c}$ into the cytoplasm. Cytochrome $\mathrm{c}$ binds the adaptor protein APAF1 (apoptotic protease activating factor 1 ) which oligomerizes into the heptameric apoptosome. As a consequence, initiator procaspases 9 are recruited and activated due to their proximity at the apoptosome, followed by activation of executioner procaspases. The resulting down-stream caspase cascade resembles the one induced by the extrinsic pathway, i.e. caspase 3 can be activated not only by caspase 8 and 10 (extrinsic pathway), but also by caspase 9 (intrinsic pathway), leading to activation of further caspases. 
A characteristic of apoptosis lies in the cleavage of PARP-1 (poly(ADP-ribose) polymerase-1) by caspase 3 (Kaufmann, Desnoyers et al. 1993; Lazebnik, Kaufmann et al. 1994). PARP-1 is a nuclear enzyme with an important role in DNA repair. Upon cleavage (by caspase 3 , but also by caspase 7), its recruitment to sites of DNA damage is prevented. Cleaved caspase 3 and cleaved PARP-1 are valuable markers of apoptosis which we used for immunoblotting.

In order to amplify the caspase cascade, the extrinsic pathway sometimes leads to activation of the intrinsic pathway. This is mediated by activating a Bcl-2 family member called Bid. After the extrinsic pathway is activated via death receptors, caspase 8 cleaves Bid, resulting in a truncated molecule named tBid. tBid can inhibit anti-apoptotic Bcl-2 proteins at mitochondria and triggers assembly of pro-apoptotic proteins which results in cytochrome c release. In this way, the signal arising from the extrinsic pathway is amplified by combining it with the intrinsic pathway (Figure 2.9).

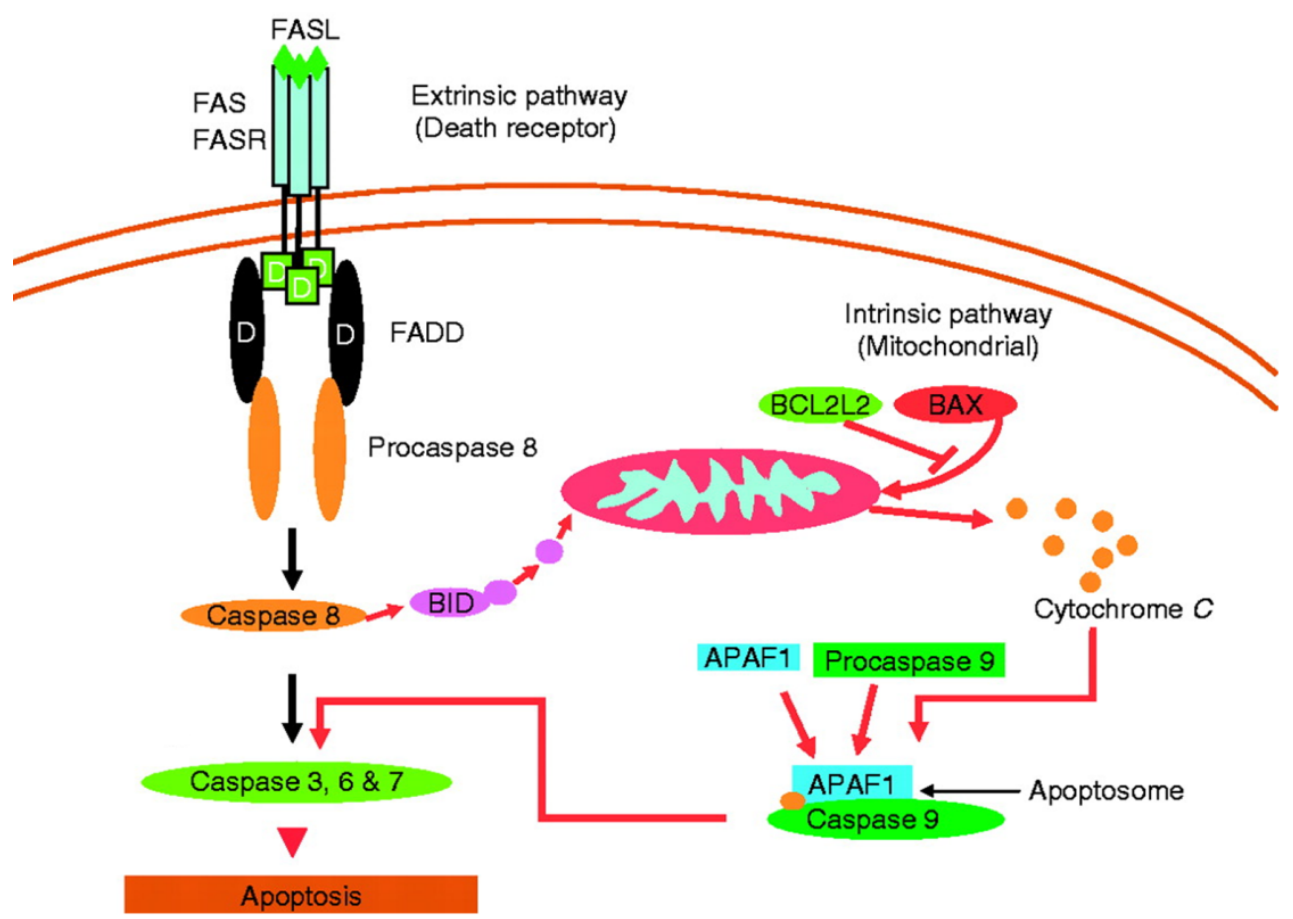

Figure 2.9: Simplified scheme of apoptosis pathways in the cell.

Depicted is the extrinsic and intrinsic apoptosis pathway. For details see text (taken from Ruwanpura, McLachlan et al. 2010). FADD = Fas-Associated protein with Death Domain.

\subsubsection{The role of p53 in apoptosis}

The tumor suppressor p53 performs important tasks during apoptosis, mainly via the mitochondrial pathway. After p53 stabilization and activation, it transactivates pro-apoptotic genes like Puma, Noxa and Bid, but can also repress anti-apoptotic genes like Bcl-2 and survivin (Moll, Marchenko et al. 2006). Puma (abbreviation for p53 upregulated modulator of 
apoptosis) was shown to interact with anti-apoptotic Bcl-2 proteins, resulting in release of Bax and Bak to promote apoptosis (Nakano and Vousden 2001; Willis, Fletcher et al. 2007). Whether there is a direct interaction or an indirect mechanism between Puma and Bax and Bak is still in debate. Besides its role as a transcription factor, p53 interacts with Bcl family members like $\mathrm{Bcl}-\mathrm{XL}$ and $\mathrm{Bcl}-2$ and stimulates oligomerization of the proapoptotic proteins Bax and Bak (Mihara, Erster et al. 2003; Chipuk, Kuwana et al. 2004; Tomita, Marchenko et al. 2006).

\subsubsection{Ubiquitination in apoptotic pathways}

Several ubiquitin ligases and DUBs have been shown to play an important role in apoptosis. These include Mdm2 (by regulating p53) and inhibitor of apoptosis (IAP) proteins. Furthermore, ubiquitin ligase complexes have significant impact on regulation of apoptosis. For instance, the multi-subunit ubiquitin ligase $\mathrm{SCF}^{\beta-\mathrm{TRCP}}$ is an important regulator of apoptosis with substrates like procaspase 3, p53 and the p53 family member p63 (Tan, Gallegos et al. 2006; Gallegos, Litersky et al. 2008; Xia, Padre et al. 2009). Besides ubiquitin ligases, DUBs are involved in apoptosis regulation, for example HAUSP (USP7), TNFAIP3 and CYLD (Vucic, Dixit et al. 2011).

\subsubsection{Feedback mechanisms between DDR, cell cycle regulation and apoptosis pathways}

It is a well-known fact that pathways regulating DDR, cell cycle and apoptosis cannot be regarded as separated, but often as interdependent. An obvious example is that induction of the DDR can lead to apoptosis if damaged DNA is irreparable. On the other hand, induction of apoptosis via the extrinsic pathway, i.e. by binding of an extracellular ligand, finally results in activation of endonucleases that break down DNA and thus elicit a DDR to DNA breaks. In fact, proteins have been described to be involved in both DDR and apoptosis. The mechanisms which decide whether a cell conducts DNA repair or goes into apoptosis are not well understood. One crucial issue is the localization of proteins that influences their function. Another aspect, especially applying to ubiquitin ligases and DUBs, concerns the knowledge that enzymes can have different substrates, depending on the pathways involved. Still, open questions remain of how decisions are made in the cell.

\subsection{The ubiquitin ligase G2E3}

We performed a high-content siRNA screen to identify new regulators in the DNA damage response to cisplatin. As detailed in the results section, we studied the ubiquitin ligase G2E3 in more detail.

G2E3 was originally identified in a global gene expressing profiling with the GenBank reference KIAA1333 when Crawford et al. investigated transcriptional control of gene 
expression in G2/M-phase (Crawford and Piwnica-Worms 2001). Additionally, they studied gene expression after DNA damage treatment using $y$-irradiation. The authors conducted a microarray analysis of HeLa cells after double thymidine block and identified genes with maximal expression in G2- and M-phase. Interestingly, many of these genes were downregulated in response to $y$-irradiation. One of the genes showing a maximal mRNA expression in G2/M-phase and decreased mRNA levels upon $\mathrm{Y}$-irradiation was G2E3 (G2specific E3 ligase).

\subsubsection{Domains and ubiquitin ligase activity of G2E3}

G2E3 was proposed to have ubiquitin ligase activity since it consists of four domains that can act as E3 ligases. Three of these domains have similarity to both RING and PHD domains and the fourth $\mathrm{C}$-terminal domain is a HECT domain (Figure 2.10). Domain structures were identified by Brooks et al. using SMART and PFAM (Brooks, Banerjee et al. 2007). It was shown that HECT is catalytically inactive, but controls subcellular localization of G2E3 (Brooks, Helton et al. 2008). Reasons for lack of activity of the HECT domain are numerous: not matching amino acids in the E2 binding site and at the C-terminus of the HECT domain and poorly conserved residues surrounding the active site. Using an in vitro ubiquitination assay, PHD/RING2 and PHD/RING3 domain have been reported to possess ubiquitin ligase activity and to catalyze Lys48-linked poly-ubiquitination (Brooks, Helton et al. 2008). The authors tested seven out of 35 known E2 ubiquitin-conjugating enzymes and detected high reactivity with UbcH5a. Naturally, they cannot exclude that PHD/RING1 and HECT domain have in vivo ubiquitin ligase activity, perhaps with other E2 enzymes. Furthermore, they provide evidence that G2E3 is auto-ubiquitinated in an in vitro assay. Thus, G2E3 has ubiquitin ligase activity though the endogenous substrate is not known.

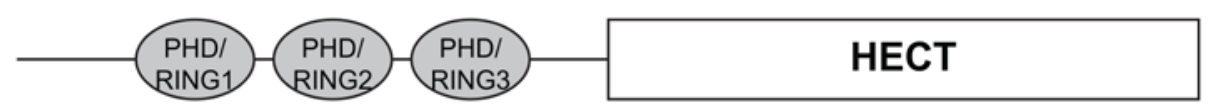

Figure 2.10: Domain structure of G2E3.

The scheme shows three domains with homology to both PHD and RING domain as well as a C-terminal HECT domain. The HECT domain is catalytically inactive, but controls subcellular localization of G2E3. PHD/RING2 and PHD/RING3 domain have been reported to possess ubiquitin ligase activity and to catalyze Lys48-linked poly-ubiquitination in an in vitro ubiquitination assay (taken from Brooks, Helton et al. 2008).

\subsubsection{Localization of G2E3}

It was reported by Brooks et al. that overexpressed GFP-G2E3 localizes to the nucleus of different cell types (including Cos-7, SiHa and BSC-40 cells). It was found in the nucleoli of HeLa cells and relocalizing to the nucleoplasm in response to DNA damage ( $\gamma$-irradiation, doxorubicin and etoposide treatment) in this cell line (Brooks, Banerjee et al. 2007). The 
authors state that GFP-G2E3 is not nuclear in primary WI-38 fibroblasts, the only nontransformed cell line they examined. Transformed cells harbor differing characteristics which could account for the difference. Certainly, different localization can implicate different protein functions. Furthermore, the authors report that G2E3 is exported from the nucleus of Cos-7 cells in a CRM1-independent manner (Brooks, Banerjee et al. 2007). CRM1 (exportin 1) is the major transport receptor for export of proteins out of the nucleus.

\subsubsection{G2E3 is repressed by p53}

The large intergenic noncoding RNA lincRNA-p21 was described to be a p53 target in response to DNA damage (Huarte, Guttman et al. 2010). Expression of lincRNA-p21 was shown to repress and activate different genes involved in apoptosis and cell cycle arrest. Besides many other genes, it was reported that p53 represses G2E3 expression via lincRNAp21. Gene repression via lincRNA-p21 is mediated by interaction with hnRNP-K (heterogeneous nuclear ribonucleoprotein $\mathrm{K}$ ) which had been shown before to interact with repressive complexes. Huarte et al. show that hnRNP-K binds to the promoters of genes that are normally repressed in a p53- and lincRNA-p21-dependent fashion.

\subsubsection{Inactivation of G2E3 in mice and of its ortholog pie in Drosophila}

It was reported that G2E3 is essential for early embryonic development since G2E3 knockout mice display early embryonic lethality due to strong apoptosis of the blastocysts (Brooks, Helton et al. 2008). Heterozygous mice are phenotypically normal with no detectable changes in growth, viability, fertility or development. Using $\beta$-galactosidase as a marker under the control of the endogenous G2E3 promoter, the authors investigated protein expression in heterozygous mice. They show prevalent G2E3 expression within the central nervous system and during limb bud formation in the developing embryo (Brooks, Helton et al. 2008). In adult mice, $\beta$-galactosidase expression was enriched in brain (Purkinje cells of the cerebellum) and testis (interstitial cells and cells lining the ductus deferens).

Remarkably, a G2E3 ortholog exists in Drosophila, called pineapple eye (pie) (Shi, Stampas et al. 2003; Brooks, Helton et al. 2008). The RING/PHD domain of both proteins is highly conserved. It was reported that like G2E3 pie is required for cell survival. Shi et al. investigated the adult eye phenotype and found that inactivation of pie leads to increased apoptosis (Shi, Stampas et al. 2003). However, the authors could not identify the molecular and biochemical function of pie. A recent publication reports that lack of pie does not result in apoptosis in germline stem cells (GSCs) of the Drosophila ovary (Xing, Kurtz et al. 2012). In this study, GSCs were used as a model to study adult stem cell renewal and pie was identified to be required for GSC self-renewing. As ubiquitin ligases often have different substrates and different functions, it is possible that pie exerts different functions depending on the cell type. More research is needed to elucidate the role of pie in Drosophila. 
Taken together, these results suggest that the ubiquitin ligase G2E3 could play a role in cell cycle regulation and in the DDR. Furthermore, G2E3 is important for cell survival.

\subsection{Scope of the thesis}

Despite detailed insights into the cellular response to damaged DNA and the consequences, it is not surprising that open questions remain. For example, it has been shown how the chemotherapeutic cisplatin induces crosslinking of DNA. However, the cellular and molecular mechanisms of subsequently activated signaling and repair pathways are incompletely understood. Thus, identifying new proteins that regulate the DDR to cisplatin would help us to understand activated pathways in more detail. Since ubiquitination plays a major role in the DDR, we applied a high-content siRNA screen targeting human ubiquitin ligases and DUBs to find new regulators in the DDR to cisplatin. We thereby detected phosphorylation of the histone variant $\mathrm{H} 2 \mathrm{AX}$ (yielding $\mathrm{YH} 2 \mathrm{AX}$ ), a marker for DNA damage. We identified a multitude of known and unknown regulators of the DDR to cisplatin. Knockdown of one of the candidates, the ubiquitin ligase G2E3, led to decrease in $\mathrm{yH} 2 \mathrm{AX}$ levels upon cisplatin treatment. G2E3 had previously been proposed to play a role in the DDR and in cell survival. However, little was known about the underlying mechanisms. Therefore, the present work aimed at understanding how G2E3 is involved in the cellular response to DNA damage. The work presented here suggests that G2E3 is a DNA damage-responsive, cell cycle-dependent survival factor. We found that G2E3 mRNA and protein levels are down-regulated upon DNA damage. Knockdown of G2E3 resulted in p53-independent apoptosis and decreased proliferation in colon carcinoma and osteosarcoma cell lines. Furthermore, we verified that G2E3 levels are maximal in G2-phase, suggesting a cell cycle-dependent regulation of G2E3. In summary, our results suggest that G2E3 is a modulator of cell proliferation, survival and the DDR whose loss may contribute to apoptosis upon DNA damage. 


\section{Materials}

\subsection{Technical devices}

Table 3.1: Technical devices

\section{Device}

Automated Cell Counter Countess $\AA$

Biomek 2000 Laboratory Automation

Workstation

Blotting chamber

Cell counting chamber Neubauer improved

Centrifuge 5415R

Centrifuge 5810R

Centrifuge Megafuge 1.0R

Chemiluminescence imager Chemocam HR 163200

Cytometer Celigo

DNA gel chamber

Electrophoresis system for SDS-PAGE

Electroporator GenePulser II

FACS machine EasyCyte plus

Foil swelding machine Vacupack plus

Freezer $-20^{\circ} \mathrm{C}$

Freezer $-80^{\circ} \mathrm{C}$

Heating Block

Heating Block HLC

Ice-machine $B 100$

Incubator for bacteria

Incubator for bacteria Minitron

Incubator for cell culture Hera Cell 150

Laminar flow cabinet Hera Safe

Liquid nitrogen tank LS 4800

Luminometer DLReady ${ }^{\mathrm{TM}}$ Centro LB 960

Magnetic stirrer MR3001

Microscope Axovert 40C

Microscope Axioscope 2 Plus

Microscope, automated Pathway 855

Microwave

Mini Centrifuge MCF-2360

PCR machine for qPCR CFX96, C1000

PCR machine Primus 25 advanced

pH-meter WTW-720

Pipet Multipette

Pipet, electric Portable-XP

Pipets Eppendorf Research Series 2100

(0.1-2.5 $\mu \mathrm{L} ; 0.5-10 \mu \mathrm{L} ; 10-100 \mu \mathrm{L} ; 100-$

$1000 \mu \mathrm{L})$

\section{Company}

Invitrogen, Life Technologies

Beckman Coulter

Biozym

Brand

Eppendorf

Eppendorf

Heraeus, Thermo Scientific

Intas Science Imaging Instruments

Cyntellect

Biotech Service Blu

Amersham Biosciences, GE Healthcare

Bio-Rad Laboratories

Guava Technologies, Millipore

Krups

Liebherr

Heraeus, Thermo Scientific

Grant Instruments

HLC Biotech

Ziegra

Memmert

Infors HT

Heraeus, Thermo Scientific

Heraeus, Thermo Scientific

Taylor-Wharton

Bertold Technologies

Heidolph

Zeiss

Becton Dickinson

Cinex

LMS

Bio-Rad Laboratories

Peqlab

WTW

Eppendorf

Drummond

Eppendorf 
Pipette, multichannel Research Plus

Power supply unit Powerpack P25T

Refrigerator $4^{\circ} \mathrm{C}$

Roller RM5 V-30

Rotating wheel Test-tube rotator 34528

Rotator PTR 300

Scales Acculab ALC-6100.1

Scales LE623S

Scanner CanoScan 8600F

Sequencer, automated $A B I 3100$

Shaker PROMAX 2020

Sonication device Bioruptor

Spectrophotometer NanoDrop ND-1000

Thermomixer comfort

UV-transilluminator Intas UV system Gel

Jet Imager

Vacuum pump

Vortex Genie 2

Water bath TW 20

\author{
Eppendorf \\ Biometra \\ Liebherr \\ CAT \\ Snijders \\ Grant Instruments \\ Sartorius \\ Sartorius \\ Canon \\ Applied Biosystems, Life Technologies \\ Heidolph \\ Diagenode \\ PeqLab \\ Eppendorf \\ Intas Science Imaging Instruments \\ IBS Integra Biosciences \\ Scientific Industries \\ Julabo Labortechnik
}

\subsection{Consumables}

Table 3.2: Consumables

\begin{tabular}{ll} 
Product & Company \\
\hline 96-well plates for flow cytometry & Becton Dickinson \\
96-well plates for microscopy, clear bottom & Becton Dickinson \\
96-well plates for microscopy, clear bottom & Corning \\
96-well plates for qPCR & 4titude \\
96-well plates Optiplate ${ }^{\mathrm{TM}}$ 96 for luciferase assay & Perkin Elmer \\
Bacteria culture dishes & Sarstedt \\
Bacteria culture vials $(14 \mathrm{~cm})$ & Becton Dickinson \\
Cell culture dishes $(10 \mathrm{~cm}, 15 \mathrm{~cm})$ & Greiner \\
Cell culture plates $(6$-well, 12 -well) & Greiner \\
Cell scraper $(16 \mathrm{~cm}, 25 \mathrm{~cm})$ & Sarstedt \\
Cryo tubes Cryoline & Nunc, Thermo Scientific \\
Electroporation cuvette Gene Pulser & Bio-Rad Laboratories \\
Filter tips $(10 \mu \mathrm{l})$ & Starlab \\
Filter tips $(20 \mu \mathrm{l}, 200 \mu \mathrm{l}, 1,000 \mu \mathrm{l})$ & Sarstedt \\
Parafilm & Brand \\
Pipet tips $(10 \mu \mathrm{l}, 20-200 \mu \mathrm{l}, 1,000 \mu \mathrm{l})$ & Greiner \\
Pipet tips for screen $(50 \mu \mathrm{l}, 200 \mu \mathrm{l})$ & Beckman Coulter \\
Protran nitrocellulose transfer membrane & Whatman \\
Reaction tube $(0.2 \mathrm{ml})$ & Sarstedt \\
Reaction tube $(0.5 \mathrm{ml}, 1.5 \mathrm{ml}, 2.0 \mathrm{ml})$ & Eppendorf \\
Reaction tube $(15 \mathrm{ml}, 50 \mathrm{ml})$ & Greiner \\
Reservoir & Beckman Coulter \\
Reservoir (divided by length) & Beckman Coulter \\
Safe-lock reaction tube $(1.5 \mathrm{ml})$ & Eppendorf \\
Sealing foil for 96 -well plate & Becton Dickinson
\end{tabular}


Sterile filter

Syringe

Syringe cannula (different sizes)

Transparent sealing foil for 96-well plate

Whatman paper
Millipore, Merck

Henke-Sass

B.Braun

4titude

Whatman

\subsection{Chemicals and reagents}

Table 3.3: Chemicals and reagents

\begin{tabular}{|c|c|}
\hline Substance & Company \\
\hline Acetic acid & Roth \\
\hline Acrylamide/bisacrylamide (A/BA) & Roth \\
\hline Adenosin triphosphate (ATP) & Fermentas, Thermo Scientific \\
\hline Agar & Sigma-Aldrich \\
\hline Agarose & Roth \\
\hline Albumin Fraction V (Bovine Serum Albumine, BSA) & Roth \\
\hline Ammonium persulfate (APS) & Roth \\
\hline Ammonium sulfate $\left(\left(\mathrm{NH}_{4}\right)_{2} \mathrm{SO}_{4}\right)$ & Roth \\
\hline Ampicillin & AppliChem \\
\hline Aprotinin & AppliChem \\
\hline Bromophenol blue & Sigma-Aldrich \\
\hline Calcium chloride dihydrate $\left(\mathrm{CaCl}_{2} \times 2 \mathrm{H}_{2} \mathrm{O}\right)$ & Roth \\
\hline Chloroform & Roth \\
\hline Complete Mini, EDTA-free Protease Inhibitor Mix & Roche \\
\hline Coelenterazine & Promega \\
\hline Coenzyme A sodium salt hydrate & Sigmal-Aldrich \\
\hline Dimethyl sulfoxide (DMSO) & AppliChem \\
\hline Dithiotreitol (DTT) & Sigma-Aldrich \\
\hline D-Luciferin & $\mathrm{ICN}$ \\
\hline DNA ladder GeneRuler & Fermentas, Thermo Scientific \\
\hline Deoxyribonucleotide triphosphates (dNTPs) & Bio-Budget \\
\hline $\begin{array}{l}\text { Deoxyribonucleotide triphosphates (dNTPs) in } \\
\text { single tubes }\end{array}$ & Primetech \\
\hline Dipotassium phosphate $\left(\mathrm{K}_{2} \mathrm{HPO}_{4}\right)$ & Roth \\
\hline Dithiothreitol (DTT) & Roth \\
\hline DNA stain clear G (39804) & Serva \\
\hline Ethanol $99.8 \%$ & Roth \\
\hline Ethanol 99.9\% p.a. (EtOH) & Merck \\
\hline Ethylene diamine tetraacetatic acid (EDTA) & Roth \\
\hline Ethylene glycol tetraacetic acid (EGTA) & Roth \\
\hline Fetal calf serum HyClone & Thermo Scientific \\
\hline Formaldehyde, $37 \%$ solution & Roth \\
\hline Glycerol & Roth \\
\hline Glycine & Roth \\
\hline Glycogen blue & Ambion, Life Technologies \\
\hline Glycylglycine & AppliChem \\
\hline Guava ICF Cleaning Solution & Millipore, Merck \\
\hline HEPES & Roth \\
\hline Hi-Di Formamide & Applied Biosystems, Life Technologies \\
\hline
\end{tabular}


Hoechst 33342

Hydrogen chloride $(\mathrm{HCl})$

Isoamyl alcohol

Isopropanol

Kanamycin sulfate

Leupeptin Hemisulfat

Lipofectamine $^{\text {TM }} 2000$ (LF2000)

Magnesium chloride $\left(\mathrm{MgCl}_{2}\right)$ for PCR

Magnesium chloride hexahydrate $\left(\mathrm{MgCl}_{2} \times 6 \mathrm{H}_{2} \mathrm{O}\right)$

Magnesium sulfate $\left(\mathrm{MgSO}_{4}\right)$

Methanol $>99 \%$ (MetOH)

N-ethylmaleimide (04260)

Nonidet P-40 substitute (NP-40)

Nuclease free water

Page Ruler ${ }^{\mathrm{TM}}$ Prestained Protein Ladder

Passive Lysis Buffer (E1941)

Pefabloc SC protease inhibitor

Pepstatin A

Ponceau S

Potassium chloride $(\mathrm{KCl})$

Potassium hydrogenphosphate $\left(\mathrm{KH}_{2} \mathrm{PO}_{4}\right)$

Powdered milk

Propidium iodide $(\mathrm{PI})$

Protein A Sepharose (PAS)

Protein G Sepharose (PGS)

RNase inhibitor

Roti-Phenol

Rotiphorese Gel 30

Sodium acetate (NaAc)

Sodium azide $\left(\mathrm{NaN}_{3}\right)$

Sodium bicarbonate $\left(\mathrm{NaHCO}_{3}\right)$

Sodium chloride $(\mathrm{NaCl})$

Sodium deoxycholate

Sodium dodecyl sulfate (SDS)

Sodium hydrogenphosphate heptahydrate

$\left(\mathrm{Na}_{2} \mathrm{HPO}_{4} \times 7 \mathrm{H}_{2} \mathrm{O}\right)$

Sodium hydroxide $(\mathrm{NaOH})$

Sucrose

SYBR Green

Tetracycline

Tetramethylethylenediamine (TEMED)

Thymidine

Trasylol

Trehalose

TRIS

Trisamine (Tris)

Triton X-100

Trizol

Tween 20

Yeast extract

$\beta$-Mercaptoethanol
Invitrogen, Life Technologies

Roth

Roth

Th. Geyer

AppliChem

AppliChem

Invitrogen, Life Technologies

Fermentas, Thermo Scientific

Roth

AppliChem

Roth

Fluka

Sigma Aldrich

Ambion, Life Technologies

Fermentas, Thermo Scientific

Promega

Roth

AppliChem

Roth

Roth

Roth

Roth

Sigma-Aldrich

Invitrogen, Life Technologies

GE Healthcare

Fermentas, Thermo Scientific

Roth

Roth

Roth

AppliChem

Roth

Roth

AppliChem

Roth

Roth

Sigma-Aldrich

Sigma-Aldrich

Invitrogen, Life Technologies

Sigma-Aldrich

Roth

Sigma-Aldrich

Bayer, Leverkusen

Sigma-Aldrich

Tris(hydroxymethyl)aminomethane

Roth

Applichem

Invitrogen, Life Technologies

Applichem

Sigma-Aldrich

Roth 


\subsection{Buffers and Solutions}

\begin{tabular}{lr}
\multicolumn{2}{l}{ RIPA lysis buffer, pH 7.5 } \\
\hline Triton X-100 & $1.0 \%$ \\
Sodium deoxycholate & $1.0 \%$ \\
SDS & $0.1 \%$ \\
$\mathrm{NaCl}$ & $150 \mathrm{mM}$ \\
EDTA & $10 \mathrm{mM}$ \\
Tris- $\mathrm{HCl}, \mathrm{pH} 7.5$ & $20 \mathrm{mM}$ \\
Trasylol & $50,000 \mathrm{KIU}$ \\
dissolved in $\mathrm{H}_{2} \mathrm{O}$ &
\end{tabular}

Cell lysis buffer

\begin{tabular}{lr}
\hline Urea & $2 \mathrm{M}$ \\
RIPA lysis buffer & $100 \%$ \\
protease inhibitors: & \\
Pefabloc & $10 \mu \mathrm{M}$ \\
Pepstatin A & $1 \mu \mathrm{g} / \mathrm{ml}$ \\
Leupeptin/Aprotinin & $1 \mu \mathrm{g} / \mathrm{ml}$ \\
& \\
Laemmli buffer, 6x & \\
\hline Tris pH 6.8 & $0.35 \mathrm{M}$ \\
Glycerin & $30.00 \%$ \\
SDS & $10.00 \%$ \\
Dithiotreitol & $9.30 \%$ \\
Bromophenol blue & $0.02 \%$ \\
dissolved in $\mathrm{H}_{2} \mathrm{O}$ &
\end{tabular}

\begin{tabular}{ll} 
Ponceau S solution & \\
\hline Ponceau S & $0.5 \%$ \\
Acetic acid & $1.0 \%$ \\
dissolved in $\mathrm{H}_{2} \mathrm{O}$ &
\end{tabular}

10x Phosphate buffered saline (PBS), pH 7.5

$\begin{array}{lr}\mathrm{NaCl} & 240.0 \mathrm{mM} \\ \mathrm{KCl} & 2.7 \mathrm{mM} \\ \mathrm{Na}_{2} \mathrm{HPO}_{4} \times 7 \mathrm{H}_{2} \mathrm{O} & 8.1 \mathrm{mM} \\ \mathrm{KH}_{2} \mathrm{PO}_{4} & 1.5 \mathrm{mM} \\ \text { dissolved in } \mathrm{H}_{2} \mathrm{O} & \end{array}$

\section{ColP buffer}

\begin{tabular}{lr}
\hline Tris- $\mathrm{HCl}, \mathrm{pH} 7.5$ & $50 \mathrm{mM}$ \\
Sodium chloride & $300 \mathrm{mM}$ \\
NP-40 & $1 \%$ \\
Sodium deoxycholate & $0.1 \%$ \\
Complete Mini, & 1 tablet \\
Protease Inhibitor Mix & \\
dissolved in $\mathrm{H}_{2} \mathrm{O}$ &
\end{tabular}

SDS running buffer

\begin{tabular}{lr}
\hline Tris & $25.0 \mathrm{mM}$ \\
Glycin & $86.1 \mathrm{mM}$ \\
SDS & $3.5 \mathrm{mM}$
\end{tabular}

dissolved in $\mathrm{H}_{2} \mathrm{O}$

Tris buffered saline + Tween 20

(TBST), pH 7.6

\begin{tabular}{lr}
\hline Tris & $50 \mathrm{mM}$ \\
$\mathrm{NaCl}$ & $150 \mathrm{mM}$ \\
Tween 20 & $0.1 \%$ \\
dissolved in $\mathrm{H}_{2} \mathrm{O}$ &
\end{tabular}

Western blot blocking solution

Milk powder $5 \%$ dissolved in TBST

Western blot blocking solution for phospho-antibodies

BSA $5 \%$

dissolved in TBST

10x Western Salt buffer, pH 8.3

\begin{tabular}{lr}
\hline Tris & $250 \mathrm{mM}$ \\
Glycin & $1,92 \mathrm{M}$ \\
SDS & $0.02 \%$
\end{tabular}

dissolved in $\mathrm{H}_{2} \mathrm{O}$

Western blot transfer buffer, pH 8.3

10x Western Salt buffer $10 \%$

$\mathrm{MetOH}$

$20 \%$

dissolved in $\mathrm{H}_{2} \mathrm{O}$

Firefly Buffer

\begin{tabular}{lr}
\hline Glycylglycine & $25 \mathrm{mM}$ \\
K2HPO4 & $15 \mathrm{mM}$ \\
EGTA pH 8.0 & $4 \mathrm{mM}$ \\
dissolved in $\mathrm{H}_{2} \mathrm{O}$ &
\end{tabular}

\section{Renilla Buffer}

$\begin{array}{lr}\mathrm{NaCl} & 1,1 \mathrm{M} \\ \mathrm{Na} 2 \mathrm{EDTA} & 2.2 \mathrm{mM} \\ \mathrm{K} 2 \mathrm{HPO} 4 \mathrm{pH}^{2} .1 & 0.22 \mathrm{M} \\ \text { dissolved in } \mathrm{H}_{2} \mathrm{O} & \end{array}$


DNA gel loading buffer, $6 x$

\begin{tabular}{lr}
\hline Sucrose & $40 \%$ \\
Glycerin & $10 \%$ \\
Bromophenol blue & $0.25 \%$ \\
dissolved in $\mathrm{H}_{2} \mathrm{O}$ &
\end{tabular}

TAE buffer

\begin{tabular}{lr}
\hline Tris & $40 \mathrm{mM}$ \\
Acetic acid & $20 \mathrm{mM}$ \\
EDTA & $2 \mathrm{mM}$
\end{tabular}

dissolved in $\mathrm{H}_{2} \mathrm{O}$

IF blocking solution

\begin{tabular}{lr}
\hline FCS & $5 \%$ \\
Triton X-100 & $0.1 \%$ \\
dissolved in PBS &
\end{tabular}

qPCR reaction mix

10x qPCR reaction buffer

SYBR Green

$\mathrm{MgCl}_{2}$

$10 \%$

1:80,000

$3 \mathrm{mM}$

Trehalose in $10 \mathrm{mM}$ Tris, $\quad 300 \mathrm{mM}$

$\mathrm{pH} 8,5$

dNTPs

Triton X-100

$0.2 \mathrm{mM}$

$0.25 \%$

$20 \mathrm{U} / \mathrm{ml}$

Taq polymerase
Luciferase Assay Reagent 'Firefly'

\begin{tabular}{lr}
\hline $\mathrm{MgSO}_{4}$ & $15 \mathrm{mM}$ \\
ATP pH 7.0 & $4 \mathrm{mM}$ \\
Dithiothreitol & $1.25 \mathrm{mM}$ \\
Coenzyme A & $0.1 \mathrm{mM}$ \\
Luciferin & $80 \mu \mathrm{M}$
\end{tabular}

dissolved in Firefly buffer

Luciferase Assay Reagent 'Renilla'

\begin{tabular}{lr}
\hline $\mathrm{BSA}$ & $0.5 \mathrm{mg} / \mathrm{ml}$ \\
$\mathrm{NaN}_{3}$ & $1.5 \mathrm{mM}$ \\
Coelenterazine & $1.5 \mu \mathrm{M}$ \\
dissolved in Renilla buffer &
\end{tabular}

qPCR reaction buffer, 10x

\begin{tabular}{lr}
\hline Tris- $\mathrm{HCl}, \mathrm{pH} 8,8$ & $750 \mathrm{mM}$ \\
$\left(\mathrm{NH}_{4}\right)_{2} \mathrm{SO}_{4}$ & $200 \mathrm{mM}$ \\
Tween 20 & $0.1 \%$ \\
dissolved in $\mathrm{H}_{2} \mathrm{O}$ &
\end{tabular}

dissolved in $\mathrm{H}_{2} \mathrm{O}$

(shock-frozen in liquid nitrogen and

kept at $-20^{\circ} \mathrm{C}$ )

\subsection{Chemotherapeutics and pharmacological inhibitors}

Table 3.4: Chemotherapeutics

\begin{tabular}{lll} 
Name & Systematic name & Company \\
\hline Cisplatin & cis-diammine-dichloroplatinum (II) & Cis-Gry, Teva Deutschland \\
Neocarzinostatin (NCS) & & Sigma-Aldrich, \#N9162
\end{tabular}

Table 3.5: Inhibitors

\begin{tabular}{lll} 
Name & Target & Company \\
\hline N-ethylmaleimide & DUBs & Fluka, \#04260 \\
Nutlin-3 & Mdm2 & Sigma-Aldrich,\#N6287 \\
MG132 & Proteasome & Calbiochem, \#474791 \\
Z-VAD & Caspases & Sigma, \#V116-2mg
\end{tabular}




\subsection{Enzymes and buffers}

Table 3.6: Enzymes and buffers

\begin{tabular}{ll} 
Reagent & Company \\
\hline Buffer for Kpnl & Fermentas, Thermo Scientific \\
Buffer for M-MuLV RT, 10x & New England Biolabs (NEB) \\
Buffer for Taq $\left(\mathrm{KCl}^{+},-\mathrm{MgCl}_{2}\right), 10 \mathrm{x}$ & Fermentas, Thermo Scientific \\
Calf Intestine Alkaline Phosphatase & Fermentas, Thermo Scientific \\
Cloned Pfu reaction buffer, 10x & Stratagene \\
Kpnl & Fermentas, Thermo Scientific \\
M-MuLV Reverse transcriptase $(\mathrm{RT})$ & New England Biolabs (NEB) \\
Pfu Turbo DNA polymerase $(2.5 \mathrm{U} / \mu \mathrm{l})$ & Stratagene \\
RNase A $(1 \mathrm{mg} / \mathrm{ml})$ & Qiagen, Venlo, Netherlands \\
T4 ligase $(200 \mathrm{U} / \mu \mathrm{l})$ & Fermentas, Thermo Scientific \\
T4 ligase buffer & Fermentas, Thermo Scientific \\
Taq DNA polymerase $(\mathrm{Taq})$ & Fermentas, Thermo Scientific \\
Taq DNA polymerase (Taq) for qPCR & Primetech \\
Xbal & Fermentas, Thermo Scientific
\end{tabular}

\subsection{Kits}

Table 3.7: Kits

\begin{tabular}{ll} 
Name & Company \\
\hline BigDye Terminator v3.1 Cycle Sequencing kit & Invitrogen, Life Technologies \\
Guava Check Kit & Millipore, Merck \\
Immobilon Western HRP Substrate Peroxide Solution & Millipore, Merck \\
Invisorb Spin Plasmid Mini Kit Two & Invitec, Stratec \\
Pierce ${ }^{\circledR}$ BCA Protein Assay Kit & Thermo Scientific \\
PureYield ${ }^{\text {TM }}$ Plasmid Midiprep System & Promega \\
QIAquick ${ }^{\circledR}$ PCR Purification Kit (250) & Qiagen \\
SuperSignal West Femto Maximum Sensitivity Substrate & Thermo Scientific
\end{tabular}

\subsection{Oligonucleotides}

For the high-content siRNA screen on human ubiquitin ligases and deubiquitinating enzymes, the Silencer ${ }^{\circledR}$ Select Ubiquitin Library (Ambion, catalog Number: 4392425, AM16998) was used. 
Table 3.8: Small interfering RNAs from Ambion/Life Technologies

\begin{tabular}{|c|c|c|}
\hline Target & Sequence & SiRNA ID \\
\hline BRCA1 & $\begin{array}{l}\text { sense: 5'-AAUGCCAAAGUAGCUAAUGUAtt-3' } \\
\text { antisense: 5'-UACAUUAGCUACUUUGGCAUUtt-3' }\end{array}$ & $\begin{array}{l}\text { AM16210 } \\
\text { (silencer) }\end{array}$ \\
\hline Chk1 & $\begin{array}{l}\text { sense: 5'-GCAACAGUAUUUCGGUAUAtt-3' } \\
\text { antisense: 5'-UAUACCGAAAUACUGUUGCca-3' }\end{array}$ & $\begin{array}{l}\text { AM51331 } \\
\text { (silencer) }\end{array}$ \\
\hline $\begin{array}{l}\text { control siRNA } \\
\text { scrambled No. } 1\end{array}$ & undisclosed & $\begin{array}{l}4390844 \\
\text { (silencer select) }\end{array}$ \\
\hline $\begin{array}{l}\text { control siRNA } \\
\text { scrambled No. } 2\end{array}$ & undisclosed & $\begin{array}{l}4390847 \\
\text { (silencer select) }\end{array}$ \\
\hline G2E3-A & $\begin{array}{l}\text { sense: 5‘-GAUGGUAAAUCUACAACAAtt-3' } \\
\text { antisense: 5'-UUGUUGUAGAUUUACCAUCtt-3' }\end{array}$ & $\begin{array}{l}\text { s31128 } \\
\text { (silencer select) }\end{array}$ \\
\hline G2E3-B & $\begin{array}{l}\text { sense: 5'-GAAGGGUCCUUGUCAAAGAtt-3' } \\
\text { antisense: 5'-UCUUUGACAAGGACCCUUCaa-3' }\end{array}$ & $\begin{array}{l}\text { s31129 } \\
\text { (silencer select) }\end{array}$ \\
\hline G2E3-C & $\begin{array}{l}\text { sense: 5'-GGAUGUCUCAGACUUAUAAtt-3' } \\
\text { antisense: 5'- UUAUAAGUCUGAGACAUCCaa-3' }\end{array}$ & $\begin{array}{l}\text { s31130 } \\
\text { (silencer select) }\end{array}$ \\
\hline MDM2 & $\begin{array}{l}\text { sense: 5'-GCCAUUGCUUUUGAAGUUAtt-3' } \\
\text { antisense: 5'-UAACUUCAAAAGCAAUGGCtt-3' }\end{array}$ & $\begin{array}{l}4390828 \\
\text { (silencer select) }\end{array}$ \\
\hline p53 & $\begin{array}{l}\text { sense: 5‘-GUAAUCUACUGGGACGGAAtt-3' } \\
\text { antisense: 5'-UUCCGUCCCAGUAGAUUACca-3' }\end{array}$ & $\begin{array}{l}\text { s605 } \\
\text { (silencer select) }\end{array}$ \\
\hline RBBP6 & $\begin{array}{l}\text { sense: 5'-CGACUUAAAGAAGCAGAUUtt-3' } \\
\text { antisense: 5'-AAUCUGCUUCUUUAAGUCGca-3' }\end{array}$ & $\begin{array}{l}\text { s11844 } \\
\text { (silencer select) }\end{array}$ \\
\hline RBBP6 & $\begin{array}{l}\text { sense: 5‘-UGUUAUAAGUCGAACUGAAtt-3' } \\
\text { antisense: 5'-UUCAGUUCGACUUAUAACAta-3' }\end{array}$ & $\begin{array}{l}\text { S11845 } \\
\text { (silencer select) }\end{array}$ \\
\hline RBBP6 & $\begin{array}{l}\text { sense: 5'-GCGAUGGCAACUACAAAAGtt-3' } \\
\text { antisense: 5'-CUUUUGUAGUUGCCAUCGCtg-3' }\end{array}$ & $\begin{array}{l}143012 \\
\text { (silencer) }\end{array}$ \\
\hline RNF8 & $\begin{array}{l}\text { sense: 5'-GGACAAUUAUGGACAACAAtt-3' } \\
\text { antisense: 5'-UUGUUGUCCAUAAUUGUCCtg-3' }\end{array}$ & $\begin{array}{l}\text { AM16104 } \\
\text { (silencer) }\end{array}$ \\
\hline STUB1/CHIP & $\begin{array}{l}\text { sense: 5'-GUCUGUUCGUGGGCCGAAAtt-3' } \\
\text { antisense: 5'-UUUCGGCCCACGAACAGACga-3' }\end{array}$ & $\begin{array}{l}\text { s195025 } \\
\text { (silencer select) }\end{array}$ \\
\hline STUB1/CHIP & $\begin{array}{l}\text { sense: 5'-CGCUGGUGGCCGUGUAUUAtt-3' } \\
\text { antisense: 5'-UAAUACACGGCCACCAGCGgg-3' }\end{array}$ & $\begin{array}{l}\text { s195026 } \\
\text { (silencer select) }\end{array}$ \\
\hline STUB1/CHIP & $\begin{array}{l}\text { sense: 5'-GAGCUAUGAUGAGGCCAUCtt-3' } \\
\text { antisense: 5'-GAUGGCCUCAUCAUAGCUCtc-3' }\end{array}$ & $\begin{array}{l}215047 \\
\text { (silencer) }\end{array}$ \\
\hline
\end{tabular}


Table 3.9 Primers

\begin{tabular}{|c|c|c|}
\hline Name & Sequence & Application \\
\hline CMV promoter forward & 5'-CGC AAA TGG GCG GTA GGC GTG-3' & $\begin{array}{l}\text { sequencing } \\
\text { of plasmids }\end{array}$ \\
\hline Seq22_KIAA1333* & 5'-CAG AAA GAG ATG TTG AGA ATG-3' & $\begin{array}{l}\text { sequencing } \\
\text { of } \mathrm{G} 2 \mathrm{E} 3\end{array}$ \\
\hline Seq3_KIAA1333* & 5'-GGA ATA GTG CCT TAG ATG C-3' & $\begin{array}{l}\text { sequencing } \\
\text { of G2E3 }\end{array}$ \\
\hline Seq4_KIAA1333* & 5'-GGA GAA AAT TCA GGC TTA TCC-3' & $\begin{array}{l}\text { sequencing } \\
\text { of G2E3 }\end{array}$ \\
\hline HA-G2E3-Xbal-Fwd & $\begin{array}{l}\text { 5'-GCC GCC TCT AGA AAT GAA AGT AAA CCT } \\
\text { GGT GAC-3، }\end{array}$ & cloning \\
\hline HA-G2E3-KpnI-Rev & $\begin{array}{l}\text { 5'-CGG CGG GGT ACC TTA ATG TCC AAT GTA } \\
\text { ATG AG-3‘ }\end{array}$ & cloning \\
\hline anchored oligo-dT & $5^{\prime}-\mathrm{dT}_{23} \mathrm{VN}-3^{\prime}$ & RT-PCR \\
\hline random nonamer & 5'-NNNNNNNNN-3' & RT-PCR \\
\hline GAPDH forward & 5'-TGA AGG TCG GAG TCA ACG GAT TTG GT-3' & qPCR \\
\hline GAPDH reverse & 5'-GCA GAG ATG ATG ACC CTT TTG GCT C-3' & \\
\hline p21 forward & 5'-TAG GCG GTT GAA TGA GAG G-3' & qPCR \\
\hline p21 reverse & 5'-AAG TGG GGA GGA GGA AGT AG-3' & \\
\hline Mdm2 forward & 5'-TCA GGA TTC AGT TTC AGA TCA G-3' & qPCR \\
\hline Mdm2 reverse & 5'-CTA TTG GAA ATG CAC TTC ATG C-3' & \\
\hline p53 forward & 5'-ATG GAG GAG CCG CAG TCA GAT C-3' & qPCR \\
\hline p53 reverse & 5'-GGG AGC AGC CTC TGG CAT TCT G-3' & \\
\hline G2E3-for2 & 5'-GGC GTG CCC CGA CGT ACA G-3' & qPCR \\
\hline G2E3-rev1 & 5'-AGC AAG GTT CTG TGA GTC ACC AGG-3' & \\
\hline
\end{tabular}

${ }^{*}$ G2E3 was originally identified in a global gene expressing profiling with the GenBank reference KIAA1333. 


\subsection{Plasmids}

Table 3.10: Plasmids

\begin{tabular}{ll} 
Name & Description \\
\hline pGL3-PG13-Luc & pGL3 reporter plasmid containing 13 binding sites for p53 \\
& upstream of Firefly luciferase gene (Kern, Pietenpol et al. \\
& 1992) \\
\hline pRL-tk-RLuc & pRL reporter plasmid (Promega) with thymidine kinase \\
& promoter upstream of Renilla luciferase gene \\
\hline pRc/CMV-p53 & pRc/CMV vector (Invitrogen) with entire wild-type human p53 \\
& cDNA. (Lin, Chen et al. 1994) \\
\hline pcDNA3- $\Delta$ Np63-alpha & pcDNA3 expression vector (Invitrogen) with human $\Delta$ Np63- \\
& alpha cDNA \\
\hline pcDNA3 & expression vector (Invitrogen) for the exogenous expression of \\
& proteins under the control of a CMV promoter in eukaryotic \\
& cells \\
\hline pcDNA3-GFP & expression vector for green fluorescent protein (GFP) \\
\hline pCMV-Mdm2 & expression vector with entire human Mdm2 cDNA (kindly \\
& provided by Bert Vogelstein) \\
\hline pCMV-Mdm2-RING-mut & expression vector with mutated RING domain of human Mdm2 \\
\hline pCGN-HA & expression vector for the exogenous expression of proteins \\
& with an N-terminal hemagglutinin (HA)-tag under the control of \\
& a CMV promoter in eukaryotic cells; includes ampicillin \\
& resistance gene \\
\hline pCGN-HA-G2E3 & expression vector with entire human G2E3 cDNA (Franziska \\
& Schmidt) \\
\hline pEGFP-C3-G2E3 & pEGFP-C3 (Clontech) is an expression vector for the \\
& exogenous expression of proteins with a N-terminal GFP-tag \\
& under the control of a CMV promoter. G2E3 was cloned into \\
& pEGFP-C3 using restriction sites for Xhol and Kpnl (Brooks, \\
& Banerjee et al. 2007)
\end{tabular}




\subsection{Antibodies}

Table 3.11: Primary antibodies for Western blot and co-immunoprecipitation (CoIP)

\begin{tabular}{|c|c|c|c|c|c|}
\hline Antibody & Source & Company & Cat. No. & Application & Dilution \\
\hline$\beta$-Actin & mouse & Abcam & ab6276-100 & WB & $50,000 x$ \\
\hline$\beta$-Galactosidase & mouse & Promega & Z378B & ColP & $\mathrm{n} / \mathrm{a}$ \\
\hline Caspase 3 & rabbit & Cell Signaling & 9662 & WB & $1000 x$ \\
\hline Chk1 (2G1D5) & mouse & Cell Signaling & 2360 & WB & $1000 x$ \\
\hline Chk2 & mouse & Calbiochem & CC44 & WB & $300 x$ \\
\hline cleaved Caspase 3 & rabbit & Cell Signaling & 9664 & WB & $800 x$ \\
\hline G2E3 & goat & Santa Cruz & sc-160340 & WB, ColP & $200 x$ \\
\hline GFP & mouse & Clontech & 632375 & WB & $2000 x$ \\
\hline HA-HRP-coupled & mouse & Santa Cruz & sc-7392 & WB & $2000 x$ \\
\hline HA-tag (16B12) & mouse & Covance & MMS-101P & WB, ColP & $2000 x$ \\
\hline $\lg G$ & mouse & $\begin{array}{l}\text { Jackson } \\
\text { ImmunoResearch }\end{array}$ & $115-007-003$ & ColP & $\mathrm{n} / \mathrm{a}$ \\
\hline Mdm2 & mouse & Calbiochem & OP46 & WB, ColP & $500 x$ \\
\hline Mdm2 (2A9) & mouse & \multicolumn{2}{|c|}{ Hybridoma supernatant } & WB & $1.25 x$ \\
\hline Myc-tag & mouse & Millipore & $05-724$ & WB, ColP & $1000 x$ \\
\hline p21 & mouse & Calbiochem & OP64 & WB & $200 x$ \\
\hline p53 (DO1) & mouse & Santa Cruz & sc-126 & WB, ColP & $1000 x$ \\
\hline p53-HRP-Coupled & mouse & Santa Cruz & SC-126HRP & WB & $750 x$ \\
\hline PARP & mouse & Calbiochem & AM30 & WB & $1000 x$ \\
\hline phospho-Chk1 (Ser317) & rabbit & Cell Signaling & 2344 & WB & $1000 x$ \\
\hline phospho-Chk2 (Thr68) & rabbit & Cell Signaling & 2661 & WB & $1000 x$ \\
\hline phospho-H2AX (Ser319) & mouse & Millipore & $05-636$ & WB & $2000 x$ \\
\hline
\end{tabular}

All primary antibodies were diluted in Western blot blocking solution with $5 \%$ milk powder. Antibodies against phospho-Chk1 and phospho-Chk2 were diluted in Western blot blocking solution with $5 \%$ BSA. 
Table 3.12: Primary antibodies for immunofluorescence

\begin{tabular}{lllll} 
Antibody & Source & Company & Cat. No. & Dilution \\
\hline 53BP1 & rabbit & Santa Cruz & sc-22760 & 300x \\
\hline H2AX pS319 & mouse & Millipore & 05-636 & 1500x \\
\hline HA-tag (16B12) & mouse & Covance & MMS-101P & $300 x$ \\
\hline HA-tag & rabbit & Santa Cruz & sc805 & 200x \\
\hline Mdm2 & mouse & Calbiochem & OP46 & 500x \\
\hline Myc-tag & rabbit & Abcam & ab9106 & $300 x$ \\
\hline p53 (FL393) & rabbit & Santa Cruz & sc-6243 & $300 x$ \\
\hline p53 (DO1) & mouse & Santa Cruz & sc-126 & 500x
\end{tabular}

All primary antibodies were diluted in IF blocking solution with $5 \%$ FCS.

Table 3.13: Secondary antibodies for Western blot

\begin{tabular}{llll} 
Antibody & Company & Cat. No. & Dilution \\
\hline $\begin{array}{l}\text { HRP-coupled AffiniPure F(ab')2 } \\
\text { fragment, anti mouse IgG }(\mathrm{H}+\mathrm{L})\end{array}$ & Jackson Immunoresearch & $711-036-152$ & $10,000 x$ \\
\hline $\begin{array}{l}\text { HRP-coupled AffiniPure F(ab')2 } \\
\text { fragment, anti rabbit IgG }(\mathrm{H}+\mathrm{L})\end{array}$ & Jackson, Immunoresearch & $715-036-150$ & $10,000 \mathrm{x}$ \\
\hline $\begin{array}{l}\text { HRP-coupled AffiniPure F(ab')2 } \\
\text { fragment, anti goat IgG }(\mathrm{H}+\mathrm{L})\end{array}$ & Jackson, Immunoresearch & $705-036-147$ & $10,000 \mathrm{x}$
\end{tabular}

All secondary antibodies were diluted in Western blot blocking solution with $5 \%$ milk powder.

Table 3.14: Secondary antibodies for immunofluorescence

\begin{tabular}{llll} 
Antibody & Company & Cat. No. & Dilution \\
\hline Alexa-Fluor-488 goat anti mouse & Invitrogen, Life Technologies & A-11017 & 500x \\
\hline Alexa-Fluor-488 goat anti rabbit & Invitrogen, Life Technologies & A-11034 & 500x \\
\hline Alexa-Fluor-546 goat anti mouse & Invitrogen, Life Technologies & A-11003 & 500x \\
\hline Alexa-Fluor-546 goat anti rabbit & Invitrogen, Life Technologies & A-10040 & 500x
\end{tabular}

All secondary antibodies were diluted in IF blocking solution with $5 \%$ FCS. 


\subsection{Human cell culture}

Table 3.15: Human cell lines

\begin{tabular}{ll} 
Cell line & Origin \\
\hline H1299 & $\begin{array}{l}\text { human non-small cell lung carcinoma cell line, homozygous partial } \\
\text { deletion of TP53 gene }\end{array}$ \\
HCT116 p53 & human colon carcinoma cell line \\
HCT116 p53 & p53-deficient human colon carcinoma cell line (Bunz 1998) \\
SJSA & human osteosarcoma cell line \\
U2OS & human osteosarcoma cell line
\end{tabular}

Table 3.16: Media and reagents for eukaryotic cell culture

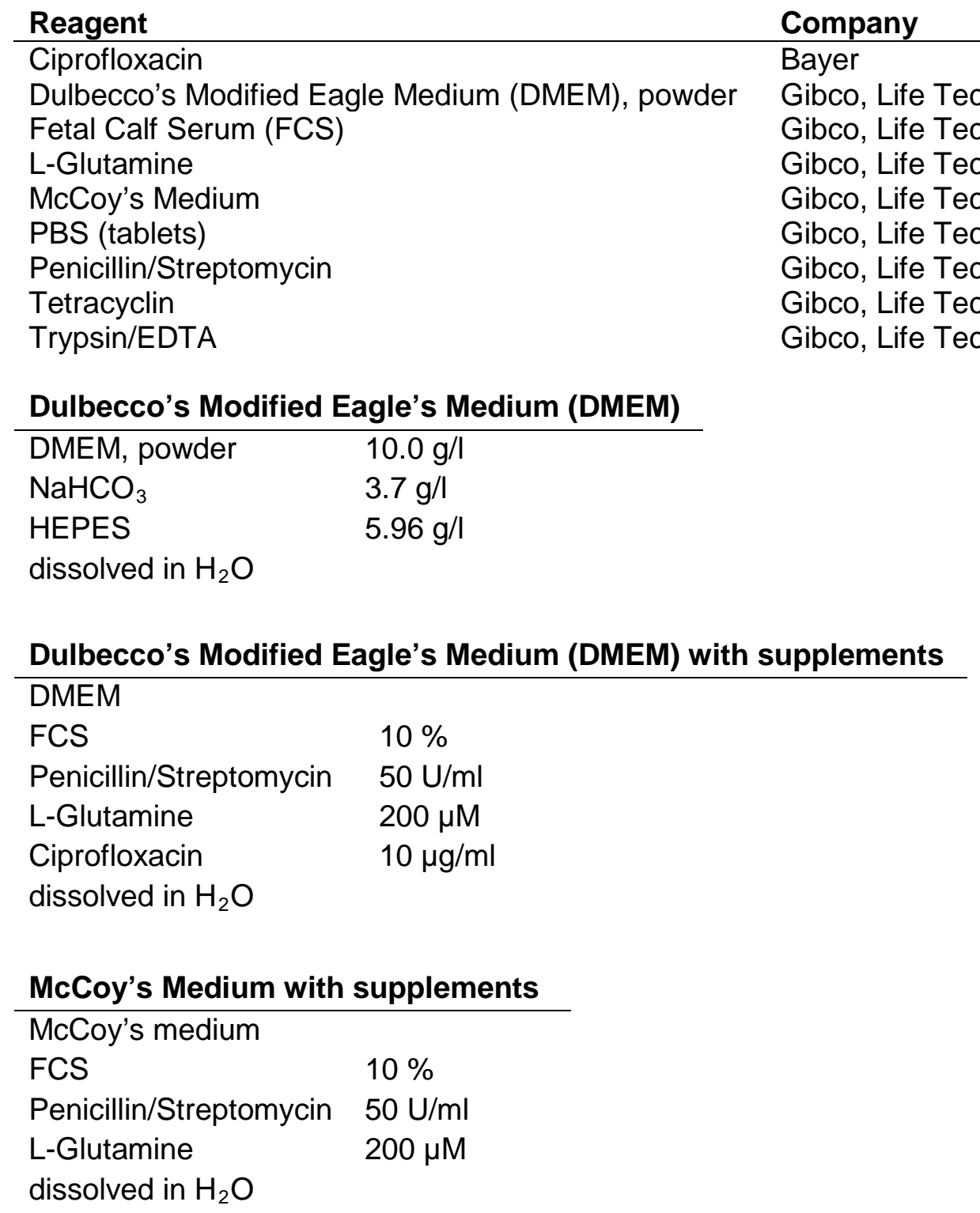




\subsection{Bacteria}

Table 3.17: Bacteria strains

\begin{tabular}{lll} 
Strain & Description & Company \\
\hline DH10B ElectroMAX & electro-competent E.coli & Invitrogen, Life Technologies \\
DH10B & chemically competent E. coli & self-made
\end{tabular}

Table 3.18: Bacteria culture media

\section{YT medium}

\begin{tabular}{ll}
\hline Tryptone & $1.6 \%$ \\
Yeast extract & $1.0 \%$ \\
$\mathrm{NaCl}$ & $0.5 \%$ \\
& \\
2YT agar & \\
\hline YT agar & $15 \%$ \\
2YT medium & $100 \%$
\end{tabular}

\subsection{Software and databases}

Table 3.19: Software

\begin{tabular}{ll} 
Name & Company \\
\hline Adobe Photoshop CS5 & Adobe Systems, San Jose, CA, United States \\
\hline AttoVision (BD Pathway) & Becton Dickinson \\
\hline BioEdit v7.0.5 & $\begin{array}{l}\text { Tom Hall, Ibis Biosciences, Carlsbad, CA, United } \\
\text { States }\end{array}$ \\
\hline Celigo Software & Cyntellect \\
\hline CFX Manager Software (qPCR cycler) & Bio-Rad \\
\hline Excel & Microsoft \\
\hline Fiji (image processing) & General Public License \\
\hline Guava Express Software & Millipore, Merck \\
\hline Intas ChemoStar Imager & Intas Science Imaging Instruments \\
\hline ModFit LT & Verity Software House, Topsham, ME, United States \\
\hline NanoDrop Software & Peqlab \\
\hline UV imager software & Intas Science Imaging Instruments
\end{tabular}


Table 3.20: Databases

\begin{tabular}{ll} 
Name & Source and details \\
\hline CASVM Server 1.0 & $\begin{array}{l}\text { www.casbase.org } \\
\text { server for prediction of caspase substrates cleavage sites } \\
\text { (Wee, Tan et al. 2007) } \\
\text { (for G2E3, selected scanning window size was "all") }\end{array}$ \\
\hline Ensembl Genome Browser & $\begin{array}{l}\text { www.ensembl.org } \\
\text { genome database for vertebrates and other eukaryotic species }\end{array}$ \\
\hline GeneSapiens database & $\begin{array}{l}\text { www.genesapiens.org } \\
\text { human gene expression data source } \\
\text { (Kilpinen, Autio et al. 2008) }\end{array}$ \\
\hline PhosphoSitePlus ${ }^{\circledR}$ & www.phosphosite.org \\
& $\begin{array}{l}\text { online systems biology resource with information and tools to } \\
\text { study protein post-translational modifications } \\
\text { (Hornbeck, Kornhauser et al. 2012) }\end{array}$
\end{tabular}




\section{Methods}

\subsection{Cell biology}

\subsubsection{Culturing of human cells}

All work with cell cultures was conducted under sterile conditions. Human cell lines were cultured at $37{ }^{\circ} \mathrm{C}, 5 \% \mathrm{CO}_{2}$ and humidified atmosphere in cell culture dishes. Specific culture media were used for the different cell lines (Table 4.1). For sub-cultures, medium was removed and the cells were washed with PBS. Cells were incubated with $0.1 \%$ trypsin/EDTA at $37^{\circ} \mathrm{C}$ for $5 \mathrm{~min}$ in order to detach the cells from the bottom of the cell culture dish. Trypsin was inactivated by the addition of culture medium containing FCS. Cells were reseeded in a ratio of $1: 2$ to $1: 15$.

Table 4.1: Culture media for human cell lines

\begin{tabular}{ll} 
Cell line & Culture medium \\
\hline H1299 & DMEM with supplemtents \\
HCT116 p53 & McCoy's with supplemtents \\
HCT116 p53 & McCoy's with supplemtents \\
SJSA & DMEM with supplemtents \\
U2OS & DMEM with supplemtents
\end{tabular}

For experiments, cells were counted and seeded in desired amounts in 6-, 12- or 96-well cell culture plates. To determine the cell number, cells were centrifuged for 5 min at $209 \mathrm{~g}$, medium was removed and fresh medium was added. Cells were counted using a Neubauer counting chamber (for HCT116 cell lines) or the Automated Cell Counter Countess ${ }^{\circledR}$ (for H1299, SJSA, U2OS cells).

\subsubsection{Freezing and thawing of cells}

For long-term storage, cells were stored in liquid nitrogen at $-196{ }^{\circ} \mathrm{C}$. Therefore, cells of low passage number in $15 \mathrm{~cm}$ cell culture dishes were washed with PBS and trypsinized with $0.1 \%$ trypsin/EDTA at $37^{\circ} \mathrm{C}$ for $5 \mathrm{~min}$. After inactivation of trypsin with culture medium, cells were centrifuged for $5 \mathrm{~min}$ at $209 \mathrm{~g}$ and resuspended in $5 \mathrm{ml}$ pre-cooled FCS with $10 \%$ DMSO on ice. The suspension was aliquoted into five cryo vials and stored at $-80{ }^{\circ} \mathrm{C}$ for $24 \mathrm{~h}$. Subsequently, aliquots were transferred into liquid nitrogen until further use.

For thawing of cells stored at $-196{ }^{\circ} \mathrm{C}$, cryo vials were warmed up in a water bath of $37^{\circ} \mathrm{C}$. Cells were transferred into a $15 \mathrm{ml}$ reaction tube filled with $3 \mathrm{ml}$ pre-warmed culture medium. 
Cells were centrifuged for $5 \mathrm{~min}$ at $209 \mathrm{~g}$, the supernatant containing DMSO was removed and the cells carefully resuspended in $1 \mathrm{ml}$ fresh culture medium. The cells were seeded in a cell culture dish. After $24 \mathrm{~h}$, medium was exchanged to remove dead cells. Prior to experiments, cells were sub-cultured at least four times.

\subsubsection{Transfection of human cells}

For transient transfection of human cells with expression vectors, cells were seeded one day before transfection (forward transfection). For transient transfection of cells with siRNAs, cells were transfected and seeded at the same time (reverse transfection).

\subsubsection{Transient transfection with expression vectors}

For transient transfection with expression vectors in order to overexpress proteins, the desired number of cells was seeded the day before (Table 4.2). The cells were transfected at a confluence of about $80 \%$ using the lipid-based transfection reagent Lipofectamine 2000. For this purpose, two different solutions were prepared in $1,5 \mathrm{ml}$ reaction tubes. Solution $\mathrm{A}$ contained culture medium without supplements and plasmid DNA, solution B contained culture medium without supplements and LF2000:

Table 4.2: Amounts of culture medium without supplements, plasmid DNA and LF2000 for different cell lines and cell numbers

\begin{tabular}{|c|c|c|c|c|}
\hline Cell line & Cell number & Wells per plate & Solution A & Solution B \\
\hline \multirow[t]{2}{*}{ U2OS } & 11,500 & 96 & $25 \mu \mathrm{l}$ DMEM(-) & 25 l DMEM(-) \\
\hline & & & + 200 ng DNA & $+0.5 \mu \mathrm{l} \mathrm{LF} 2000$ \\
\hline \multirow[t]{2}{*}{ U2OS, H1299 } & 150,000 & 12 & $100 \mu \mathrm{l}$ DMEM(-) & $100 \mu \mathrm{l}$ DMEM(-) \\
\hline & & & $+1.2 \mu \mathrm{g}$ DNA & $+4 \mu \mathrm{l}$ LF2000 \\
\hline \multirow[t]{2}{*}{ U2OS, H1299 } & 300,000 & 6 & $200 \mu \mathrm{l}$ DMEM(-) & $200 \mu \mathrm{l}$ DMEM(-) \\
\hline & & & $+2.4 \mu \mathrm{g}$ DNA & 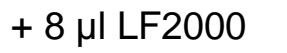 \\
\hline
\end{tabular}

Both solutions were vortexed. Solution B was incubated for $5 \mathrm{~min}$ at room temperature. Thereafter, both solutions were mixed by carefully pipetting up and down and incubated for $20 \mathrm{~min}$ at room temperature. The transfection mix was added dropwise to the cells seeded the day before. After $4 \mathrm{~h}$ of incubation at $37^{\circ} \mathrm{C}$, the medium was exchanged by fresh culture medium. Subsequently, cells were incubated for $24-48 \mathrm{~h}$ at $37^{\circ} \mathrm{C}$.

Expression vectors which were used are listed in Table 3.10. 


\subsubsection{Transient transfection with siRNAs}

For the knockdown of proteins, cells were transiently reverse transfected with siRNAs. Transient transfection with siRNAs was performed using Lipofectamine ${ }^{\mathrm{TM}} 2000$ with a final concentration of $10 \mathrm{nM}$ per siRNA. For this purpose, two different solutions were prepared. Solution A contained siRNA in culture medium without supplements, whereas solution B contained LF2000 in culture medium without supplements. For required amounts, see Table 4.3:

Table 4.3: Amounts of culture medium without supplements, siRNA and LF2000 for different cell lines and cell numbers

\begin{tabular}{|c|c|c|c|c|}
\hline Cell line & Cell number & Wells per plate & Solution A & Solution B \\
\hline \multirow[t]{2}{*}{ U2OS } & 8,500 & 96 & $25 \mu \mathrm{l}$ DMEM(-) + & $14.75 \mu \mathrm{L}$ DMEM(-) \\
\hline & & & 1.5 pmol siRNA & $+0.25 \mu \mathrm{l} \mathrm{LF} 2000$ \\
\hline \multirow[t]{2}{*}{ U2OS } & 100,000 & 12 & $67.5 \mu \mathrm{l}$ DMEM(-) + & $28.65 \mu \mathrm{L}$ DMEM(-) \\
\hline & & & 15 pmol siRNA & $+1.35 \mu \mathrm{l} \mathrm{LF} 2000$ \\
\hline \multirow[t]{2}{*}{ HCT116 } & 180,000 & 12 & $67.5 \mu \mathrm{l}$ McCoy(-) + & $28.65 \mu \mathrm{l}$ McCoy(-) \\
\hline & & & 15 pmol siRNA & $+1.35 \mu \mathrm{l}$ LF2000 \\
\hline \multirow[t]{2}{*}{ U2OS } & 220,000 & 6 & $135 \mu \mathrm{l} \mathrm{McCoy}(-)+$ & $57.3 \mu \mathrm{l}$ McCoy(-) \\
\hline & & & 30 pmol siRNA & $+2.7 \mu \mathrm{l}$ LF2000 \\
\hline \multirow[t]{2}{*}{ НСТ116 } & 360,000 & 6 & $135 \mu \mathrm{l} \mathrm{McCoy}(-)+$ & $57.3 \mu \mathrm{l}$ McCoy(-) \\
\hline & & & 30 pmol siRNA & $+2.7 \mu \mathrm{l}$ LF2000 \\
\hline
\end{tabular}

Solution A and solution B were vortexed. Solution B was incubated for $5 \mathrm{~min}$ at room temperature. Thereafter, both solutions were mixed by carefully pipetting up and down and incubated for $20 \mathrm{~min}$ at room temperature. The transfection mix was added dropwise to empty wells of the cell culture plate. Afterwards, cells of desired number were added to the well. Medium was exchanged with fresh culture medium after $24 \mathrm{~h}$ of incubation at $37^{\circ} \mathrm{C}$. The total incubation time after transfection was $48-64 \mathrm{~h}$ at $37^{\circ} \mathrm{C}$, depending on the experimental setup.

For double-transfection with two siRNAs, the total amount of siRNA was divided in halves and otherwise the protocol was used as described above.

The used siRNAs are listed in Table 3.8.

\subsubsection{Chemical treatment}

For the treatment of cells, drugs were pre-dissolved in $\mathrm{H}_{2} \mathrm{O}$ or DMSO. In order to treat cells, drugs were added to pre-warmed culture medium at concentrations specified in Table 4.4. As control, cells were treated with an equal amount of the corresponding solvent $\left(\mathrm{H}_{2} \mathrm{O}\right.$ or DMSO). 
Table 4.4: Concentrations for chemical treatment

\begin{tabular}{lllll} 
Chemical & Stock & Final conc. & Solvent & Incubation time \\
\hline Cisplatin & $3,33 \mathrm{mM}$ & $30 \mu \mathrm{M}$ & $\begin{array}{l}\text { physiological salt } \\
\text { solution }\end{array}$ & $8 \mathrm{~h}, 16 \mathrm{~h}$ \\
\hline MG132 & $10 \mathrm{mM}$ & $20 \mu \mathrm{M}$ & DMSO & $4 \mathrm{~h}$ \\
\hline $\begin{array}{l}\text { Neocarzinostatin } \\
\text { (NCS) }\end{array}$ & ca. $0,5 \mathrm{mg} / \mathrm{ml}$ & $150 \mathrm{ng} / \mathrm{ml}$ & $\begin{array}{l}20 \mathrm{mM} \text { MES buffer, } \\
\mathrm{pH} 5.5\end{array}$ & $2 \mathrm{~h}$ \\
\hline Nutlin-3 & $20 \mathrm{mM}$ & $10 \mu \mathrm{M}$ & $\mathrm{DMSO}$ & $16 \mathrm{~h}$ \\
\hline Thymidine & $200 \mathrm{mM}$ & $2 \mathrm{mM}$ & $\mathrm{H}_{2} \mathrm{O}$ & $16 \mathrm{~h}$ \\
\hline Z-VAD & $20 \mathrm{mM}$ & $50 \mu \mathrm{M}$ & DMSO & $16 \mathrm{~h}$
\end{tabular}

\subsubsection{Generation of cell lysates for SDS-PAGE analysis}

For immunoblot analysis, cells were grown, transfected and treated in 12-well plates. All steps of cell harvest and lysis were performed on ice. Cells were harvested by scraping the cells in the culture medium of the well. The cell suspension was transferred to a $1.5 \mathrm{ml}$ reaction tube and centrifuged ( $5 \mathrm{~min}, 845 \mathrm{~g}$ ). The cell pellet was washed with $1 \mathrm{ml}$ PBS and centrifuged again (5 min, $845 \mathrm{~g}$ ). The pellet was resuspended in cell lysis buffer containing RIPA, urea and protease inhibitors (see 3.4). For the cell lines U2OS, H1299 and SJSA cells, $60 \mu \mathrm{l}$ cell lysis buffer was used per sample. For HCT116 cells, $160 \mu \mathrm{l}$ cell lysis buffer was used per sample. After cell harvest, proteins were stored at $-80{ }^{\circ} \mathrm{C}$ or used to determine the protein concentration. Protein concentration of each sample was determined using Pierce ${ }^{\circledR}$ BCA Protein Assay Kit (Thermo Scientific). After adjusting the protein concentrations with RIPA to equal amounts, $10 \mu \mathrm{l}$ 6x Laemmli buffer was added to each sample. The samples were incubated for $5 \mathrm{~min}$ at $95{ }^{\circ} \mathrm{C}$ for protein denaturation. Afterwards, samples were shaken for $15 \mathrm{~min}$ at $1400 \mathrm{rpm}$ and room temperature using the Thermomixer comfort to shear the DNA. Samples were stored at $-20^{\circ} \mathrm{C}$ or directly used for SDS-PAGE.

\subsubsection{Isolation of RNA}

For quantification of mRNA levels of genes of interest, RNA was isolated from human cell lines based on the guanidinium thiocyanate-phenol-chloroform extraction protocol (Chomczynski and Sacchi 1987). For this purpose, cells were grown in 6-well cell culture plates. Medium was removed and cells were washed once with PBS and incubated with $1 \mathrm{ml}$ Trizol for $5 \mathrm{~min}$ at room temperature. The solution was transferred to a $1.5 \mathrm{ml}$ reaction tube. Samples were stored at $-80{ }^{\circ} \mathrm{C}$ for later use or the procedure of RNA isolation was continued. Next, $200 \mu$ l Chloroform per $1 \mathrm{ml}$ Trizol were added to the reaction tube. The tubes were shaken vigorously for $15 \mathrm{sec}$ and incubated for $3 \mathrm{~min}$ at room temperature. The samples were centrifuged $\left(12,000 \mathrm{~g}, 15 \mathrm{~min}, 4^{\circ} \mathrm{C}\right)$. The colorless, upper phase (ca. $\left.500 \mu \mathrm{l}\right)$ containing RNA was transferred to another $1.5 \mathrm{ml}$ reaction tube. After adding the same volume of isopropanol, the tubes were shaken vigorously for $15 \mathrm{sec}$ and incubated at least 
$2 \mathrm{~h}$ at $-20{ }^{\circ} \mathrm{C}$. After centrifugation $\left(12,000 \mathrm{~g}, 10 \mathrm{~min}, 4^{\circ} \mathrm{C}\right)$, the supernatant was discarded and the pellet containing the precipitated RNA was washed with $1 \mathrm{ml} 75 \%$ Ethanol. The samples were centrifuged $\left(7,500 \mathrm{~g}, 5 \mathrm{~min}, 4^{\circ} \mathrm{C}\right)$ and the supernatant was discarded. The pellet was dried at $37^{\circ} \mathrm{C}$ and then resuspended in $20 \mu \mathrm{l}$ RNase-free water. The concentration and purity of RNA samples was determined using the spectrophotometer NanoDrop ND-1000 (PeqLab). The absorbance at $230 \mathrm{~nm}, 260 \mathrm{~nm}$ and $280 \mathrm{~nm}$ was measured. Absorbance at $260 \mathrm{~nm}$ was used to calculate the RNA concentration. Sufficient RNA purity was provided if the following ratios were measured:

$A_{260} / A_{280}>1.8$

$A_{260} / A_{230}>2.0$

If RNA purity was not sufficient, a second purification step was performed. Therefore, the RNA was suspended in a total volume of $50 \mu \mathrm{l}$ RNase-free water per sample. For better visualization, $1 \mu \mathrm{l}$ Glycogen Blue was added to later stain the RNA pellet blue. For precipitation, $3 \mathrm{M}$ sodium acetate was added at 1:10 dilution $(5 \mu \mathrm{l})$ and $62.5 \mu \mathrm{l} 100 \%$ ethanol (1.25x). The tubes were incubated in liquid nitrogen for $5 \mathrm{~min}$ and then centrifuged $(16,000 \mathrm{~g}$, $15 \mathrm{~min}, 4^{\circ} \mathrm{C}$ ). The supernatant was removed and $200 \mu \mathrm{l} 70 \%$ ethanol was added per sample. After centrifugation $\left(16,000 \mathrm{~g}, 5 \mathrm{~min}, 4^{\circ} \mathrm{C}\right)$, the supernatant was removed and the pellet was dried at $37{ }^{\circ} \mathrm{C}$. The pellet was dissolved in $20 \mu \mathrm{l}$ RNase-free water. RNA concentration and purity were measured using the spectrophotometer NanoDrop ND-1000. RNA samples were stored at $-80{ }^{\circ} \mathrm{C}$ or used for cDNA synthesis and quantification of messenger RNA by qPCR (see 4.2.2).

\subsubsection{Flow cytometry}

Flow cytometry was used to investigate the cell cycle profile of human cells based on their DNA content (Van Dilla, Trujillo et al. 1969). For this purpose, DNA was stained with propidium iodide (PI) after permeabilization of the cell membrane and degradation of RNA using RNase (Krishan 1975). PI intercalates with the DNA. Cells in $\mathrm{G}_{2} / \mathrm{M}$-phase contain the double amount of DNA than cells in $\mathrm{G}_{0^{-}}$or $\mathrm{G}_{1}$-phase. The DNA content of cells in $\mathrm{S}$-phase is between the content of cells in $G_{0} / G_{1}$ - and $G_{2} / M$-phase. The DNA content of each cell was determined by PI fluorescence intensity.

Cells were harvested as described above (for details see 4.1.1) and all cells (also from growth medium) were collected. Cells were centrifuged (400 g, $7 \mathrm{~min}$ ) and resuspended in $500 \mu \mathrm{l}$ PBS on ice. Cells were fixed with ice-cold $100 \% \mathrm{EtOH}$ by adding $1.5 \mathrm{ml} 100 \% \mathrm{EtOH}$ dropwise to the cells while slowly vortexing them. Cells were incubated at $-20{ }^{\circ} \mathrm{C}$ for one to four days, then centrifuged (400 g, $10 \mathrm{~min}$ ) and rehydrated in PBS for $10 \mathrm{~min}$. After centrifugation (400 g, $10 \mathrm{~min}$ ), cells were resuspended in $100 \mu \mathrm{l}$ RNase A (1 mg/ml) and incubated at $37{ }^{\circ} \mathrm{C}$ for $30 \mathrm{~min}$ in order to degrade RNA. Prior to analysis, samples were diluted by adding 200-400 $\mu$ PBS depending on the cell number per sample. $200 \mu \mathrm{l}$ of this solution were pipetted into a 96-well plate for flow cytometry (Becton Dickinson). Propidium 
iodide (Sigma-Aldrich) was added in a final concentration of $30 \mu \mathrm{g} / \mathrm{ml}$. The cell cycle profile was obtained using the flow cytometer Guava EasyCyteplus by measuring 10,000 events per sample. The percentage of cells in each cell cycle phase was determined using the ModFit software.

\subsubsection{Cell synchronization by double thymidine block}

Cells can be synchronized in G1-phase by adding thymidine which inhibits DNA synthesis due to an imbalance in the cellular nucleotide pool (Xeros 1962). For synchronization of cell cultures, thymidine was added to the culture medium at a final concentration of $2 \mathrm{mM}$ for $16 \mathrm{~h}$. Thymidine was washed away by adding pre-warmed culture medium to the cells for $5 \mathrm{~min}$ for five times. Subsequently, cells were incubated for $9 \mathrm{~h}$. Afterwards, a second treatment with $2 \mathrm{mM}$ thymidine for $16 \mathrm{~h}$ was performed in order to arrest all cells at the G1/S-transition. After washing away thymidine by adding culture medium for five times (5 min each), cells were released in fresh culture medium. Cell cycle progression was monitored by taking a sample every $2 \mathrm{~h}$ and analyzing the DNA content of the samples by flow cytometry (see 4.1.7).

\subsubsection{Proliferation assay}

Proliferation of cells was investigated by measuring cell confluence over time using the Celigo cell cytometer (Cyntellect) which contained an embedded bright-field microscope. After rapid bright field imaging, images were segmented and analyzed for quantification of cell confluence. Cells were transfected and seeded in 12-well plates at low density $(100,000$ cells for HCT116 cells, 50,000 cells for U2OS). Cell confluence was measured daily for one week and every two days afterwards.

\subsection{Molecular Biology}

\subsubsection{Polymerase chain reaction}

Polymerase chain reaction (PCR) is used to rapidly amplify a specific DNA template (Mullis and Faloona 1987). Two sequence-specific primers are necessary which are complementary to the $3^{\prime}$ ends of the sense and anti-sense strand of the DNA template. A basic PCR comprises three steps: Firstly, the double-stranded DNA becomes single-stranded after denaturation at high temperature. Secondly, the primers anneal to the DNA template after the temperature is lowered. Thirdly, new DNA is synthesized starting at the primers using deoxyribonucleotide triphosphates (dNTPs) and a thermostable polymerase with an optimal temperature of around $70{ }^{\circ} \mathrm{C}$. Up to 40 repetitions of these steps lead to amplification of the DNA template in a near-exponential manner. The amount of template was chosen depending on the source of DNA. PCR was performed using the PCR machine 
Primus 25 advanced. Annealing temperatures lower than the melting temperatures of the primers were chosen. Elongation time was adjusted depending on the length of the product.

\subsubsection{Quantification of messenger RNA by PCR}

Quantification of messenger RNA (mRNA) is used to investigate gene expression on the basis of the amount of the transcribed gene in a sample. Since RNA cannot be amplified by PCR, it has to be converted into DNA first using the enzyme reverse transcriptase. Afterwards, mRNA is quantified by real-time PCR. These steps are explained below.

\subsubsection{Reverse transcription}

Reverse transcription of mRNA is done by a reverse transcriptase (RT) derived from moloney murine leukemia virus (M-MuLV). For synthesis of complementary DNA (cDNA), $1 \mu \mathrm{g}$ total RNA was mixed with $2 \mu \mathrm{l}$ primer which consisted of a combination of anchored oligo-dT primers (using $50 \mu \mathrm{M} \mathrm{dT}{ }_{23} \mathrm{VN}$ ) and random nonamer primers (using $15 \mu \mathrm{M}$ nonamer primers). Furthermore, $4 \mu \mathrm{l}$ dNTP mix (2.5 mM of each deoxyribonucleotide triphosphate, i.e. dCTP, dATP, dTTP, dGTP) and nuclease-free water to a total volume of $16 \mu$ l was added. The sample was heated to $70{ }^{\circ} \mathrm{C}$ for $5 \mathrm{~min}$, centrifuged briefly and put on ice. The following components were added per sample ( $4 \mu$ total volume, Table 4.5$)$ :

\section{Table 4.5: Reaction mix for RT}

\begin{tabular}{lr} 
Component & Volume [ $\mu \mathrm{l}]$ \\
\hline 10x Reaction Buffer for M-MuLV Reverse Transcriptase (NEB) & 2.0 \\
RNase Inhibitor (10 U, NEB) & 0.25 \\
M-MuLV Reverse Transcriptase (25 U, NEB) & 0.125 \\
$\mathrm{H}_{2} \mathrm{O}$ & 1.625
\end{tabular}

Samples were incubated at $42{ }^{\circ} \mathrm{C}$ for $1 \mathrm{~h}$. Subsequently, the reverse transcriptase was inactivated at $95{ }^{\circ} \mathrm{C}$ for $5 \mathrm{~min}$. Finally, the samples were diluted to a final volume of $50 \mu \mathrm{l}$ by adding $30 \mu \mathrm{l}$ nuclease-free water and stored at $-20^{\circ} \mathrm{C}$ or used for quantitative real-time PCR (qPCR).

For each sample, a control was prepared without reverse transcriptase (instead, an equal volume of nuclease-free water was added) to check for contamination with genomic DNA: During $\mathrm{qPCR}$, no product should be obtained if RT was not added. However, a contamination with genomic DNA could lead to a PCR product.

\subsubsection{Quantitative real-time PCR}

Quantitative real-time PCR is used to acquire semi-quantitative measurements of gene expression. A PCR reaction requires a DNA template to be amplified. In the case of qPCR, 
the template is cDNA. Primer pairs were established for the detection of the specific genes of interest, amplifying cDNA fragments of these genes with a product size of 200-300 bp. If possible, a sequence for the primers was used that enabled intron-spanning qPCR in order to exclude the amplification of genomic DNA, potentially present due to contamination. Primer sequences used for qPCR are shown in Table 3.9. For the preparation of the qPCR reaction mix, a self-made 10x qPCR reaction buffer was prepared (for components see 3.4). The qPCR reaction mix contained amongst others dNTPs, the dye SYBR Green and Taq polymerase. SYBR Green is a dye which binds DNA and is used to detect and quantify PCR products.

For qPCR, the following components with the exception of cDNA were mixed as a master mix in $1.5 \mathrm{ml}$ reaction tubes on ice (Table 4.6):

Table 4.6: Reaction mix for qPCR

\begin{tabular}{llll} 
Component & Stock conc. & {$[\mu \mathrm{l}]$ for 1 sample } & Final conc. \\
\hline qPCR reaction mix & & 14 & \\
forward primer & $10 \mathrm{pmol} / \mu \mathrm{l}$ & 0.75 & $0.3 \mathrm{pmol} / \mu \mathrm{l}$ \\
reverse primer & $10 \mathrm{pmol} / \mu \mathrm{l}$ & 0.75 & $0.3 \mathrm{pmol} / \mu \mathrm{l}$ \\
$\mathrm{H}_{2} \mathrm{O}$ & & 8.5 & \\
cDNA & & 1 &
\end{tabular}

$24 \mu \mathrm{l}$ aliquots of the master mix were pipetted in the wells of a 96-well plate for qPCR on ice. $1 \mu \mathrm{l}$ of the respective cDNA was added. Samples without reverse transcriptase and samples with $\mathrm{H}_{2} \mathrm{O}$ instead of cDNA were used as negative controls for each primer pair. The plate was sealed, centrifuged briefly and placed into the PCR machine for qPCR CFX96, C1000 (Bio-Rad). The following program was applied (Table 4.7):

Table 4.7: Cycler program for qPCR

$\begin{array}{lll}\text { Step } & \text { Temperature } & \text { Time } \\ \text { DNA denaturation } & 95^{\circ} \mathrm{C} & 2 \mathrm{~min} \\ \text { DNA denaturation } & 95^{\circ} \mathrm{C} & 15 \mathrm{sec} \\ \text { primer annealing and elongation } & 60^{\circ} \mathrm{C} & 1 \mathrm{~min}-\text { plate read } \\ & 79^{\circ} \mathrm{C} & 1 \mathrm{sec}-\text { plate read } \\ & 84^{\circ} \mathrm{C} & 1 \mathrm{sec}-\text { plate read } \\ \text { melting curve } & 55^{\circ} \mathrm{C}-95^{\circ} \mathrm{C} \text { (increment } 0.5^{\circ} \mathrm{C} \text { ) }\end{array}$


Semi-quantitative analysis of mRNA expression was conducted by measuring the $\mathrm{C}_{\mathrm{t}}$-values of the reference gene GAPDH and the gene of interest. The $\Delta \Delta C_{t}$ method was applied to calculate the relative expression of the investigated genes (Livak and Schmittgen 2001). The difference in expression is specified as $n$-fold expression. Therefore, the $C_{t}$-value of the genes of interest is subtracted from the $C_{t}$-value of the reference gene $\left(\Delta C_{t}\right)$. Then, the $\Delta \mathrm{C}_{\mathrm{t}}$-values of the two groups (e.g. untreated/treated) are subtracted $\left(\Delta \Delta \mathrm{C}_{\mathrm{t}}\right)$ :

$\Delta \Delta \mathrm{C}_{\mathrm{t}}=\left(\Delta \mathrm{C}_{\mathrm{t}}(\mathrm{GAPDH}\right.$, treated $)-\mathrm{C}_{\mathrm{t}}($ target gene, treated $\left.)\right)-\left(\left(\mathrm{C}_{\mathrm{t}}(\mathrm{GAPDH}\right.\right.$, untreated $)-\mathrm{C}_{\mathrm{t}}($ target gene, untreated $\left.)\right)$

Subsequently, $\Delta \Delta C_{t}$ is inserted in the following equation: $n$-fold expression $=2^{\Delta \Delta C t}$

\subsubsection{Luciferase reporter assay}

\subsubsection{Theoretical background}

Luciferase reporter assays are used to investigate the regulation of gene expression at the level of transcription. Here, the impact on the transcriptional activity of p53 was measured using the Dual Luciferase Assay as described by McNabb et al. (McNabb, Reed et al. 2005). Since two luciferase reporter genes are used, the assay is referred to as Dual Luciferase Assay. The expression of the first reporter (Firefly luciferase) changes depending on the transcriptional activity, whereas the second reporter (Renilla luciferase) serves as an internal control.

Here, a p53-responsive promoter was coupled to the reporter gene Firefly luciferase. The reporter plasmid pGL3-PG13-Luc was used, containing 13 p53 binding sites upstream of the Firefly luciferase gene (according to human p53 consensus binding site 5 '-PPPC(A/T)(T/A)GYYY-3'). The Firefly luciferase enzyme catalyzes the oxidation of the substrate luciferin, leading to emission of chemiluminescence with an emission maximum at $562 \mathrm{~nm}$. Promoter activity is determined based on the assumption that the amount of emitted light is proportional to the amount of luciferase in the sample and hence proportional to the activity of the corresponding promoter. In order to correct for differences in transfection efficiency, cell lysis and pipetting, the Renilla luciferase gene under the control of a constitutively active promoter (thymidine kinase promoter) was used. For this purpose, the reporter plasmid pRL-tk-RLuc was cotransfected in cells of all samples. Renilla luciferase catalyzes the oxidation of the substrate coelenterazine which leads to emission of chemiluminescence with an emission maximum at $482 \mathrm{~nm}$.

Plasmids encoding reporter genes and the genes of interest were transfected in a suitable cell line. Here, p53 ${ }^{-/}$cells (H1299 lung carcinoma cells) were used to avoid endogenous p53 background level. Also, this cell line is easily transfectable and sensitive to changes in promoter activity. 


\subsubsection{Transfection and luciferase reaction assay}

H1299 cells were transfected in 12 wells. For details of transfection, see 4.1.3.1. Cells were transfected with pGL3-PG13-Luc, pRL-tk-RLuc and pRc/CMV-p53. As positive controls, cells were additionally transfected with plasmids pCMV-Mdm2 and pcDNA3- $\Delta$ Np63-alpha. The proteins encoded by these plasmids, $\mathrm{Mdm} 2$ and $\Delta$ Np63-alpha, both repress p53 transcriptional activity. The impact of HA-G2E3 on p53 transcriptional activity was investigated by transfection with different amounts of pCGN-HA-G2E3. $24 \mathrm{~h}$ after transfection, cells were lysed by scraping in the medium and transferred to a $1.5 \mathrm{ml}$ reaction tube. After centrifugation ( $5 \mathrm{~min}, 845 \mathrm{~g}, 4^{\circ} \mathrm{C}$ ), the supernatant was discarded. The pellet was resuspended in $100 \mu \mathrm{l} 1 \mathrm{x}$ Passive Lysis Buffer (Promega) and shaken for $15 \mathrm{~min}$ at room temperature and $1400 \mathrm{rpm}$. After centrifugation for $1 \mathrm{~min}$ at $18,407 \mathrm{~g}, 20 \mu \mathrm{l}$ of the supernatant were pipetted into a 96-well plate for luciferase assay (Optiplate ${ }^{\mathrm{TM}}$ 96, Perkin Elmer). $20 \mu \mathrm{l}$ of Passive Lysis Buffer were used as blank value. All samples were pipetted in triplicates. Luciferase Assay Reagent 'Firefly' (containing amongst others the substrate luciferin) and 'Renilla' (containing the substrate coelenterazine) were prepared fresh each time and kept at room temperature (for components, see 3.4). Firefly and Renilla buffer stock solutions were kept at room temperature. Chemiluminescence emitted by Firefly and Renilla luciferase was quantified using the luminometer DLReady ${ }^{\mathrm{TM}}$ Centro LB 960 (Bertold Technologies). The plate-reading device had two injectors to dispense each assay reagent. The following program was used (Table 4.8):

\section{Table 4.8: Program for Dual Luciferase Assay}

\begin{tabular}{llll} 
Step & Action & Time & Volume $[\boldsymbol{\mu l}]$ \\
\hline 1 & inject Luciferase Assay Reagent 'Firefly' & & 100 \\
2 & delay & $2 \mathrm{sec}$ & \\
3 & quantitate Firefly luciferase activity & $10 \mathrm{sec}$ & \\
4 & delay & $2 \mathrm{sec}$ & \multirow{2}{*}{100} \\
5 & inject Luciferase Assay Reagent 'Renilla' & & \\
6 & delay & $2 \mathrm{sec}$ & \\
7 & quantitate Renilla luciferase activity & $10 \mathrm{sec}$ &
\end{tabular}

When Luciferase Assay Reagent 'Firefly' was injected, the Firefly luciferase signal was generated and quantified. Addition of the Luciferase Assay Reagent 'Renilla' quenched the signal and simultaneously activated Renilla luciferase whose signal was also quantified.

For analysis, the average per triplicate was calculated. After subtraction of blank value (Passive Lysis Buffer only) from Firefly and Renilla luciferase values, the ratio of the Firefly value to the Renilla value was calculated in order to normalize each sample. 


\subsubsection{Heat-shock transformation of chemically competent bacteria}

Amplification of plasmid DNA was performed using the chemically competent Escherichia coli strain DH10B. For transformation, $1 \mu$ plasmid DNA was mixed gently with $50 \mu \mathrm{l}$ of chemically competent bacteria in 1.5 reaction tubes. The samples were incubated on ice for $30 \mathrm{~min}$, followed by incubation for $10 \mathrm{~min}$ at $37^{\circ} \mathrm{C}$. Afterwards, samples were incubated for $10 \mathrm{~min}$ on ice and $200 \mu \mathrm{l} 2 \mathrm{YT}$ medium was added to the bacteria. The bacteria were incubated for 30 to $60 \mathrm{~min}$ at $37^{\circ} \mathrm{C}$ and $220 \mathrm{rpm}$ using a Thermomixer comfort. The bacteria were plated on agar plates with ampicillin $(200 \mu \mathrm{g} / \mathrm{ml})$ or kanamycin $(25 \mu \mathrm{g} / \mathrm{ml})$ and incubated at $37^{\circ} \mathrm{C}$ overnight for selection of transformed cells.

\subsubsection{Transformation of electro-competent bacteria}

Transformation of bacteria with ligation reactions was performed using the electro-competent E.coli strain DH10B ElectroMAX (Invitrogen). For transformation, $7 \mu$ l bacteria culture were gently mixed with $0.3 \mu$ ligation reaction in a $1.5 \mathrm{ml}$ reaction tube. The mix was transferred between the metal plates of an electroporation cuvette (Bio-Rad). Electroporation was performed using a GenePulser II electroporator (Bio-Rad) with the parameters Ec1 - $1.8 \mathrm{kV}$ (200 $\Omega, 25 \mu \mathrm{F}) .150 \mu \mathrm{l}$ 2YT medium were added to the bacteria. Bacteria were plated on agar plates with ampicillin $(200 \mu \mathrm{g} / \mathrm{ml})$ or kanamycin $(25 \mu \mathrm{g} / \mathrm{ml})$ for selection of transformed cells and incubated at $37^{\circ} \mathrm{C}$ overnight.

\subsubsection{Isolation of plasmid DNA}

Plasmid DNA was isolated from bacteria that were grown overnight at $37^{\circ} \mathrm{C}$ in $200 \mathrm{ml} 2 \mathrm{YT}$ medium containing ampicillin $(200 \mu \mathrm{g} / \mathrm{ml})$ or kanamycin $(25 \mu \mathrm{g} / \mathrm{ml})$. For isolation and purification of plasmid DNA, the PureYield ${ }^{\mathrm{TM}}$ Plasmid Midiprep System (Promega) was used according to the manufacturer's instructions. For isolation of plasmid DNA from smaller volumes, the Invisorb Spin Plasmid Mini Kit Two (Invitec) was used according to the manual. Therefore, bacteria were grown overnight at $37{ }^{\circ} \mathrm{C}$ in $5 \mathrm{ml}$ of $2 \mathrm{YT}$ medium containing ampicillin or kanamycin.

\subsubsection{Determination of nucleic acid concentrations}

The concentration of DNA and RNA was determined using the spectrophotometer NanoDrop ND-1000 (PeqLab). The extinction at a wavelength of $260 \mathrm{~nm}$ was measured from a drop of $2 \mu$ nucleic acid sample.

\subsubsection{DNA gel electrophoresis}

To separate DNA fragments by size, agarose gel electrophoresis was performed. Therefore, $1 \%$ agarose gels were prepared in TAE buffer. DNA was made visible by adding 
DNA stain clear $G$ (Serva) to the agarose gel before casting. $10 \mu \mathrm{l}$ of samples were mixed with $1 \mu \mathrm{l} 6 \mathrm{x}$ DNA gel loading buffer (see 3.4) before loading into gel pockets. A DNA ladder (Thermo Scientific) with bands of defined size was also loaded to determine the sizes of the DNA fragments. Agarose gel electrophoresis was performed for 30-60 min at 100-130 V. DNA fragments were visualized by UV light using a Gel Jet Imager (Intas Science Imaging Instruments).

\subsubsection{Cloning of HA-G2E3 into pCGN-HA}

The G2E3 gene was cloned into the vector pCGN-HA in order to overexpress a hemagglutinin (HA)-tagged G2E3 protein. The cloning strategy was to amplify the G2E3 gene using PCR and the pEGFP-C3-G2E3 vector of Brooks et al. (Brooks, Banerjee et al. 2007). Primers were designed to include $\mathrm{Xbal}$ and $\mathrm{Kpnl}$ restriction sites. A restriction digest with Xbal and Kpnl was performed for both insert (PCR product) and vector (pCGN-HA). After purification and ligation, bacteria were transformed with the newly generated plasmid pCGN-HA-G2E3 and colonies were picked for amplification and isolation (for details on transformation and isolation of plasmid DNA, see 4.2 .5 and 4.2.6). Finally, the correct sequence of pCGN-HA-G2E3 was verified by sequencing (for details, see 4.2.10).

The G2E3 gene was amplified by PCR using the PCR reaction mix and cycler program described in Table 4.9 and Table 4.10. Elongation time was calculated as 2 min for each $\mathrm{kb}$ of plasmid length plus $2 \mathrm{~min}$. Since the G2E3 gene consists of $2240 \mathrm{bp}$, an elongation time of 7 min was used. The reaction was done five times in parallel to gain a high amount of DNA. Amplification was checked by agarose gel electrophoresis. Primers used for cloning were HA-G2E3-Xbal-Fwd and HA-G2E3-KpnI-Rev, whose sequences are listed in Table 3.9.

Table 4.9: PCR reaction mix

\begin{tabular}{lll} 
Component & Final conc. & Per reaction $[\mu \mathrm{l}]$ \\
\hline 10x cloned Pfu reaction buffer (Stratagene) & $10 \%$ & 5.0 \\
dNTPs $(20 \mathrm{mM})$ & $200 \mu \mathrm{M}$ & 0.5 \\
Primer forward $(5 \mu \mathrm{M})$ & $250 \mathrm{nM}$ & 2.5 \\
Primer reverse $(5 \mu \mathrm{M})$ & $250 \mathrm{nM}$ & 2.5 \\
DNA template (plasmid, $100 \mathrm{ng} / \mu \mathrm{l})$ & $100 \mathrm{ng}$ & 1.0 \\
Pfu Turbo polymerase (Stratagene, $2.5 \mathrm{U} / \mu \mathrm{l})$ & $2.5 \mathrm{U}$ & 1.0 \\
$\mathrm{H}_{2} \mathrm{O}$ & & $\mathrm{ad} 50$
\end{tabular}


Table 4.10: Cycler program for PCR

\begin{tabular}{lll|l} 
Step & Temperature & Time & \\
DNA denaturation & $95^{\circ} \mathrm{C}$ & $2 \mathrm{~min}$ & \\
DNA denaturation & $95^{\circ} \mathrm{C}$ & $30 \mathrm{sec}$ & \\
primer annealing & $58^{\circ} \mathrm{C}$ & $1 \mathrm{~min}$ & $30 \mathrm{x}$ \\
elongation & $72^{\circ} \mathrm{C}$ & $7 \mathrm{~min}$ & \\
final elongation & $72^{\circ} \mathrm{C}$ & $10 \mathrm{~min}$ &
\end{tabular}

The PCR product was purified using the QIAquick® PCR Purification Kit (Qiagen) according to the manufacturer's instructions. The sample was eluted from the column using nucleasefree water. The purified PCR product was used for restriction digest with Xbal and Kpnl. The following restriction digest was performed with the insert (PCR product) and vector (pCGN-HA) (Table 4.11):

Table 4.11: Reaction mix for restriction digest

\begin{tabular}{lll} 
Component & Insert & Vector \\
\hline 10x buffer for Kpnl (Thermo Scientific) & $10 \mu \mathrm{l} \mathrm{PCR} \mathrm{product}$ & $5 \mu \mathrm{g}$ \\
Xbal $(10 \mathrm{U} / \mu \mathrm{l})$ & $4 \mu \mathrm{l}$ & $8 \mu \mathrm{l}$ \\
$\mathrm{Kpnl}(10 \mathrm{U} / \mu \mathrm{l})$ & $1 \mu \mathrm{l}$ & $2 \mu \mathrm{l}$ \\
$\mathrm{H}_{2} \mathrm{O}$ & ad $20 \mu \mathrm{l}$ & ad $50 \mu \mathrm{l}$
\end{tabular}

To gain a higher amount of insert and vector, reactions were performed in parallel five times for the insert and three times for the vector. The samples were incubated at $37^{\circ} \mathrm{C}$ for $4 \mathrm{~h}$. Enzymes were inactivated by incubation at $80^{\circ} \mathrm{C}$ for $30 \mathrm{~min}$.

The vector was dephosporylated by adding $1 \mu$ of Calf Intestine Alkaline Phosphatase (CIAP, Fermentas, $1 \mathrm{U} / \mu \mathrm{l}$ ) for $75 \mathrm{~min}$ at $37^{\circ} \mathrm{C}$ to prevent self-ligation. Insert and vector were purified using the QIAquick ${ }^{\circledR}$ PCR Purification Kit (Qiagen) according to the manufacturer's instructions. For ligation of insert and vector, different ratios of insert to vector were used $(1: 3,1: 5,1: 10$ and controls without insert and without vector). $1 \mu \mathrm{l}$ T4 ligase (Fermentas, $200 \mathrm{U} / \mu \mathrm{l}$ ) and $1 \mu \mathrm{l}$ of $10 \mathrm{x}$ ligase buffer (Fermentas) were added to the reaction mix of vector and insert with addition of nuclease-free water to a final volume of $10 \mu$. Samples were incubated at $15{ }^{\circ} \mathrm{C}$ overnight. Electro-competent bacteria (Invitrogen) were transformed with ligation reactions as described in 4.2.5. Bacteria were plated on agar plates with ampicillin $(200 \mu \mathrm{g} / \mathrm{ml})$ and incubated at $37{ }^{\circ} \mathrm{C}$ overnight in order to select for cells transformed with pCGN-HA-G2E3. A Colony PCR was used to screen bacteria colonies for the presence of HA-G2E3. Single colonies were picked from agar plates. The pipet tip was smeared into a $0.2 \mathrm{ml}$ reaction tube and afterwards stored at $4{ }^{\circ} \mathrm{C}$ in a $2 \mathrm{ml}$ reaction tube. PCR reaction mix 
was added into the $0.2 \mathrm{ml}$ reaction tubes containing bacteria. Primers used for Colony PCR were CMV promoter forward and G2E3-Rev1, whose sequences are listed in Table 3.9.

The following PCR reaction mix was used (Table 4.12):

Table 4.12: PCR reaction mix

\begin{tabular}{lll} 
Component & Final conc. & Per reaction $[\mu \mathrm{l}]$ \\
\hline 10x Taq buffer $\left(\mathrm{KCl}^{+},-\mathrm{MgCl}_{2}\right)$ & $10 \%$ & 2.00 \\
dNTPs $(20 \mathrm{mM})$ & $200 \mu \mathrm{M}$ & 0.20 \\
Primer forward $(10 \mu \mathrm{M})$ & $200 \mathrm{nM}$ & 0.40 \\
Primer reverse $(10 \mu \mathrm{M})$ & $200 \mathrm{nM}$ & 0.40 \\
$\mathrm{MgSO}_{4}(25 \mathrm{mM})$ & $3 \mathrm{mM}$ & 2.40 \\
DNA template & bacterial colonies & \\
Taq polymerase $(5 \mathrm{U} / \mu \mathrm{l})$ & $1.25 \mathrm{U} /$ reaction & 0.25 \\
$\mathrm{H}_{2} \mathrm{O}$ & & $\mathrm{ad} 20.00$
\end{tabular}

Colony PCR was performed using the PCR machine Primus 25 advanced. The following cycler program was used (Table 4.13):

Table 4.13: Cycler program for Colony PCR

\begin{tabular}{|c|c|c|}
\hline $\begin{array}{l}\text { Step } \\
\text { lysis of bacteria, } \\
\text { DNA denaturation }\end{array}$ & $\begin{array}{l}\text { Temperature } \\
95^{\circ} \mathrm{C}\end{array}$ & $\begin{array}{l}\text { Time } \\
5 \text { min }\end{array}$ \\
\hline DNA denaturation & $95^{\circ} \mathrm{C}$ & $30 \mathrm{sec}$ \\
\hline primer annealing & $50^{\circ} \mathrm{C}$ & $30 \mathrm{sec}$ \\
\hline elongation & $72{ }^{\circ} \mathrm{C}$ & $1 \mathrm{~min}$ \\
\hline
\end{tabular}

Agarose gel electrophoresis was used to check for the amplification of the PCR product indicating a successful transformation of the bacterial colony. Pipet tips with positive bacterial colonies were transferred into $5 \mathrm{ml} 2 \mathrm{YT}$ medium containing ampicillin to grow bacteria. Plasmids were isolated as described in 4.2.6. Plasmid sequence was determined as described in 4.2.10 with the primers listed in Table 3.9. 


\subsubsection{Sequencing of DNA}

Plasmid DNA was sequenced using the BigDye ${ }^{\circledR}$ Terminator v3.1 Cycle Sequencing Kit (Invitrogen). The method of sequencing used was originally developed by Sanger and colleagues (Sanger, Nicklen et al. 1977). It consists of a sequencing PCR in which fluorescently labeled dideoxynucleotide triphosphates (ddNTPs) are employed besides dNTPs. These ddNTPs lack the 3'-OH group which leads to termination of the elongation step if instead of dNTP such a ddNTP is incorporated. For this reason, the approach is also called chain-termination method. Chain-termination leads to PCR products of different sizes which are separated in a gel matrix. Since the termini are labeled by fluorescent ddNTPs, the sequence can be determined in automated sequencing machines.

Here, the sequencing PCR was performed with $300 \mathrm{ng}$ plasmid DNA which was mixed with the appropriate primer, sequencing mix (containing polymerase, dNTPs and ddNTPs) and sequencing buffer according to the manufacturer's protocol. The following program was used for the sequencing PCR (Table 4.14):

Table 4.14: Cycler program for sequencing PCR

\begin{tabular}{lll|l} 
Step & Temperature & Time & \\
DNA denaturation & $96{ }^{\circ} \mathrm{C}$ & $2 \mathrm{~min}$ & \\
DNA denaturation & $96{ }^{\circ} \mathrm{C}$ & $10 \mathrm{sec}$ & \\
primer annealing & $55^{\circ} \mathrm{C}$ & $30 \mathrm{sec}$ & $26 \mathrm{x}$ \\
elongation & $60^{\circ} \mathrm{C}$ & $4 \mathrm{~min}$ &
\end{tabular}

After the PCR reaction, an ethanol precipitation was performed. To this end, the PCR product was gently mixed with $1 \mu \mathrm{l} 125 \mathrm{mM} \operatorname{EDTA}(\mathrm{pH} 8), 1 \mu \mathrm{l} 3 \mathrm{M}$ sodium acetate and $50 \mu \mathrm{l}$ $100 \%$ ethanol. After incubation at room temperature for $5 \mathrm{~min}$, samples were centrifuged at $18,407 \mathrm{~g}$ for $15 \mathrm{~min}$. The supernatant was discarded. After washing the pellet with $70 \mu \mathrm{l}$ $70 \%$ ethanol, samples were centrifuged at $18,407 \mathrm{~g}$ for $5 \mathrm{~min}$. The supernatant was removed and the pellet was dried at $37{ }^{\circ} \mathrm{C}$. Afterwards, the pellet was resuspended in $15 \mu \mathrm{l}$ $\mathrm{Hi}$-Di Formamide and sequenced using an ABI 3100 Automated Capillary Sequencer. 


\subsection{Biochemistry}

\subsubsection{Separation of proteins by SDS-PAGE and Immunoblot analysis}

\subsubsection{SDS-PAGE}

SDS-PAGE (Sodium dodecyl sulfate polyacrylamide gel electrophoresis) was developed by Shapiro et al. (Shapiro, Vinuela et al. 1967). It is a method whereby proteins are separated depending on their electrophoretic mobility and molecular weight. Using a sample buffer devised by Laemmli (Laemmli 1970), all proteins are bound by the anionic detergent sodium dodecyl sulfate (SDS) and are denatured by boiling in the presence of SDS. Thus, all proteins have a constant negative charge and move to the anode if an electric field is applied. The proteins migrate within a bipartite gel. Within the upper stacking gel with large pores, the denatured proteins are cumulated between the leading chloride ions and the trailing Glycine ions. For the stacking gel, an acrylamide/bisacrylamide (A/BA) concentration of $5 \%$ and a $\mathrm{pH}$ of 6.8 were used. Subsequently, the proteins enter the resolving gel with an A/BA concentration of $12 \%$ and therefore smaller pores and a pH of 8.8. Depending on the desired separation and the molecular weight of proteins, higher and lower percentages of A/BA might be used for the resolving gel. The proteins are separated depending on their molecular weight: Proteins with larger weight travel slower through the pores of the gel than those with lower weight. Details on the composition of the gels can be found in Table 4.15. First, the resolving gel was casted between two glass plates and covered by 2-propanol to obtain an even surface. After polymerization, 2-propanol was removed and the stacking gel was poured on top of the resolving gel. A comb with either 10 or 15 slots was inserted into the stacking gel to form slots for sample loading. Cell lysates were prepared as described in 4.1.5. Before loading into the gel, samples were heated at $95{ }^{\circ} \mathrm{C}$ for $5 \mathrm{~min}$ and centrifuged ( $2 \mathrm{~min}, 9,391 \mathrm{~g}$ ). $18 \mu \mathrm{l}$ or $25 \mu \mathrm{l}$ of cell lysates were loaded into the pockets of stacking gels with 15 or 10 slots, respectively. A prestained protein ladder was loaded into one pocket to estimate the size of the proteins investigated. The gels were run at 80 to $130 \mathrm{~V}$ for 2.5 to $3 \mathrm{~h}$.

Table 4.15: Composition of gels for SDS-PAGE

\begin{tabular}{lll} 
Component for... & ...one stacking gel $\mathbf{( 5 \% )}$ & ...one resolving gel $\mathbf{( 1 2} \%)$ \\
\hline Acrylamide/Bisacrylamide & $500 \mu \mathrm{l}$ & $4.0 \mathrm{ml}$ \\
Tris- $\mathrm{HCl}, \mathrm{pH} 6.8(1 \mathrm{M})$ & $380 \mu \mathrm{l}$ & - \\
Tris- $\mathrm{HCl}, \mathrm{pH} 8.8(1.5 \mathrm{M})$ & - & $2.5 \mathrm{ml}$ \\
$\mathrm{SDS}(10 \%)$ & $30 \mu \mathrm{l}$ & $100 \mu \mathrm{l}$ \\
$\mathrm{H}_{2} \mathrm{O}$ & $2.1 \mathrm{ml}$ & $3.3 \mathrm{ml}$ \\
APS $(10 \%)$ & $30 \mu \mathrm{l}$ & $100 \mu \mathrm{l}$ \\
TEMED & $3 \mu \mathrm{l}$ & $4 \mu \mathrm{l}$
\end{tabular}




\subsubsection{Immunoblotting}

After separation of proteins by SDS-PAGE, they can be investigated by immunoblotting (also: Western blotting). This method was developed by Renart, Reiser et al. and further developed by Towbin, Staehelin et al. (Renart, Reiser et al. 1979; Towbin, Staehelin et al. 1979). Immunoblotting permits visualization of protein levels and post-translational modifications, but also investigation of protein interactions after co-immunoprecipitation (CoIP). For immunoblotting, proteins were transferred from the gel onto a nitrocellulose membrane with a pore size of $0.2 \mu \mathrm{m}$ using the tank-blot technique (also: wet-blot, Bittner, Kupferer et al. 1980). On the anode side, a stack consisting of one sponge, three Whatman papers and a nitrocellulose membrane was assembled. The gel was placed on top of this stack, followed by three Whatman papers and another sponge. All components were soaked in Western blot transfer buffer. The stack was embedded by two plastic holders and vertically inserted into a blotting chamber filled with Western blot transfer buffer. An electric field was applied for $120 \mathrm{~min}$ at $100 \mathrm{~V}$ and $4{ }^{\circ} \mathrm{C}$ whereby proteins got bound to the membrane. Afterwards, the membrane was incubated in Ponceau S solution for $5 \mathrm{~min}$ in order to stain the proteins and thereby control the quality of the immunoblotting.

\subsubsection{Immunostaining}

To visualize specific proteins bound to the membrane, an immunostaining was conducted. Proteins were detected using a combination of two antibodies. While the primary antibody recognizes specifically an epitope of the protein of interest, the secondary antibody binds to the constant region of the primary antibody. Proteins bound by the primary antibody can be detected due to horseradish peroxidase (HRP)-conjugation of the secondary antibody and the usage of enhanced chemiluminescence (ECL) solutions. HRP catalyzes the oxidation of luminol by peroxide. The subsequent emission of visible light can be visualized by camera and indicates position and amount of the protein of interest on the membrane (Thorpe, Kricka et al. 1985). Besides whole proteins, also protein modifications can be investigated using antibodies directed against epitopes of post-translational modifications.

For immunostaining, the membrane was incubated in blocking solution containing $5 \%$ milk powder in TBST for $1 \mathrm{~h}$. This was followed by incubation of the membrane with primary antibody diluted in blocking solution for $2 \mathrm{~h}$ at room temperature or overnight at $4{ }^{\circ} \mathrm{C}$. Dilution ratios of applied primary antibodies are listed in Table 3.11. Thereafter, the membrane was rinsed three times in TBST and incubated in blocking solution for $30 \mathrm{~min}$, followed by incubation with a HRP-conjugated secondary antibody at a dilution of 1:10,000 for $1 \mathrm{~h}$ at room temperature. Applied secondary antibodies are listed in Table 3.13. Afterwards, the membrane was rinsed three times in TBST, incubated in blocking solution for 30 min and again rinsed three times in TBST. The washing steps in blocking solution were performed under gentle shaking at room temperature. Substrate solution was added to the membrane to induce chemiluminescence: Immobilon Western HRP Substrate Peroxide Solution for strong 
signals and SuperSignal West Femto Maximum Sensitivity Substrate for weak signals. The signal was detected using the Intas ChemoStar Imager Software.

\subsubsection{Co-immunoprecipitation}

Co-immunoprecipitation (ColP) is the immunoprecipitation of protein complexes and used to investigate the physical interaction of proteins. For this purpose, cell lysates are incubated with an antibody which precipitates a known protein which is thought to have one or more interaction partners. Using this antibody, ideally entire protein complexes can be precipitated which makes it possible to identify known and unknown interaction partners of the protein of interest. After the antibody-antigen reaction, sepharose beads coupled to protein $A$ or protein $G$ are added. Protein $A$ and protein $G$ are bacterial proteins which bind to antibodies from many mammalian species. Thus, the protein of interest and its interaction partners get precipitated by protein $A$ or protein $G$ sepharose via the antibody bound to it. Centrifugation and several washing steps are applied to purify the protein complex. Immunoblotting is used to investigate the precipitated proteins and their putative interaction partners. Salt and detergent concentration of the buffers can be varied in order to detect weak or strong protein interactions. Here, a high salt ColP buffer (see 3.4) was prepared and filtrated through a $0.2 \mu \mathrm{m}$ membrane filter. In some cases (then mentioned in the figure legend) the DUB inhibitor N-ethylmaleimide was added to the buffer in a concentration of $10 \mu \mathrm{M}$.

Physical interactions of endogenous and exogenous G2E3, Mdm2 and p53 were assessed using ColP. For ColP of endogenous proteins, four to six $15 \mathrm{~cm}$ cell culture dishes with adherent cells of $90 \%$ confluence were used per sample. Cells were washed once with PBS and harvested by scraping in $500 \mu \mathrm{l}$ ColP buffer per cell culture dish. For ColP of exogenous proteins, U2OS cells in 6-well cell culture plates were transiently transfected with plasmids encoding HA-G2E3, p53 and Mdm2. Empty vector pcDNA3 was used as control. Cells were washed once with PBS and harvested by scraping in $400 \mu \mathrm{l}$ ColP buffer. Cells from two wells with the same transfection mix were combined to yield more lysate. All steps were performed at $4{ }^{\circ} \mathrm{C}$ or on ice if not stated otherwise. Cell lysates were transferred into $1.5 \mathrm{ml}$ reaction tubes and pressed five times through a $26 \mathrm{G}$ cannula attached to a $1 \mathrm{ml}$ syringe, followed by sonication for $15 \mathrm{~min}$ at medium power with $15 \mathrm{sec}$ on/off using the sonication device Bioruptor. Afterwards, cell debris was removed by centrifugation (15 min, 16,000 g). The supernatant was transferred to a new $1.5 \mathrm{ml}$ reaction tube and incubated with $50 \mu \mathrm{l}$ protein $\mathrm{G}$ sepharose (PGS) for $1 \mathrm{~h}$ on a rotating wheel for pre-clearing. PGS was washed three times in ColP buffer before being added to the solution. Pre-clearing is necessary to remove all proteins that bind sepharose beads unspecifically. The pellet (resolved in CoIP buffer and 6x Laemmli buffer) and an aliquot of supernatant with 6x Laemmli buffer were stored for further analysis by SDS-PAGE and Western blot to investigate the quality of cell lysis. After pre-clearing, samples were centrifuged (4 min, $845 \mathrm{~g}$ ). As input control, $60 \mu \mathrm{l}$ supernatant were taken from each sample. $20 \mu \mathrm{l} 6 \mathrm{x}$ Laemmli buffer were added to input 
samples which were boiled at $95{ }^{\circ} \mathrm{C}$ for $5 \mathrm{~min}$. The remaining supernatant was split in equal parts in several $1.5 \mathrm{ml}$ reaction tubes for incubation with $2 \mu \mathrm{g}$ of different antibodies: mouse-anti-p53 (Santa Cruz), mouse-anti-Mdm2 (Calbiochem) and control antibodies mouseanti- $\beta$-Galactosidase (Promega) and mouse-anti-IgG (Jackson ImmunoResearch), see also Table 3.11. For goat-anti-G2E3 antibody (Santa Cruz) $4 \mu \mathrm{g}$ were used.

As further controls for the specificity of the antibodies, they were added to $1.5 \mathrm{ml}$ reaction tubes without cell lysates (filled with ColP buffer only). All samples were incubated overnight on a rotating wheel. Then, $25 \mu \mathrm{l}$ PGS beads were added per sample, followed by incubation on a rotating wheel for 1 to $2 \mathrm{~h}$ to allow coupling of antibodies to PGS. The beads were centrifuged ( $2 \mathrm{~min}, 845 \mathrm{~g}$ ) and washed five times with $800 \mu \mathrm{l}$ ColP buffer with intermediate centrifugation steps (2 min, $845 \mathrm{~g}$ ). After the last washing step, cells were centrifuged again $(2 \mathrm{~min}, 4000 \mathrm{~g}$ ). The supernatant was removed and the beads were resuspended in $25 \mu \mathrm{l}$ $3 x$ Laemmli buffer, shortly vortexed and boiled at $95{ }^{\circ} \mathrm{C}$ for $5 \mathrm{~min}$. Samples were stored at $-20{ }^{\circ} \mathrm{C}$ or analysed by immunoblotting.

\subsubsection{Immunofluorescence staining and microscopy}

Immunofluorescence microscopy is applied to visualize proteins using a combination of a primary antibody against the protein of interest and a fluorophore-coupled secondary antibody. After excitation of the fluorophore, the emitted fluorescence is detected by a fluorescence microscope.

Cells were transfected and seeded in triplicates in 96-well imaging plates (Becton Dickinson), for cell numbers see 4.1.3.1 and 4.1.3.2. All steps of immunofluorescence staining were performed at room temperature. After removing culture medium, cells were fixed by applying $100 \mu \mathrm{l} 3.7 \%$ formaldehyde in PBS for $40 \mathrm{~min}$. Then, cells were washed twice with PBS. For permeabilization, cells were incubated with $100 \mu \mathrm{l} 0.5 \%$ Triton X-100 in PBS for 15 min. All following steps were performed using blocking solution containing $0.1 \%$ Triton $X-100$ and $5 \%$ FCS in PBS. Cells were incubated in $100 \mu$ l blocking solution for 15 min to block unspecific binding sites. Blocking solution contained Triton X-100 to keep the cells in a permeabilized state. $70 \mu \mathrm{l}$ primary antibody diluted in blocking solution was added to the cells for $1 \mathrm{~h}$ (for dilutions of primary and secondary antibodies Table 3.12 and Table 3.14). Cells were washed three times with $100 \mu$ l blocking solution for 5 min each to remove unbound primary antibodies. Then, $70 \mu \mathrm{l}$ secondary antibody in blocking solution was added to the cells and incubated for $45 \mathrm{~min}$ in the dark. Secondary antibodies were coupled to fluorophores; here Alexa488 and Alexa 546 were used. Furthermore, the nuclear stain Hoechst 33342 was added in a dilution of 1:2000 to the solution to stain nuclei. Cells were then washed for $5 \mathrm{~min}$ in blocking solution, followed by two times washing with PBS for 5 min each. Finally, cells were kept in $200 \mu \mathrm{l}$ PBS and the plate was sealed with aluminium foil to prevent bleaching of fluorophores by ambient light. Immunofluorescence pictures were taken 
using the high-content imaging platform BD Pathway 855 System (Becton Dickinson). For each well, nine single pictures were taken using a 10x magnification. For quantification of fluorescence intensity, the images were processed using the AttoVision software (Becton Dickinson): Cell nuclei were defined as regions of interest (ROI) on the basis of Hoechst staining. The average relative fluorescence intensity of the protein of interest within these ROls was determined. Thereafter, the average fluorescence intensity per well was calculated. Background signals were subtracted, followed by a calculation of the average intensity of the well triplicates of each sample.

If single pictures were taken, a magnification of 40x was used to take pictures of nuclei (Hoechst stain) and the immunostained protein(s) of interest. Background subtraction was performed using the image processing software Fiji with a rolling ball between 50 (for strong subtraction) and 1000 (for slight subtraction). Merged pictures were created using Fiji.

\subsubsection{Statistical analysis}

Calculations were performed with Microsoft Excel. To investigate statistical significance, an unpaired, two-tailed student's t-test was conducted with an assumed significance for $p$-values $<0.05$. Asterisks are used to visualize $p$-values in the following way:

$$
\begin{array}{ll}
\star * \star & =p<0.001 \\
\star * & =p<0.01 \\
\star & =p<0.05 \\
\text { n.s. } & =\text { not significant }
\end{array}
$$

The number of independent experiments is stated with "n". Error bars are depicted as standard deviation (SD) or standard error of the mean (SEM).

\subsubsection{High-content siRNA screen}

\subsubsection{1 siRNA library}

For the high-content siRNA screen on ubiquitin ligases and deubiquitinating enzymes, the Silencer ${ }^{\circledR}$ Select Ubiquitin Library (Ambion) was used. The library was obtained as lyophilised siRNAs in 96-well plates and was dissolved in nuclease-free water to a final siRNA concentration of $5 \mu \mathrm{M}$. From this, dilution plates with a concentration of $167 \mathrm{nM}$ were prepared. Transfection with siRNAs was performed with a final concentration of $10 \mathrm{nM}$ per SiRNA. Automated pipetting was performed by the Biomek 2000 Laboratory Automation Workstation (Beckman Coulter).

The library consisted of siRNAs against 327 human ubiquitin ligases and 92 deubiquitinating enzymes (DUBs) with three different siRNAs per gene. The three different siRNAs targeting one gene were located on different 96-well plates in individual wells. The three 96-well plates with siRNAs against the same genes were treated side-by-side for transfection, 
immunofluorescence staining and imaging. In total, fifteen 96-well plates were screened. Per plate, eight internal controls were loaded.

\subsubsection{High-content siRNA screen procedure}

U2OS cells were transfected with siRNAs in 96-well plates for microscopy (Becton Dickinson) using the Biomek 2000 Laboratory Automation Workstation (Beckman Coulter) and incubated for $48 \mathrm{~h}$. The transfection procedure according to which the robot was programmed is described in 4.1.3.2. During the last $16 \mathrm{~h}$ of the incubation time, cells were treated with $30 \mu \mathrm{M}$ cisplatin, followed by fixation and immunofluorescence staining of $\mathrm{YH} 2 \mathrm{AX}$. For immunostaining, $\mathrm{YH} 2 \mathrm{AX}$ antibody (Millipore, 05-636) was used at a dilution of 1:1500 and detected by Alexa546-coupled secondary antibody. Hoechst 33342 was used to stain nuclei. For each well, nine images were taken with 10x magnification. Then, automated microscopy and image analysis were performed using the BD Pathway 855 System (Becton Dickinson). For details on immunofluorescence staining and microscopy, see 4.3.3.

Eight internal controls were used per plate: two negative controls (control siRNA scrambled No. 1 and No. 2) and four positive controls. As positive controls, knockdowns of genes were performed for which a significant change in $\mathrm{YH} 2 \mathrm{AX}$ fluorescence intensity was already established: Knockdown of Chk1 and p53 lead to increase in $\mathrm{yH} 2 \mathrm{AX}$ levels, whereas knockdown of RNF8 and BRCA1 lead to decrease in $\mathrm{YH} 2 \mathrm{AX}$ levels. Furthermore, cells in two wells were transfected with control siRNA scrambled No. 1 and No. 2 and left untreated to monitor successful cisplatin treatment.

\subsubsection{High-content siRNA screen data acquisition and analysis}

Image analysis was performed using the AttoVision Software (Becton Dickinson). First, nuclei were defined as regions of interest (ROIs) on the basis of Hoechst staining. For analysis, ca. 1000-3000 nuclei per well were utilized. The average $\mathrm{yH} 2 \mathrm{AX}$ fluorescence intensity within these ROIs was determined and the average fluorescence intensity per well was calculated. Data were normalized to correct for differences between the plates due to variations during transfection and immunofluorescence staining.

Normalization of screen data was performed using a robust z-score. The z-score is defined as the number of standard deviations from the mean. It gives information on the strength of an effect relative to the rest of the samples (Birmingham, Selfors et al. 2009). Since the z-score is sensitive to outliers, the robust z-score is generally used for siRNA screens. Here, the mean and standard deviation are substituted by median and median absolute deviation (MAD):

$$
\mathrm{z}=\frac{\text { sample value }- \text { sample median }}{\text { sample median absolute deviation }}
$$


Sample value refers to the average $\mathrm{yH} 2 \mathrm{AX}$ fluorescence intensity per well. Sample median and sample median absolute deviation were calculated per plate. Using these values, the robust z-score was calculated for each well of the 96-well plate and thus for each siRNA.

\subsubsection{Hit Identification Strategy}

After normalization of data, a hit identification strategy was applied to take into account how many of the three different siRNAs per gene led to a significant decrease or increase of $\mathrm{yH} 2 \mathrm{AX}$ fluorescence intensity. Hit identification was based on robust z-scores. Every siRNA with a robust $z$-score of $\geq 2$ or $\leq-2$ was considered as a hit. Also, the sum and the average of all three z-scores per gene were calculated to identify general trends. Candidates were identified if at least two siRNAs reached the threshold of $\geq 2$ or $\leq-2$.

\subsubsection{Validation of screen results and follow-up}

After identification of candidate genes that show a strong down- or up-regulation of $\mathrm{yH} 2 \mathrm{AX}$ after knockdown, screen results were validated in a secondary screen. Therefore, knockdown of candidate genes was performed with the same procedure used for the high-content siRNA screen. 


\section{Results}

\subsection{A high-content siRNA screen identifies new regulators in the DDR to cisplatin}

Cisplatin is a chemotherapeutic agent for the treatment of testicular, ovarian, lung, cervical, head and neck cancer. It induces intra- and inter-strand crosslinking of DNA and thus prevents separation of strands during transcription and replication. Cisplatin treatment is known to activate various signaling and repair pathways. However, the cellular and molecular mechanisms of cisplatin treatment are incompletely understood. Therefore, our aim was to find new regulators in the DNA damage response (DDR) to cisplatin which would help to understand these pathways in more detail. Secondly, we hoped to identify proteins whose inhibition or stabilization could sensitize cancer cells to chemotherapeutic treatment, which could be targets to improve therapy in the future.

Ubiquitin ligases and deubiquitinating enzymes (DUBs) play a major role in the DDR. Examples are the ubiquitin ligases RNF8 and RNF168 that regulate the response to DNA double-strand breaks (DSBs) (Huen, Grant et al. 2007; Mailand, Bekker-Jensen et al. 2007; Doil, Mailand et al. 2009). Another important ubiquitin ligase is BRCA1 with different important roles in the DDR, in DNA repair and in cell cycle checkpoint control (reviewed in Huen, Sy et al. 2010). Additionally, Mdm2, the main negative regulator of the tumor suppressor p53, is an ubiquitin ligase which is posttranslationally modified after DNA damage (Khosravi, Maya et al. 1999).

Considering the importance of the ubiquitin system in the DDR and open questions in the response to cisplatin treatment, we decided to perform a high-content siRNA screen and to deplete cells from human ubiquitin ligases and DUBs.

\subsubsection{High-content siRNA screen procedure}

For the high-content screen, U2OS cells were transfected with a siRNA library targeting 327 human ubiquitin ligases and 92 DUBs. These were the genes known at the time of library preparation in 2008. Till now, more than 600 E3 ligases and ca. 100 DUBs have been identified (Jackson and Durocher 2013). During the screen, three different siRNAs per gene were used. The osteosarcoma cell line U2OS was chosen as it is widely used to study the DDR and is appropriate for siRNA screening due to its good transfection efficiency and suitable morphology for immunofluorescence microscopy (Doil, Mailand et al. 2009; Beck, Nahse et al. 2010; Cotta-Ramusino, McDonald et al. 2011). 
The procedure of high-content siRNA screening is depicted in Figure 5.1. U2OS cells were transfected with siRNAs and treated with cisplatin. Cells were fixed and subsequently stained for phospho-H2AX. Phosphorylation of the histone variant H2AX at Ser139 (then named $\mathrm{YH} 2 \mathrm{AX}$ ) was used as mark of DNA damage induction and quantified by automated microscopy and image analysis as explained in section 4.3.5 and Figure 5.1. $\mathrm{yH} 2 \mathrm{AX}$ was selected since it is a suitable read-out widely used in the field of DDR research (reviewed in Fernandez-Capetillo, Lee et al. 2004; Stucki and Jackson 2006). Moreover, other groups have used it already as marker in siRNA screening (e.g. Paulsen, Soni et al. 2009; Higgins, Prevo et al. 2010). Here, we chose $\mathrm{yH} 2 \mathrm{AX}$ to gain insight into the different molecular pathways activated upon cisplatin treatment and to identify which ubiquitin ligases and DUBs influence them.

\section{High-content siRNA screen procedure:}

1) Reverse transfection of U2OS (human osteosarcoma) cells with siRNAs against 327 human ubiquitin ligases and 92 DUBs ( 3 siRNAs per gene)

2) $30 \mu \mathrm{M}$ cisplatin for $16 \mathrm{~h}$, total incubation time $48 \mathrm{~h}$

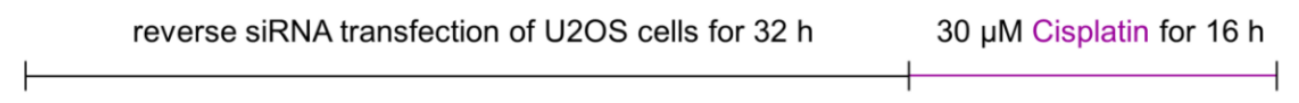

3) Fixation, immunofluorescence staining of $\mathrm{yH} 2 \mathrm{AX}$

4) Automated microscopy and image analysis using the BD Pathway System:

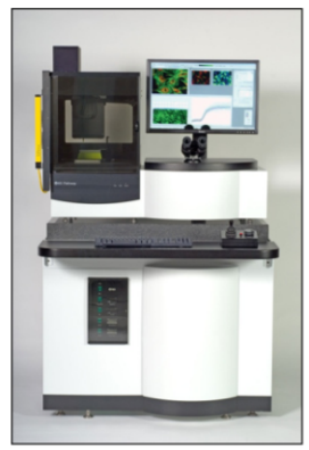

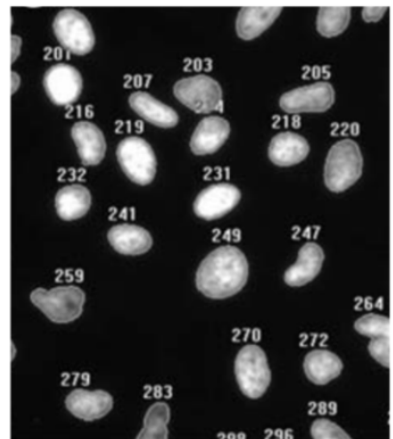

(4.1)

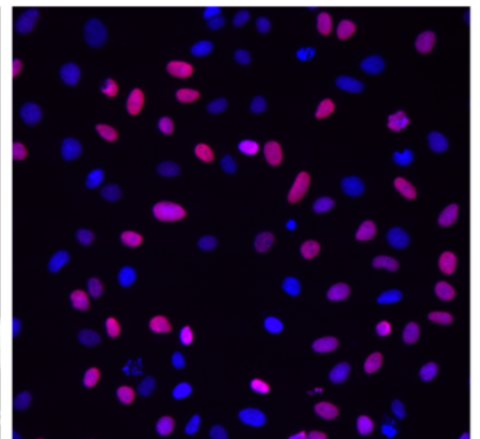

(4.2)
YH2AX

Hoechst

4.1) Define nuclei (Hoechst) as „regions of interest“ (ROls)

4.2) Measure fluorescence intensity of $\mathrm{yH} 2 \mathrm{AX}$ within ROls

4.3) Determine average intensity per well

4.4) Constrain data using a robust z-score:

$\mathrm{z}=\frac{\text { sample value }- \text { sample median }}{\text { sample median absolute deviation }}$

4.5) Validate results in secondary screen

Figure 5.1: High-content siRNA screen procedure to identify new regulators in the DNA damage response to cisplatin.

(Pictures of microscope and numbered nuclei taken from BD Pathway User's Manual - AttoVision $1.5,2006)$ 
As statistical measure of $\mathrm{H} 2 \mathrm{AX}$ phosphorylation, a robust z-score was assigned to each SiRNA. For details on analysis and controls, refer to 4.3.5. Every siRNA with a robust z-score of $\geq 2$ or $\leq-2$ was considered as a hit. Candidates were identified if at least two siRNAs reached the threshold of $\geq 2$ or $\leq-2$. Figure 5.2 shows candidates with substantial increase (positive robust z-score) and decrease (negative robust z-score) in $\mathrm{yH} 2 \mathrm{AX}$ fluorescence intensity. Increased $\mathrm{H} 2 \mathrm{AX}$ phosphorylation after knockdown suggests that the encoded protein inhibits the DDR, whereas decreased $\mathrm{yH} 2 \mathrm{AX}$ levels propose that the encoded protein supports the DDR upon cisplatin treatment.

Upon identification of candidate genes that show a strong down- or up-regulation of $\mathrm{yH} 2 \mathrm{AX}$ after knockdown, screen results were validated in a secondary screen. Therefore, knockdown of candidate genes was performed using the same procedure as for the high-content siRNA screen. This second screen was performed for 29 genes that were identified to show a downregulation of $\mathrm{yH} 2 \mathrm{AX}$ fluorescence intensity after knockdown and for 13 genes with an upregulation of $\mathrm{YH} 2 \mathrm{AX}$. After validation, additional siRNAs were obtained for a total of 10 candidates that showed the strongest changes in $\mathrm{yH} 2 \mathrm{AX}$ levels. These top candidates were validated by investigating $\mathrm{yH} 2 \mathrm{AX}$ levels through immunofluorescence staining and immunoblotting as well as further parameters. 


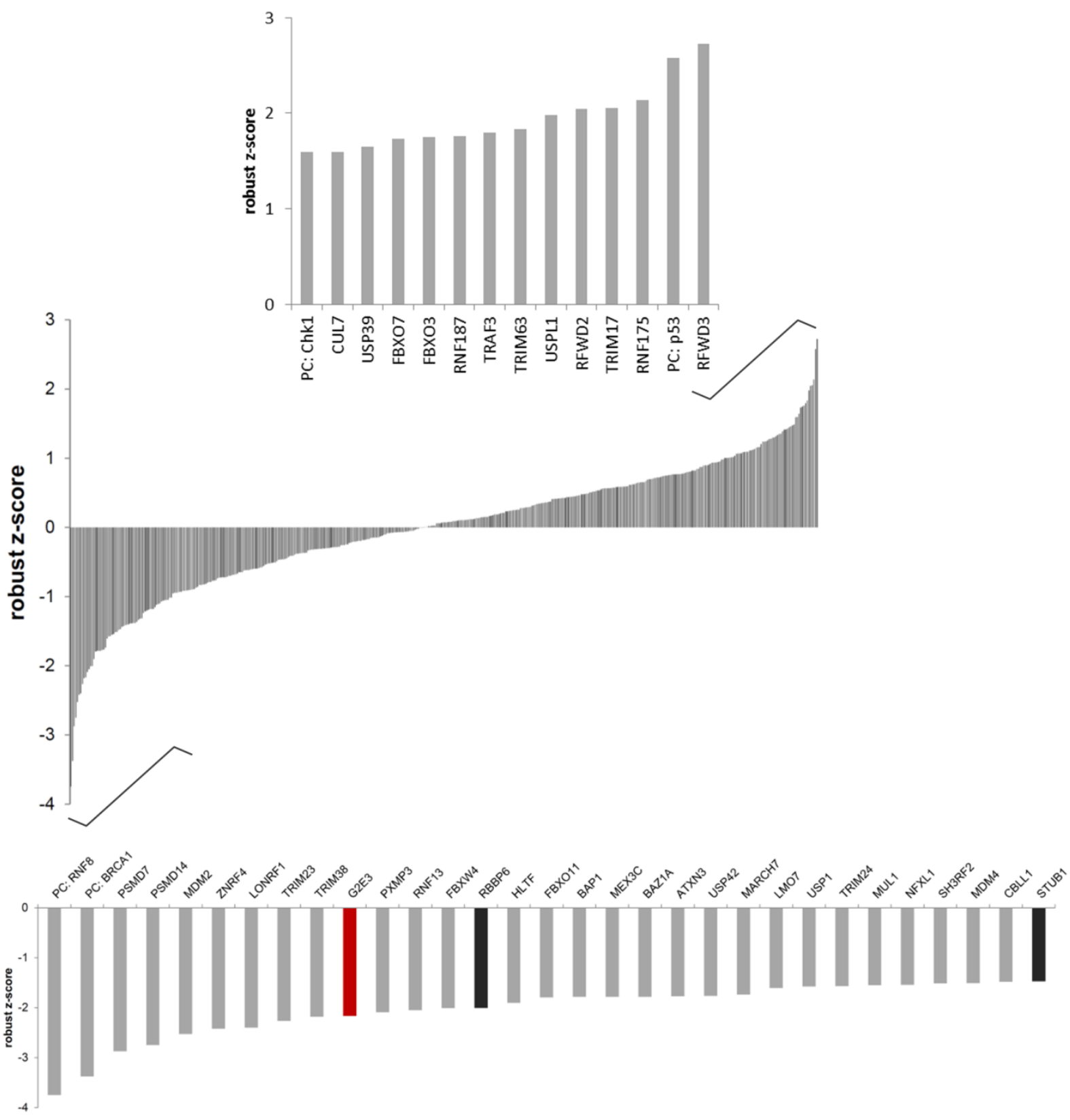

Figure 5.2: High-content siRNA screen results: The influence of 327 human ubiquitin ligases and 92 DUBs on H2AX phosphorylation.

U2OS cells were transfected with siRNAs targeting 327 human ubiquitin ligases and 92 DUBs using three different siRNAs per gene. Cells were treated with $30 \mu \mathrm{M}$ cisplatin for $16 \mathrm{~h}$ (total incubation time $48 \mathrm{~h}$ ), fixed and stained for $\mathrm{yH} 2 \mathrm{AX}$. Automated microscopy and image analysis was performed using the BD Pathway System. A robust z-score was assigned to each siRNA as a measure of H2AX phosphorylation. Candidates with significant increase (positive robust z-score) and decrease (negative robust z-score) in $\mathrm{yH} 2 \mathrm{AX}$ fluorescence intensity are depicted as average robust z-score of three siRNAs per gene. Marked in red is candidate G2E3 and marked in dark grey are candidates RBBP6 and STUB1, used for further studies as detailed in the text. PC = positive control. 


\subsubsection{Candidates identified by high-content siRNA screening}

We identified various genes that showed a strong decrease in H2AX phosphorylation upon knockdown. Interestingly, plenty of them were described before to be involved in the DDR and DNA repair, but also in the p53-pathway. These will be discussed in more detail in section 6.4. Unexpectedly, we did not identify many genes with a strong increase in $\mathrm{yH} 2 \mathrm{AX}$ fluorescence intensity upon knockdown. These could have been candidates whose inhibition would sensitize cells to cisplatin. Still, it would be interesting to explore these genes further.

Together, these results of known regulators of the DDR and p53-pathway suggest that the developed screen procedure was suitable to identify new regulators in the DDR after cisplatin treatment. After further validation, we decided to study the ubiquitin ligase G2E3 whose knockdown led to decrease in $\mathrm{YH} 2 \mathrm{AX}$ levels upon cisplatin treatment. We were interested in G2E3 since it had been proposed to play a role in the DDR and in cell survival, but only little was known about the underlying mechanisms. G2E3 was reported to show a maximal mRNA expression

G2/M-phase and decreased mRNA levels upon y-irradiation (thus G2E3 is the abbreviation for G2-specific E3 ligase) (Crawford and Piwnica-Worms 2001). Localization of G2E3 was proposed to be regulated by DNA damage (Brooks, Banerjee et al. 2007). G2E3 consists of four domains that can act as E3 ligases (three domains with similarity to both RING and PHD domains and a fourth HECT domain), and in vitro ubiquitin ligase activity was shown for the PHD/RING2 and PHD/RING3 domain (Brooks, Helton et al. 2008). Furthermore, Brooks et al. established a G2E3 knock-out mouse which displays early embryonic lethality (Brooks, Helton et al. 2008). Together, these findings motivated us to study the role of G2E3 in the DDR, in cell survival and in cell cycle regulation.

\subsection{Investigation of the ubiquitin ligase G2E3 as a regulator of the DDR to cisplatin treatment}

\subsubsection{Knockdown of G2E3 decreases phosphorylation of H2AX in U2OS cells}

Using the described high-content siRNA screen, we found that knockdown of G2E3 led to decreased H2AX phosphorylation in cisplatin treated U2OS cells. We used immunofluorescence staining and immunoblotting to validate this observation (Figure 5.3). Figure 5.3A shows that depletion of G2E3 by three different siRNAs resulted in decreased $\mathrm{YH} 2 \mathrm{AX}$ levels as seen by immunofluorescence staining. Additionally, decreased phosphorylation of H2AX after knockdown of G2E3 by three different siRNAs was revealed using immunoblotting (Figure 5.3B). The three siRNAs efficiently depleted cells of G2E3 as seen by qPCR analysis (Figure 5.3C). Unfortunately, a high-quality antibody to stain endogenous G2E3 protein was not commercially available. 
A
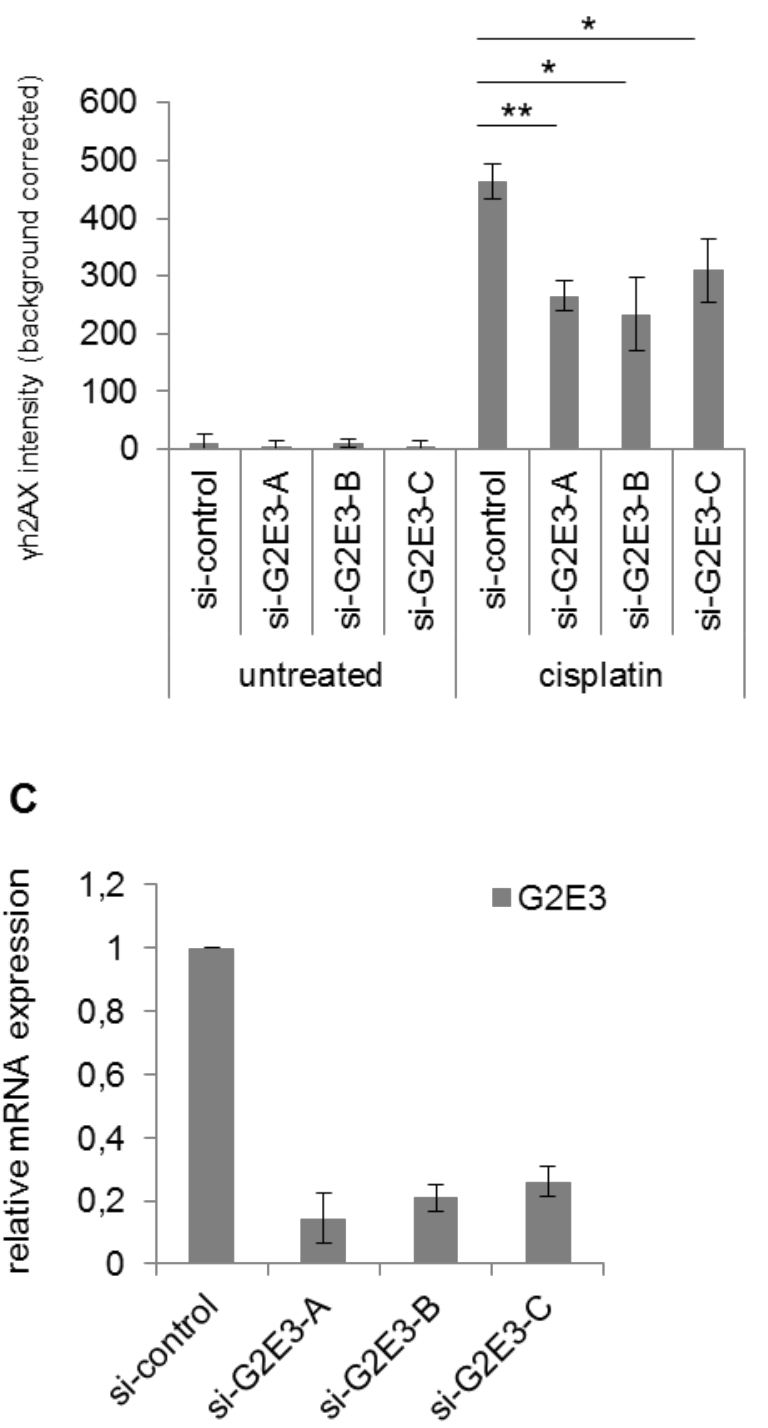

B

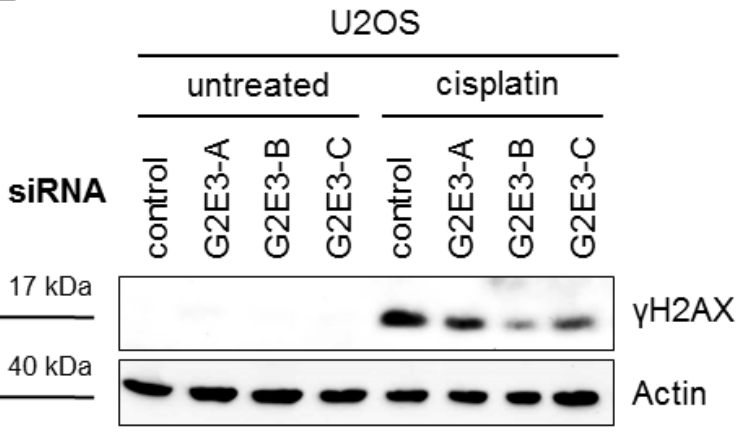

Figure 5.3: Knockdown of G2E3 decreases phosphorylation of H2AX in U2OS cells after cisplatin treatment.

(A) U2OS cells were transfected with three different siRNAs against G2E3. Cells were either left untreated or treated with $30 \mu \mathrm{M}$ cisplatin for $16 \mathrm{~h}$ (total incubation time $64 \mathrm{~h}$ ), fixed and stained for $\mathrm{yH} 2 \mathrm{AX}$. Automated microscopy and image analysis was performed using the BD Pathway System. Results were corrected for background fluorescence. Error bars are represented as SD $(n=3)$. ${ }^{*}=p<0.05,{ }^{* *}=p<0.01$ (student's t-test). (B) U2OS cells were depleted of G2E3 by siRNA-mediated knockdown. Cells were either left untreated or treated with $30 \mu \mathrm{M}$ cisplatin for $16 \mathrm{~h}$ (total incubation time $64 \mathrm{~h}$ ). Cell lysates were analyzed by immunoblotting for $\mathrm{yH} 2 \mathrm{AX}$ levels. Actin staining served as loading control. (C) Knockdown efficiency of G2E3 siRNAs. U2OS cells were harvested $64 \mathrm{~h}$ after knockdown. G2E3 mRNA levels were analyzed by qPCR. Results were normalized to expression of the reference gene GAPDH. Error bars are represented as SD $(n=3)$.

\subsubsection{G2E3 does not influence pChk1 and pChk2 levels in the DDR to cisplatin}

Crosslinking of DNA induced by cisplatin treatment leads to stalled replication forks. This results in DNA single-strand breaks that activate the ATR-Chk1 pathway. During repair of these lesions, DNA double-strand breaks are induced which activate the ATM-Chk2 pathway. Both pathways lead to activation of the tumor suppressor p53. Since ATM (350 kDa) and ATR (300 kDa) are large-size proteins and their activation is difficult to detect in immunoblotting, we determined pChk1 and pChk2 levels. Chk1 and Chk2 are the second line activation regulators which also give insight into activation of these pathways. In order to study whether G2E3 plays a role in these pathways, we depleted p53-proficient and p53deficient cells of G2E3 and assessed pChk1 and pChk2 levels by immunoblotting. Both Chk1 and Chk2 become phosphorylated upon cisplatin treatment. However, we could not observe strong changes in pChk1 and pChk2 levels upon G2E3 knockdown in p53-proficent and 
p53-deficient cell lines when compared to control knockdown. Here we depict pChk2 levels in p53-proficient U2OS cells (Figure 5.4A) and pChk1 levels in p53-deficient HCT116 $\mathrm{p53}^{-{ }^{-}}$cells (Figure 5.4B). Certainly, we cannot exclude that G2E3 plays a direct role in these pathways. Further studies are needed to access the role of G2E3 in the DDR.
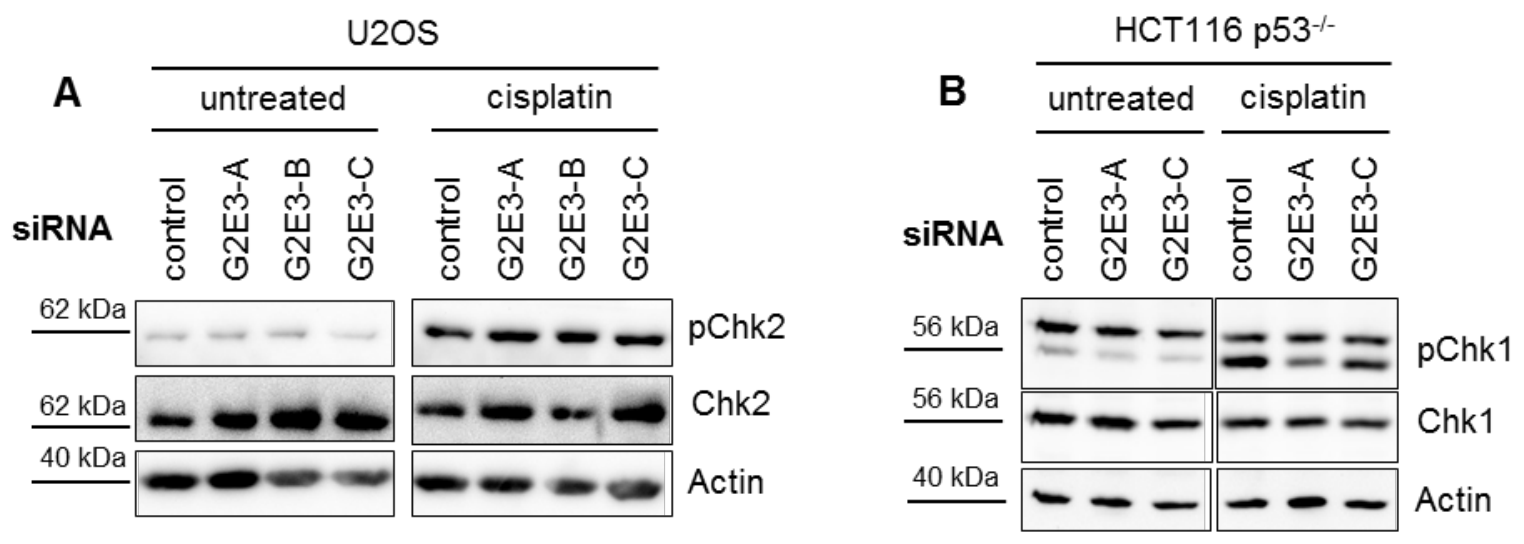

Figure 5.4: G2E3 in the DNA damage response after cisplatin treatment: G2E3 knockdown does not influence pChk1 and pChk2 levels.

(A) U2OS cells were depleted of G2E3 using three different siRNAs and either left untreated or treated with $30 \mu \mathrm{M}$ cisplatin for $8 \mathrm{~h}$ (total incubation time $55 \mathrm{~h}$ ). Cell lysates were analyzed by immunoblotting for pChk2 and total Chk2 levels. Actin staining served as loading control. (B) HCT116 p53 ${ }^{-{ }_{-}}$cells were transfected with two different siRNAs against G2E3 and either left untreated or treated with $30 \mu \mathrm{M}$ cisplatin for $16 \mathrm{~h}$ (total incubation time $64 \mathrm{~h}$ ). Cell lysates were analyzed by immunoblotting for pChk1 and total Chk1 levels. Actin staining served as loading control.

\subsubsection{Subcellular localization of overexpressed G2E3}

Many proteins involved in the DDR and cell cycle regulation are characterized by changing their localization upon treatment with DNA-damaging reagents. Often, nucleo-cytoplasmic exchange is observed, e.g. for p53 (reviewed in O'Brate and Giannakakou 2003) and for the localization of cyclins and CDKs (reviewed in Yang and Kornbluth 1999). Therefore, we were interested in studying the localization of G2E3 within the cell. Since no antibody to detect endogenous G2E3 is commercially available, we cloned and overexpressed a HA-tagged version of G2E3 in U2OS cells, followed by immunofluorescence staining. As depicted in Figure 5.5 (upper panel), HA-G2E3 was localized to the nucleus and subnuclear structures of U2OS cells. We co-stained nucleoli using nucleophosmin and PML bodies, but could not observe a co-localization (data not shown). Upon cisplatin treatment, HA-G2E3 was still localized to nuclei of cells, but excluded from some areas of the nucleus (Figure 5.5, lower panel). Brooks et al. showed that in HeLa cells, GFP-G2E3 is primarily localized to the nucleolus, but localized to the nucleoplasm in a diffuse manner after DNA damage ( $\gamma$-irradiation, doxorubicin and etoposide treatment) (Brooks, Banerjee et al. 2007). These results suggest that localization of G2E3 changes upon DNA damage. 
HA-tag
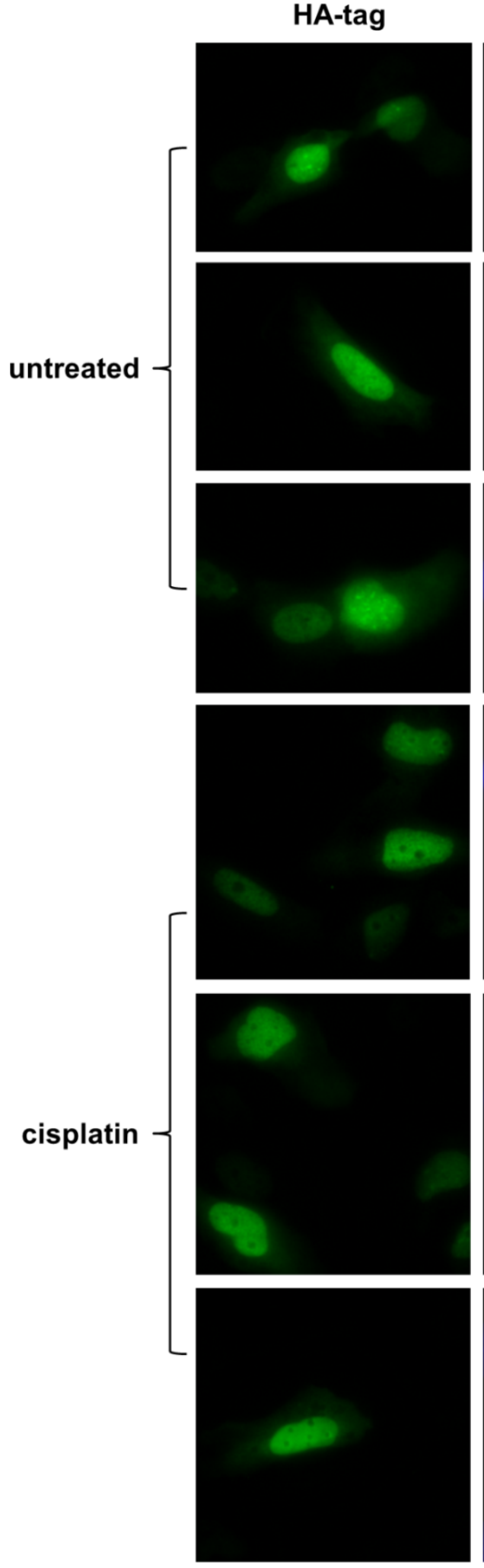

Hoechst
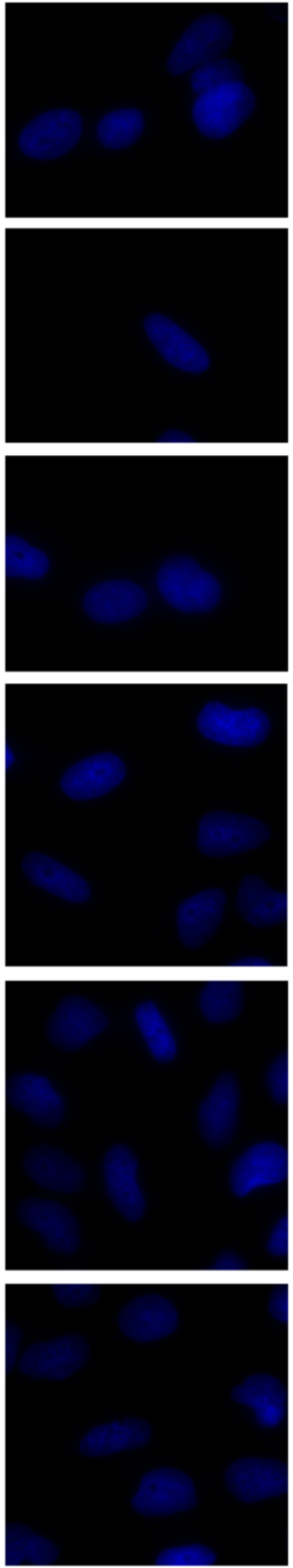

Merge
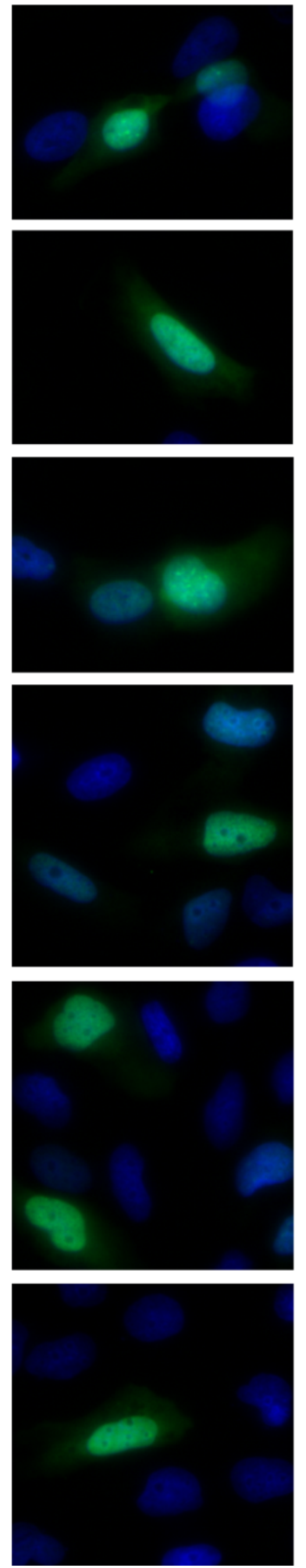

Figure 5.5: Overexpressed HA-G2E3 localizes to nuclei and subnuclear structures in untreated cells and to nuclei with exclusion from some areas in cisplatin treated cells.

U2OS cells were transiently transfected with a plasmid encoding HA-G2E3 for $24 \mathrm{~h}$ and either left untreated or treated with $30 \mu \mathrm{M}$ cisplatin during the last $4 \mathrm{~h}$. Cells were fixed and stained for HA-tag and Hoechst. Microscopy was performed using the BD Pathway System. 


\subsection{G2E3 as a regulator of apoptosis and cell cycle}

\subsubsection{Knockdown of G2E3 results in p53-independent apoptosis in colon carcinoma and osteosarcoma cell lines}

Phosphorylation of H2AX is commonly used as marker of DNA damage, but was also found during apoptosis after induction of DNA fragmentation (Rogakou, Nieves-Neira et al. 2000). A link between apoptosis and DDR was also suggested by another group who showed that Chk2- and H2AX-associated signal transduction can be activated by death receptor signaling (Solier, Sordet et al. 2009). Therefore, we were interested to investigate the effect of G2E3 depletion on apoptosis. We depleted colon carcinoma (HCT116) and osteosarcoma (U2OS, SJSA) cell lines of G2E3, followed by cisplatin treatment and immunoblotting (Figure 5.6A-D). Apoptosis was accelerated upon G2E3 knockdown in all cell lines, as detected by the apoptotic markers cleaved caspase 3 and cleaved PARP-1. Even in untreated cells, induction of apoptosis upon G2E3 knockdown was observed in some cases, giving a hint for its important role in cell survival (Figure 5.6A-C). Since p53 is an important regulator of apoptosis, we used HCT116 p53 $^{-/-}$cells to investigate whether p53 is required for apoptosis upon G2E3 knockdown. Strikingly, in p53-deficient cells, knockdown of G2E3 also leads to increased apoptosis (Figure 5.6B). This result suggests that G2E3 plays a p53-independent role in apoptosis and could function as an anti-apoptotic protein in the cell. These results are in line with Brooks, Helton et al. (2008) who established a G2E3 knock-out mouse which is characterized by early embryonic lethality. The reasons are massive apoptosis and involution of the blastocyst. In order to investigate the p53-dependency of their observations, they established double heterozygous mice for G2E3 and p53 (i.e. G2E3 $3^{-/+}$and $\mathrm{p} 53^{-/+}$).

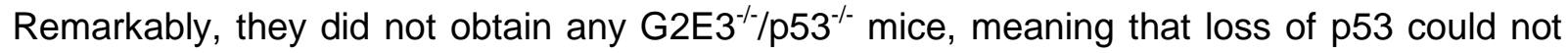
rescue the lethal phenotype of G2E3 knock-out mice.

In summary, G2E3 knockdown leads to increased apoptosis in various cell lines in a p53-independent manner. These results suggest that G2E3 plays an important role in cell survival.

Interestingly, knockdown of G2E3 led to decreased H2AX phosphorylation only in U2OS cells as seen before in Figure 5.3, but not in HCT116 and SJSA cells, arguing for a cell typespecific effect of G2E3 depletion on $\mathrm{YH} 2 \mathrm{AX}$ levels. 

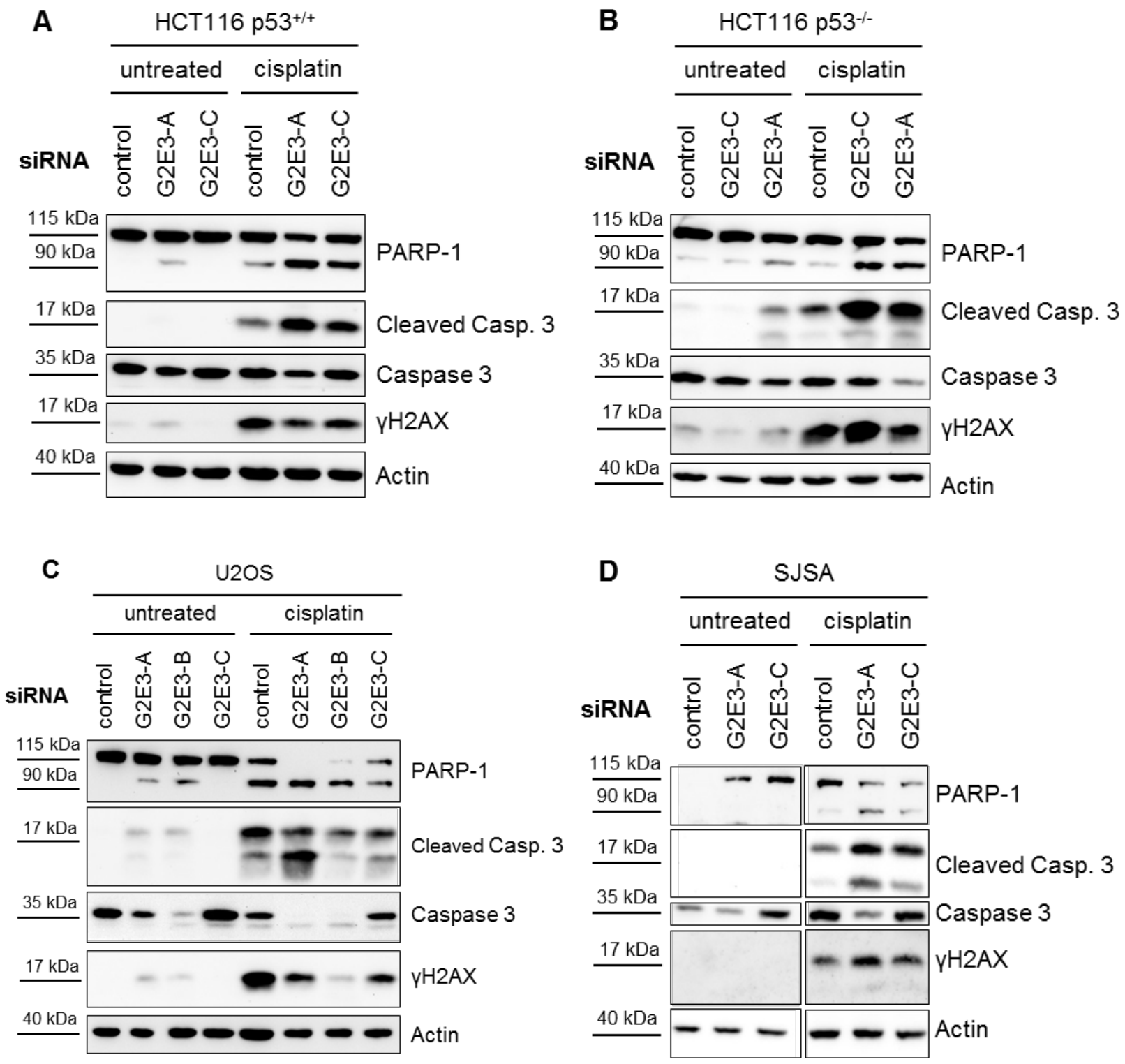

Figure 5.6: Knockdown of G2E3 results in apoptosis in colon carcinoma (HCT116) and osteosarcoma (U2OS, SJSA) cell lines.

(A) HCT116 p53 ${ }^{+/+}$, (B) HCT116 p53 ${ }^{-/-}$, (C) U2OS and (D) SJSA cells were depleted of G2E3 by siRNA-mediated knockdown with two to three different siRNAs and either left untreated or treated with $30 \mu \mathrm{M}$ cisplatin for $16 \mathrm{~h}$ (total incubation time $64 \mathrm{~h}$ ). Cell lysates were analyzed by immunoblotting. Markers for apoptosis are cleaved caspase 3 (Cleaved Casp. 3), total caspase 3 and cleaved PARP-1 (total protein at $115 \mathrm{kDa}$ and cleaved PARP-1 at $90 \mathrm{kDa}$ ). $\mathrm{yH} 2 \mathrm{AX}$ staining was used as control for cisplatin treatment. Actin staining served as loading control. 


\subsubsection{Proliferation rate of cancer cells is decreased following depletion of G2E3}

To further evaluate the role of G2E3 in cell survival, we set out to study its impact on cell proliferation. We measured cell confluence over time after G2E3 knockdown in U2OS,

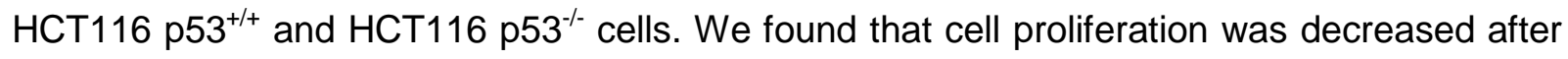
G2E3 knockdown with three different siRNAs in all cell lines (Figure 5.7A-C). The reason for reduced proliferation could be an increased susceptibility to apoptosis after G2E3 knockdown (as seen in Figure 5.6) or induction of cell cycle arrest. A main regulator of the cell cycle is p53, but also p53-independent cell cycle regulation exists. Interestingly, cell proliferation is also alleviated in p53-deficient HCT116 cells (Figure 5.7B). To clarify if G2E3 also plays a role in cell cycle regulation, we continued to study if G2E3 knockdown affects the cell cycle profile.
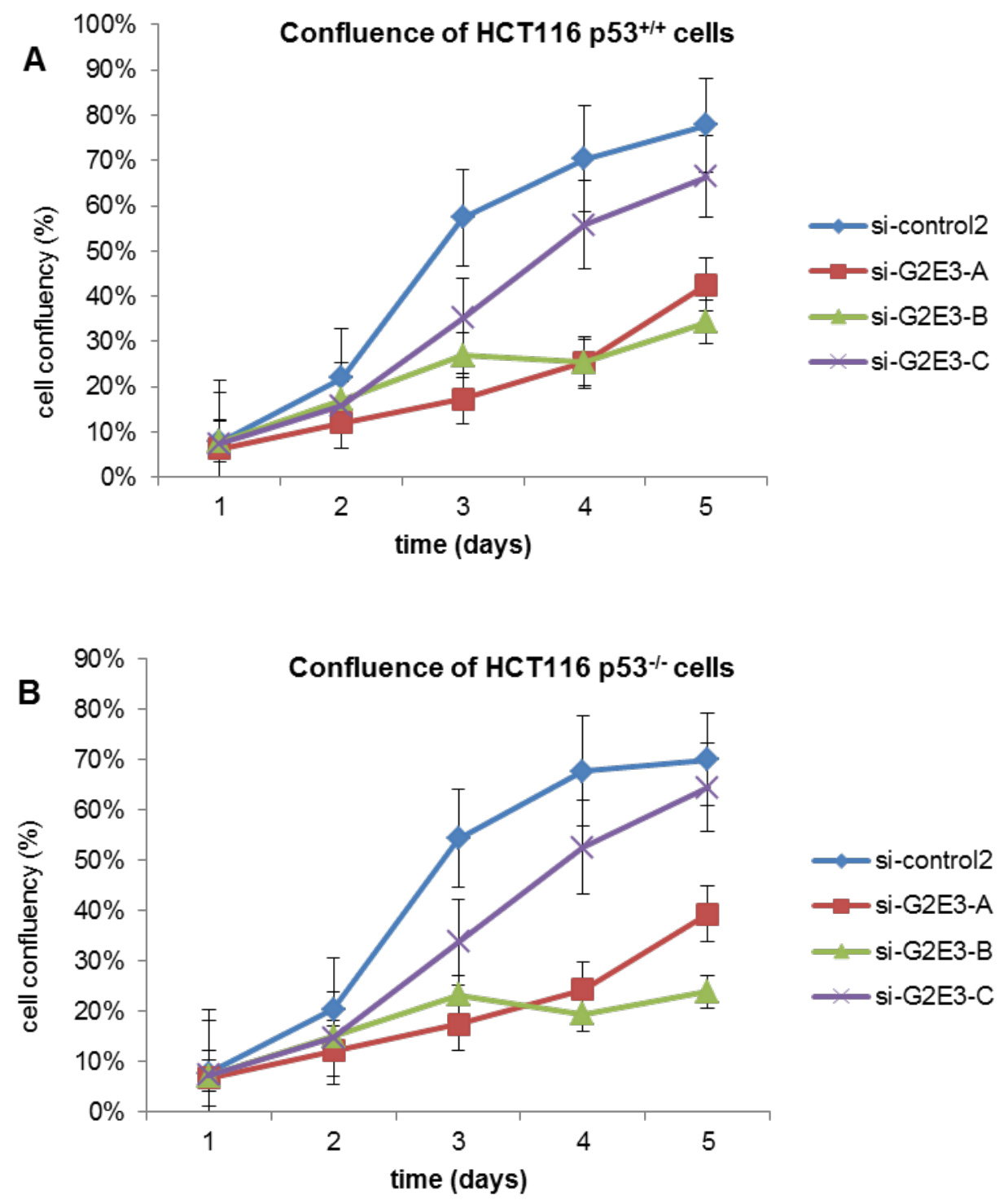


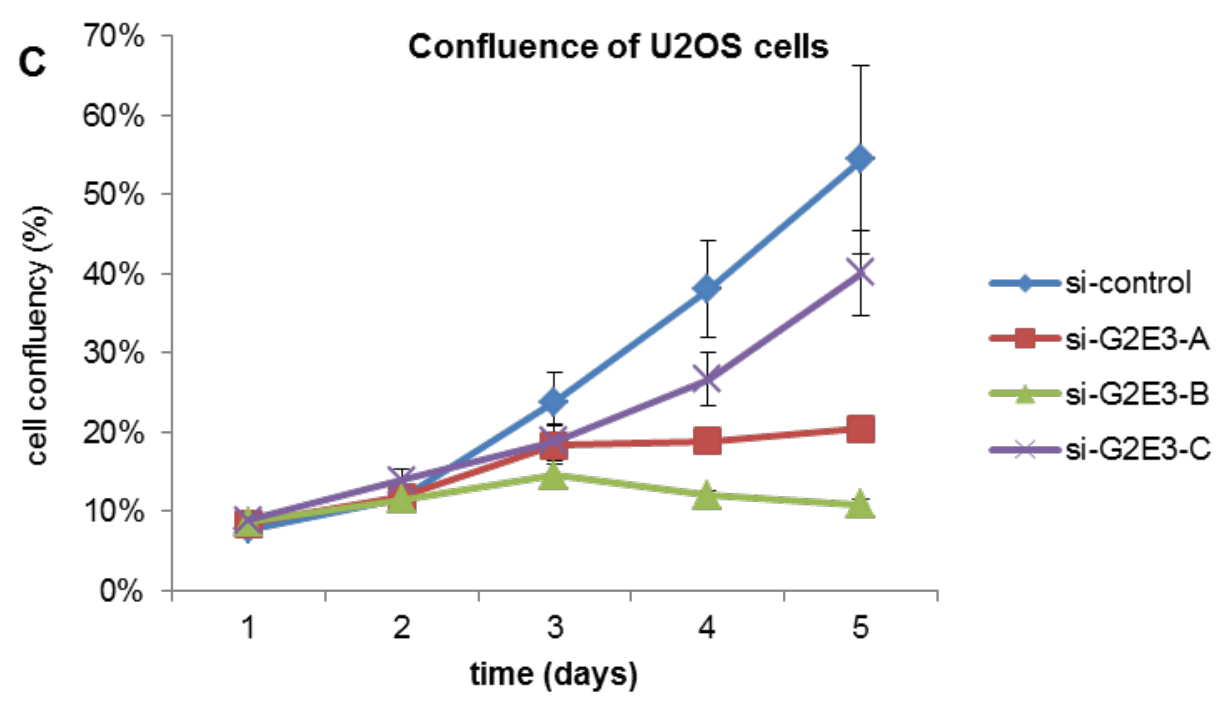

Figure 5.7: Proliferation rate of cells is decreased following depletion of G2E3.

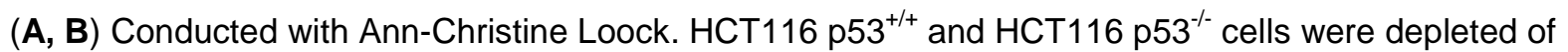
G2E3 by siRNA-mediated knockdown with three different siRNAs. Error bars are represented as SEM $(n=4)$. (C) U2OS cells were depleted of G2E3 by siRNA-mediated knockdown with three different siRNAs. Error bars are represented as SEM $(n=3)$. Cell proliferation was investigated by measuring cell confluence over five days with the Celigo cell cytometer (Cyntellect).

\subsubsection{Knockdown of G2E3 results in G1-arrest and decreased percentage of cells in S-phase in untreated as well as cisplatin treated U2OS cells}

To further explore whether the decrease in cell proliferation is due to increased apoptosis and/or cell cycle arrest, we performed cell cycle analysis using flow cytometry of propidium iodide stained U2OS cells after G2E3 knockdown (Figure 5.8). Thereby, knockdown of Mdm2, which results in a G1-arrest, served as positive control for induction of cell cycle arrest. This was previously shown in untreated and UV-irradiated U2OS cells (Kranz, Dohmesen et al. 2008). It is generally accepted that Mdm2 inhibits p53 functions like induction of G1-arrest and apoptosis. In this way, Mdm2 knockdown leads to increased p53 activity as seen by G1-arrest in Figure 5.8A. Mdm2 was also shown to positively regulate transition from G1- to S-phase by stimulating the S-phase inducing transcription factor E2F1 (Martin, Trouche et al. 1995) and by inhibiting retinoblastoma protein (RB) (Xiao, Chen et al. 1995). This is a second explanation why Mdm2 knockdown results in G1-arrest. G1-arrest leads to a decreased percentage of cells in S-phase. We found that depletion of G2E3 resulted in G1-arrest and reduced number of cells in S-phase. This was true not only for untreated (Figure 5.8), but also for cisplatin treated U2OS cells (Figure 5.9). These observations suggest that G2E3 knockdown has an impact on the cell cycle of U2OS cells. 
A

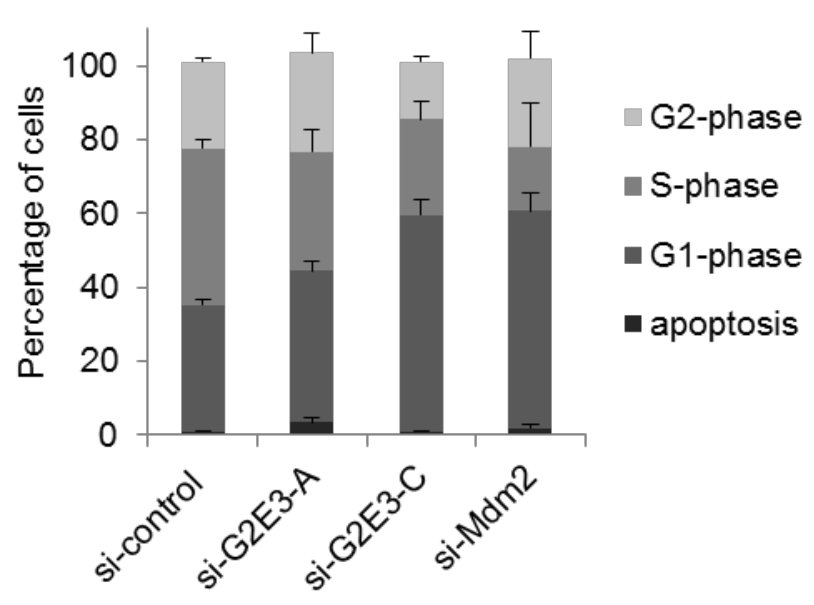

B

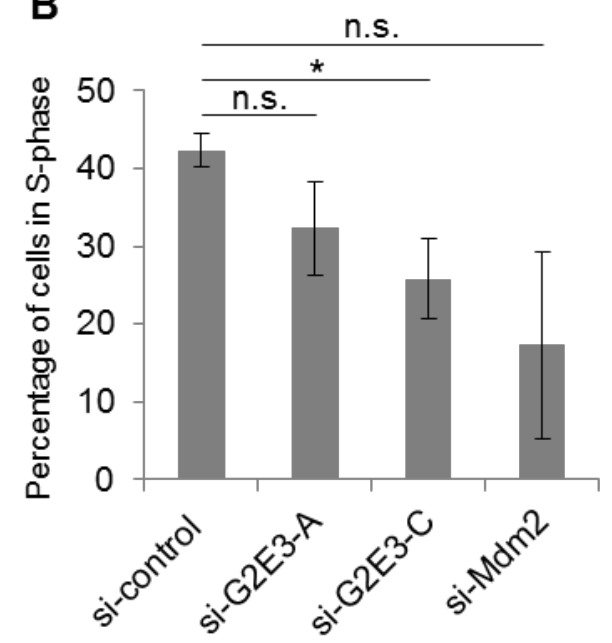

Figure 5.8: Knockdown of G2E3 results in G1-arrest and decreased percentage of cells in Sphase in untreated cells.

(A, B) U2OS cells were depleted of G2E3 and Mdm2 by siRNA-mediated knockdown. Cell cycle analysis was performed by flow cytometry of propidium iodide stained cells. Percentage of cells in S-phase is depicted separately for improved visualization (B). Error bars are represented as $\mathrm{SD}(\mathrm{n}=3) .{ }^{*}=p<0.05$, n.S. $=$ not significant (student's t-test).

A

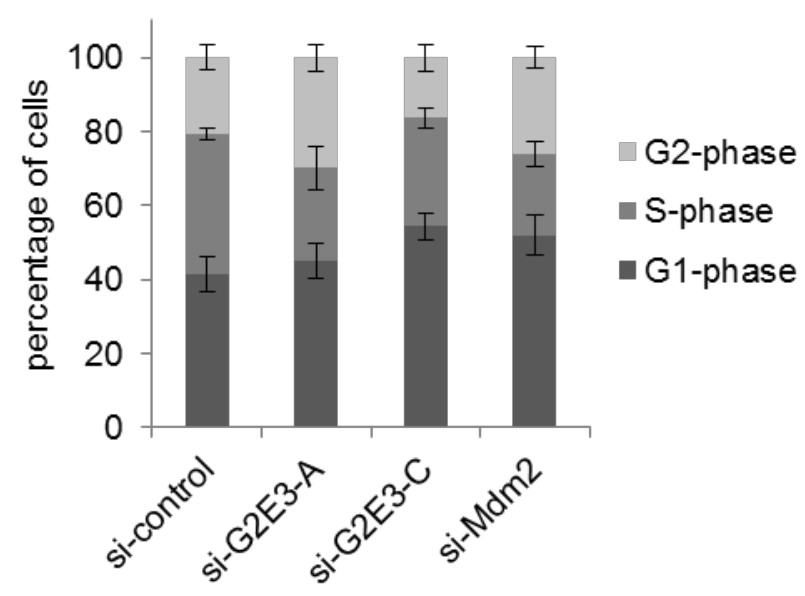

B

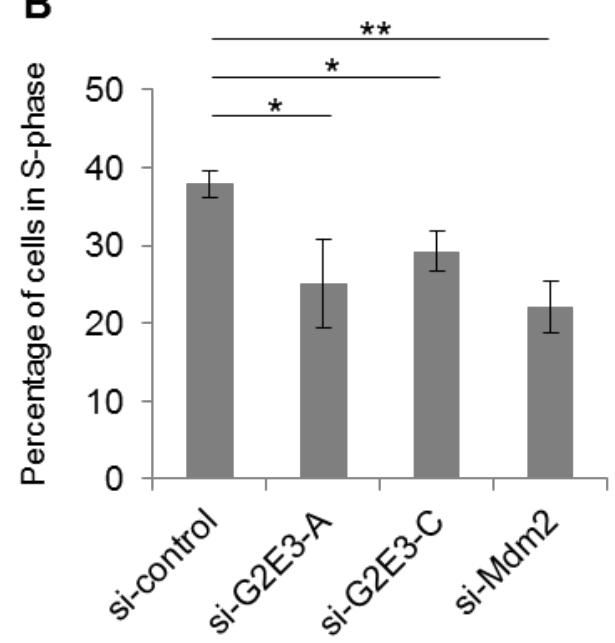

Figure 5.9: Knockdown of G2E3 results in G1-arrest and decreased percentage of cells in Sphase after cisplatin treatment.

(A, B) U2OS cells were depleted of G2E3 and Mdm2 by siRNA-mediated knockdown and treated with $30 \mu \mathrm{M}$ cisplatin for $16 \mathrm{~h}$ (total incubation time $64 \mathrm{~h}$ ). Cell cycle analysis was performed by flow cytometry of propidium iodide stained cells. Percentage of cells in S-phase is depicted separately for improved visualization $(\mathbf{B})$. Error bars are represented as SD $(\mathrm{n}=3) .{ }^{*}=p<0.05,{ }^{*}=p<0.01$ (student's t-test). 


\subsection{G2E3 in the p53-pathway}

\subsubsection{Knockdown of G2E3 results in p53-dependent p21 induction in U2OS cells}

As described above, G2E3 knockdown led to G1-arrest and lower percentage of cells in $\mathrm{S}$-phase in untreated as well as cisplatin treated cells. Cell cycle arrest is mainly regulated by p53 and its target gene p21, a cyclin-dependent kinase inhibitor. Our purpose was to analyze whether knockdown of G2E3 would result in induction of these known cell cycle regulators. Indeed, analysis by immunoblotting revealed that p53 and p21 were induced upon G2E3 knockdown in U2OS cells (Figure 5.10A, columns 1, 2 and 3). Knockdown of Mdm2 served as positive control since it causes p53 induction and p21 expression. We also performed a double-knockdown of Mdm2 and G2E3 to investigate whether induction of p21 after G2E3 knockdown depends on Mdm2 (Figure 5.10A, columns 4, 5 and 6). No additive effect after double-knockdown of G2E3 and Mdm2 was observed regarding p21 levels, which could mean that induction of p21 after G2E3 depletion is dependent on Mdm2. Furthermore, we demonstrated with three different siRNAs targeting G2E3 that transcription of p21 was slightly induced upon G2E3 knockdown (Figure 5.10B). This was dependent on p53 since a doubleknockdown of G2E3 and p53 abolished p21 induction, as depicted in Figure 5.10C (columns 4, 5 and 6).

Knockdown of G2E3 in U2OS cells led to induction of G1-arrest as seen by flow cytometry (Figure 5.8 and Figure 5.9) and induction of p53 and p21 (Figure 5.10). These results suggest that reduction in $\mathrm{H} 2 \mathrm{AX}$ phosphorylation upon G2E3 knockdown in cisplatin treated U2OS cells (Figure 5.3) could be explained by induction of cell cycle arrest: Arrested cells do not continue replicating their DNA and are therefore less prone to be harmed by cisplatin treatment. This hypothesis is supported by the fact that also Mdm2 knockdown led to induction of G1-arrest and exhibited decreased $\mathrm{yH} 2 \mathrm{AX}$ levels upon cisplatin treatment as seen in the screen (Figure 5.2). Reduced phosphorylation of H2AX upon Mdm2 knockdown was also detected in UV-irradiated U2OS cells (Kranz, Dohmesen et al. 2008).

These results point towards a connection between G2E3 and the p53-pathway and motivated us to investigate this relationship in more detail. 


A
\begin{tabular}{|l|l|l|l|l|l|l|l|}
\hline control & $x$ & $x$ & $x$ & & & $x$ & $x$ \\
\hline G2E3-A & & $x$ & & $x$ & & & \\
\hline \multirow{\frac{c}{\omega}}{c}{ G2E3-C } & & & $x$ & & $x$ & & \\
\hline Mdm2 & & & & $x$ & $x$ & $x$ & \\
\hline p53 & & & & & & & $x$ \\
\hline
\end{tabular}

$\mathrm{Mdm} 2 \stackrel{100 \mathrm{kDa}}{ }$

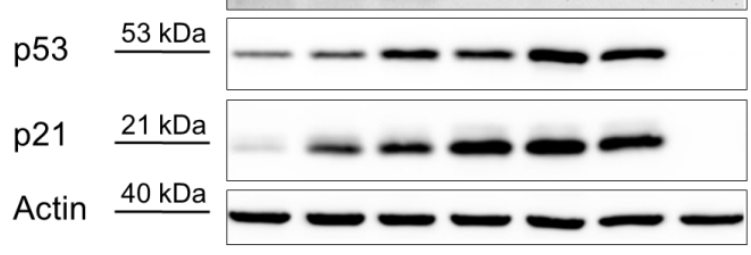

\begin{tabular}{|c|c|c|c|c|c|c|c|}
\hline control & $x$ & $x$ & $x$ & & & $x$ & $x$ \\
\hline G2E3-A & & $x$ & & $x$ & & & \\
\hline G2E3-C & & & $x$ & & $x$ & & \\
\hline p53 & & & & $x$ & $x$ & $x$ & \\
\hline Mdm2 & & & & & & & $x$ \\
\hline
\end{tabular}

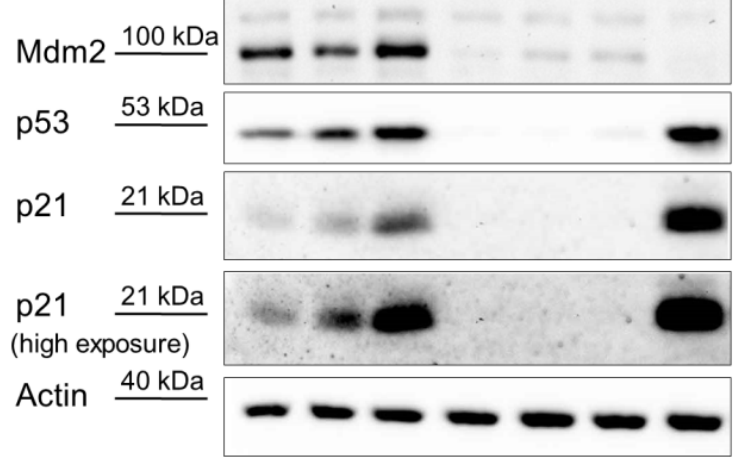

B

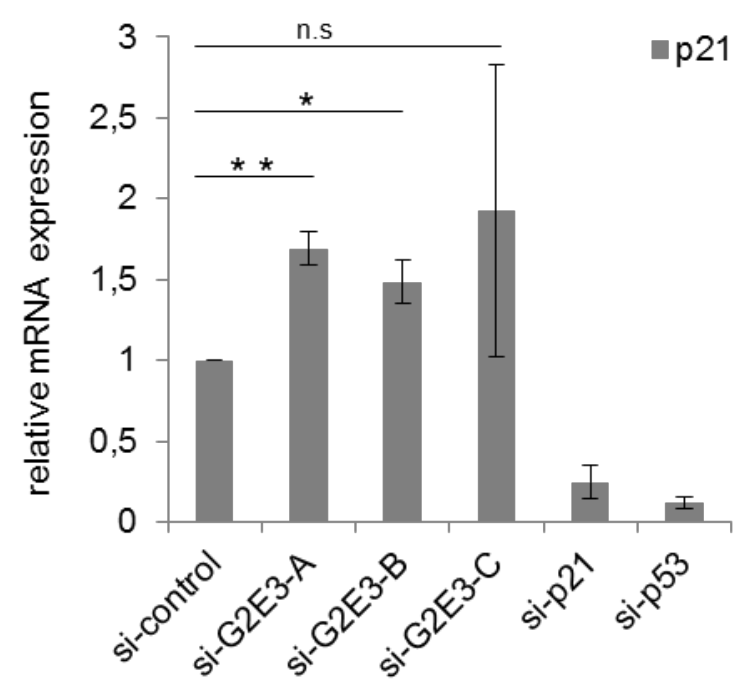

Figure 5.10: Knockdown of G2E3 results in p53-dependent p21 induction in U2OS cells.

(A) U2OS cells were transfected with combinations of siRNAs targeting G2E3 and Mdm2 as indicated. Knockdown of p53 served as control. After $48 \mathrm{~h}$, cells were harvested and cell lysates were analyzed by immunoblotting using the indicated antibodies. Actin staining served as loading control. (B) U2OS cells were depleted of G2E3, p21 and p53 by siRNAmediated knockdown. After $64 \mathrm{~h}$, cells were harvested and p21 mRNA levels were analyzed by qPCR. Results were normalized to expression of the reference gene GAPDH. Error bars are represented as SD $(n=3)$. ${ }^{*}=p<0.05,{ }^{*}=p<0.01$, n.s. $=$ not significant (student's t-test). (C) U2OS cells were transfected with combinations of siRNAs targeting G2E3 and p53 as indicated. Knockdown of Mdm2 served as control. After $64 \mathrm{~h}$, cells were harvested and cell lysates were analyzed by immunoblotting using the indicated antibodies. Actin staining served as loading control. 


\subsubsection{Depletion of the p53-pathway regulators RBBP6 and STUB1 results in decreased yH2AX levels similar to G2E3 knockdown}

Considering the obtained results, we started to investigate the role of G2E3 in the p53-pathway. Interestingly, knockdown of two more screen candidates led to a decrease in $\mathrm{yH} 2 \mathrm{AX}$ levels comparable to G2E3 depletion (Figure 5.2) which are known as regulators of the p53-pathway: RBBP6 (or PACT) and STUB1 (or CHIP). The Retinoblastoma binding protein 6 (RBBP6) interacts with Mdm2 and enhances Mdm2-mediated ubiquitination and degradation of p53 due to increased p53-Mdm2-affinity (Li, Deng et al. 2007). Furthermore, RBBP6 knockdown attenuates the interaction of p53 and Mdm2 and reduces polyubiquitination of p53 and thus enhances p53 accumulation which leads to apoptosis and cell growth retardation. The ubiquitin ligase STUB1 (or CHIP) was identified to target p53 for proteasomal degradation (Esser, Scheffner et al. 2005).

Decrease in H2AX phosphorylation after knockdown of RBBP6 and STUB1 and cisplatin treatment could be validated by immunoblotting with three different siRNAs targeting each gene (Figure 5.11A,B). Knockdown of RBBP6 and STUB1 also led to induction of p21 in untreated and cisplatin treated cells, suggesting a G1-arrest.

A
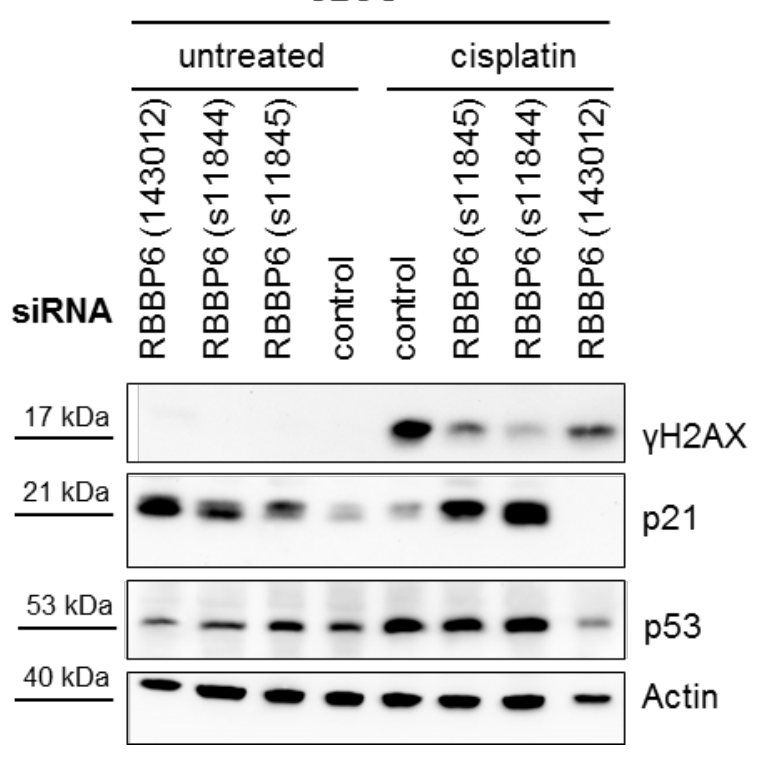

B

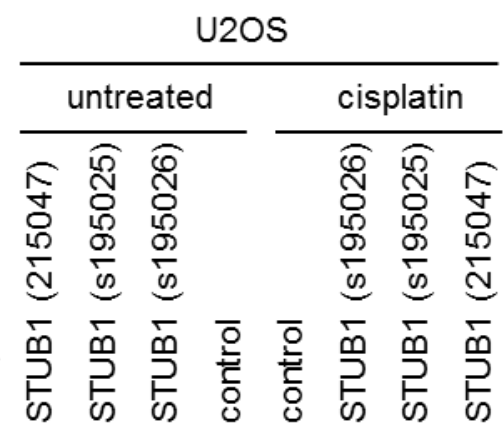

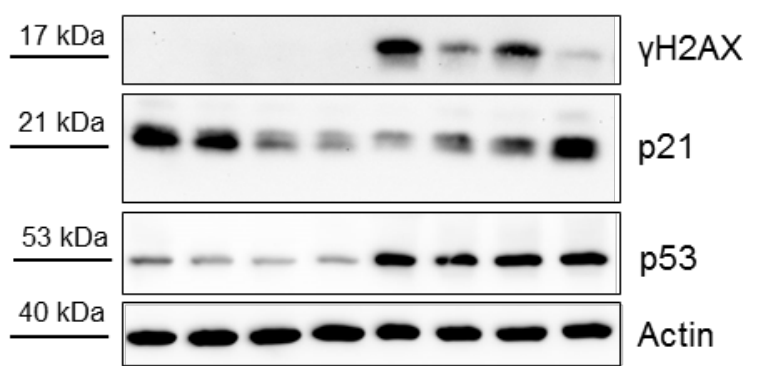

Figure 5.11: Knockdown of RBBP6 or STUB1/CHIP decreases phosphorylation of H2AX in U2OS cells.

U2OS cells were transfected with three different siRNAs targeting (A) RBBP6 or (B) STUB1/CHIP and either left untreated or treated with $30 \mu \mathrm{M}$ cisplatin for $16 \mathrm{~h}$ (total incubation time $64 \mathrm{~h}$ ). Cell lysates were analyzed by immunoblotting using the indicated antibodies. Actin staining served as loading control. 
Since RBBP6, STUB1 and Mdm2 are involved in the p53-pathway and led to decreased H2AX phosphorylation and p21 induction upon knockdown similar to G2E3 depletion, we assumed that G2E3 might play a role in the p53-pathway and continued our studies in this direction.

\subsubsection{Overexpressed Mdm2 and G2E3 co-localize and relocalize to subnuclear structures in untreated and cisplatin treated cells}

With the aim to study the role of G2E3 in the p53-pathway, we next asked whether G2E3 might co-localize with p53 and Mdm2. To this end, we co-expressed Mdm2 and a HA-tagged version of G2E3 in U2OS cells. Since both proteins are ubiquitin ligases and could potentially ubiquitinate or even degrade each other, we additionally applied the proteasome inhibitor MG132. Remarkably, we observed a co-localization of co-expressed HA-G2E3 and Mdm2, both relocalizing to subnuclear structures in untreated U2OS cells (Figure 5.12). Colocalization could be detected in approx. $50 \%$ of cells expressing both HA-G2E3 and Mdm2. We wondered whether co-localization would be dependent on the ubiquitin ligase activity of Mdm2. Therefore, we co-expressed HA-G2E3 and a version of Mdm2 harboring a mutated RING domain (Mdm2 RING mutant). Interestingly, HA-G2E3 and Mdm2 RING mutant could still co-localize and relocalize to subnuclear structures. Hence, colocalization of these proteins was independent of Mdm2 ubiquitin ligase activity. Furthermore, HA-G2E3 and Mdm2 still co-localized upon cisplatin treatment (Figure 5.13) as well as upon NCS treatment, showing that damaged DNA did not affect or abolish co-localization of both proteins. However, when co-expressing HA-G2E3 and p53, we could not observe a co-localization of both proteins (data not shown). We also investigated co-localization of HA-G2E3 with p14-ARF, a regulator of Mdm2, but did not detect any.

The co-localization of HA-G2E3 and Mdm2 was a first hint that these proteins could be found in a complex. To validate the interaction between HA-G2E3 and Mdm2, we performed co-immunoprecipitation experiments. 


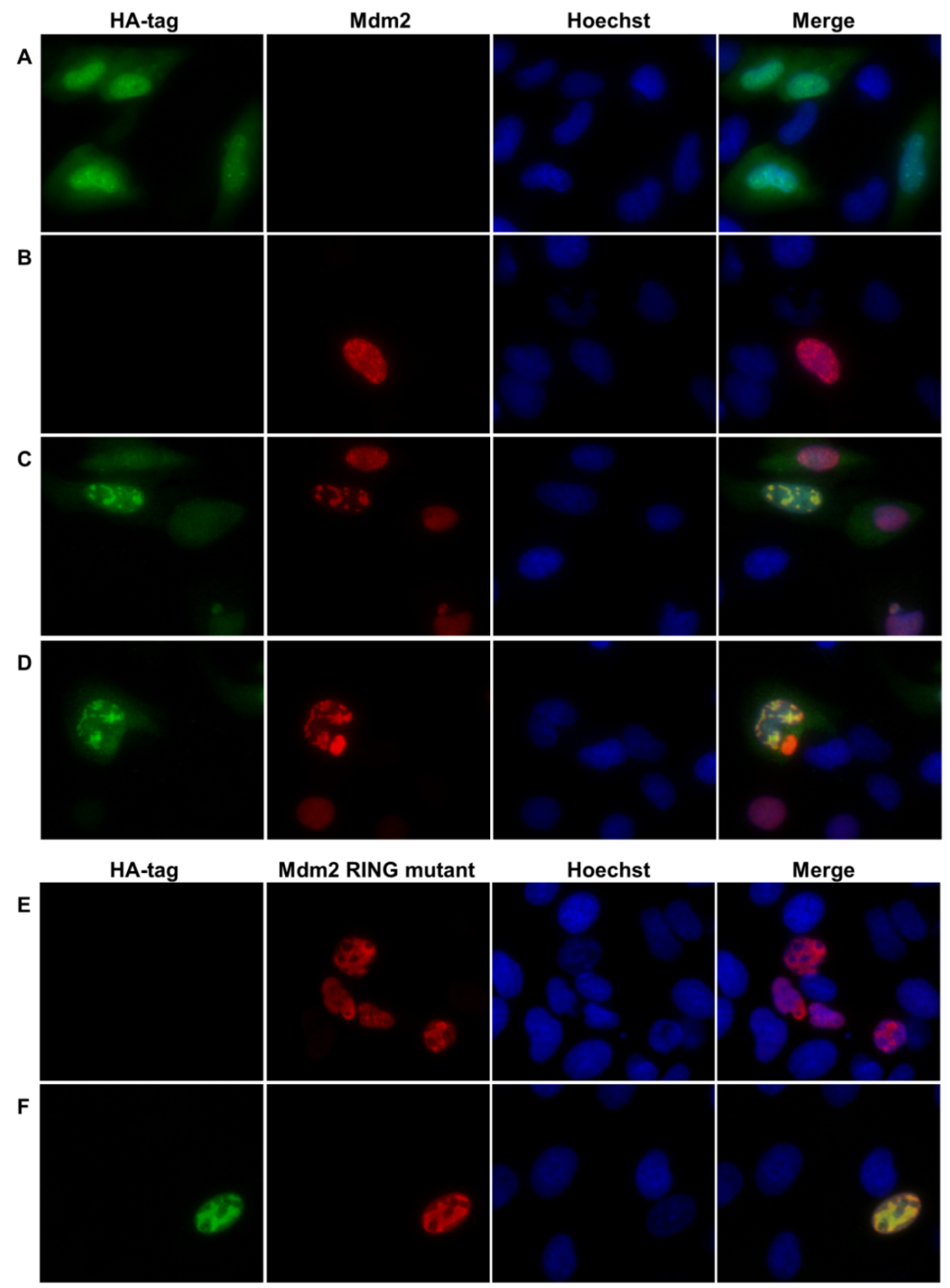

Figure 5.12: Overexpressed Mdm2 and G2E3 co-localize and relocalize to subnuclear structures in untreated cells. Co-localization is independent of Mdm2 ubiquitin ligase activity since Mdm2 RING mutant and G2E3 also co-localize.

U2OS cells were transiently transfected with plasmids encoding (A) HA-G2E3, (B) Mdm2, (C,D) HA-G2E3 and Mdm2, (E) Mdm2 RING mutant and (F) HA-G2E3 and Mdm2 RING mutant for 24 $\mathrm{h}$ and treated with $20 \mu \mathrm{M}$ of the proteasome inhibitor MG132 during the last $4 \mathrm{~h}$. Cells were fixed and stained for HA-tag, Mdm2 and Hoechst. Microscopy was performed using the BD Pathway System. 


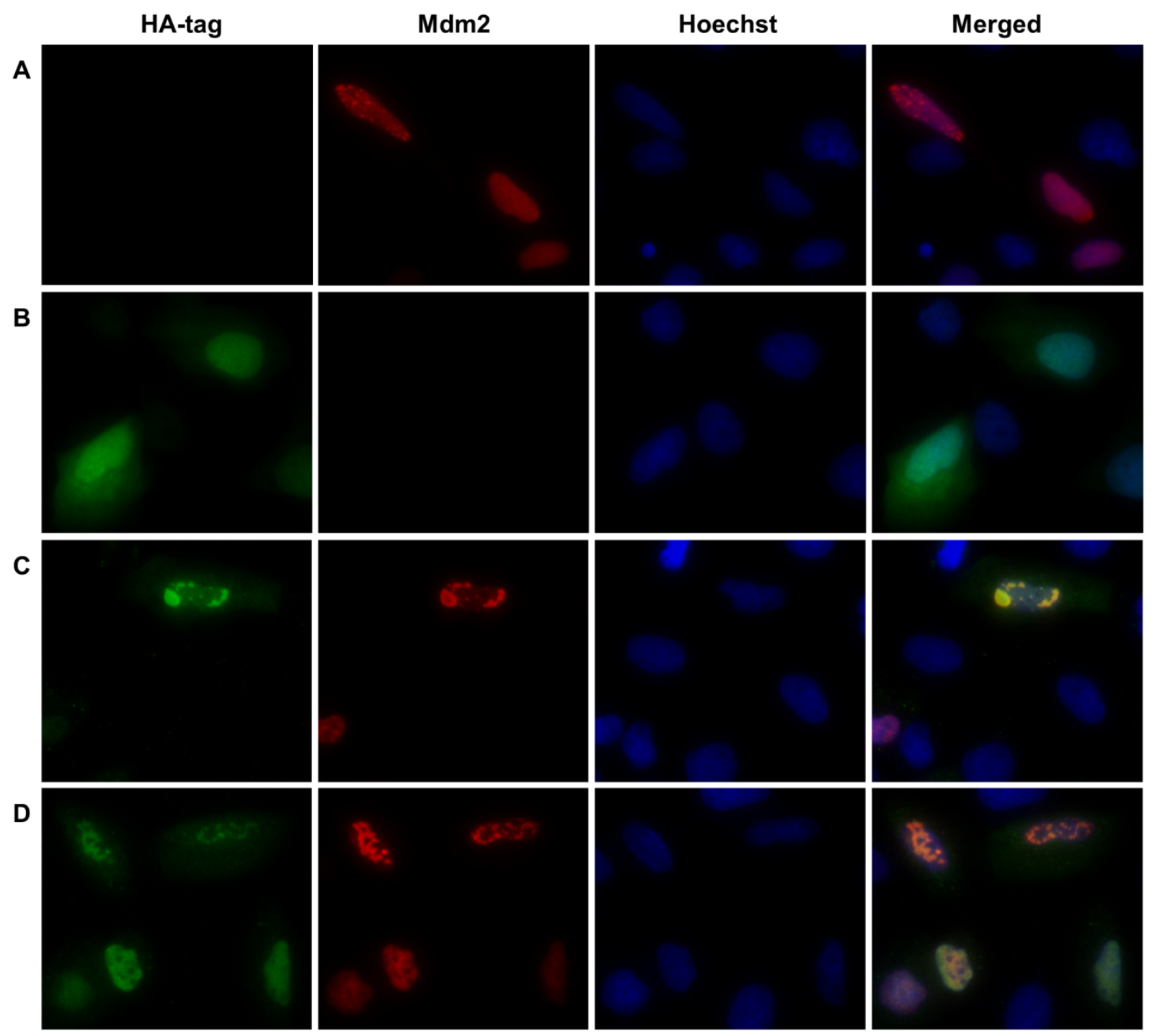

Figure 5.13: Overexpressed Mdm2 and G2E3 co-localize and relocalize to subnuclear structures in cisplatin treated cells.

U2OS cells were transiently transfected with plasmids encoding (A) Mdm2, (B) HA-G2E3, (C,D) HA-G2E3 and Mdm2 for $24 \mathrm{~h}$ and treated with $30 \mu \mathrm{M}$ cisplatin and $20 \mu \mathrm{M}$ of the proteasome inhibitor MG132 during the last $4 \mathrm{~h}$. Cells were fixed and stained for HA-tag, Mdm2 and Hoechst. Microscopy was performed using the BD Pathway System. 


\subsubsection{Overexpressed G2E3 and Mdm2 are found in a complex}

Since co-expressed Mdm2 and HA-G2E3 were found to co-localize, we wanted to test whether both proteins can be found in a complex. Therefore, we performed coimmunoprecipitation (CoIP) experiments. We co-expressed Mdm2 and HA-G2E3 in U2OS cells. Since both proteins are ubiquitin ligases and could potentially ubiquitinate or degrade each other, we applied the proteasome inhibitor MG132, as was done for immunofluorescence experiments in Figure 5.12 and Figure 5.13. We were able to precipitate overexpressed Mdm2 using a Mdm2 antibody and overexpressed HA-G2E3 using a HA-tag antibody. We found HA-G2E3 bound to precipitated Mdm2. Vice versa, Mdm2 was bound by precipitated HA-G2E3 (Figure 5.14). These results argue in favor of an interaction of G2E3 and Mdm2 when co-expressed.

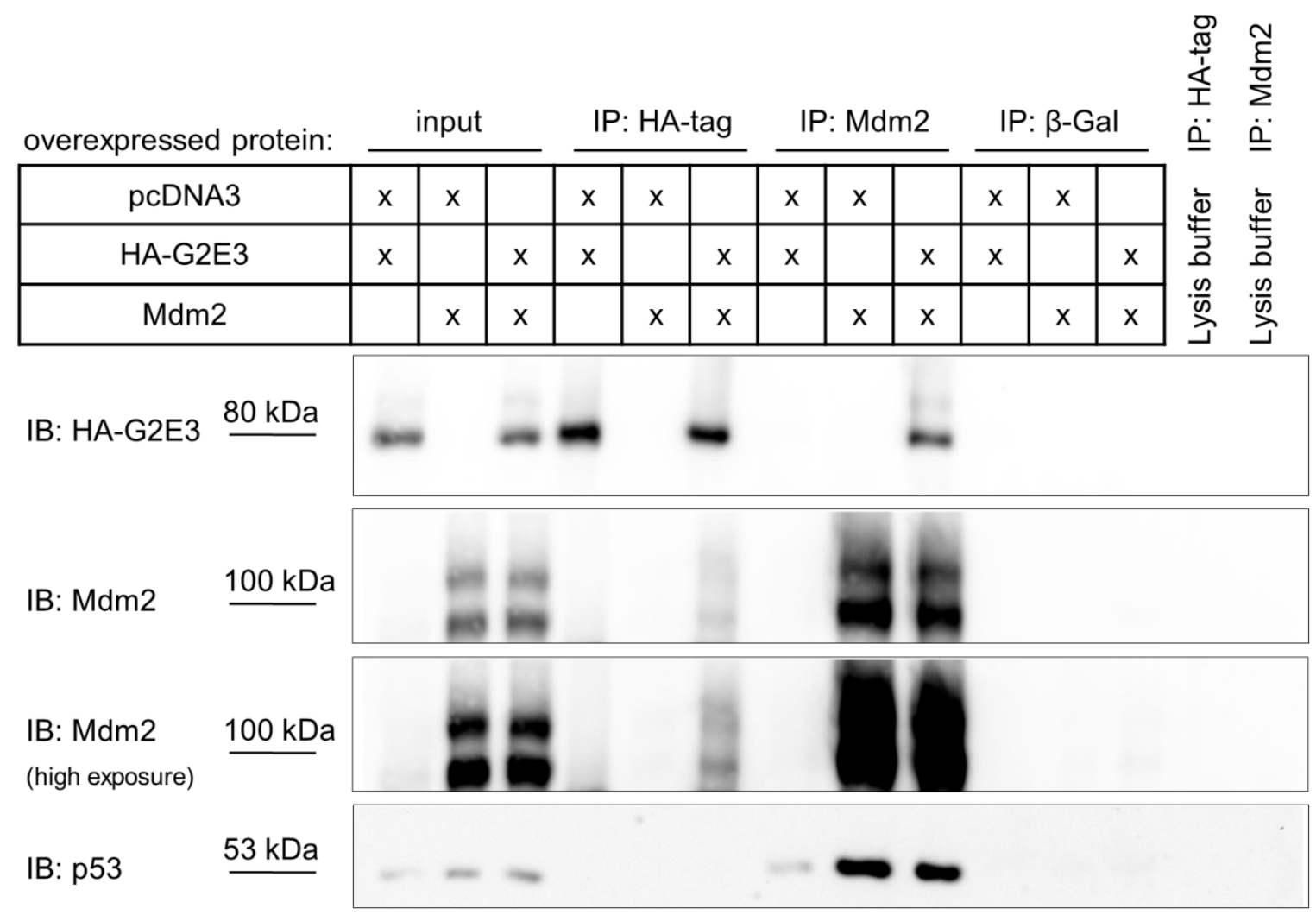

Figure 5.14: Overexpressed G2E3 and Mdm2 are found in a complex.

Conducted by Ann-Christine Loock. U2OS cells were transiently transfected with plasmids encoding Mdm2 and HA-G2E3 for $24 \mathrm{~h}$. An empty plasmid (pcDNA3) was transfected as control. During the last $4 \mathrm{~h}$, cells were treated with $20 \mu \mathrm{M}$ of the proteasome inhibitor MG132. Immunoprecipitation using a Mdm2 and a HA-tag-specific antibody was performed and precipitated proteins were analyzed by immunoblotting. To control for unspecific binding, $\beta$-Galactosidase ( $\beta$-Gal) was used as control antibody. As further control, lysis buffer without cell lysate was incubated with the indicated antibodies. 
Here, two bands for Mdm2 were detected at around $100 \mathrm{kDa}$. For Mdm2, different splice variants, post-translational modifications and various isoforms are known (for details see section 2.3.2.2). Full-length $\mathrm{Mdm} 2$ at $97 \mathrm{kDa}$ is often seen as two bands in Western blot which are supposed to be isoforms. Mdm2 transcripts initiated from the p53-activated (P2) promoter are preferentially the $97 \mathrm{kDa}$ isoform. This isoform was shown to be responsible for p53 degradation (Cheng and Cohen 2007). Also, lower bands at $60 \mathrm{kDa}$ are often observed. Additional Mdm2 proteins seem to exist due to differences in mRNA splicing and posttranslational modifications (Olson, Marechal et al. 1993). The mechanisms and biological roles of Mdm2 isoforms are largely unknown.

\subsubsection{Mdm2 and p53 interact independently of co-expressed HA-G2E3}

Since Mdm2 binds and inhibits p53, we addressed the question whether interaction with p53 would be disturbed by Mdm2-G2E3-interaction. We conducted ColP of combinations of coexpressed HA-G2E3, Mdm2 and p53 alone, in pairs and of all three proteins together in U2OS cells (Figure 5.15). Input samples of all combinations are depicted in Figure 5.15A. We found that Mdm2 and p53 could interact independently of co-expressed HA-G2E3 (Figure $5.15 \mathrm{~B}$, columns $\mathrm{M}$ and $\mathrm{N}$, and Figure $5.15 \mathrm{C}$, columns $\mathrm{F}$ and $\mathrm{G}$ ). We further investigated whether the interaction of Mdm2 and G2E3 would be disrupted by co-expressing p53. Interestingly, we observed that HA-G2E3 and Mdm2 interacted independently of coexpressed p53 (Figure 5.15B, columns D, G, K and N). We also studied whether G2E3 could bind p53. This was the case though the interaction was only weakly detectable and independent of co-expressed Mdm2 (Figure 5.15B and Figure 5.15C, columns E and G in each sub-figure).

These results suggest that the three proteins form a complex when overexpressed, but that binding between two interaction partners is independent of the third one. Whether all three proteins are bound to each other or whether G2E3 is bound to Mdm2 and p53 to Mdm2 without interacting with G2E3 is not known. Further studies are necessary to answer these questions as discussed in section 6.2.2. 


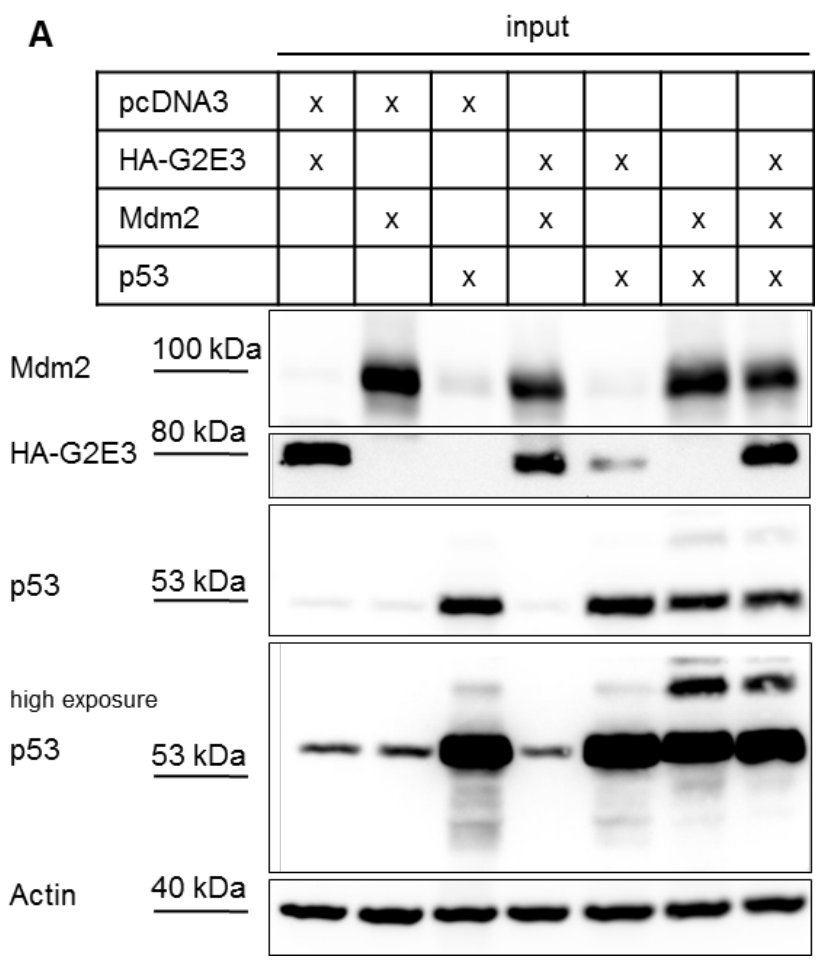

\begin{tabular}{|c|c|c|c|c|c|c|c|c|c|c|c|c|c|c|}
\hline B & \multicolumn{7}{|c|}{ IP: HA-tag } & \multicolumn{7}{|c|}{ IP: Mdm2 } \\
\hline pcDNA3 & $x$ & $x$ & $x$ & & & & & $x$ & $x$ & $x$ & & & & \\
\hline HA-G2E3 & $x$ & & & $x$ & $x$ & & $x$ & $x$ & & & $x$ & $x$ & & $x$ \\
\hline Mdm2 & & $\mathrm{x}$ & & $x$ & & $x$ & $x$ & & $x$ & & $x$ & & $x$ & $\mathrm{x}$ \\
\hline p53 & & & $x$ & & $x$ & $x$ & $x$ & & & $x$ & & $x$ & $x$ & $\mathrm{x}$ \\
\hline & A & $B$ & C & D & $E$ & $\mathrm{~F}$ & G & $\mathrm{H}$ & 1 & $\mathrm{~J}$ & $\mathrm{~K}$ & L & M & $\mathrm{N}$ \\
\hline
\end{tabular}

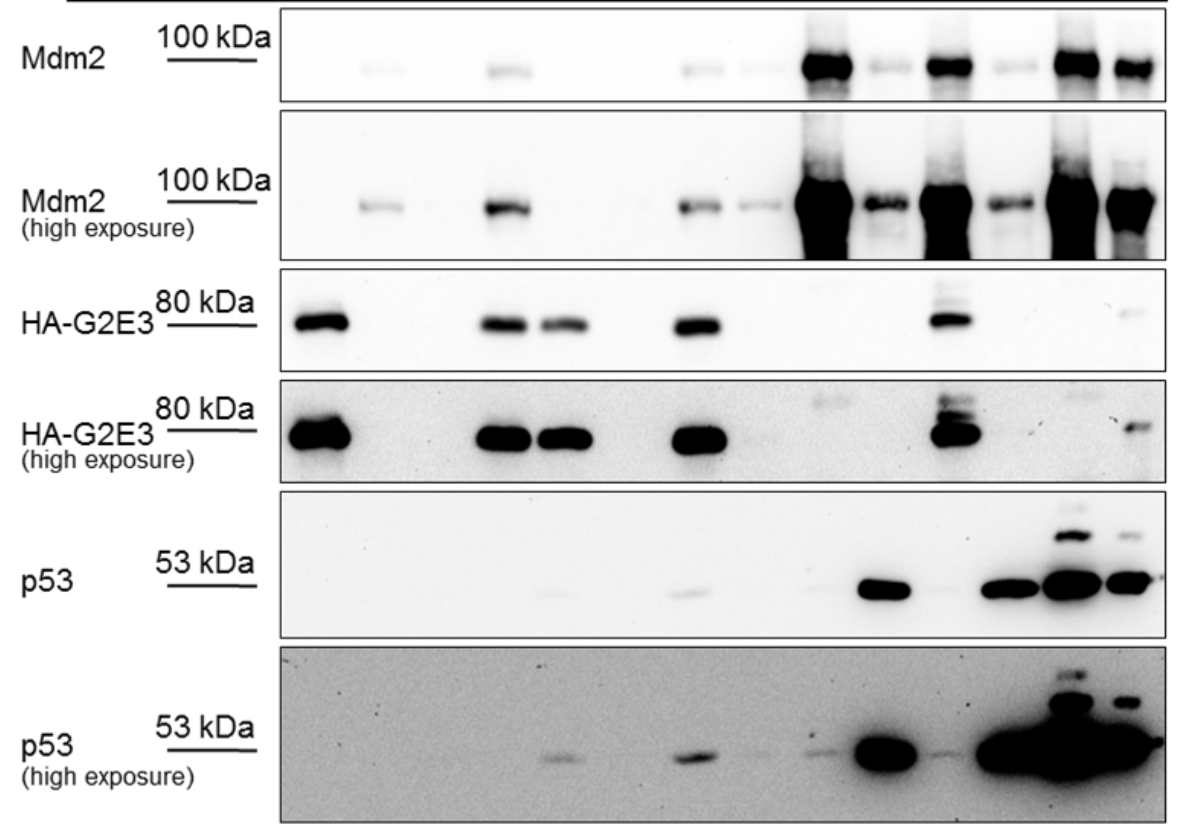




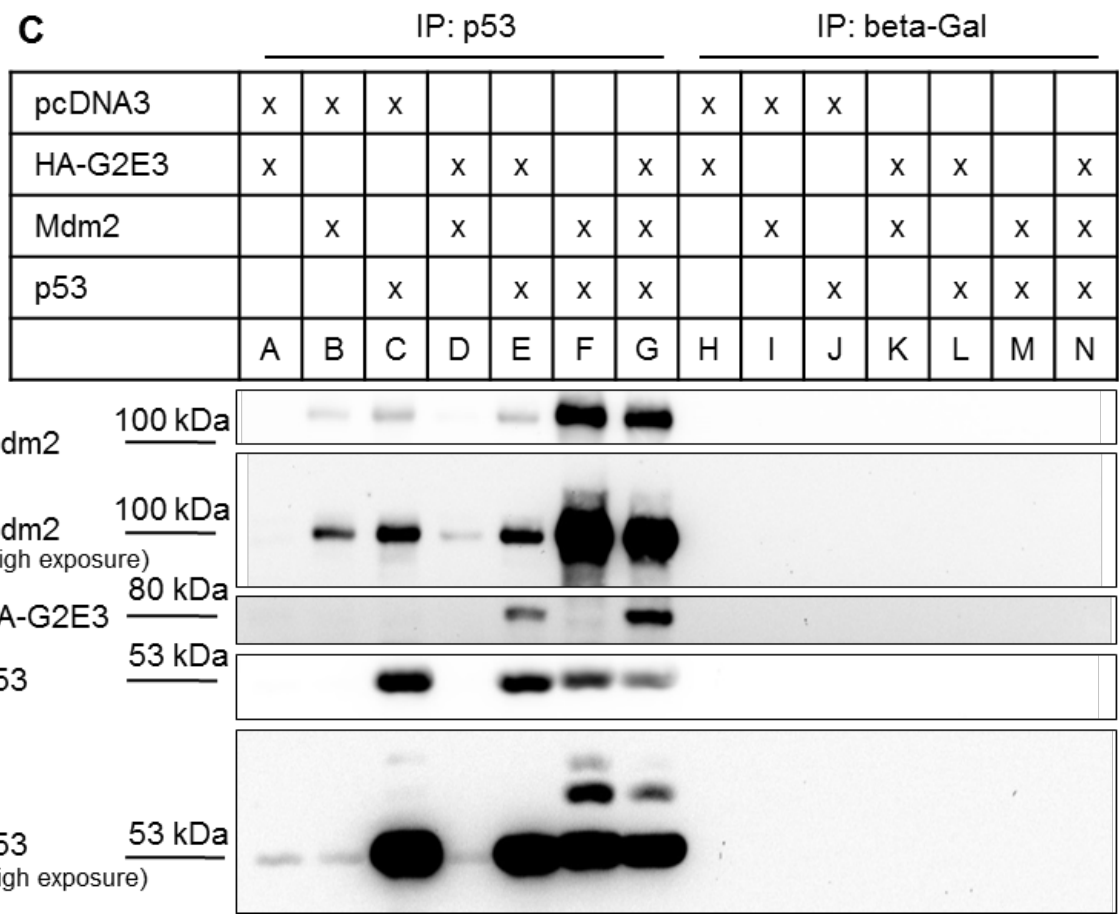

Figure 5.15: Mdm2 and p53 interact independently of co-expressed HA-G2E3. HA-G2E3Mdm2-interaction is independent of co-expressed p53. Overexpressed G2E3 and p53 are found in a complex.

U2OS cells were transiently transfected with plasmids encoding Mdm2, p53 and HA-G2E3 for 24 h. The ratio was $40 \% \mathrm{HA}-\mathrm{G} 2 \mathrm{E} 3,35 \% \mathrm{Mdm} 2,25 \% \mathrm{p} 53$, filled with empty plasmid (pcDNA3) up to $100 \%$. During the last $4 \mathrm{~h}$, cells were treated with $20 \mu \mathrm{M}$ of the proteasome inhibitor MG132. Cells were harvested for co-immunoprecipitation (CoIP). The DUB inhibitor N-ethylmaleimide was added to the ColP buffer. (A) Immunoblotting of input samples before immunoprecipitation is depicted. (B) Immunoprecipitation using a Mdm2 and a HA-tag-specific antibody was performed and precipitated proteins were analyzed for Mdm2, p53 and HA-G2E3 by immunoblotting. (C) Immunoprecipitation using a p53 and $\beta$-Galactosidase ( $\beta$-Gal) antibody was performed and precipitated proteins were analyzed by immunoblotting using the indicated antibodies.

$\beta-G a l$ was used as control antibody for (B) and (C) to detect unspecific binding. 


\subsubsection{An endogenous interaction of G2E3 and Mdm2 is not detectable independent of p53-status}

When we observed an interaction of co-expressed Mdm2, G2E3 and p53, we next wanted to check for an endogenous interaction. Mdm2 and p53 are low-abundant proteins, mainly because p53 is kept at low levels by ubiquitin-mediated degradation through Mdm2. Given the fact that we wanted to precipitate endogenous proteins of low concentration and were not provided with a high-quality G2E3-antibody, we used four to six $15 \mathrm{~cm}$ cell culture dishes to precipitate endogenous p53, Mdm2 and G2E3. We used SJSA cells with a comparatively high Mdm2 expression since the mdm2 gene is ca. 25-fold amplified in this cell line (Chen, Lu et al. 1999; Tovar, Rosinski et al. 2006). We performed ColPs in p53-proficient cell lines (U2OS, SJSA, Figure 5.16B,C) and p53-deficient cell lines (H1299 and HCT116 p53 ${ }^{-1-}$, Figure 5.16A). As was done for immunofluorescence and exogenous ColP experiments, we inhibited the proteasome by MG132 treatment since Mdm2 and G2E3 could potentially ubiquitinate or degrade each other. MG132 treatment was only used for p53-deficient cell lines, since it would lead to accumulation and thus activation of p53 in p53-proficient cells. It was reported that p53 can repress and activate gene expression via the large intergenic noncoding RNA lincRNA-p21 which is a p53-target in response to DNA damage (Huarte, Guttman et al. 2010). One of the genes repressed via p53 and lincRNA-p21 was G2E3. Activated p53 could thus repress G2E3 mRNA expression which would have resulted in even lower endogenous G2E3 levels.

We were able to precipitate endogenous Mdm2, p53 and G2E3 with the respective antibodies. However, we could not detect any interaction between the proteins under the conditions applied. Even the interaction of Mdm2 and p53 was not detectable in p53proficient U2OS and SJSA cells. This could be due to the fact that we did not inhibit the proteasome by MG132 treatment which supports detection of the Mdm2-p53-interaction as seen in overexpression experiments (Figure 5.15). One reason for not detecting an endogenous interaction of G2E3 with Mdm2 or p53 could be extremely low levels of detectable endogenous G2E3. G2E3 was also not measurable in input samples (Figure 5.16A-C). Interestingly, the molecule size of G2E3 was smaller in SJSA cells (ca. $65 \mathrm{kDa}$ ) than the reported size of $80 \mathrm{kDa}$ which was detected in all other cell lines. SJSA cells could harbor a G2E3 isoform. This is possible considering that 15 G2E3 transcripts including eight protein-coding transcripts are listed in the genome database Ensembl in 2013. 

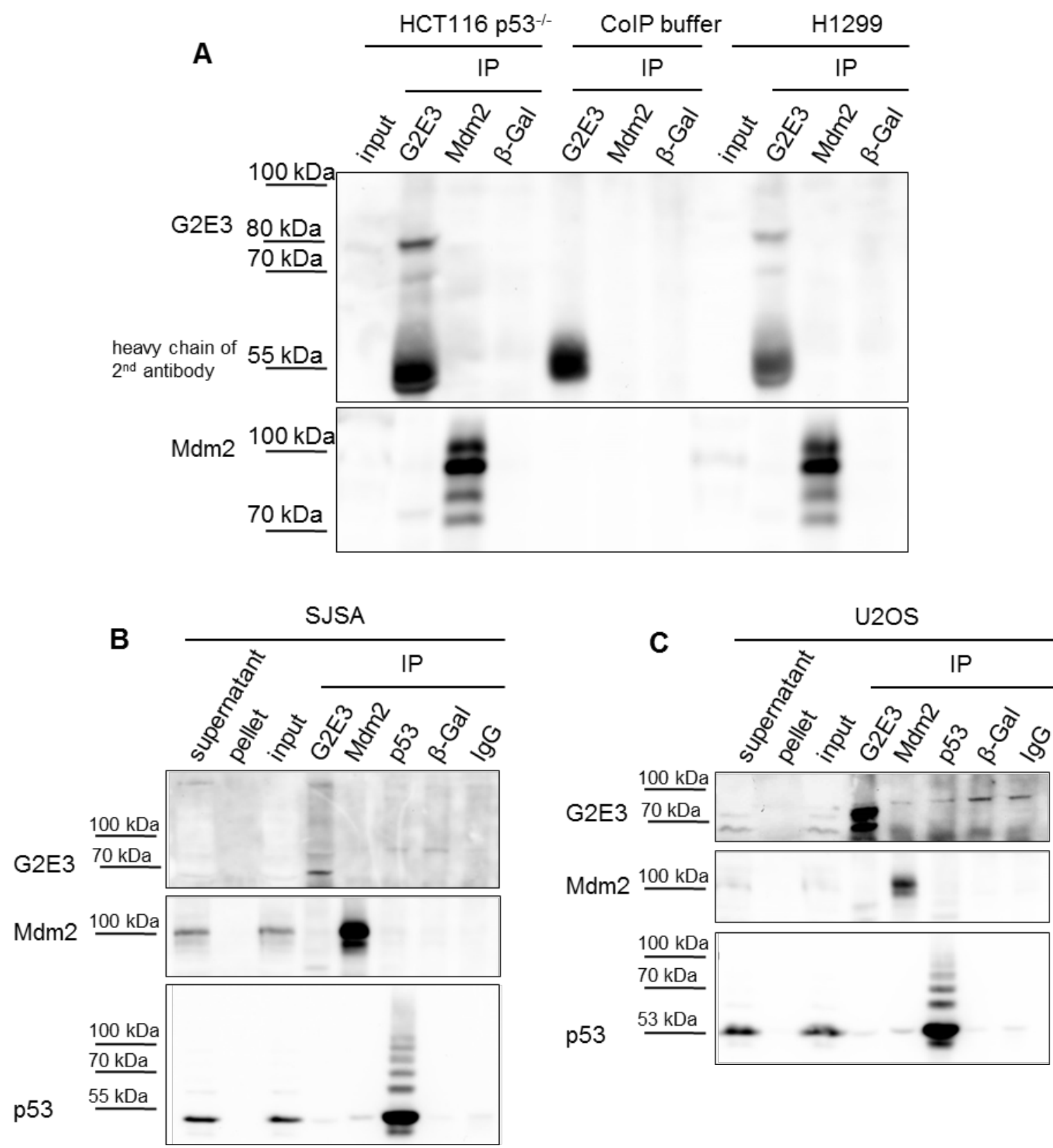

Figure 5.16: An endogenous interaction of G2E3 and Mdm2 is not detectable in p53-proficient (U2OS, SJSA) and p53-deficient (H1299 and HCT116 p53 ${ }^{-1}$ ) cell lines.

(A) $\mathrm{H} 1299$ and HCT116 p53 ${ }^{-/}$cells were treated with $20 \mu \mathrm{M}$ of the proteasome inhibitor MG132 for 4 $\mathrm{h}$ and harvested for co-immunoprecipitation (CoIP). The DUB inhibitor $\mathrm{N}$-ethylmaleimide was added to the ColP buffer. Immunoprecipitation using a Mdm2- and a G2E3-specific antibody was performed and precipitated proteins were analyzed by immunoblotting. A $\beta$-Galactosidase ( $\beta$-Gal) antibody was used to control for unspecific binding. (B) SJSA and (C) U2OS cells without MG132 treatment were harvested for CoIP. The DUB inhibitor N-ethylmaleimide was added to the ColP buffer. Immunoprecipitation using a Mdm2, a p53 and a G2E3-specific antibody was performed and precipitated proteins were analyzed by immunoblotting using the indicated antibodies. Immunoprecipitation using a $\beta$-Galactosidase ( $\beta$-Gal) and Immunoglobulin $G$ (IgG) antibody was performed as control to detect unspecific binding. 


\subsubsection{Overexpressed G2E3 has no impact on p53 transcriptional activity and on Mdm2-dependent inhibition of p53 transactivation}

Activation and stabilization of the tumor suppressor p53 turns on expression of genes that are involved in cell cycle arrest and apoptosis. Many positive and negative regulators of p53 activity are known. To shed more light on the functional relevance of the interaction between HA-G2E3, Mdm2 and p53, we investigated the impact of G2E3 on p53 transcriptional activity. To this end, we performed a luciferase reporter assay in p53-deficient $\mathrm{H} 1299$ cells by coexpressing different combinations of p53, Mdm2 and HA-G2E3 (Figure 5.17). We made use of a reporter construct harboring a p53-responsive promoter containing 13 p53 binding sites upstream of the Firefly luciferase gene.

As expected, co-expression of $\mathrm{Mdm} 2$, the ubiquitin ligase negatively regulating $\mathrm{p} 53$, led to concentration-dependent decrease in p53 transcriptional activity. We overexpressed the p53 family member $\Delta$ Np63 as an additional positive control. P63 was shown to activate and repress transcription of a $\beta$-galactosidase reporter gene downstream of p53 DNA-binding sites (Yang, Kaghad et al. 1998): Thereby, the so-called TAp63 isoform can transactivate p53 target genes and thus mimic p53 function, whereas the $\Delta \mathrm{Np} 63$ isoform lacks the $\mathrm{N}$-terminal transactivation domain and has a dominant negative effect on p53. As expected, overexpression of $\Delta$ Np63 suppressed p53 transcriptional activity (Figure 5.17). On the contrary, we did not observe an impact of overexpressed HA-G2E3 on p53 activity under the conditions applied and using different plasmid amounts. Furthermore, overexpressed HA-G2E3 did not influence the negative regulation of Mdm2 on p53. Mdm2 repressed p53 activity in a concentration-dependent manner which was not affected by co-expression of HAG2E3. We conclude that G2E3 does not impair p53 transcriptional activity and Mdm2dependent inhibition of p53 transactivation. It should be further tested if G2E3 affects p53 transcriptional activity upon cisplatin treatment. 


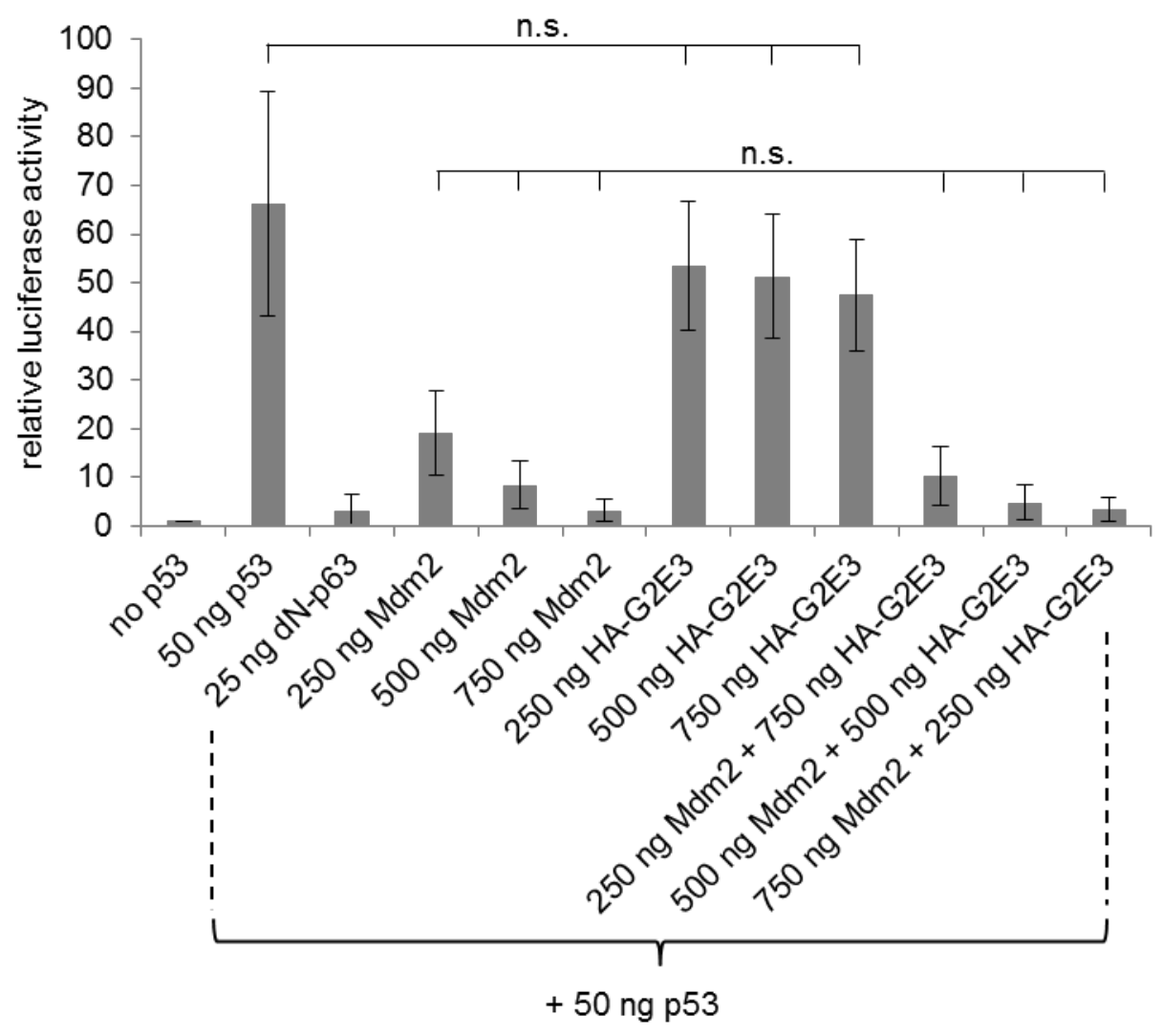

Figure 5.17: Overexpressed G2E3 has no impact on p53 transcriptional activity and on Mdm2dependent inhibition of p53 transactivation.

Luciferase assay: p53-deficient $\mathrm{H} 1299$ cells were transfected with the reporter plasmid pGL3-PG13-Luc to detect p53 transcriptional activity and with different combinations of plasmids encoding the proteins $\mathrm{p} 53, \Delta \mathrm{Np} 63, \mathrm{Mdm} 2$ and HA-G2E3. After $24 \mathrm{~h}$ of transfection, cells were lysed and luciferase activity was determined and normalized to co-transfected Renilla. Error bars are represented as SD $(n=5)$.

\subsubsection{Co-expression of Mdm2 and HA-G2E3 does not affect their protein levels}

To elucidate the function of G2E3, we wanted to clarify whether the ubiquitin ligases G2E3 and Mdm2 regulate each other by ubiquitination and degradation. Furthermore, we investigated whether G2E3 could ubiquitinate p53.

Whereas substrates for G2E3 are not established, it is known that Mdm2 ubiquitinates not only itself and p53 (Fang, Jensen et al. 2000), but also proteins like IGF-1R (insulin-like growth factor 1 receptor) (Girnita, Girnita et al. 2003), PCAF (p300/CREB-binding proteinassociated factor) (Jin, Zeng et al. 2004) and E-cadherin (Yang, Zong et al. 2006). We coexpressed HA-G2E3 and Mdm2 and investigated their protein levels and ubiquitination status after treatment with the proteasome inhibitor MG132 by immunoblotting. We did not detect mono- or poly-ubiquitination of HA-G2E3, Mdm2 and p53. Also, no increased degradation of one of the proteins was observed and protein levels did not change under the conditions 
applied (Figure 5.18). Mdm2 and p53 are high-turnover proteins: p53 has a half-life of about 30 min (Maltzman and Czyzyk 1984) and Mdm2 of about 20 min (Olson, Marechal et al. 1993) in untreated cells. Due to this fact, treating the cells with MG132 for $4 \mathrm{~h}$ led to accumulation of p53 and Mdm2 (Figure 5.18). Interestingly, treatment with MG132 also caused accumulation of HA-G2E3 which appears to be a high-turnover protein, too.

As seen in Figure 5.18 and also in Figure 5.15A, co-expression of HA-G2E3, Mdm2 and p53 did not lead to ubiquitination or degradation of HA-G2E3 and Mdm2. Furthermore, HA-G2E3 did not affect regulation of p53 levels by Mdm2. We therefore concluded that G2E3 did not ubiquitinate and/or degrade Mdm2 and vice versa. Moreover, G2E3 did not ubiquitinate and/or degrade p53.

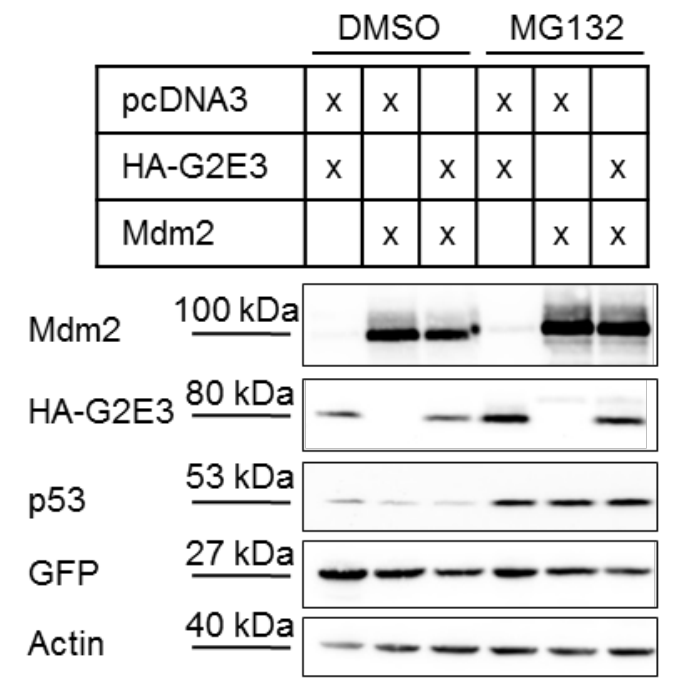

Figure 5.18: Co-expression of Mdm2 and HA-G2E3 does not affect their protein levels.

U2OS cells were transiently transfected with plasmids encoding Mdm2 (50 \%) and HA-G2E3 (50 \%) for $24 \mathrm{~h}$. During the last $4 \mathrm{~h}$, cells were treated with $20 \mu \mathrm{M}$ of the proteasome inhibitor MG132 (or DMSO as control). Cell lysates were analyzed by immunoblotting using the indicated antibodies. Coexpression of $5 \%$ GFP plasmid served as control for transfection efficiency. Actin staining served as loading control. 


\subsubsection{Overexpressed HA-G2E3 does not affect Mdm2 and p53 levels in cisplatin treated cells, but HA-G2E3 levels are down-regulated by cisplatin treatment}

Overexpressed HA-G2E3 does not affect Mdm2 and p53 levels as stated previously (Figure 5.18). We next asked whether G2E3 would have an influence on Mdm2 or p53 levels following cisplatin treatment. Therefore, we overexpressed HA-G2E3 in the presence of cisplatin and explored Mdm2 and p53 levels by immunblotting (Figure 5.19). Just as in untreated cells, HA-G2E3 did not influence Mdm2 and p53 levels upon cisplatin treatment. Surprisingly, cisplatin treatment led to strong decrease in HA-G2E3 levels. Phosphorylated Chk1 was used as a control for cisplatin treatment which activates the ATR-Chk1 pathway. Phospho-Chk1 levels did not change upon HA-G2E3 overexpression which means that HAG2E3 did not influence this parameter of the DDR to cisplatin treatment.

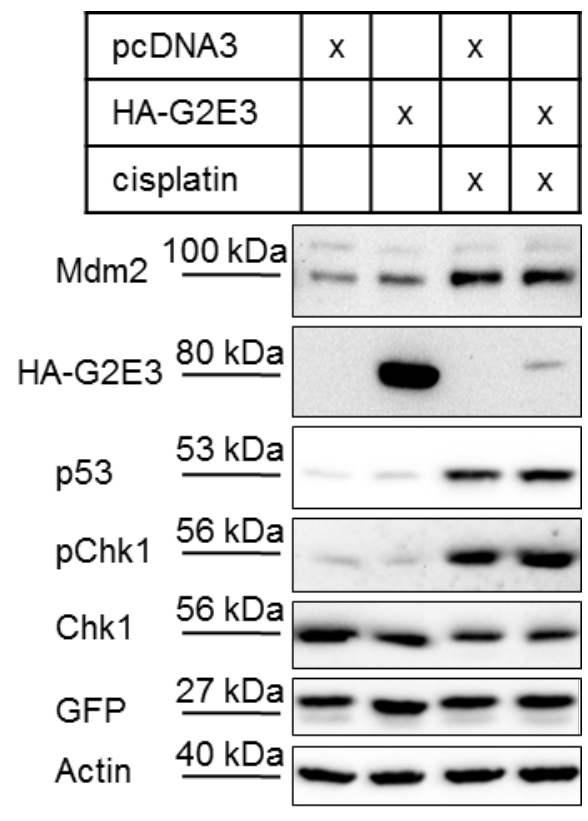

Figure 5.19: Overexpressed HA-G2E3 does not affect Mdm2 and p53 levels in cisplatin treated U2OS cells. HA-G2E3 protein levels are down-regulated by cisplatin treatment.

U2OS cells were transiently transfected with a plasmid encoding HA-G2E3 or with an empty plasmid (pcDNA3) as control. Cells were either left untreated or treated with $30 \mu \mathrm{M}$ cisplatin for $16 \mathrm{~h}$ (total incubation time ca. $48 \mathrm{~h}$ ). Cell lysates were analyzed by immunoblotting using the indicated antibodies. Staining of pChk1 was used as control for cisplatin treatment. Coexpression of $5 \%$ GFP plasmid served as control for transfection efficiency. Actin staining served as loading control. 
In order to investigate whether HA-G2E3 levels are decreased due to reduced G2E3 protein stability, we overexpressed HA-G2E3 in the presence of cisplatin and the proteasome inhibitor MG132. Extenuated HA-G2E3 levels were not rescued by MG132 treatment, which means that G2E3 protein stability was not affected (Figure 5.20A). Decreased HA-G2E3 levels could also be the result of increased apoptosis and thus proteolytic cleavage following cisplatin treatment. To test this possibility, we analyzed if caspase inhibition by Z-VAD treatment would abrogate decreased HA-G2E3 levels upon cisplatin treatment. Z-VAD is an irreversible, cell permeable caspase inhibitor that was shown to inhibit apoptosis induced by Fas (Chow, Weis et al. 1995), cycloheximide, etoposide and staurosporine (Zhu, Fearnhead et al. 1995). Interestingly, Z-VAD treatment indeed rescued the decrease in HA-G2E3 levels, arguing for an apoptosis-dependent cleavage of HA-G2E3 (Figure 5.20B). To explore this further, we used the CASVM software (Wee, Tan et al. 2007) to predict caspase cleavage sites based on algorithms developed by Wee et al. (Wee, Tan et al. 2006). We found 27 potential caspase cleavage sites for G2E3. To assess if HA-G2E3 was cleaved upon cisplatin treatment, we looked for fragments of HA-G2E3 by immunoblotting, but unfortunately could not detect any using the HA-tag antibody (data not shown). This was probably because the antibody only detects the HA-tag, which allows detection only of tagged fragments. Since three potential cleavage sites are at amino acid 8, 21 and 22, fragments could be very small and difficult to observe whereas the bigger fragment(s) would not contain the HA-tag anymore. We suggest investigating GFP-tagged G2E3 since GFP-tag is larger compared to HA-tag and is not cleaved by caspases. Thus, overexpressing GFP-G2E3 would enable us to detect potential G2E3 cleavage fragments. To determine G2E3 caspase cleavage sites in more detail, a systematic approach with mutated G2E3 protein forms should be conducted.

Furthermore, we were interested if phosphorylation of $\mathrm{H} 2 \mathrm{AX}$ is only caused by activation of the ATR-Chk1 and ATM-Chk2 pathway or if induction of apoptosis contributed to it. We found that under the conditions applied ( $30 \mu \mathrm{M}$ cisplatin treatment for $16 \mathrm{~h}$ ), $\mathrm{yH} 2 \mathrm{AX}$ levels are decreased upon cisplatin treatment and caspase inhibition by Z-VAD compared to cisplatin treatment alone (Figure 5.20B). Thus, phosphorylation of H2AX upon cisplatin treatment is to some extent due to apoptosis. 
A

\begin{tabular}{|l|l|l|l|l|l|l|l|l|}
\hline pcDNA3 & $x$ & & $x$ & & $x$ & & $x$ & \\
\hline HA-G2E3 & & $x$ & & $x$ & & $x$ & & $x$ \\
\hline Cis-Platin & - & - & - & - & + & + & + & + \\
\hline MG132 & - & - & + & + & - & - & + & + \\
\hline
\end{tabular}
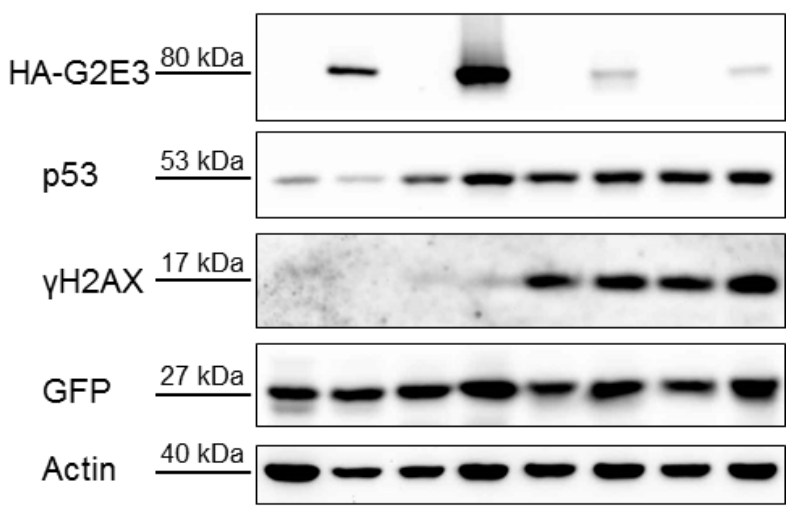

B

\begin{tabular}{|l|c|c|c|c|c|c|c|c|}
\hline pcDNA3 & $x$ & & $x$ & & $x$ & & $x$ & \\
\hline HA-G2E3 & & $x$ & & $x$ & & $x$ & & $x$ \\
\hline Cis-Platin & - & - & - & - & + & + & + & + \\
\hline Z-VAD & - & - & + & + & - & - & + & + \\
\hline
\end{tabular}

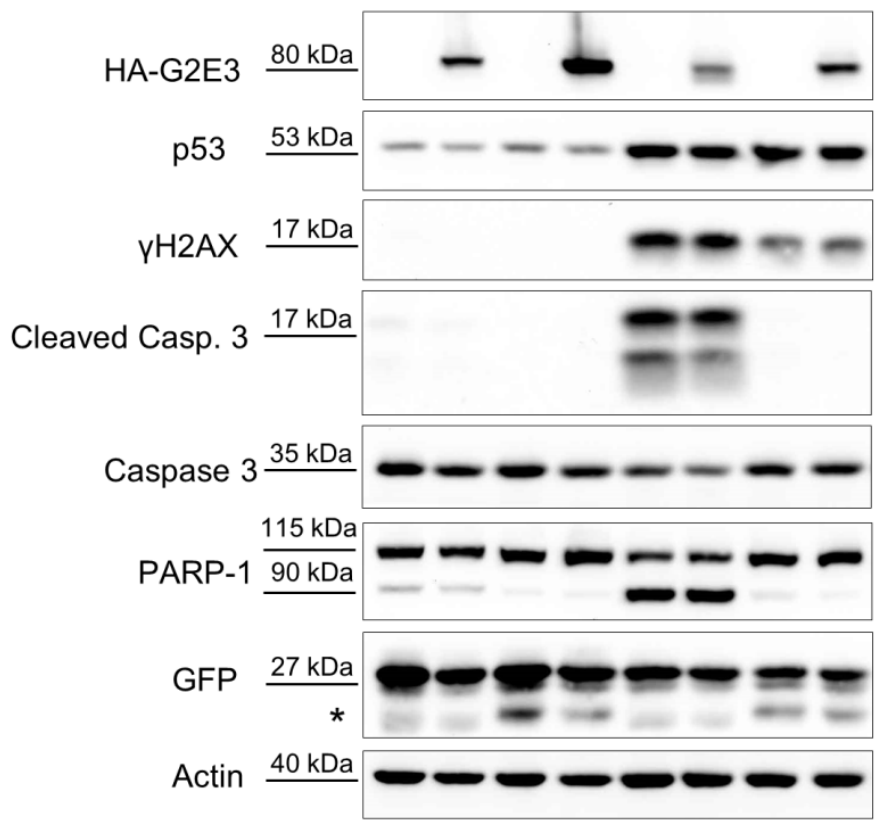

Figure 5.20: Decrease in HA-G2E3 protein levels upon cisplatin treatment is not due to proteasome activity, but dependent on apoptosis.

U2OS cells were transiently transfected with a plasmid encoding HA-G2E3 or with an empty plasmid (pcDNA3) as control. Coexpression of $5 \%$ GFP plasmid served as control for transfection efficiency $(*=$ unspecific band). (A) Cells were either left untreated or treated with $30 \mu \mathrm{M}$ cisplatin for $16 \mathrm{~h}$. During the last $4 \mathrm{~h}$, cells were treated with $20 \mu \mathrm{M}$ of the proteasome inhibitor MG132 (or DMSO as control). Total incubation time was ca. $48 \mathrm{~h}$. Cell lysates were analyzed by immunoblotting using the indicated antibodies. $\mathrm{YH} 2 \mathrm{AX}$ staining was used as control for cisplatin treatment. Actin staining served as loading control. (B) Cells were either left untreated or treated with $30 \mu \mathrm{M}$ cisplatin and/or $50 \mu \mathrm{M}$ caspase inhibitor Z-VAD for $16 \mathrm{~h}$ (DMSO as control). Total incubation time was ca. $48 \mathrm{~h}$. Cell lysates were analyzed by immunoblotting using the indicated antibodies. Markers for apoptosis are cleaved caspase 3 (Cleaved Casp. 3), total caspase 3 and cleaved PARP-1 (total protein at $115 \mathrm{kDa}$ and cleaved PARP-1 at $90 \mathrm{kDa}$ ). $\mathrm{yH} 2 \mathrm{AX}$ staining was used as control for cisplatin treatment. Actin staining served as loading control. 


\subsubsection{Loss of G2E3 results in decreased Mdm2 protein levels after cisplatin and neocarzinostatin treatment independent of p53-status}

So far, overexpression and co-expression of HA-G2E3 and Mdm2 did not reveal the relevance of their interaction. Thus, we conducted G2E3 knockdown experiments and investigated its impact on Mdm2. We already could show that knockdown of G2E3 induces p53 and p21 in U2OS cells, but had no impact on Mdm2 levels in this cell line (Figure 5.10). Interestingly, we noticed that G2E3 knockdown led to a strong decrease in Mdm2 levels after

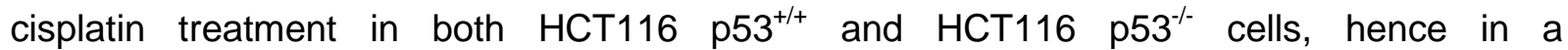
p53-independent manner (Figure 5.21A,B). Furthermore, we detected decreased Mdm2 levels upon G2E3 knockdown also in neocarzinostatin treated HCT116 p53 $^{-/-}$cells (Figure $5.21 \mathrm{C}$ ). Interestingly, decrease in Mdm2 protein levels was also seen in untreated cells after G2E3 knockdown, but to a lesser extent.
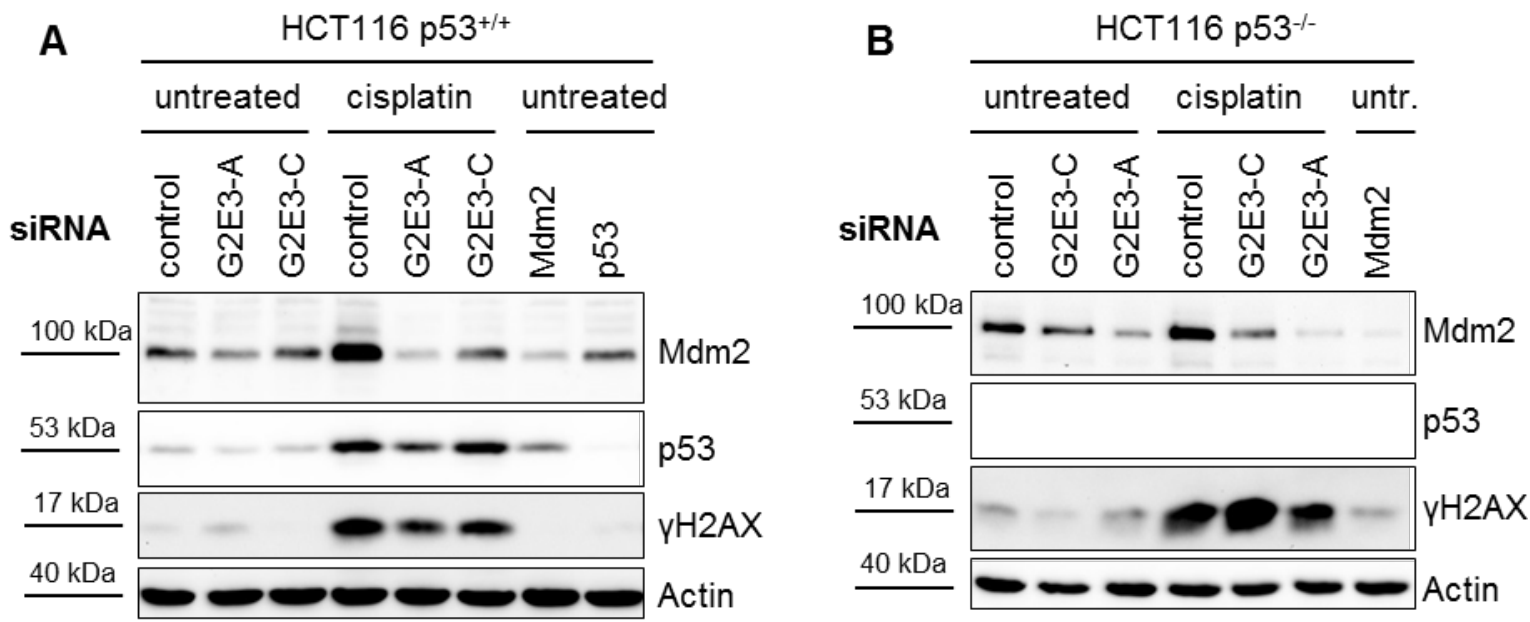

Figure 5.21: Knockdown of G2E3 results in decreased Mdm2 protein levels after cisplatin and neocarzinostatin treatment independent of p53-status.

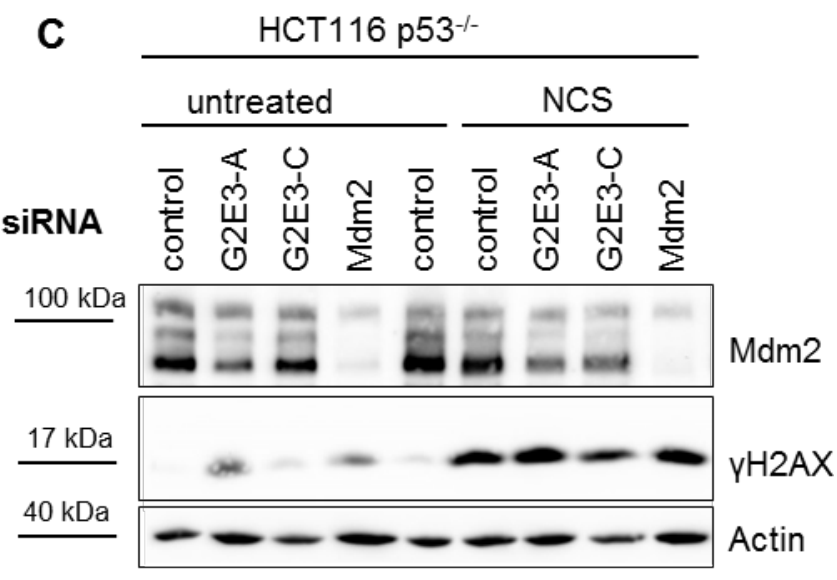

(A) HCT116 p53 ${ }^{+/+}$and (B) HCT116 p53 ${ }^{-/-}$cells were depleted of G2E3, Mdm2 and p53 by siRNA-mediated knockdown and either left untreated (untr.) or treated with $30 \mu \mathrm{M}$ cisplatin for $16 \mathrm{~h}$ (total incubation time $64 \mathrm{~h}$ ). Cell lysates were analyzed by immunoblotting using the indicated antibodies. $\mathrm{yH} 2 \mathrm{AX}$ staining was used as control for cisplatin treatment. Actin staining served as loading control. (C) Conducted by Ann-Christine Loock. HCT116 ${\mathrm{p} 53^{-/-}}^{-}$cells were depleted of G2E3 and Mdm2 by siRNA-mediated knockdown and either left untreated or treated with $150 \mathrm{ng} / \mathrm{ml}$ neocarzinostatin (NCS) for $2 \mathrm{~h}$ (total incubation time $48 \mathrm{~h}$ ). Cell lysates were analyzed by immunoblotting using the indicated antibodies. $\mathrm{yH} 2 \mathrm{AX}$ staining was used as control for NCS treatment. Actin staining served as loading control. 
In the hope to identify the relationship between G2E3 and Mdm2, we explored the reasons for this observation. We tested whether decreased Mdm2 level upon G2E3 knockdown in cisplatin or neocarzinostatin treated cells were due to an impact of G2E3 knockdown on Mdm2 mRNA levels, Mdm2 protein stability or due to an indirect effect.

\subsubsection{G2E3 knockdown does neither affect Mdm2 mRNA levels nor Mdm2 protein stability}

We first investigated how G2E3 knockdown affects Mdm2 mRNA levels. Mdm2 is transcriptionally regulated by a p53-independent (P1) and a p53-responsive (P2) promoter that both encode full-length Mdm2 (see section 2.3.2.2). We determined Mdm2 mRNA level

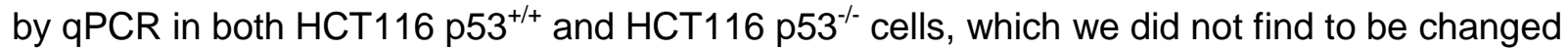
upon G2E3 knockdown in untreated and cisplatin treated cells (Figure 5.22A,B). We concluded that the decrease in Mdm2 levels after depletion of G2E3 was not regulated on the transcriptional level.

To analyze whether Mdm2 protein stability was changed, we treated cells with the proteasome inhibitor MG132 after G2E3 knockdown and cisplatin treatment. We used HCT116 p53 ${ }^{--}$cells to prevent accumulation and activation of p53 upon MG132 treatment. This would induce Mdm2 on the transcriptional level and by this would complicate the experimental setting due to additionally affecting Mdm2 expression. Interestingly, G2E3 knockdown did not impair Mdm2 protein stability since Mdm2 levels remained unchanged after proteasome inhibition using MG132 (Figure 5.22C). 

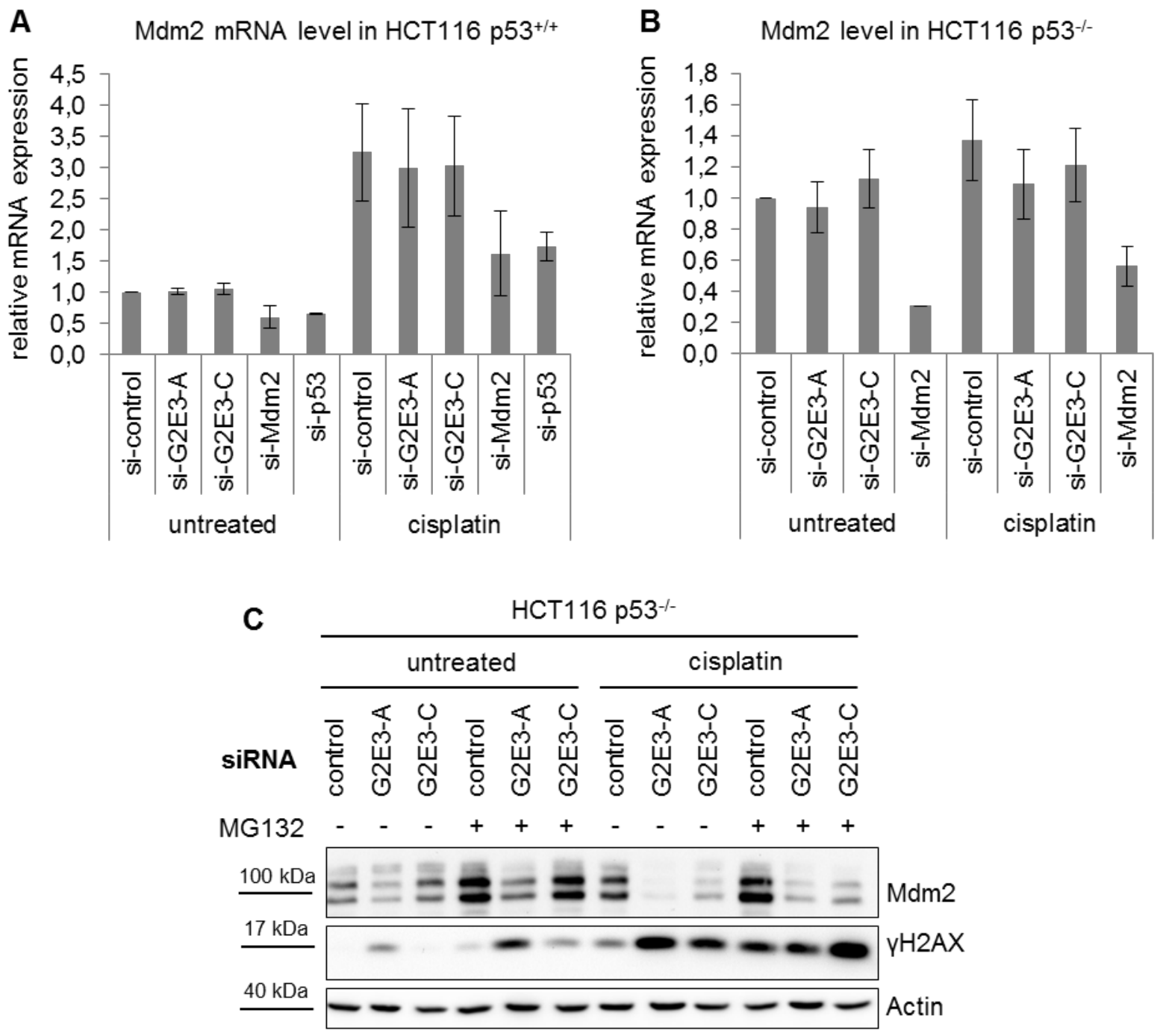

Figure 5.22: G2E3 knockdown does neither affect Mdm2 mRNA levels nor Mdm2 protein stability.

(A) HCT116 p53 ${ }^{+/+}$and (B) HCT116 p53 $3^{-/-}$cells were depleted of G2E3, Mdm2 and p53 by siRNAmediated knockdown and either left untreated or treated with $30 \mu \mathrm{M}$ cisplatin for $16 \mathrm{~h}$ (total incubation time $64 \mathrm{~h}$ ). Cells were harvested and Mdm2 mRNA levels were analyzed by qPCR. Results were normalized to expression of the reference gene GAPDH. Error bars are represented as SEM $(n=3)$. (C) Conducted by Ann-Christine Loock. HCT116 p53 ${ }^{-1-}$ cells were transfected with two different siRNAs targeting G2E3 and either left untreated or treated with $30 \mu \mathrm{M}$ cisplatin for $16 \mathrm{~h}$. During the last $4 \mathrm{~h}$, cells were treated with $20 \mu \mathrm{M}$ of the proteasome inhibitor MG132 (or DMSO as control). Cell lysates were analyzed by immunoblotting using the indicated antibodies. $\mathrm{yH} 2 \mathrm{AX}$ staining was used as control for cisplatin treatment. Actin staining served as loading control. 


\subsubsection{Apoptosis induced by G2E3 knockdown results in decrease of Mdm2 protein levels in p53-proficient, but not in p53-deficient cells}

As shown in Figure 5.22, G2E3 knockdown did not affect Mdm2 mRNA levels and Mdm2 protein stability. We therefore reasoned that an indirect effect could be the explanation for the decrease in Mdm2 levels upon G2E3 knockdown. Depletion of G2E3 causes increased apoptosis in cisplatin treated cells (Figure 5.6). It had previously been reported that Mdm2 can be cleaved during apoptosis by a caspase 3-like activity (Chen, Marechal et al. 1997; Erhardt, Tomaselli et al. 1997). However, the identity of the responsible caspase remained unknown. Only recently, it has been revealed that Mdm2 is a direct target of caspase 2 cleavage in response to DNA damage (Oliver, Meylan et al. 2011).

Hence, we asked whether induction of apoptosis after G2E3 knockdown could be the cause for decreased Mdm2 levels. Therefore, HCT116 p53 ${ }^{+/+}$cells were depleted of G2E3 by siRNA and either left untreated or treated with cisplatin and/or the caspase inhibitor Z-VAD. Interestingly, upon cisplatin treatment and caspase inhibition, Mdm2 protein levels after G2E3 knockdown were comparable to Mdm2 protein levels after control knockdown (Figure 5.23A). The reduction in Mdm2 protein levels in this cell line seemed to depend on apoptosis induced by G2E3 knockdown. Surprisingly, caspase inhibition did not rescue the decrease in Mdm2 levels in G2E3 depleted HCT116 $\mathrm{p5}^{-/-}$cells (Figure 5.23B). Here, the mechanism seemed to

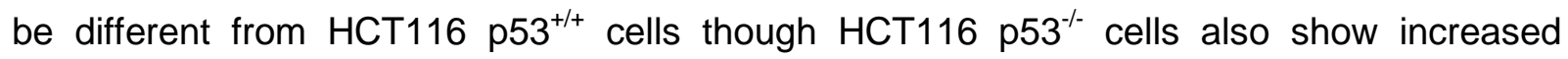
apoptosis upon G2E3 knockdown and cisplatin treatment, as seen in Figure 5.6B.

In summary, decrease in Mdm2 levels can be rescued by caspase inhibition using Z-VAD in p53-proficient, but not in p53-deficient HCT116 cells.

As was shown in Figure 5.20B, phosphorylation of $\mathrm{H} 2 \mathrm{AX}$ upon cisplatin treatment in U2OS cells was due to activation of the ATR-Chk1 and the ATM-Chk2 pathway, but also to some extent due to apoptosis. Also in HCT116 p53 ${ }^{+/+}$and HCT116 p53 ${ }^{-/-}$cells, $\mathrm{YH} 2 \mathrm{AX}$ levels in control transfected cells were lower after cisplatin and Z-VAD treatment compared to cisplatin alone (Figure 5.23A,B). This means that phosphorylation of $\mathrm{H} 2 \mathrm{AX}$ after cisplatin treatment was in part apoptosis-dependent under the conditions applied. Unexpectedly, knockdown

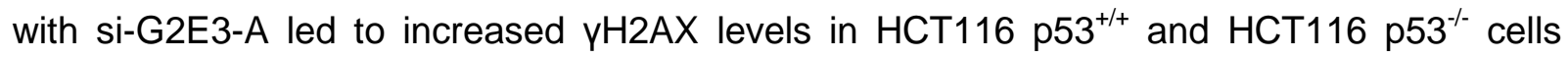
independent of Z-VAD treatment (Figure 5.23A,B) which is difficult to explain. For this siRNA, the impact on phosphorylation of $\mathrm{H} 2 \mathrm{AX}$ seemed to be apoptosis-independent. 

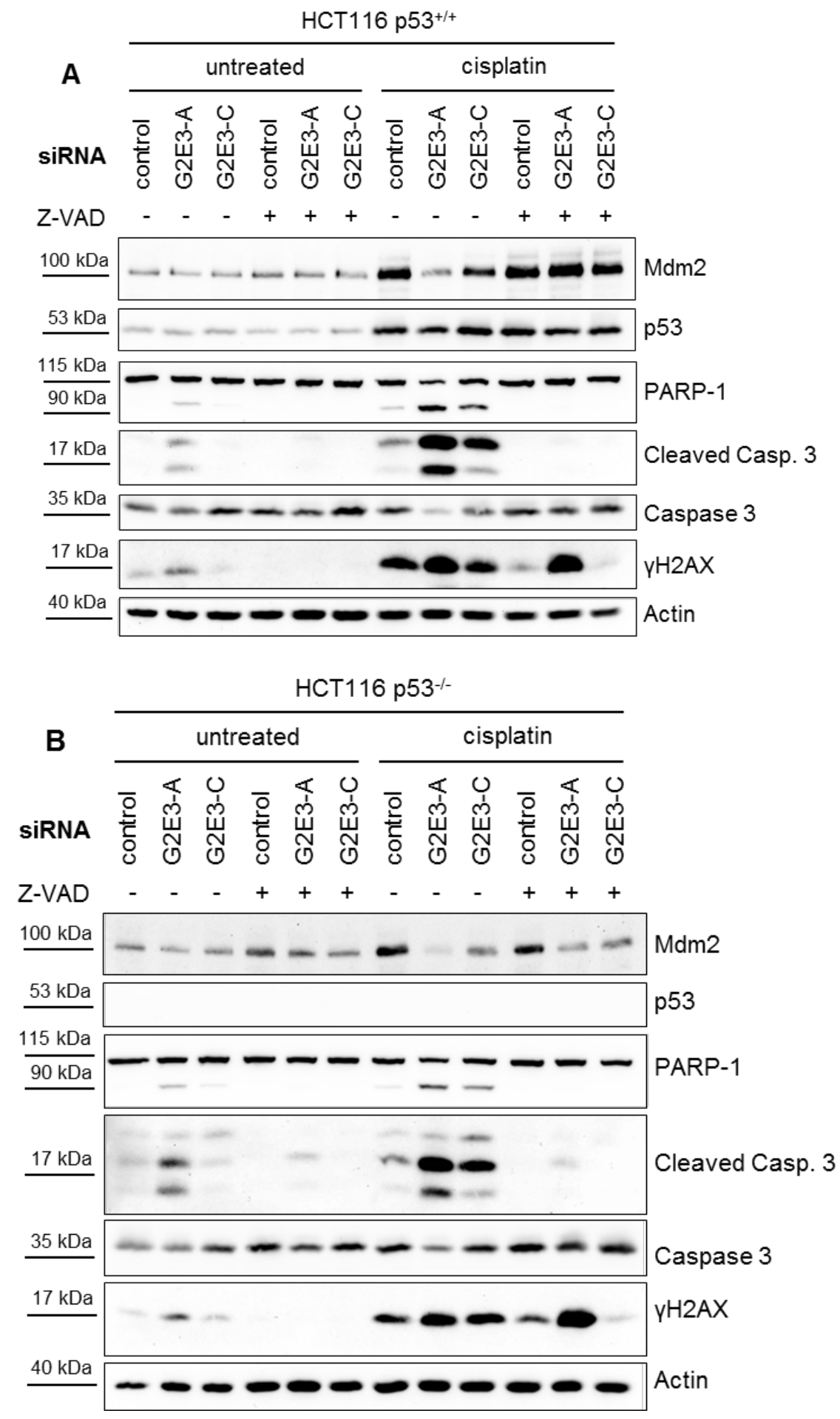

Figure 5.23: Apoptosis induced by G2E3 knockdown results in decrease of Mdm2 protein levels in p53-proficient, but not in p53-deficient cells.

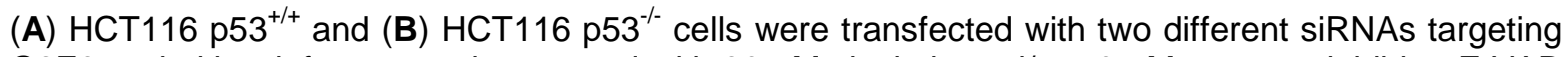
G2E3 and either left untreated or treated with $30 \mu \mathrm{M}$ cisplatin and/or $50 \mu \mathrm{M}$ caspase inhibitor Z-VAD for $16 \mathrm{~h}$ (DMSO as control). Cell lysates were analyzed by immunoblotting using the indicated antibodies. Markers for apoptosis are cleaved caspase 3 (Cleaved Casp. 3), total caspase 3 and cleaved PARP-1 (total protein at $115 \mathrm{kDa}$ and cleaved PARP-1 at $90 \mathrm{kDa}$ ). $\mathrm{yH} 2 \mathrm{AX}$ staining was used as control for cisplatin treatment. Actin staining served as loading control. 


\subsection{Regulation of G2E3 expression - G2E3 levels and cell cycle dependency}

\subsubsection{G2E3 levels are maximal in G2-phase}

The group of Crawford et al. performed a global gene expression profiling in HeLa cells after double thymidine block and identified genes with maximal expression in G2- and M-phase that were down-regulated in response to $y$-irradiation (Crawford and Piwnica-Worms 2001). In their publication, G2E3 was one of the candidates with mRNA expression maximal in G2-phase and decreased mRNA levels upon $\mathrm{y}$-irradiation. HeLa cells, used in the microarray study, do not have functional p53 due to infection with human papillomavirus (HPV). The viral protein E6 binds p53 (Werness, Levine et al. 1990) and together with the cellular protein E6-AP leads to its ubiquitin-dependent degradation (Scheffner, Werness et al. 1990; Huibregtse, Scheffner et al. 1991; Scheffner, Huibregtse et al. 1993). In contrast, U2OS cells contain wild-type, functional p53 and we set out to test whether G2E3 expression is also maximal in G2-phase of U2OS cells. To this end, we synchronized U2OS cells by double thymidine block in G1-phase. After release from the block, we harvested cells at different timepoints to analyze G2E3 mRNA levels during the cell cycle. Cell cycle phases were monitored by flow cytometry of propidium iodide stained cells (Figure 5.24A). We found that G2E3 expression was indeed maximal in G2-phase in U2OS cells (Figure 5.24B). In contrast to HeLa cells with a four times higher G2E3 expression in G2-phase compared to S-phase, we found a twofold higher G2E3 expression in U2OS cells.

\section{A}

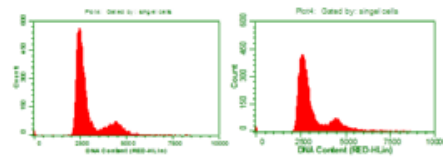

Oh

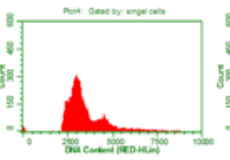

$4 \mathrm{~h}$

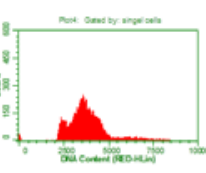

$6 \mathrm{~h}$

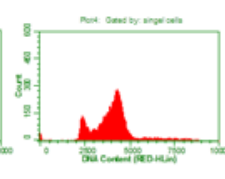

$8 \mathrm{~h}$

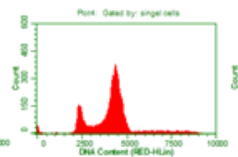

$10 \mathrm{~h}$

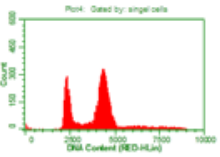

$12 \mathrm{~h}$

B

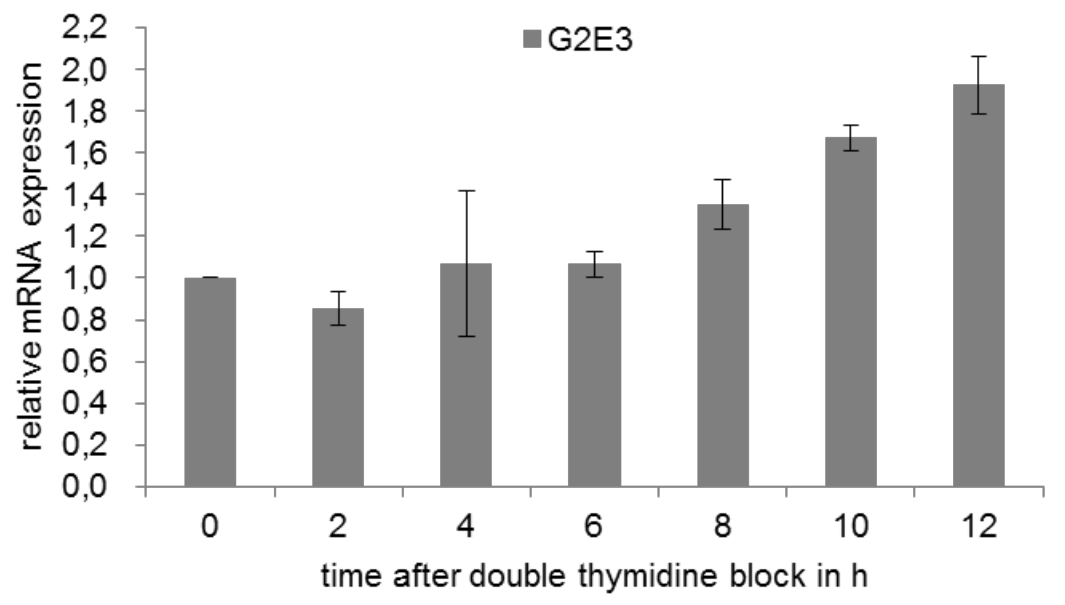

Figure 5.24: G2E3 levels are maximal in G2-phase. Legend on next page. 
Figure 5.24: G2E3 levels are maximal in G2-phase.

(A) U2OS cells were arrested in G1-phase using a double thymidine block and cell cycle phases were monitored by flow cytometry of propidium iodide stained cells. For each of the three independent experiments, flow cytometry data was acquired. Here, data are only shown for the first experiment, but equivalent synchronization was achieved each time. After release from the double thymidine block, cells proceeded into S-phase (0-4 h), then entered G2-phase (6-10 h) and underwent mitosis, whereupon they reentered G1-phase. (B) U2OS cells were harvested at each timepoint. G2E3 mRNA levels were analyzed by qPCR. Results were normalized to expression of the reference gene GAPDH. Error bars are represented as SD $(n=3)$.

\subsubsection{Endogenous G2E3 mRNA and protein levels are decreased after DNA damage independent of p53-activation or -status}

As mentioned earlier, G2E3 mRNA expression was reported to be decreased upon Y-irradiation (Crawford and Piwnica-Worms 2001). It was of interest to us whether G2E3 mRNA expression is also decreased upon treatment with other DNA-damaging reagents like cisplatin and NCS. To this end, we treated U2OS cells with cisplatin and NCS and determined G2E3 mRNA level by qPCR. Indeed, we observed a down-regulation of G2E3 expression after DNA damage (Figure 5.25A). As mentioned above, it was reported that p53 can repress G2E3 transcription via the large intergenic noncoding RNA lincRNA-p21 which is a p53-target in response to DNA damage (Huarte, Guttman et al. 2010). In order to identify the mechanism of G2E3 down-regulation, we tested whether decrease in G2E3 mRNA levels upon cisplatin and NCS treatment is due to induction of p53. We depleted cells of p53 by siRNA and determined G2E3 mRNA level. Interestingly, reduction in G2E3 expression did not depend on p53 since decrease in G2E3 levels could not be rescued by p53 depletion (Figure $5.25 \mathrm{~A})$. This result was further confirmed by treatment of HCT116 $\mathrm{p5}^{+/+}$and HCT116 $\mathrm{p} 53^{-/-}$ cells with cisplatin (Figure 5.25B). Again, G2E3 mRNA levels were decreased upon cisplatin treatment. This was the case for both p53-proficient and p53-deficient cells, arguing for a p53-independent mechanism.

Furthermore, we explored whether we can detect G2E3 down-regulation upon DNA damage also on the protein level. Due to the antibody of bad quality, we precipitated G2E3 out of four $15 \mathrm{~cm}$ cell culture dishes that were treated with cisplatin and the proteasome inhibitor MG132. We found that also G2E3 protein levels are decreased after cisplatin treatment (Figure 5.25C). These results suggest that G2E3 does not only regulate parameters within the DDR, but that it is furthermore affected by DNA-damaging treatment itself. 
A

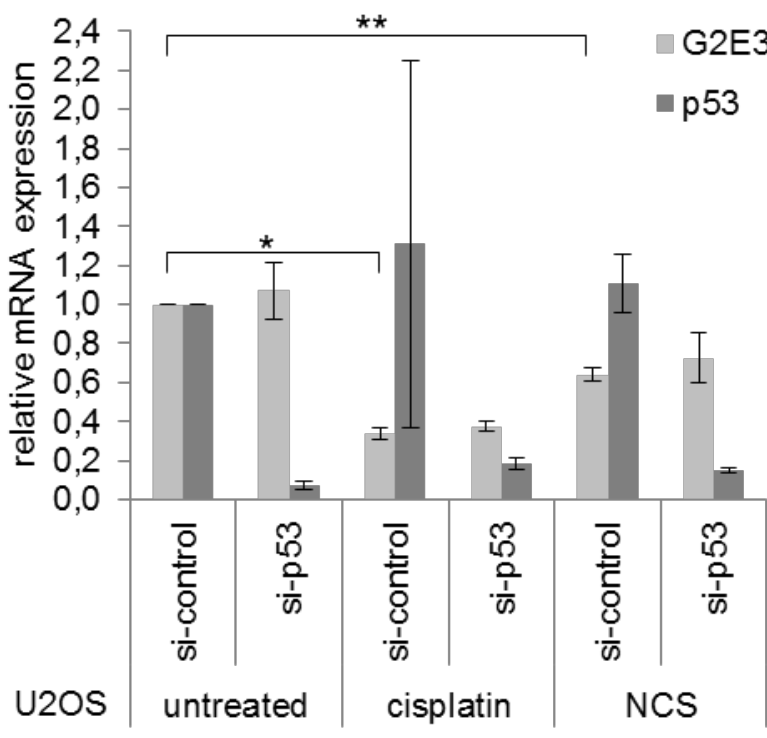

B

$\square$ HCT116 p53+/+ $\square$ HCT116 p53-/G2E3 mRNA level

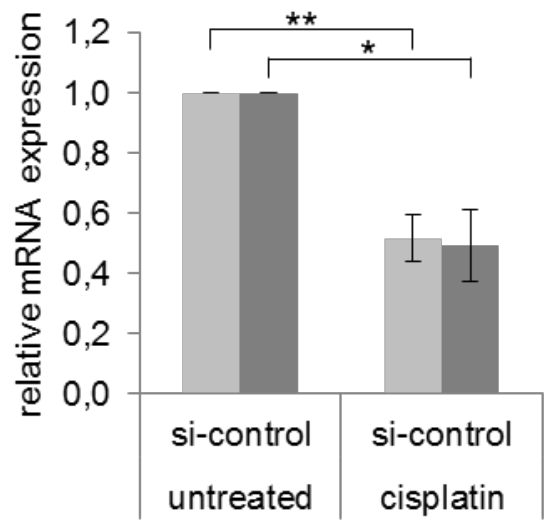

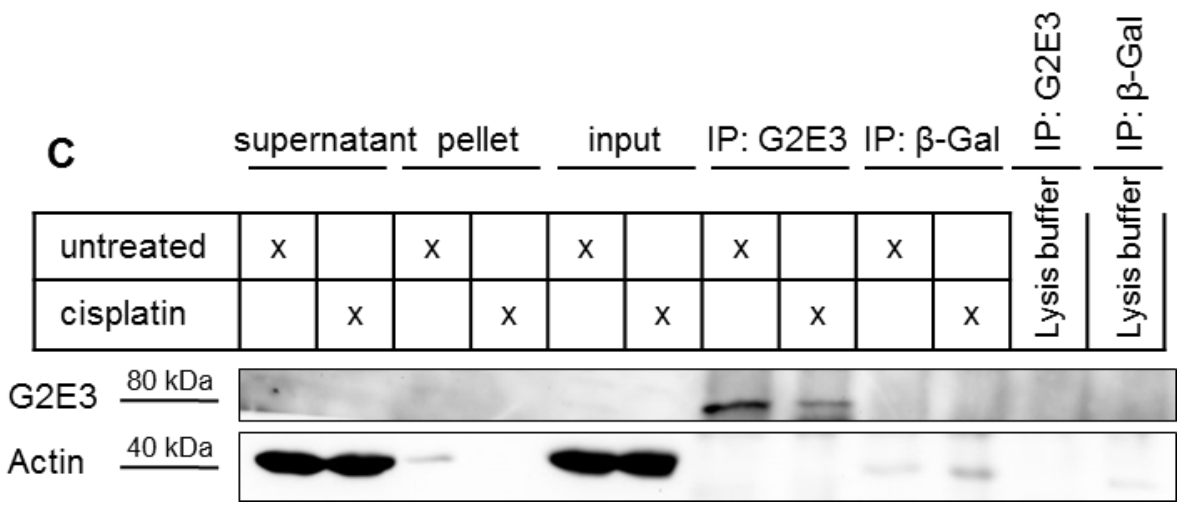

Figure 5.25: Endogenous G2E3 mRNA and protein levels are decreased after DNA damage independent of p53-activation or -status.

(A) U2OS cells were transfected with control- and p53-siRNA and either left untreated or treated with $30 \mu \mathrm{M}$ cisplatin for $16 \mathrm{~h}$ or $150 \mathrm{ng} / \mathrm{ml}$ neocarzinostatin (NCS) for $2 \mathrm{~h}$ (total incubation time $64 \mathrm{~h}$ ). Cells were harvested and G2E3 and p53 mRNA levels were analyzed by qPCR. Results were normalized to expression of the reference gene GAPDH. Error bars are represented as SD $(n=3) .{ }^{*}=p<0.05$, $\star *=p<0.01$ (student's t-test). (B) HCT116 $\mathrm{p5}^{+/+}$and HCT116 $\mathrm{p5} 3^{-1-}$ cells were transfected with si-control and either left untreated or treated with $30 \mu \mathrm{M}$ cisplatin for $16 \mathrm{~h}$ (total incubation time $64 \mathrm{~h}$ ). Cells were harvested and G2E3 mRNA levels were analyzed by qPCR. Results were normalized to expression of the reference gene GAPDH. Error bars are represented as SD $(n=3) .{ }^{*}=p<0.05$, $\star \star ~=p<0.01$ (student's t-test) (C) U2OS cells were either left untreated or treated with $30 \mu \mathrm{M}$ cisplatin for $16 \mathrm{~h}$ and during the last $4 \mathrm{~h}$ with $20 \mu \mathrm{M}$ of the proteasome inhibitor MG132. Cells were harvested and immunoprecipitation using a G2E3-specific antibody was performed. Precipitated G2E3 was analyzed by immunoblotting using the indicated antibodies. To control for unspecific binding, $\beta$ Galactosidase ( $\beta-\mathrm{Gal})$ was used as control antibody. As further control, lysis buffer without cell lysate was incubated with the indicated antibodies. 


\section{Discussion}

The chemotherapeutic cisplatin is widely used to treat various solid tumors, including testicular, lung and head and neck cancer. By inducing crosslinking of DNA, it prevents separation of strands during transcription and replication. As a result, complex signaling and repair pathways are induced. However, the cellular and molecular mechanisms upon cisplatin treatment are incompletely understood. The discovery of new regulators in the DNA damage response (DDR) to cisplatin would help us to extend our knowledge of the pathways activated. Since ubiquitination plays a major role in the DDR, we applied a high-content siRNA screen targeting human ubiquitin ligases and deubiquitinating enzymes to identify new regulators in the DDR to cisplatin.

One of these candidates was the ubiquitin ligase G2E3 whose knockdown led to decreased $\mathrm{YH} 2 \mathrm{AX}$ levels after cisplatin treatment. We got interested in G2E3 since it had been proposed to play a role in the DDR and in cell survival, but only little was known about underlying mechanisms.

G2E3 had previously been defined as G2-specific E3 ligase since it showed maximal mRNA expression in G2/M-phase (Crawford and Piwnica-Worms 2001) and contains two E3 ligase domains with in vitro ubiquitin ligase activity (Brooks, Helton et al. 2008). Further studies proposed a change in G2E3 localization upon DNA damage (Brooks, Banerjee et al. 2007). Moreover, a G2E3 knock-out mouse was reported to display embryonic lethality (Brooks, Helton et al. 2008), pointing towards an important role of G2E3 in cell survival. Together, these data motivated us to study the role of G2E3 in the DDR, in cell survival and in cell cycle regulation.

\subsection{G2E3 - a DNA damage-responsive, cell cycle-dependent survival factor}

\subsubsection{Summary and implications of our findings}

In the work presented here, we found G2E3 to modulate cellular proliferation, survival and the DDR. We show that G2E3 is regulated in a DNA damage-responsive manner since G2E3 mRNA as well as protein levels are decreased upon DNA damage treatment (Figure 5.19 and Figure 5.25). Knockdown of G2E3 resulted in p53-independent apoptosis and decreased proliferation (Figure 5.6 and Figure 5.7). Furthermore, we verified previous findings that G2E3 levels are maximal in G2-phase, arguing for a cell cycle-dependent regulation of G2E3 (Figure 5.24 and Crawford and Piwnica-Worms, 2001). 
Thus, we propose a model in which G2E3 acts as a pro-survival factor that protects normal cells against cell death. Upon DNA damage, G2E3 supports cells to go into apoptosis by its down-regulation (Figure 6.1).

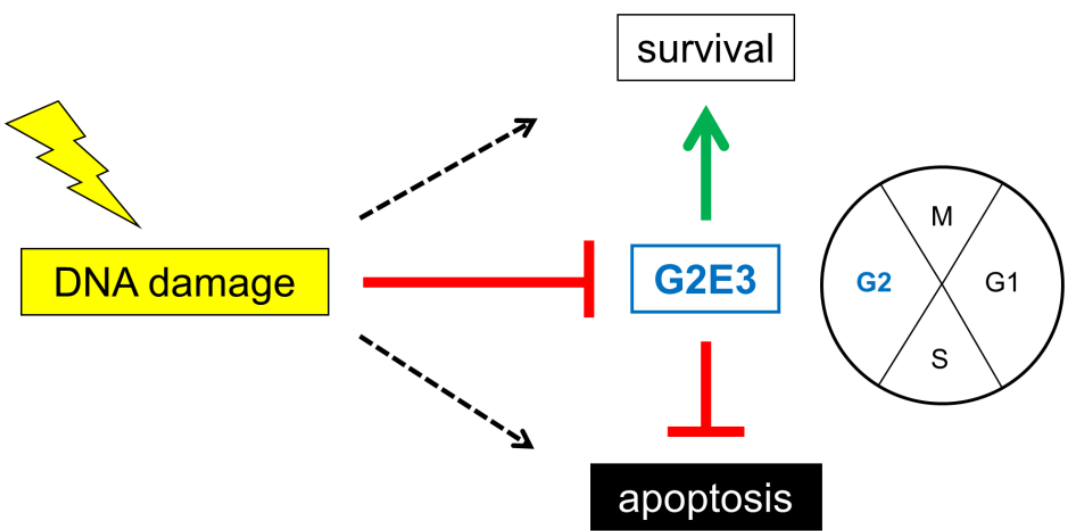

Figure 6.1: Model of G2E3 affecting cellular survival.

G2E3 is down-regulated in a DNA damage-responsive manner. G2E3 knockdown induces p53-independent apoptosis and decreased proliferation. G2E3 expression is cell cycle-dependent, with maximal levels in G2-phase. We propose an anti-apoptotic role of G2E3 in healthy cells. Upon DNA damage, down-regulation of G2E3 might support cells to go into apoptosis.

\subsubsection{Interdependence of apoptosis and the DNA damage response}

There is increasing evidence that pathways regulating DDR, cell cycle and apoptosis cannot be regarded as separated, but often as interdependent. Examples include induction of apoptosis if DNA damage is irreparable, or activation of the DDR when endonucleases break down DNA during the apoptotic process. However, open questions remain as to how decisions are made in the cell and which parameters decide on cell survival versus apoptosis. Our findings suggest a role of G2E3 in regulation of cellular proliferation, survival and the DDR. Examples for proteins that have been described to be involved in both DDR and apoptosis include $\mathrm{yH} 2 \mathrm{AX}$ and p53. Phosphorylation of H2AX at Ser139 does not only represent a marker of damaged DNA, as it can be also detected after initiation of DNA fragmentation during apoptosis (Rogakou, Nieves-Neira et al. 2000). Moreover, a recent paper showed that $\mathrm{H} 2 \mathrm{AX}$ is involved in mechanisms which decide whether a cell conducts DNA repair or induces apoptosis. Cook et al. reported that upon DNA damage, the protein tyrosine phosphatase EYA can dephosphorylate H2AX at Tyr142 promoting DNA repair. The authors show that this phosphorylation of $\mathrm{H} 2 \mathrm{AX}$ affects the decision of repair/survival versus apoptosis (Cook, Ju et al. 2009). The tumor suppressor p53 is another example for a protein that interconnects DDR, apoptosis and cell cycle regulation. It has cytoplasmic functions in mitochondrial apoptosis, but also acts as a transcription factor not only for apoptosis genes, but also genes inducing cell cycle arrest like p21. Naturally, localization of a protein in the cell 
determines its functions. Protein export, as seen for p53, can balance cellular responses like cell cycle arrest with apoptosis (Vousden 2006). Nevertheless, p53 is often lost or dysregulated during tumorigenesis and it is not well understood which proteins decide on cell survival or cell death in this situation. Since G2E3 is a DNA damage-responsive, cell cycledependent protein, it could play an essential role in the decision process of survival versus apoptosis independently of p53.

Here, we want to discuss our findings pointing to an important role of G2E3 in cell proliferation, survival and the DDR.

\subsubsection{Regulation of G2E3}

\subsubsection{DNA damage-responsive regulation of G2E3 mRNA levels}

We found that endogenous G2E3 mRNA levels were decreased upon cisplatin and NCS treatment (Figure 5.25A). This is in line with a microarray analysis performed in HeLa cells where G2E3 mRNA levels were down-regulated upon y-irradiation (Crawford and PiwnicaWorms 2001). We had reasoned that G2E3 might be transcriptionally repressed by p53 via the large intergenic noncoding RNA lincRNA-p21 which is a p53-target in response to DNA damage (Huarte, Guttman et al. 2010). However, we found that down-regulation of G2E3 upon DNA damage was independent of p53-activation or -status (Figure 5.25A,B). Since regulation of G2E3 on the transcriptional level was independent of p53, further possibilities have to be considered. Much is known about transcriptional activation, but much less about transcriptional repression, especially in response to DNA damage. Further transcription factors that could be involved in regulation of G2E3 expression include those of the E2F family. In mammals, eight E2F family members are known. E2F1, E2F2 and E2F3A can interact with $\mathrm{RB}$ and are believed to function mainly in transcriptional activation (Polager and Ginsberg 2009). On the other hand, E2F4, E2F5, E2F6, E2F7 and E2F8 have been shown to play a role in gene repression, which suggests a possible involvement of these family members in repression of G2E3 levels upon DNA damage. A hint towards a potential regulation of G2E3 by E2F comes from a recent paper. Varanasi et al. have performed a microarray analysis in untreated Saos2 cells transfected with control or E2F3 siRNA to identify transcriptional targets of E2F3 (Varanasi, Do et al. 2012). They identified Rad18, a protein involved in DNA repair, and characterized the relationship of E2F3 and Rad18 further. Interestingly, their microarray revealed G2E3 to be repressed upon E2F3 knockdown. Hence, it is possible that E2F3 leads to transcriptional activation of G2E3. However, the fact that E2F3 is induced upon DNA damage by transcriptional and posttranslational mechanisms and required for DNA damage-induced apoptosis, argues against this idea (Martinez, Goluszko et al. 2010). In this way, active E2F3 would lead to G2E3 expression upon DNA damage which is not the case since G2E3 levels are down-regulated upon DNA damage. 
Which makes the picture even more complicated is the existence of extensive crosstalk between the RB-E2F and Mdm2-p53 pathway. For instance, E2F7 is up-regulated by p53 upon DNA damage, leading to E2F7-mediated transcriptional repression (Carvajal, Hamard et al. 2012). In order to test whether transcription factors of the E2F family are involved in repression of G2E3 expression upon DNA damage, we suggest performing knockdown of each of these transcription factors, followed by treatment with a DNA-damaging agent and detection of G2E3 mRNA levels thereafter (similar to our experiment in Figure 5.25A). Although there are also p53-independent functions of E2Fs, we suggest performing the experiments exploring if E2Fs are involved in G2E3 transcription in a $\mathrm{p53}^{-/-}$background.

Another possibility to find out how G2E3 expression is regulated would be to identify the transcription factor that activates G2E3 expression and which might be repressed upon DNA damage. This could be investigated by analyzing the G2E3 promoter region for conserved binding sites of known transcription factors. Additionally, p63 and p73 should be investigated as potential transcription factors regulating G2E3 expression. Due to high sequence homology with p53, p63 and p73 can activate some target genes of p53. Here, we want to focus on p73. Like p53, p73 has been shown to be activated upon treatment with cytotoxic agents like cisplatin and doxorubicin (Gong, Costanzo et al. 1999; Irwin, Kondo et al. 2003). P73 can mediate p53-independent transcription and has been shown to repress gene expression, for example of the human telomerase reverse transcriptase (hTERT) (Racek, Mise et al. 2005). Thus, p73 activation after cisplatin treatment could lead to G2E3 repression. These are examples of transcription factors that could regulate G2E3 expression, further possibilities exist. For future investigations, it is of importance to understand how G2E3 expression is regulated since transcriptional control contributes to the decision in which process a protein is involved.

\subsubsection{DNA damage-responsive regulation of G2E3 protein levels}

Besides DNA damage-dependent down-regulation of G2E3 mRNA levels, we found overexpressed HA-G2E3 protein levels to be down-regulated by cisplatin treatment (Figure 5.19). This effect could be rescued by caspase inhibition using Z-VAD (Figure 5.20B), suggesting a caspase-dependent cleavage of G2E3. Therefore, we propose that G2E3 is not only regulated on the level of gene expression, but also on the protein level. We found G2E3 to have 27 potential caspase cleavage sites (see section 5.4.9) using the CASVM prediction software (Wee, Tan et al. 2007). A systematic approach with G2E3 plasmids containing mutated caspase cleavage sites should be performed to determine if G2E3 can be proteolytically cleaved by caspases. Furthermore, overexpression of GFP-tagged G2E3 followed by cisplatin treatment would potentially enable us to detect a G2E3 cleavage fragment since a GFP-tag is larger compared to HA-tag and is not cleaved by caspases.

Up to now, we could not elucidate whether decreased levels of overexpressed HA-G2E3 upon cisplatin treatment are dependent on the DDR or apoptosis. In order to test this, we 
suggest inducing DNA damage-independent apoptosis, e.g. by activating the extrinsic pathway with TRAIL or FAS ligand. Furthermore, we found also endogenous G2E3 protein levels to be decreased upon cisplatin treatment (Figure 5.25C). It should be investigated whether this decrease can be rescued by caspase inhibition using Z-VAD or whether it is dependent on regulation on the transcriptional level as seen in Figure 5.25A,B.

\subsubsection{Cell cycle-dependent regulation of G2E3 levels}

Besides its DNA damage-responsive regulation, G2E3 expression is cell cycle-dependent. We found G2E3 levels to be maximal in G2-phase of U2OS cells (Figure 5.24B). This is consistent with the microarray analysis of HeLa cells showing up-regulation of G2E3 mRNA levels in G2-phase (Crawford and Piwnica-Worms 2001). In contrast to HeLa cells with a four times higher G2E3 expression in G2-phase compared to S-phase, we found a twofold higher G2E3 expression in U2OS cells. This difference could be due to cell type-specific effects. For instance, the protein regulating G2E3 expression could be differently expressed in HeLa cells compared to U2OS cells. Furthermore, both cell lines vary in their p53 activity. Unlike HeLa cells with compromised p53 function, U2OS cells feature functional p53 which potentially could repress G2E3 expression via lincRNA-p21 as described above (Huarte, Guttman et al. 2010). However, induction of lincRNA-p21 had only been reported in response to DNA damage, whereas here untreated cells were investigated. Hence, further mechanisms could apply.

Up-regulation of G2E3 expression in G2-phase could possibly be associated with a function of G2E3 during the cell cycle. Many more proteins with cell cycle specific expression have been described. Genes specifically expressed in G2/M-phase include cyclin B1, Cdc25C and PLK1 (Polo-like kinase1) (Sadhu, Reed et al. 1990; Hamanaka, Smith et al. 1995; Lee, Yuan et al. 1995).

PLK1 is an important regulator of mitotic entry, progression and exit. Interestingly, it exhibits characteristics similar to our studies of G2E3. Besides being expressed in G2-phase, it has been reported to be inhibited in response to DNA damage (van Vugt, Smits et al. 2001). Furthermore, PLK1 blocks p53-independent apoptosis by inhibition of the p53-family member p73-alpha through interaction and phosphorylation (Koida, Ozaki et al. 2008). Since we have not yet identified the mechanism of G2E3's pro-survival function, it should be investigated whether G2E3 could inhibit p73. Knockdown of PLK1 inhibits proliferation, connected to cell cycle arrest in G2/M-phase and induction of apoptosis (Tyagi, Bhui et al. 2010). This is similar to our observations that G2E3 depletion blocks proliferation and induces apoptosis, though G2E3 knockdown induces a G1- and not a G2/M-arrest in U2OS cells. Furthermore, Tyagi et al. show that depletion of PLK1 renders cells more sensitive to cisplatin. Since we do not know how G2E3 levels are decreased upon DNA damage, we were interested in the mechanism of PLK1 down-regulation upon DNA damage which was investigated very recently (Qin, Gao et al. 2013). PLK1 is regulated by protein degradation of a protein called 
Bora. Qin et al. show that upon phosphorylation by ATR, Bora is degraded by the multisubunit ubiquitin ligase SCF ${ }^{\beta-T R C P}$ which leads to a yet not explainable inhibition of PLK1. Interestingly, SCF ${ }^{\beta-T R C P}$ was also shown to target Mdm2 for degradation and has further substrates relevant in apoptosis like procaspase 3, p53 and the p53 family member p63 (Tan, Gallegos et al. 2006; Gallegos, Litersky et al. 2008; Xia, Padre et al. 2009; Inuzuka, Tseng et al. 2010). It would be very interesting to elucidate whether G2E3 down-regulation is mediated in a similar fashion. Apart from comparable characteristics of PLK1 and G2E3, the question remains whether both proteins are also regulated in a similar fashion or not. We show that G2E3 is transcriptionally regulated (Figure $5.25 \mathrm{~A}, \mathrm{~B}$ ) and could probably be cleaved by caspases (Figure 5.20B). However, we have further evidence that G2E3 is regulated on the protein level. We observed an accumulation of overexpressed HA-G2E3 after $4 \mathrm{~h}$ of treatment with the proteasome inhibitor MG132 (Figure 5.18). This finding hints at an ubiquitin-dependent regulation of G2E3. With the objective of exploring whether G2E3 could be ubiquitinated, we investigated the existence of G2E3 post-translational modifications using the PhosphoSitePlus ${ }^{\circledR}$ online systems biology resource. PhosphoSitePlus ${ }^{\circledR}$ provides information and tools to study protein post-translational modifications (Hornbeck, Kornhauser et al. 2012). According to the database, human G2E3 was found by mass spectrometry to be ubiquitinated at Lys442. Thus, degradation of G2E3 by another ubiquitin ligase like SCF ${ }^{\beta-T R C P}$ could be possible. This could be tested by inactivation of $\beta$-TRCP, the F-box protein component of the ubiquitin ligase complex. An approach using shRNA-mediated depletion of $\beta$-TRCP has been proven successful for demonstrating that Mdm2 and Bora stability are controlled by SCF ${ }^{\beta-T R C P}$ (Inuzuka, Tseng et al. 2010; Qin, Gao et al. 2013). Furthermore, coimmunoprecipitation of G2E3 and $\beta$-TRCP should be conducted to check for a direct interaction of both proteins. On the other hand, G2E3 has been shown to be autoubiquitinated using an in vitro assay and to catalyze Lys48-linked poly-ubiquitination, a signal for proteasomal degradation (Brooks, Helton et al. 2008). Thus, it is possible that G2E3 protein levels are also or additionally regulated by auto-degradation.

\subsubsection{The role of G2E3 in apoptosis}

\subsubsection{How could G2E3 be involved in p53-independent apoptosis?}

Besides its DNA damage-responsive, cell cycle-dependent features, we found G2E3 to affect cell survival. Depletion of G2E3 resulted in p53-independent apoptosis in colon carcinoma and osteosarcoma cell lines (Figure 5.6). This result suggests that G2E3 is an anti-apoptotic protein that is down-regulated upon DNA damage, thereby promoting apoptosis. The role of G2E3 in cell survival was also shown in G2E3 knock-out mice which die at a very early stage in development due to apoptosis and involution of the blastocyst (Brooks, Helton et al. 2008). In order to investigate the p53-dependency of their observations, the authors established double heterozygous mice for G2E3 and p53 (i.e. G2E3 ${ }^{+/}$and $\mathrm{p} 53^{+/-}$). Remarkably, they did 
not obtain any $\mathrm{G} 2 \mathrm{E} 3^{-/} / \mathrm{p} 53^{-/-}$mice, meaning that loss of $\mathrm{p} 53$ could not rescue the lethal phenotype of G2E3 knock-out mice.

The finding that apoptosis induced by G2E3 depletion is p53-independent (Figure 5.6B and Brooks, Helton et al. (2008)) raises the question of how G2E3 protects cells against apoptosis. The ubiquitin ligase was localized predominantly in the nucleus (Figure 5.5). Therefore, G2E3 might not play a role in cytoplasmic and mitochondrial apoptotic processes. Rather, G2E3 could influence transcription of apoptotic genes. Three domains of G2E3 have similarity to both PHD and RING domains. PHD domains infrequently have E3 activity, but bind methylated histones and are involved in chromatin-mediated gene regulation (Musselman and Kutateladze 2011). It is not known whether G2E3 can bind chromatin and hence affect gene expression. This could be tested by performing a chromatin fractionation and exploring if G2E3 is enhanced in the chromatin-bound fraction. Furthermore and perhaps more likely, G2E3 could influence proteins that regulate expression of apoptotic genes. In such a scenario, G2E3 could either suppress transcription factors of pro-apoptotic genes or support the activity of anti-apoptotic gene regulators. Since we do not have evidence for such a mechanism, we can only speculate of how this could be accomplished. As an example, p53-independent apoptosis can be mediated by the p53-related transcription factor p73. Urist et al. have shown that Chk1 and Chk2 stabilize the transcription factor E2F1 in response to DNA damage which is then capable of inducing p73 expression (Urist, Tanaka et al. 2004). It is well established that p73 can bind to p53 DNA-binding sites and thus activate expression of p53-responsive genes involved in apoptosis, cell cycle arrest and senescence (Jost, Marin et al. 1997). How exactly p73 induces apoptosis is not completely understood. However, it has been shown that p73 can induce apoptosis via transactivation of genes like Puma (Melino, Bernassola et al. 2004). The authors imply that Puma leads to mitochondrial translocation of Bax, further leading to cytochrome $c$ release during the intrinsic pathway. The impact of p73 on translocation of Bax seems to be indirect since p73 localizes to the nucleus while inducing cell death. G2E3 is also a nuclear protein which could conduct its pro-survival role by inhibition of p73 or other nuclear proteins which indirectly affect apoptotic signaling in the cytoplasm. On this line, p73 transcriptional activity has been shown to be repressed by mono-ubiquitination of p73 through the Cullin4A ubiquitin ligase (Malatesta, Peschiaroli et al. 2012). Thus, repression of $\mathrm{p} 73$ by ubiquitination could be a possible, though speculative mechanism explaining the pro-survival role of G2E3.

Although we found overexpressed G2E3 to be localized predominantly in the nucleus (Figure 5.5), it is not impossible that it also plays a role in cytoplasmic events. Brooks et al. described G2E3 to possess a CRM1-independent nuclear export domain and a sequence that antagonizes the nuclear export signal (Brooks, Banerjee et al. 2007). Furthermore, the authors found that G2E3 is exported from the nucleus of Cos-7 cells in a CRM1-independent manner. Therefore, we reasoned that G2E3 could have a supportive function on p53independent pro-survival proteins in the cell. Since we found an interaction of co-expressed G2E3 and Mdm2 (Figure 5.14 and Figure 5.15), it is a possibility that G2E3 supports Mdm2 in 
carrying out an anti-apoptotic action. Interestingly, Mdm2 has been shown to prevent apoptosis by increasing the expression of XIAP (X-chromosome-linked inhibitor of apoptosis protein) (Gu, Zhu et al. 2009). The authors report binding of Mdm2 to XIAP mRNA which enhances translation and thus increases XIAP expression. Hence, G2E3 could perhaps support Mdm2 in enhancing XIAP expression. This could be explored by detection of XIAP protein levels after G2E3 and Mdm2 knockdown as well as double-knockdown of both proteins under the conditions used in the paper of $\mathrm{Gu}$ et al. Another option of how G2E3 could support anti-apoptotic processes in the cell is by regulating the important pro-survival regulator Bcl-2. Bcl-2 was shown to prevent p53-independent cell death in lymphoid cells (Strasser, Harris et al. 1994). Thus, it should be investigated whether G2E3 affects Bcl-2, for example by detecting Bcl-2 mRNA and protein levels after G2E3 knockdown.

These examples point out that it should be clarified whether G2E3 can affect cytoplasmic apoptotic regulators or not. Regulation of such proteins could be either indirect or mediated by G2E3 export into the cytoplasm. Consequently, it should be investigated by subcellular fractionation whether G2E3 is present in the cytoplasm.

It is of note that the ubiquitin ligase activity of G2E3 could be important for its anti-apoptotic function. As a possibility, G2E3 could promote ubiquitination and degradation of pro-apoptotic proteins. Several ubiquitin ligases and DUBs have been shown to play a role in apoptosis. These include Mdm2 (by regulating p53) and aforementioned inhibitor of apoptosis (IAP) proteins. The ubiquitin ligase XIAP not only binds and blocks the catalytic activity of caspases 3, 7 and 9, but also reduces their levels by ubiquitination and hence degradation (Suzuki, Nakabayashi et al. 2001; Vucic, Dixit et al. 2011). Furthermore, c-IAP1 (cellular inhibitor of apoptosis 1) promotes ubiquitination of caspase 3 and 7 (Choi, Butterworth et al. 2009) and regulates XIAP and C-IAP2 (Conze, Albert et al. 2005; Vucic, Dixit et al. 2011). In addition, ubiquitin ligase complexes have significant impact on regulation of apoptosis. As mentioned before, the multi-subunit ubiquitin ligase $\mathrm{SCF}^{\beta-\mathrm{TRCP}}$ is an important regulator of apoptosis with substrates like procaspase 3 and the p53 family members p53 and p63 (Tan, Gallegos et al. 2006; Gallegos, Litersky et al. 2008; Xia, Padre et al. 2009). Hence, it should be investigated whether G2E3 E3 ligase activity is necessary for its pro-survival function. To this end, G2E3 mutants without ubiquitin ligase activity should be designed and the survival of cells after cisplatin treatment should be compared between wild-type and mutant G2E3. If G2E3 ubiquitin ligase activity is a prerequisite for its pro-survival role, the endogenous substrate(s) of G2E3 have to be identified as discussed in more detail below (see section 6.3).

\subsubsection{Could G2E3 inhibit apoptosis through checkpoint regulation?}

Interestingly, it has been demonstrated that p53-independent apoptosis can be enhanced by inactivation of cell cycle checkpoints. For instance, cancer cells without p53 depend on ATM/ATR-p38-MK2 signaling in order to arrest the cell cycle (Reinhardt, Aslanian et al. 2007). Without this response, cells run into apoptosis and mitotic catastrophe. Thus, G2E3 
could also be an important cell cycle checkpoint regulator whose loss (by knockdown or down-regulation following DNA damage) leads to induction of apoptosis. This raises the question whether G2E3 is directly involved in prevention of apoptosis or whether its loss indirectly causes apoptosis since it is an important regulator of the cell cycle and DDR. Our findings that G2E3 represents a strongly regulated, DNA damage-responsive, cell cycledependent protein argue in favor of the latter case.

As mentioned earlier, G2E3 knock-out in mice die at a very early stage in development (Brooks, Helton et al. 2008). During embryonic development, cell division has to be correctly coordinated and mutations have to be prevented. Thus, proteins that regulate cell cycle, checkpoints and the DDR are among the most important factors during embryogenesis. Their inactivation often causes developmental abnormalities or embryonic lethality. Examples of proteins whose inactivation causes embryonic lethality in mice include cell cycle proteins such as cyclin B1 and A2 (Murphy, Stinnakre et al. 1997; Brandeis, Rosewell et al. 1998) and CDK11 (Li, Inoue et al. 2004). Also, inactivation of DDR regulators like ATR, Chk1, BRCA1, BRCA2 and Rad51 results in embryonic lethality in mice (Liu, Flesken-Nikitin et al. 1996; Tsuzuki, Fujii et al. 1996; Ludwig, Chapman et al. 1997; Brown and Baltimore 2000; Liu, Guntuku et al. 2000). On the other hand, inactivation of ATM and FANC proteins causes developmental abnormalities as seen in the respective diseases ataxia telangiectasia and Fanconi anemia (Savitsky, Bar-Shira et al. 1995; Elson, Wang et al. 1996; Niedernhofer, Lalai et al. 2005). Hence, it is a possibility that G2E3 is an important regulator of DDR and cell cycle whose loss promotes apoptosis induction.

However, arguments that support a direct role of G2E3 in suppressing apoptosis come from insights of the mechanisms underlying embryonic lethality of some genes mentioned above. Besides G2E3 knock-out, apoptosis-dependent embryonic lethality has also been shown in ATR and Chk1 knock-out mice (Brown and Baltimore 2000; Liu, Guntuku et al. 2000). Brown et al. show that $\mathrm{ATR}^{-/-}$blastocyst cells die of caspase-dependent apoptosis, probably due to chromosomal breaks and accompanying loss of genomic integrity. Further on, Liu et al. report

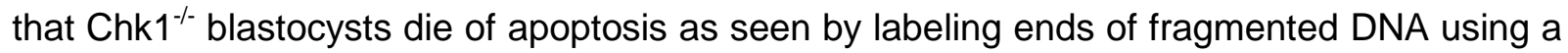
TUNEL (Terminal deoxynucleotidyl transferase dUTP nick end labeling) assay. Apoptosis in $\mathrm{Chk1}^{-1-}$ blastocysts is p53-independent, just as in G2E3 knock-out cells. The authors report that double-knockout of Chk1 and p53 cannot rescue or delay early lethality in Chk1 $^{-1-}$ embryos (Liu, Guntuku et al. 2000). ATR and Chk1 were first reported to be involved in signaling of single-stranded DNA, but furthermore have been shown to suppress apoptosis in response to replicative stress in both p53-proficient and p53-deficient cells (Myers, Gagou et al. 2009).

Thus, G2E3 could also be a regulator of DDR and cell cycle with an additional role in protecting cells against apoptosis. Further investigations are needed to clarify G2E3 function. Since G2E3 knock-out mice display embryonic lethality, generation of a conditional G2E3 
knock-out mouse would constitute a promising possibility to investigate the role of G2E3 in apoptosis, but also in cell cycle regulation and DDR.

\subsubsection{Does G2E3 protect Mdm2 against caspase cleavage?}

We were interested in consequences of G2E3 function and studied the impact of G2E3 depletion in the cell. Thereby we found that loss of G2E3 resulted in decreased Mdm2 protein levels after cisplatin and neocarzinostatin treatment independently of p53-status (Figure 5.21). This result suggests that G2E3 regulates Mdm2 levels independently of $p 53$, the principal transcription factor for Mdm2 expression. Looking more closely at the underlying mechanism, we found that inhibition of apoptosis could rescue decreased Mdm2 protein levels after G2E3 knockdown in p53-proficient, but not in p53-deficient HCT116 cells (Figure 5.23). This finding suggests that apoptosis induced by G2E3 knockdown in p53-proficient cells causes caspase-dependent cleavage of Mdm2. Interestingly, Mdm2 had previously been reported to be cleaved by a caspase 3-like activity (Chen, Marechal et al. 1997; Erhardt, Tomaselli et al. 1997). Chen et al. reported that this cleavage leads to removal of the Cterminal RING domain of Mdm2, still allowing binding to p53. It had furthermore been shown that truncated versions of Mdm2 that cannot target p53 for degradation anymore result in increased p53 levels (Pochampally, Fodera et al. 1999; Honda and Yasuda 2000). However, the identity of the responsible caspase remained unknown. Only recently, it has been revealed that Mdm2 is a direct target of caspase 2 cleavage in response to DNA damage (Oliver, Meylan et al. 2011). Thus, upon DNA damage, p53 is activated and its stability is promoted by caspase 2-mediated cleavage of Mdm2.

With these findings in mind, our results could be explained by two different mechanisms: First, G2E3 could protect Mdm2 against cleavage by caspase 2, hence G2E3 knockdown results in proteolytic cleavage of Mdm2. Secondly, decreased Mdm2 levels could indirectly depend on G2E3 knockdown since it induces apoptosis. Thus, it is of importance to elucidate whether the response of Mdm2 after apoptosis is directly dependent on G2E3 or not. We suggest performing a double-knockdown of G2E3 and caspase 2, followed by cisplatin treatment and subsequent detection of Mdm2 protein levels.

Since reduction in Mdm2 levels can only be rescued by caspase inhibition in p53-proficient cells, the mechanism of decreased Mdm2 levels after G2E3 knockdown seems to be different in p53-deficient cells. In p53-proficient cells, cisplatin treatment leads to activation of p53 which at a later stage activates Mdm2 expression. Upon caspase inhibition, Mdm2 is not cleaved by caspases anymore, thus p53-dependent transcription of Mdm2 could result in the rescue of decreased Mdm2 levels which we observe. However, in p53-deficient cells, Mdm2 does not seem to be cleaved by caspases since Z-VAD treatment could not rescue decreased Mdm2 levels. So far, we have no explanation for this difference in p53-deficient cells. It is possible that in HCT116 p53 ${ }^{+/+}$cells p53 is to some extent involved in apoptosis

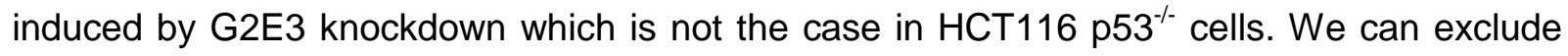


that G2E3 knockdown affects Mdm2 mRNA levels and Mdm2 protein stability in p53-deficient cells (Figure 5.22B,C). Since Mdm2 levels in HCT116 $\mathrm{p5}^{-{ }^{--}}$cells are not decreased due to apoptotic cleavage, it is a possibility that G2E3 knockdown attenuates translation of Mdm2 in these cells. Translational inhibition of Mdm2 had been shown before. Xiong et al. reported that inhibition of IGF-1R (insulin-like growth factor 1 receptor) reduces Mdm2 translation and that elF4E (eukaryotic translation initiation factor 4E) is involved (Xiong, Kou et al. 2007). In order to study translational regulation, a common method applied is polysomal profiling using sucrose gradients. Hereby, cellular components are separated by size and information can be obtained on polysomes (two or more ribosomes) and other components of the translation machinery. Hence, in order to check if G2E3 can modulate Mdm2 translation, it could be explored if the association of Mdm2 mRNA with polysomes is changed upon G2E3 knockdown.

\subsubsection{The role of G2E3 in the DDR}

By means of a high-content siRNA screen, we found that knockdown of G2E3 decreases $\mathrm{YH} 2 \mathrm{AX}$ levels in U2OS cells (Figure 5.2 and Figure 5.3) and we searched for an explanation. So far, we did not identify a direct role of G2E3 in the DDR explaining changes in $\mathrm{H} 2 \mathrm{AX}$ phosphorylation. However, we showed that knockdown of G2E3 resulted in G1-arrest and decreased percentage of cells in S-phase in untreated and cisplatin treated U2OS cells (Figure 5.8 and Figure 5.9) as well as p53-dependent p21 induction in U2OS cells (Figure 5.10). Thus, we propose that after G2E3 knockdown arrested U2OS cells do not continue replicating their DNA and are therefore less prone to be harmed by cisplatin treatment. Interestingly, Mdm2 knockdown also leads to induction of G1-arrest (Figure 5.8) and exhibits decreased $\mathrm{yH} 2 \mathrm{AX}$ levels upon cisplatin treatment as seen in the screen (Figure 5.2). This finding supports our hypothesis, as well as data of Kranz et al. that revealed reduced $\mathrm{H} 2 \mathrm{AX}$ phosphorylation upon Mdm2 knockdown in UV-irradiated U2OS cells (Kranz, Dohmesen et al. 2008).

Still, the question remains whether G2E3 plays a direct role in the DDR besides its levels being regulated in a DNA damage-responsive manner. So far, we have not identified an impact of G2E3 knockdown on the ATR-Chk1 and ATM-Chk2 pathway (Figure 5.4), two cascades that are induced upon cisplatin treatment. However, cisplatin treatment also activates the Fanconi anemia (FA) pathway. Many open questions remain as to how this pathway is functioning. Still, the key event is described as the mono-ubiquitination of the FANCD2-FANCl-complex (Ulrich and Walden 2010). This complex interacts with BRCA2 (FANCD1) and other repair enzymes. In order to check if G2E3 is involved in the FA pathway, mono-ubiquitination of FANCD2 and FANCl could be explored. Furthermore, ATM and ATR activate the p38-MK2 stress response pathway which could be affected by G2E3 knockdown. This can be investigated by exploring phospho-p38 and phospho-MK2 levels after G2E3 knockdown and cisplatin treatment. 


\subsection{A role of G2E3 in the p53-pathway?}

\subsubsection{Is G2E3 a new regulator of the p53-pathway?}

When investigating how G2E3 knockdown leads to a G1-arrest in U2OS cells (Figure 5.8), we found that the cell cycle regulators p53 and p21 were up-regulated upon G2E3 depletion (Figure 5.10). This finding led us to explore if G2E3 is involved in the p53-pathway. We got further hints in this direction when we observed that depletion of the p53-pathway regulators RBBP6 and STUB1 resulted in decreased $\mathrm{yH} 2 \mathrm{AX}$ levels after cisplatin treatment, similar to G2E3 knockdown (Figure 5.11). The ubiquitin ligase RBBP6 interacts with Mdm2 and enhances Mdm2-mediated ubiquitination and degradation of p53 due to increased p53Mdm2-affinity (Li, Deng et al. 2007). The authors report that RBBP6 knockdown attenuates the interaction of p53 and Mdm2 and reduces polyubiquitination of p53. This enhances p53 accumulation, promoting its pro-apoptotic function and repressive role in cell growth. Remarkably, RBBP6 knock-out mice show early embryonic lethality (Li, Deng et al. 2007) as it was also shown for G2E3 knock-out mice. Moreover, it was reported that RBBP6 interacts with p53 and RB (Simons, Melamed-Bessudo et al. 1997). On the other hand, STUB1 (or (HIP) is a chaperone-associated ubiquitin ligase which leads to poly-ubiquitination and proteasomal degradation of p53 (Esser, Scheffner et al. 2005). Since knockdown of Mdm2 also resulted in decreased $\mathrm{YH} 2 \mathrm{AX}$ levels upon cisplatin treatment (Figure 5.2), we were wondering whether G2E3 could be a new regulator of p53 (like CHIP) or of Mdm2 (like RBBP6). Further ubiquitin ligases and DUBs have been identified to affect the p53-pathway. For instance, Pirh2 has been shown to ubiquitinate p53, leading to its proteasomal degradation (Leng, Lin et al. 2003). Interestingly, regulation of p53 by ubiquitination does not only lead to its degradation. For example, Msl2 was reported to poly-ubiquitinate p53, resulting in nuclear export of p53 (Kruse and Gu 2009) and WWP1 was shown to stabilize p53 by ubiquitination, leading to p53 accumulation in the cytoplasm (Laine and Ronai 2007).

Thus, we posed the question whether G2E3 could be a newly identified regulator of the p53Mdm2 pathway.

\subsubsection{Do G2E3, Mdm2 and p53 interact?}

The ubiquitin system plays an important role in regulating p53 and Mdm2, with new ubiquitin ligases and DUBs being identified in the last years. This motivated us to investigate whether G2E3 affects both proteins. In the absence of a high quality antibody for G2E3, we coexpressed HA-tagged G2E3 together with Mdm2 or p53. We did not observe a co-localization of p53 and HA-G2E3, but found that co-expressed HA-G2E3 and Mdm2 co-localized and relocalized to subnuclear structures in untreated and cisplatin treated cells (Figure 5.12 and Figure 5.13). This observation suggested a possible complex formation of both proteins. Indeed, overexpressed HA-G2E3 and Mdm2 interacted as seen by co-immunoprecipitation (Figure 5.14 and Figure 5.15). Remarkably, we found that Mdm2 and p53 interacted 
independently of co-expressed HA-G2E3, and Mdm2 was bound to HA-G2E3 independently of co-expressed p53 (Figure 5.15). Furthermore, G2E3 was bound to p53 independently of co-expressed Mdm2 though the interaction was only weakly detectable (Figure 5.15). Thus, G2E3, Mdm2 and p53 might be found in a heterotrimeric complex. As an alternative, G2E3 could be bound by Mdm2, whereas p53 is bound to Mdm2 and only indirectly connected to G2E3 via Mdm2. In order to distinguish between these alternatives, ColPs with co-expressed HA-G2E3 and Mdm2 should be conducted in p53 null cells, e.g. H1299 cells. If G2E3 and Mdm2 still interact, binding would be independent of p53. On the other hand, an interaction of HA-G2E3 and p53 should be investigated in cells after Mdm2-knockdown to clarify whether both proteins are directly bound to each other. This experiment cannot be conducted in $\mathrm{Mdm}^{-/-}$cells, since those cells are not viable due to induction of p53-mediated apoptosis. Colocalization of HA-G2E3 and Mdm2 was shown in both untreated and cisplatin treated cells. Interaction of overexpressed HA-G2E3, Mdm2 and p53 was shown for untreated U2OS cells only, so ColPs upon cisplatin treatment should be performed to explore if the proteins interact also upon DNA damage. In order to identify the interacting domains of G2E3, Mdm2 and p53, ColPs could be performed with deletion mutants of these proteins (e.g. with deletion of the RING domain) to investigate if interaction still persists or not.

Still, we have to add that the ColPs were conducted with overexpressed proteins that do not reflect the in vivo situation. Thus, we were skeptical when we could not detect an endogenous interaction of G2E3 and Mdm2 independent of p53-status (Figure 5.16). This could be explained by extremely low levels of detectable endogenous G2E3, whereby endogenous G2E3 could also not be detected in input samples (Figure 5.16). Unfortunately, we were not provided with a high-quality G2E3 antibody. Another reason for low G2E3 levels could be that binding of G2E3 to Mdm2 (or p53) results in hiding of the epitope detected by the G2E3 antibody.

So far, we cannot prove an interaction of endogenous G2E3, Mdm2 and p53. Interaction of exogenous proteins should be interpreted cautiously since they sometimes do not withstand the in vivo situation. Hence, we were looking for functional consequences of this interaction. We tested whether co-expressed HA-G2E3 and Mdm2 affect each other's protein levels in untreated cells, which they did not (Figure 5.18). Additionally, overexpressed HA-G2E3 did neither affect Mdm2 nor p53 levels in cisplatin treated cells (Figure 5.19). In search of a biological significance, we examined whether G2E3 affects p53 transcriptional activity. We found that overexpressed G2E3 had no impact on p53 transcriptional activity or on Mdm2dependent inhibition of p53 transactivation (Figure 5.17).

Besides an impact on p53, interaction of G2E3 and Mdm2 could also have p53-independent consequences. For instance, Mdm2 was shown to positively regulate cell proliferation by stimulating the S-phase inducing transcription factor E2F1 (Martin, Trouche et al. 1995) and by inhibiting retinoblastoma protein (RB) (Xiao, Chen et al. 1995). Mdm2 promotes RB degradation in a proteasome-dependent, but ubiquitin-independent fashion (Sdek, Ying et al. 
2005). Furthermore, Mdm2 can antagonize the F-box protein SKP2 which targets E2F1 for degradation (Zhang, Wang et al. 2005). All these positive effects of Mdm2 on the E2F pathway are p53-independent. As G2E3 knockdown led to a decreased proliferation rate in p53-proficient and p53-deficient cell lines (Figure 5.7), it could be possible that G2E3 has an impact on Mdm2 in regulating proliferation. For example, G2E3 could be an agonist of Mdm2 which supports p53-independent functions of Mdm2 associated with cell proliferation. Hypothetically, depleting cells of G2E3 would eliminate the interaction of Mdm2 and G2E3 which potentially would inhibit cell proliferation. Thus, it should be investigated if G2E3 together with Mdm2 is a positive regulator of E2F1 activity. This could be tested by investigation of E2F1 activity and RB protein levels upon G2E3 knockdown. Furthermore, a luciferase reporter assay could be conducted by overexpressing G2E3 and detecting luciferase activity of a reporter construct harboring an E2F1-responsive promoter.

Since G2E3 is a nuclear protein, it makes sense to consider further ways of how G2E3 could affect p53-independent tasks of Mdm2 in the nucleus. Mdm2 was reported to interact with chromatin and chromatin-associated proteins independently of p53, thereby affecting gene expression and DNA repair. It can promote genetic instability and transformation by induction of chromosomal breaks and a delay in repair of DNA DSBs by interaction with Nbs1, a component of the MRN complex (Bouska, Lushnikova et al. 2008). The MRN complex is important in detection and processing of DSBs. So far, we do not have evidence that G2E3 is directly involved in DDR or repair. Still, as detailed above, three G2E3 domains possess similarity to PHD domains which in principle can bind methylated histones and have been shown to be involved in chromatin-mediated gene regulation (Musselman and Kutateladze 2011). Since it is not known whether G2E3 can bind chromatin, this could be tested by chromatin fractionation. If it does, it should be tested whether G2E3 is involved in regulation of Mdm2-dependent functions at the chromatin.

\subsection{Ubiquitin ligase activity of G2E3}

In search for a functional role of G2E3, we explored whether G2E3 can ubiquitinate and degrade Mdm2 or p53. As mentioned before, overexpressed HA-G2E3 did not affect Mdm2 and p53 levels in untreated and cisplatin treated cells (Figure 5.19) and co-expression of Mdm2 and HA-G2E3 did not influence their protein levels (Figure 5.18). In order to clarify in more detail whether G2E3 could ubiquitinate Mdm2 or p53, an in vitro ubiquitin assay could be performed, but the following issues should be thought of. G2E3 has already been described to have ubiquitin ligase activity using an in vitro ubiquitination assay and to catalyze Lys48-linked poly-ubiquitination, usually a signal for proteasomal degradation

(Brooks, Helton et al. 2008). Two of the four G2E3 domains (namely PHD/RING2 and PHD/RING3) were shown to have ubiquitin ligase activity. G2E3 harbors another PHD/RING1 and a HECT domain which were shown to exhibit no ubiquitin ligase activity in this assay. However, the authors tested only seven out of 35 known E2 ubiquitin-conjugating enzymes 
and cannot exclude that PHD/RING1 and HECT domain have in vivo ubiquitin ligase activity, perhaps with other E2 enzymes. Hence, for any in vitro ubiquitination assay, it should be taken into consideration that the $\mathrm{E} 2$ enzyme of G2E3 is not known yet, though high reactivity with the E2 enzyme UbcH5a has been detected (Brooks, Helton et al. 2008). Moreover, in vitro ubiquitination assays have been shown to be sometimes too far away from the in vivo situation since in these assays E3 ligases tend to ubiquitinate every substrate. Therefore, performing an in vitro ubiquitination assay with G2E3 might not be the most suitable approach.

The endogenous substrate(s) of G2E3 are not known. To identify G2E3 substrates, a mass spectrometric analysis could be conducted. In the past, identification of substrates of ubiquitin ligases has been proven difficult due to the diversity and high number of ubiquitinated proteins. Zhuang et al. have recently proposed a powerful tool to identify substrates (Zhuang, Guan et al. 2013). The authors were interested in finding substrates of inhibitors of apoptosis proteins (IAPS). For this purpose, they used the NEDDylator whereby a NEDD8 E2-conjugating enzyme (Ubc12) is fused to the ubiquitin ligase of interest, in their case XIAP or C-IAP1. NEDD8 is a rare ubiquitin homolog which then gets transferred to the E3 substrates. These proteins can be purified and examined by mass spectrometry. Using this technology, it would principally be possible to identify G2E3 substrates.

\subsection{A high-content siRNA screen to identify new regulators in the DDR to cisplatin}

Considering the importance of the ubiquitin system in the DDR and open questions in the response to cisplatin treatment, we performed a siRNA screen and depleted cells from human ubiquitin ligases and DUBs (Figure 5.1 and Figure 5.2). High-content siRNA screening had previously been shown to be a valuable method to identify new regulators in signaling pathways, for example in DDR and DNA repair (Higgins, Prevo et al. 2010; Cotta-Ramusino, McDonald et al. 2011).

Besides G2E3, we identified more candidates which have been shown to be involved in the DDR or p53-pathway. Identification of known regulators indicated that the developed screen procedure was suitable to identify new regulators of the DDR after cisplatin treatment.

We identified various genes that showed a strong decrease in H2AX phosphorylation upon knockdown. Interestingly, depletion of two proteasomal subunits, PSMD7 and PSMD14 (26S proteasome non-ATPase regulatory subunit 7 and 14) led to the strongest decrease in $\mathrm{YH} 2 \mathrm{AX}$ levels. The proteasomal de-ubiquitinating enzyme PSMD14 (also called POH1) had been shown to negatively regulate the RNF8-dependent response to DNA DSBS (Butler, Densham et al. 2012). Furthermore, knockdown of Mdm2 and knockdown of three regulators of the p53-Mdm2-pathway named Mdm4 (also called Mdmx), RBBP6 and STUB1 (also called CHIP) resulted in alleviated H2AX phosphorylation. RBBP6 and STUB1 have been described 
in more detail above. Mdmx is found as a heterodimer with Mdm2 and both proteins have sequence homology and a RING domain. Mdmx does not have ubiquitin ligase activity towards p53, but can repress p53 transactivation activity (Stad, Ramos et al. 2000).

We also found DUBs whose knockdown led to decreased $\mathrm{H} 2 \mathrm{AX}$ phosphorylation. Interestingly, one of them, ATXN3 (or Ataxin-3) is involved in STUB1/CHIP regulation by deubiquitinating STUB1-substrates and STUB1 itself (Scaglione, Zavodszky et al. 2011). Another identified deubiquitinating enzyme, USP1 (ubiquitin-specific protease 1), is a negative regulator of DNA damage repair which specifically deubiquitinates FANCD2, a protein involved in the Fanconi anemia pathway (Nijman, Huang et al. 2005). USP1 is also involved in translesion synthesis (TLS) since it deubiquitinates PCNA (Huang, Nijman et al. 2006). We identified two more DUBs, BAP1 and USP42, whose knockdown leads to decreased $\mathrm{H} 2 \mathrm{AX}$ phosphorylation. BAP1 was reported to interfere with BRCA1 (Jensen, Proctor et al. 1998) and to regulate H2A ubiquitination (Scheuermann, de Ayala Alonso et al. 2010). USP42 was reported to interact and deubiquitinate p53 (Hock, Vigneron et al. 2011). The authors show that USP42 function is needed for induction of p53-dependent transcription and cell cycle arrest under stress. Apart from these candidates, we identified a number of genes whose knockdown affects the DDR after cisplatin treatment and which would be interesting to investigate further.

Unexpectedly, we identified only a small number of genes with a strong increase in $\mathrm{yH} 2 \mathrm{AX}$ fluorescence intensity upon knockdown. These could have been candidates whose inhibition sensitizes cells to cisplatin. Two of the candidates with the strongest increase in $\mathrm{H} 2 \mathrm{AX}$ phosphorylation upon knockdown were RFWD2 and RFWD3 (RING finger and WD repeat domain protein 2 and 3). RFWD2 is also called COP1 and represents a negative regulator of p53 since it targets p53 for proteasomal degradation, independently of Mdm2 (Dornan, Wertz et al. 2004). Furthermore, the authors show that knockdown of COP1 sensitized U2OS cells to cell death induced by ionizing radiation. In contrast, RFWD3 is a positive regulator of p53 which mediates ubiquitination and stabilization of p53 in response to DNA damage (Fu, Yucer et al. 2010). Moreover, it is involved at stalled replication forks and ATR-dependent activation of Chk1 in response to replicative stress (Gong and Chen 2011).

Together, these results of known regulators of the DDR and p53-pathway show that the screen is suitable to identify so far unknown proteins in the response to cisplatin. Thus, the data should be further analyzed and other candidates should be characterized for their role and function in the cell, especially after cisplatin treatment. It has to be added that at the time of siRNA library preparation in 2008, less ubiquitin ligases were described than today (327 versus more than 600 in 2013). Hence, even more regulators of the DDR could exist which could be identified in different screens and systems.

Remarkably, we did not only identify proteins involved in the DDR and p53-pathway, but also regulators of apoptosis and cell cycle. This suggests that new candidates could furthermore be investigated for their role in this respect. For example, USP39 has been reported to be 
involved in mitotic progression and cytokinesis (van Leuken, Luna-Vargas et al. 2008) and TRIM17-mediated ubiquitination can initiate apoptosis (Magiera, Mora et al. 2013). Furthermore, we found several proteins connected to the endoplasmic reticulum (ER). It has been previously demonstrated that cisplatin does not only induce the DDR, but also the ER stress pathway (Mandic, Hansson et al. 2003). This is reasonable since cisplatin does not only react with DNA, but also with other nucleophilic molecules. Mandic et al. showed in enucleated cells (so-called cytoplasts, with removed nucleus) that cisplatin induces DNA damage-independent apoptosis by activating the ER-specific caspase 12, leading to activation of caspase 3 and further executioner caspases. Thus, activation of the ER stress response is a secondary mechanism to explain cytotoxic effects of cisplatin treatment. We found that knockdown of the two ER membrane-associated proteins RNF13 and ZNRF4 led to decreased $\mathrm{YH} 2 \mathrm{AX}$ levels. These two RING finger proteins have only recently been explored. RNF13 was shown to mediate ER stress-induced apoptosis (Arshad, Ye et al. 2013) and was reported to be overexpressed in pancreatic cancer (Zhang, Meng et al. 2009). ZNRF4 plays a role in ER homeostasis and regulates the stability of the ER-associated chaperone calnexin (Neutzner, Neutzner et al. 2011). Further research is necessary to understand the details of the ER stress response and how induced apoptosis is connected to phosphorylation of $\mathrm{H} 2 \mathrm{AX}$.

\subsection{Conclusions and future perspectives}

We performed a high-content siRNA screen targeting human ubiquitin ligases and deubiquitinating enzymes to identify new regulators in the DDR to cisplatin. Thereby, we identified several genes whose knockdown modulates phosphorylation of H2AX. Further studies of candidates from our screen could give insights into the cellular response to cisplatin treatment. Knockdown of one of the candidates, the ubiquitin ligase G2E3, led to decrease in $\mathrm{YH} 2 \mathrm{AX}$ levels. We studied the protein in more detail and found that G2E3 mRNA and protein levels are down-regulated upon DNA damage. Knockdown of G2E3 resulted in p53-independent apoptosis and decreased proliferation in colon carcinoma and osteosarcoma cell lines. Furthermore, we verified that G2E3 levels are maximal in G2-phase, suggesting a cell cycle-dependent regulation of G2E3. Depletion of G2E3 resulted in decreased Mdm2 protein levels after cisplatin treatment independently of the p53-status. This result suggests that G2E3 regulates Mdm2 levels independently of $\mathrm{p53}$, the principal transcription factor for Mdm2 expression. In summary, our results suggest that G2E3 is required for cell proliferation and survival. DNA damage induces a strong down-regulation of G2E3 levels, possibly contributing to apoptosis. One of the mechanisms by that G2E3 ensures cell survival could consist in the maintenance of Mdm2 levels.

In the future, increasing knowledge about proteins like G2E3 that regulate DDR, cell survival and cell cycle could lead us to new ways of cancer therapy. For instance, it would be beneficial to develop therapeutics that specifically target components of the DDR that are 
involved in ubiquitination events. These specific agents could have advantages like decreased toxicity compared to general drugs. That ubiquitination events are interesting therapeutic targets has already been shown by the proteasome inhibitor Bortezomib (marketed as Velcade). It is approved in the United States for treatment of multiple myeloma and mantle cell lymphoma (Voorhees, Dees et al. 2003; Adams and Kauffman 2004). Besides therapeutic approaches, ubiquitination could be explored for diagnostic purposes, and not only for treatment of cancer, but also of other illnesses. Numerous diseases are associated with defects in the DDR, accumulated DNA damage or impact on genome stability, like neurodegenerative disorders, immune-deficiencies and age-related diseases (Jackson and Bartek 2009).

Platinating agents like cisplatin as well as other chemotherapeutics are limited from reaching their full potential due to resistance mechanisms and toxicities. It was reported for several cancer types that patients respond initially well to cisplatin therapy, but that the relapse rate is high. Examples include treatment of small cell lung carcinomas with a relapse rate of $95 \%$ (Rabik and Dolan 2007). Another example is treatment of head and neck cancers for which cisplatin is the first-line therapy. Here, the response rate is only 20-30 \% (Jacobs, Lyman et al. 1992). Reasons for resistance towards cisplatin include increased efflux or decreased influx, detoxification mechanisms (e.g. by glutathione), increased DNA repair (e.g. through activation of NER, MMR, and/or HR pathways) and bypassing lesions during replication - or a combination of these processes (Rabik and Dolan 2007). Thus, it is of great interest to improve cisplatin therapy, by overcoming resistance or by decreasing toxicity. Since resistance mechanisms include increased DNA repair, it is one aim of research to better understand the DDR and repair pathways upon cisplatin treatment. Enzymes involved in these pathways are potentially new therapeutic targets. We hope that with more research on proteins identified in our screen, increased knowledge of signaling could one day lead to improvements in therapy, for example by applying a combination therapy of cisplatin with a specific inhibitor involved in the DDR or repair pathway.

Proteins like G2E3 that modulate different cellular responses to DNA damage are interesting therapeutic targets for cancer therapy. P53 is another good example for a protein involved in multiple responses, for example in apoptosis and cell cycle arrest. Research in the last decades has focused on elucidating the pathways up- and downstream of p53 function for a better understanding of tumorigenesis and in order to manipulate p53 for therapeutic approaches. Since p53 function is abrogated in more than $50 \%$ of human tumors (Hollstein, Sidransky et al. 1991), it is of great importance to understand the pathways involved in p53independent apoptosis. These pathways could represent important targets for cancer cells with inactivated p53. Thus, we propose to investigate in more detail how loss or downregulation of G2E3 leads to p53-independent apoptosis. 
We were interested if G2E3 could potentially play a role in cancer. Using the GeneSapiens database (for details see section 3.13), we explored G2E3 expression in healthy and cancerous tissue. GeneSapiens is the world's largest human gene expression data source. It contains information from healthy and malignant tissue types as well as tissue from nontumor diseases and includes information of tissue of origin and cancer type (Kilpinen, Autio et al. 2008). According to the database, G2E3 expression is substantially increased in testicular cancer, especially in seminoma, a germ cell tumor of the testis. Interestingly, high G2E3 expression is also found in healthy testis tissue. Furthermore, G2E3 expression is enhanced in ovarian germ cell tumors and ovarian adenocarcinoma. Our data presented here suggest that high G2E3 expression in these tumors could protect cancer cells from apoptosis. Seminoma is a well treatable and curable testicular cancer type. Since cisplatin is used to treat testicular cancer, it could be possible that cisplatin treatment of a testicular tumor with high G2E3 levels leads to down-regulation of G2E3 and induction of apoptosis. This could be tested in samples from cancer patients before and after cisplatin treatment by immunohistochemical staining of G2E3 and apoptosis markers. Brooks et al. investigated protein expression in adult heterozygous G2E3 mice using $\beta$-galactosidase as a marker under the control of the endogenous G2E3 promoter (Brooks, Helton et al. 2008). Remarkably, the authors found enriched $\beta$-galactosidase expression in brain (Purkinje cells of the cerebellum) and testis (interstitial cells and cells lining the ductus deferens). This observation of high expression of G2E3 in mice testis is consistent with human samples investigated in the GeneSapiens database. We tested several testis cancer cell lines (germ cell tumor cell lines GH and NCCIT, teratocarcinoma cell lines Tera2 and 833K), but could not observe higher G2E3 levels in this selection. More testicular cancer cell lines should be tested for G2E3 levels. Using a cell line with increased G2E3 expression would be of advantage to investigate endogenous G2E3 levels and effects of DNA damage. Also, G2E3 could be evaluated as a diagnostic or therapeutic marker of chemotherapeutic treatment. The fact that down-regulation of G2E3 leads to induction of apoptosis constitutes an interesting mechanism that should be further investigated as a potential therapeutic target. 


\section{References}

Abrous, D. N., M. Koehl, et al. (2005). "Adult neurogenesis: from precursors to network and physiology." Physiol Rev 85(2): 523-569.

Adams, J. and M. Kauffman (2004). "Development of the proteasome inhibitor Velcade (Bortezomib)." Cancer Invest 22(2): 304-311.

Agami, R. and R. Bernards (2000). "Distinct initiation and maintenance mechanisms cooperate to induce G1 cell cycle arrest in response to DNA damage." Cell 102(1): 55-66.

Alderden, R., M. Hall, et al. (2006). "The discovery and development of cisplatin." Journal of chemical ....

Arshad, M., Z. Ye, et al. (2013). "RNF13, a RING finger protein, mediates endoplasmic reticulum stress-induced apoptosis through the inositol-requiring enzyme (IRE1alpha)/c-Jun NH2-terminal kinase pathway." J Biol Chem 288(12): 8726-8736.

Barak, Y., E. Gottlieb, et al. (1994). "Regulation of mdm2 expression by p53: alternative promoters produce transcripts with nonidentical translation potential." Genes \& development 8.

Barak, Y., T. Juven, et al. (1993). "mdm2 expression is induced by wild type p53 activity." Embo J 12(2): 461-468.

Bartek, J. and J. Lukas (2003). "Chk1 and Chk2 kinases in checkpoint control and cancer." Cancer cell 3(5): 421-429.

Bartel, F., H. Taubert, et al. (2002). "Alternative and aberrant splicing of MDM2 mRNA in human cancer." Cancer cell 2(1): 9-15.

Beck, H., V. Nahse, et al. (2010). "Regulators of cyclin-dependent kinases are crucial for maintaining genome integrity in S phase." J Cell Biol 188(5): 629-638.

Bergink, S. and S. Jentsch (2009). "Principles of ubiquitin and SUMO modifications in DNA repair." Nature 458(7237): 461-467.

Bewersdorf, J., B. T. Bennett, et al. (2006). "H2AX chromatin structures and their response to DNA damage revealed by 4Pi microscopy." Proc Natl Acad Sci U S A 103(48): 1813718142.

Birmingham, A., L. Selfors, et al. (2009). "Statistical methods for analysis of high-throughput RNA interference screens." Nat Methods 6(8): 569-575.

Bittner, M., P. Kupferer, et al. (1980). "Electrophoretic transfer of proteins and nucleic acids from slab gels to diazobenzyloxymethyl cellulose or nitrocellulose sheets." Anal Biochem 102(2): 459-471.

Bouska, A., T. Lushnikova, et al. (2008). "Mdm2 promotes genetic instability and transformation independent of p53." Mol Cell Biol 28(15): 4862-4874.

Brandeis, M., I. Rosewell, et al. (1998). "Cyclin B2-null mice develop normally and are fertile whereas cyclin B1-null mice die in utero." Proc Natl Acad Sci U S A 95(8): 4344-4349.

Brooks, W., S. Banerjee, et al. (2007). "G2E3 is a nucleo-cytoplasmic shuttling protein with DNA damage responsive localization." Experimental cell research 313(4): 665-676.

Brooks, W., E. Helton, et al. (2008). "G2E3 is a dual function ubiquitin ligase required for early embryonic development." The Journal of biological chemistry 283(32): 22304-22315.

Brown, E. J. and D. Baltimore (2000). "ATR disruption leads to chromosomal fragmentation and early embryonic lethality." Genes Dev 14(4): 397-402.

Brugarolas, J., C. Chandrasekaran, et al. (1995). "Radiation-induced cell cycle arrest compromised by p21 deficiency." Nature 377(6549): 552-557.

Bunz, F. (1998). "Requirement for p53 and p21 to Sustain G2 Arrest After DNA Damage." Science 282. 
Burma, S., B. P. Chen, et al. (2001). "ATM phosphorylates histone H2AX in response to DNA double-strand breaks." J Biol Chem 276(45): 42462-42467.

Butler, L. R., R. M. Densham, et al. (2012). "The proteasomal de-ubiquitinating enzyme $\mathrm{POH} 1$ promotes the double-strand DNA break response." Embo J 31(19): 3918-3934.

Carvajal, L. A., P. J. Hamard, et al. (2012). "E2F7, a novel target, is up-regulated by p53 and mediates DNA damage-dependent transcriptional repression." Genes Dev 26(14): 1533-1545.

Chan, T. A., H. Hermeking, et al. (1999). "14-3-3Sigma is required to prevent mitotic catastrophe after DNA damage." Nature 401(6753): 616-620.

Chaturvedi, P., W. K. Eng, et al. (1999). "Mammalian Chk2 is a downstream effector of the ATM-dependent DNA damage checkpoint pathway." Oncogene 18(28): 4047-4054.

Chehab, N. H., A. Malikzay, et al. (2000). "Chk2/hCds1 functions as a DNA damage checkpoint in $\mathrm{G}(1)$ by stabilizing p53." Genes Dev 14(3): 278-288.

Chehab, N. H., A. Malikzay, et al. (1999). "Phosphorylation of Ser-20 mediates stabilization of human p53 in response to DNA damage." Proc Natl Acad Sci U S A 96(24): 1377713782.

Chen, C. Y., J. D. Oliner, et al. (1994). "Interactions between p53 and MDM2 in a mammalian cell cycle checkpoint pathway." Proc Natl Acad Sci U S A 91(7): 2684-2688.

Chen, L., W. Lu, et al. (1999). "Ubiquitous induction of p53 in tumor cells by antisense inhibition of MDM2 expression." Mol Med 5(1): 21-34.

Chen, L., V. Marechal, et al. (1997). "Proteolytic cleavage of the mdm2 oncoprotein during apoptosis." J Biol Chem 272(36): 22966-22973.

Cheng, T. H. and S. N. Cohen (2007). "Human MDM2 isoforms translated differentially on constitutive versus p53-regulated transcripts have distinct functions in the p53/MDM2 and TSG101/MDM2 feedback control loops." Mol Cell Biol 27(1): 111-119.

Chipuk, J. E., T. Kuwana, et al. (2004). "Direct activation of Bax by p53 mediates mitochondrial membrane permeabilization and apoptosis." Science 303(5660): 10101014.

Choi, Y. E., M. Butterworth, et al. (2009). "The E3 ubiquitin ligase clAP1 binds and ubiquitinates caspase-3 and -7 via unique mechanisms at distinct steps in their processing." J Biol Chem 284(19): 12772-12782.

Chomczynski, P. and N. Sacchi (1987). "Single-step method of RNA isolation by acid guanidinium thiocyanate-phenol-chloroform extraction." Anal Biochem 162(1): 156159.

Chow, S. C., M. Weis, et al. (1995). "Involvement of multiple proteases during Fas-mediated apoptosis in T lymphocytes." FEBS Lett 364(2): 134-138.

Chowdhury, D., M. C. Keogh, et al. (2005). "gamma-H2AX dephosphorylation by protein phosphatase 2A facilitates DNA double-strand break repair." Mol Cell 20(5): 801-809.

Ciccia, A., C. Ling, et al. (2007). "Identification of FAAP24, a Fanconi anemia core complex protein that interacts with FANCM." Mol Cell 25(3): 331-343.

Conze, D. B., L. Albert, et al. (2005). "Posttranscriptional downregulation of C-IAP2 by the ubiquitin protein ligase c-IAP1 in vivo." Mol Cell Biol 25(8): 3348-3356.

Cook, P. J., B. G. Ju, et al. (2009). "Tyrosine dephosphorylation of H2AX modulates apoptosis and survival decisions." Nature 458(7238): 591-596.

Cortez, D., S. Guntuku, et al. (2001). "ATR and ATRIP: partners in checkpoint signaling." Science 294(5547): 1713-1716.

Cortez, D., Y. Wang, et al. (1999). "Requirement of ATM-dependent phosphorylation of brca1 in the DNA damage response to double-strand breaks." Science 286(5442): 11621166.

Cotta-Ramusino, C., E. McDonald, et al. (2011). "A DNA damage response screen identifies RHINO, a 9-1-1 and TopBP1 interacting protein required for ATR signaling." Science (New York, N.Y.) 332(6035): 1313-1317. 
Crawford, D. and H. Piwnica-Worms (2001). "The G(2) DNA damage checkpoint delays expression of genes encoding mitotic regulators." The Journal of biological chemistry 276(40): 37166-37177.

Cummins, J. M., C. Rago, et al. (2004). "Tumour suppression: disruption of HAUSP gene stabilizes p53." Nature 428(6982): 1 p following 486.

De Bont, R. and N. van Larebeke (2004). "Endogenous DNA damage in humans: a review of quantitative data." Mutagenesis 19(3): 169-185.

Deshaies, R. J. and C. A. Joazeiro (2009). "RING domain E3 ubiquitin ligases." Annu Rev Biochem 78: 399-434.

Dikic, I., S. Wakatsuki, et al. (2009). "Ubiquitin-binding domains - from structures to functions." Nature reviews. Molecular cell biology 10(10): 659-671.

Doil, C., N. Mailand, et al. (2009). "RNF168 binds and amplifies ubiquitin conjugates on damaged chromosomes to allow accumulation of repair proteins." Cell 136(3): 435446.

Dong, Y., M. A. Hakimi, et al. (2003). "Regulation of BRCC, a holoenzyme complex containing BRCA1 and BRCA2, by a signalosome-like subunit and its role in DNA repair." Mol Cell 12(5): 1087-1099.

Dornan, D., I. Wertz, et al. (2004). "The ubiquitin ligase COP1 is a critical negative regulator of p53." Nature 429(6987): 86-92.

el-Deiry, W. S., T. Tokino, et al. (1993). "WAF1, a potential mediator of p53 tumor suppression." Cell 75(4): 817-825.

Elson, A., Y. Wang, et al. (1996). "Pleiotropic defects in ataxia-telangiectasia protein-deficient mice." Proc Natl Acad Sci U S A 93(23): 13084-13089.

Erhardt, P., K. J. Tomaselli, et al. (1997). "Identification of the MDM2 oncoprotein as a substrate for CPP32-like apoptotic proteases." J Biol Chem 272(24): 15049-15052.

Esser, C., M. Scheffner, et al. (2005). "The chaperone-associated ubiquitin ligase CHIP is able to target p53 for proteasomal degradation." J Biol Chem 280(29): 27443-27448.

Falck, J., N. Mailand, et al. (2001). "The ATM-Chk2-Cdc25A checkpoint pathway guards against radioresistant DNA synthesis." Nature 410(6830): 842-847.

Fang, S., J. Jensen, et al. (2000). "Mdm2 is a RING finger-dependent ubiquitin protein ligase for itself and p53." The Journal of biological chemistry 275(12): 8945-8951.

Fernandez-Capetillo, O., A. Lee, et al. (2004). "H2AX: the histone guardian of the genome." DNA repair 3(8-9): 959-967.

Fink, D., S. Nebel, et al. (1996). "The role of DNA mismatch repair in platinum drug resistance." Cancer Res 56(21): 4881-4886.

$\mathrm{Fu}, \mathrm{X}$., N. Yucer, et al. (2010). "RFWD3-Mdm2 ubiquitin ligase complex positively regulates p53 stability in response to DNA damage." Proc Natl Acad Sci U S A 107(10): 45794584.

Fujimoto, H., N. Onishi, et al. (2006). "Regulation of the antioncogenic Chk2 kinase by the oncogenic Wip1 phosphatase." Cell Death Differ 13(7): 1170-1180.

Furnari, B., N. Rhind, et al. (1997). "Cdc25 mitotic inducer targeted by chk1 DNA damage checkpoint kinase." Science 277(5331): 1495-1497.

Gallegos, J. R., J. Litersky, et al. (2008). "SCF TrCP1 activates and ubiquitylates TAp63gamma." J Biol Chem 283(1): 66-75.

Gatei, M., S. P. Scott, et al. (2000). "Role for ATM in DNA damage-induced phosphorylation of BRCA1." Cancer Res 60(12): 3299-3304.

Gatei, M., D. Young, et al. (2000). "ATM-dependent phosphorylation of nibrin in response to radiation exposure." Nat Genet 25(1): 115-119.

Girnita, L., A. Girnita, et al. (2003). "Mdm2-dependent ubiquitination and degradation of the insulin-like growth factor 1 receptor." Proc Natl Acad Sci U S A 100(14): 8247-8252.

Gong, J. G., A. Costanzo, et al. (1999). "The tyrosine kinase c-Abl regulates p73 in apoptotic response to cisplatin-induced DNA damage." Nature 399(6738): 806-809. 
Gong, Z. and J. Chen (2011). "E3 ligase RFWD3 participates in replication checkpoint control." J Biol Chem 286(25): 22308-22313.

Gorgoulis, V. G., L. V. Vassiliou, et al. (2005). "Activation of the DNA damage checkpoint and genomic instability in human precancerous lesions." Nature 434(7035): 907-913.

Gottifredi, V., K. McKinney, et al. (2004). "Decreased p21 levels are required for efficient restart of DNA synthesis after S phase block." J Biol Chem 279(7): 5802-5810.

Gu, L., N. Zhu, et al. (2009). "Regulation of XIAP translation and induction by MDM2 following irradiation." Cancer cell 15(5): 363-375.

Hamanaka, R., M. R. Smith, et al. (1995). "Polo-like kinase is a cell cycle-regulated kinase activated during mitosis." J Biol Chem 270(36): 21086-21091.

Harper, J. W., G. R. Adami, et al. (1993). "The p21 Cdk-interacting protein Cip1 is a potent inhibitor of G1 cyclin-dependent kinases." Cell 75(4): 805-816.

Haupt, Y., R. Maya, et al. (1997). "Mdm2 promotes the rapid degradation of p53." Nature 387(6630): 296-299.

Helleday, T., E. Petermann, et al. (2008). "DNA repair pathways as targets for cancer therapy." Nature reviews. Cancer 8(3): 193-204.

Higgins, G. S., R. Prevo, et al. (2010). "A small interfering RNA screen of genes involved in DNA repair identifies tumor-specific radiosensitization by POLQ knockdown." Cancer Res 70(7): 2984-2993.

Hirao, A., Y. Y. Kong, et al. (2000). "DNA damage-induced activation of p53 by the checkpoint kinase Chk2." Science 287(5459): 1824-1827.

Ho, T. V. and O. D. Scharer (2010). "Translesion DNA synthesis polymerases in DNA interstrand crosslink repair." Environ Mol Mutagen 51(6): 552-566.

Hochegger, H., D. Dejsuphong, et al. (2007). "An essential role for Cdk1 in S phase control is revealed via chemical genetics in vertebrate cells." J Cell Biol 178(2): 257-268.

Hock, A., A. Vigneron, et al. (2011). "Regulation of p53 stability and function by the deubiquitinating enzyme USP42." The EMBO journal 30(24): 4921-4930.

Hock, A. K., A. M. Vigneron, et al. (2011). "Regulation of p53 stability and function by the deubiquitinating enzyme USP42." Embo J 30(24): 4921-4930.

Hollstein, M., D. Sidransky, et al. (1991). "p53 mutations in human cancers." Science 253(5015): 49-53.

Honda, R. and H. Yasuda (1999). "Association of p19(ARF) with Mdm2 inhibits ubiquitin ligase activity of Mdm2 for tumor suppressor p53." Embo J 18(1): 22-27.

Honda, R. and H. Yasuda (2000). "Activity of MDM2, a ubiquitin ligase, toward p53 or itself is dependent on the RING finger domain of the ligase." Oncogene 19(11): 1473-1476.

Horn, H. F. and K. H. Vousden (2007). "Coping with stress: multiple ways to activate p53." Oncogene 26(9): 1306-1316.

Hornbeck, P. V., J. M. Kornhauser, et al. (2012). "PhosphoSitePlus: a comprehensive resource for investigating the structure and function of experimentally determined post-translational modifications in man and mouse." Nucleic Acids Res 40(Database issue): D261-270.

Huang, J. C., D. B. Zamble, et al. (1994). "HMG-domain proteins specifically inhibit the repair of the major DNA adduct of the anticancer drug cisplatin by human excision nuclease." Proc Natl Acad Sci U S A 91(22): 10394-10398.

Huang, T. T., S. M. Nijman, et al. (2006). "Regulation of monoubiquitinated PCNA by DUB autocleavage." Nat Cell Biol 8(4): 339-347.

Huarte, M., M. Guttman, et al. (2010). "A large intergenic noncoding RNA induced by p53 mediates global gene repression in the p53 response." Cell 142(3): 409-419.

Huen, M., R. Grant, et al. (2007). "RNF8 transduces the DNA-damage signal via histone ubiquitylation and checkpoint protein assembly." Cell 131(5): 901-914.

Huen, M., S. Sy, et al. (2010). "BRCA1 and its toolbox for the maintenance of genome integrity." Nature reviews. Molecular cell biology 11(2): 138-148. 
Huibregtse, J. M., M. Scheffner, et al. (1991). "A cellular protein mediates association of p53 with the E6 oncoprotein of human papillomavirus types 16 or 18." Embo J 10(13): 4129-4135.

Inuzuka, H., A. Tseng, et al. (2010). "Phosphorylation by casein kinase I promotes the turnover of the Mdm2 oncoprotein via the SCF(beta-TRCP) ubiquitin ligase." Cancer cell 18(2): 147-159.

Irwin, M. S., K. Kondo, et al. (2003). "Chemosensitivity linked to p73 function." Cancer cell 3(4): 403-410.

Itahana, K., H. Mao, et al. (2007). "Targeted inactivation of Mdm2 RING finger E3 ubiquitin ligase activity in the mouse reveals mechanistic insights into p53 regulation." Cancer cell 12(4): 355-366.

Jackson, S. and J. Bartek (2009). "The DNA-damage response in human biology and disease." Nature 461(7267): 1071-1078.

Jackson, S. P. and D. Durocher (2013). "Regulation of DNA damage responses by ubiquitin and SUMO." Mol Cell 49(5): 795-807.

Jacobs, C., G. Lyman, et al. (1992). "A phase III randomized study comparing cisplatin and fluorouracil as single agents and in combination for advanced squamous cell carcinoma of the head and neck." J Clin Oncol 10(2): 257-263.

Jensen, D. E., M. Proctor, et al. (1998). "BAP1: a novel ubiquitin hydrolase which binds to the BRCA1 RING finger and enhances BRCA1-mediated cell growth suppression." Oncogene 16(9): 1097-1112.

Jin, Y., S. X. Zeng, et al. (2004). "MDM2 mediates p300/CREB-binding protein-associated factor ubiquitination and degradation." J Biol Chem 279(19): 20035-20043.

Jones, S. N., A. E. Roe, et al. (1995). "Rescue of embryonic lethality in Mdm2-deficient mice by absence of p53." Nature 378(6553): 206-208.

Jost, C. A., M. C. Marin, et al. (1997). "p73 is a simian [correction of human] p53-related protein that can induce apoptosis." Nature 389(6647): 191-194.

Juven, T., Y. Barak, et al. (1993). "Wild type p53 can mediate sequence-specific transactivation of an internal promoter within the mdm2 gene." Oncogene 8(12): 34113416.

Kastan, M. and J. Bartek (2004). "Cell-cycle checkpoints and cancer." Nature 432(7015): 316323.

Kaufmann, S. H., S. Desnoyers, et al. (1993). "Specific proteolytic cleavage of poly(ADPribose) polymerase: an early marker of chemotherapy-induced apoptosis." Cancer Res 53(17): 3976-3985.

Kern, S. E., J. A. Pietenpol, et al. (1992). "Oncogenic forms of p53 inhibit p53-regulated gene expression." Science 256(5058): 827-830.

Khosravi, R., R. Maya, et al. (1999). "Rapid ATM-dependent phosphorylation of MDM2 precedes p53 accumulation in response to DNA damage." Proc Natl Acad Sci U S A 96(26): 14973-14977.

Kilpinen, S., R. Autio, et al. (2008). "Systematic bioinformatic analysis of expression levels of 17,330 human genes across 9,783 samples from 175 types of healthy and pathological tissues." Genome Biol 9(9): R139.

Kimura, I. (1978). "Clinical investigations of neocarzinostatin in Japan." Recent Results Cancer Res 63: 252-260.

Kinzler, K. W. and B. Vogelstein (1997). "Cancer-susceptibility genes. Gatekeepers and caretakers." Nature 386(6627): 761, 763.

Koida, N., T. Ozaki, et al. (2008). "Inhibitory role of Plk1 in the regulation of p73-dependent apoptosis through physical interaction and phosphorylation." J Biol Chem 283(13): 8555-8563.

Kolas, N., J. Chapman, et al. (2007). "Orchestration of the DNA-damage response by the RNF8 ubiquitin ligase." Science (New York, N.Y.) 318(5856): 1637-1640. 
Komander, D. and M. Rape (2012). "The ubiquitin code." Annu Rev Biochem 81: 203-229.

Kranz, D., C. Dohmesen, et al. (2008). "BRCA1 and Tip60 determine the cellular response to ultraviolet irradiation through distinct pathways." J Cell Biol 182(1): 197-213.

Krishan, A. (1975). "Rapid flow cytofluorometric analysis of mammalian cell cycle by propidium iodide staining." J Cell Biol 66(1): 188-193.

Kruse, J. P. and W. Gu (2009). "MSL2 promotes Mdm2-independent cytoplasmic localization of p53." J Biol Chem 284(5): 3250-3263.

Kubbutat, M. H., S. N. Jones, et al. (1997). "Regulation of p53 stability by Mdm2." Nature 387(6630): 299-303.

Kussie, P. H., S. Gorina, et al. (1996). "Structure of the MDM2 oncoprotein bound to the p53 tumor suppressor transactivation domain." Science 274(5289): 948-953.

Kuwana, T., L. Bouchier-Hayes, et al. (2005). "BH3 domains of BH3-only proteins differentially regulate Bax-mediated mitochondrial membrane permeabilization both directly and indirectly." Mol Cell 17(4): 525-535.

Laemmli, U. K. (1970). "Cleavage of structural proteins during the assembly of the head of bacteriophage T4." Nature 227(5259): 680-685.

Laine, A. and Z. Ronai (2007). "Regulation of p53 localization and transcription by the HECT domain E3 ligase WWP1." Oncogene 26(10): 1477-1483.

Landers, J. E., S. L. Cassel, et al. (1997). "Translational enhancement of mdm2 oncogene expression in human tumor cells containing a stabilized wild-type p53 protein." Cancer Res 57(16): 3562-3568.

Lavin, M. and N. Gueven (2006). "The complexity of p53 stabilization and activation." Cell death and differentiation 13(6): 941-950.

Lazebnik, Y. A., S. H. Kaufmann, et al. (1994). "Cleavage of poly(ADP-ribose) polymerase by a proteinase with properties like ICE." Nature 371(6495): 346-347.

Lee, D. H. and A. L. Goldberg (1998). "Proteasome inhibitors: valuable new tools for cell biologists." Trends Cell Biol 8(10): 397-403.

Lee, J. and W. Gu (2010). "The multiple levels of regulation by p53 ubiquitination." Cell death and differentiation 17(1): 86-92.

Lee, K. S., Y. L. Yuan, et al. (1995). "Plk is an M-phase-specific protein kinase and interacts with a kinesin-like protein, CHO1/MKLP-1." Mol Cell Biol 15(12): 7143-7151.

Leng, R. P., Y. Lin, et al. (2003). "Pirh2, a p53-induced ubiquitin-protein ligase, promotes p53 degradation." Cell 112(6): 779-791.

Letai, A., M. C. Bassik, et al. (2002). "Distinct BH3 domains either sensitize or activate mitochondrial apoptosis, serving as prototype cancer therapeutics." Cancer Cell 2(3): 183-192.

Li, L., B. Deng, et al. (2007). "PACT is a negative regulator of p53 and essential for cell growth and embryonic development." Proc Natl Acad Sci U S A 104(19): 7951-7956.

Li, M., C. L. Brooks, et al. (2004). "A dynamic role of HAUSP in the p53-Mdm2 pathway." Mol Cell 13(6): 879-886.

Li, M., C. L. Brooks, et al. (2003). "Mono- versus polyubiquitination: differential control of p53 fate by Mdm2." Science 302(5652): 1972-1975.

Li, M., D. Chen, et al. (2002). "Deubiquitination of p53 by HAUSP is an important pathway for p53 stabilization." Nature 416(6881): 648-653.

$\mathrm{Li}, \mathrm{T}$., A. Inoue, et al. (2004). "Failure to proliferate and mitotic arrest of CDK11(p110/p58)null mutant mice at the blastocyst stage of embryonic cell development." Mol Cell Biol 24(8): 3188-3197.

Lin, J., J. Chen, et al. (1994). "Several hydrophobic amino acids in the p53 amino-terminal domain are required for transcriptional activation, binding to $\mathrm{mdm}-2$ and the adenovirus 5 E1B 55-kD protein." Genes Dev 8(10): 1235-1246. 
Liu, C. Y., A. Flesken-Nikitin, et al. (1996). "Inactivation of the mouse Brca1 gene leads to failure in the morphogenesis of the egg cylinder in early postimplantation development." Genes Dev 10(14): 1835-1843.

Liu, Q., S. Guntuku, et al. (2000). "Chk1 is an essential kinase that is regulated by Atr and required for the G(2)/M DNA damage checkpoint." Genes Dev 14(12): 1448-1459.

Livak, K. J. and T. D. Schmittgen (2001). "Analysis of relative gene expression data using real-time quantitative PCR and the 2(-Delta Delta C(T)) Method." Methods 25(4): 402408.

Lohrum, M. A., D. B. Woods, et al. (2001). "C-terminal ubiquitination of p53 contributes to nuclear export." Mol Cell Biol 21(24): 8521-8532.

Lu, X., B. Nannenga, et al. (2005). "PPM1D dephosphorylates Chk1 and p53 and abrogates cell cycle checkpoints." Genes Dev 19(10): 1162-1174.

Ludwig, T., D. L. Chapman, et al. (1997). "Targeted mutations of breast cancer susceptibility gene homologs in mice: lethal phenotypes of Brca1, Brca2, Brca1/Brca2, Brca1/p53, and Brca2/p53 nullizygous embryos." Genes Dev 11(10): 1226-1241.

Lukas, J., C. Lukas, et al. (2011). "More than just a focus: The chromatin response to DNA damage and its role in genome integrity maintenance." Nature cell biology 13(10): 1161-1169.

Macurek, L., A. Lindqvist, et al. (2010). "Wip1 phosphatase is associated with chromatin and dephosphorylates gammaH2AX to promote checkpoint inhibition." Oncogene 29(15): 2281-2291.

Magiera, M. M., S. Mora, et al. (2013). "Trim17-mediated ubiquitination and degradation of Mcl-1 initiate apoptosis in neurons." Cell Death Differ 20(2): 281-292.

Mailand, N., S. Bekker-Jensen, et al. (2007). "RNF8 ubiquitylates histones at DNA doublestrand breaks and promotes assembly of repair proteins." Cell 131(5): 887-900.

Mailand, N., J. Falck, et al. (2000). "Rapid destruction of human Cdc25A in response to DNA damage." Science 288(5470): 1425-1429.

Malatesta, M., A. Peschiaroli, et al. (2012). "The Cul4A-DDB1 E3 ubiquitin ligase complex represses p73 transcriptional activity." Oncogene.

Maltzman, W. and L. Czyzyk (1984). "UV irradiation stimulates levels of p53 cellular tumor antigen in nontransformed mouse cells." Mol Cell Biol 4(9): 1689-1694.

Mandic, A., J. Hansson, et al. (2003). "Cisplatin induces endoplasmic reticulum stress and nucleus-independent apoptotic signaling." J Biol Chem 278(11): 9100-9106.

Marnett, L. J. and J. P. Plastaras (2001). "Endogenous DNA damage and mutation." Trends Genet 17(4): 214-221.

Martin, K., D. Trouche, et al. (1995). "Stimulation of E2F1/DP1 transcriptional activity by MDM2 oncoprotein." Nature 375(6533): 691-694.

Martinez, L. A., E. Goluszko, et al. (2010). "E2F3 is a mediator of DNA damage-induced apoptosis." Mol Cell Biol 30(2): 524-536.

Matsuoka, S., B. Ballif, et al. (2007). "ATM and ATR substrate analysis reveals extensive protein networks responsive to DNA damage." Science (New York, N.Y.) 316(5828): 1160-1166.

Matsuoka, S., M. Huang, et al. (1998). "Linkage of ATM to cell cycle regulation by the Chk2 protein kinase." Science 282(5395): 1893-1897.

Matsuoka, S., G. Rotman, et al. (2000). "Ataxia telangiectasia-mutated phosphorylates Chk2 in vivo and in vitro." Proc Natl Acad Sci U S A 97(19): 10389-10394.

McNabb, D. S., R. Reed, et al. (2005). "Dual luciferase assay system for rapid assessment of gene expression in Saccharomyces cerevisiae." Eukaryot Cell 4(9): 1539-1549.

Meek, D. W. and C. W. Anderson (2009). "Posttranslational modification of p53: cooperative integrators of function." Cold Spring Harb Perspect Biol 1(6): a000950.

Meetei, A. R., J. P. de Winter, et al. (2003). "A novel ubiquitin ligase is deficient in Fanconi anemia." Nat Genet 35(2): 165-170. 
Meetei, A. R., A. L. Medhurst, et al. (2005). "A human ortholog of archaeal DNA repair protein Hef is defective in Fanconi anemia complementation group M." Nat Genet 37(9): 958963.

Meierhofer, D., X. Wang, et al. (2008). "Quantitative analysis of global ubiquitination in HeLa cells by mass spectrometry." J Proteome Res 7(10): 4566-4576.

Melino, G., F. Bernassola, et al. (2004). "p73 Induces apoptosis via PUMA transactivation and Bax mitochondrial translocation." J Biol Chem 279(9): 8076-8083.

Menendez, D., A. Inga, et al. (2009). "The expanding universe of p53 targets." Nature reviews. Cancer 9(10): 724-737.

Mihara, M., S. Erster, et al. (2003). "p53 has a direct apoptogenic role at the mitochondria." Mol Cell 11(3): 577-590.

Moldovan, G. L., B. Pfander, et al. (2007). "PCNA, the maestro of the replication fork." Cell 129(4): 665-679.

Moll, U. M., N. Marchenko, et al. (2006). "p53 and Nur77/TR3 - transcription factors that directly target mitochondria for cell death induction." Oncogene 25(34): 4725-4743.

Momand, J., D. Jung, et al. (1998). "The MDM2 gene amplification database." Nucleic Acids Res 26(15): 3453-3459.

Momand, J., G. P. Zambetti, et al. (1992). "The mdm-2 oncogene product forms a complex with the p53 protein and inhibits p53-mediated transactivation." Cell 69(7): 1237-1245.

Montes de Oca Luna, R., D. S. Wagner, et al. (1995). "Rescue of early embryonic lethality in mdm2-deficient mice by deletion of p53." Nature 378(6553): 203-206.

Mullis, K. B. and F. A. Faloona (1987). "Specific synthesis of DNA in vitro via a polymerasecatalyzed chain reaction." Methods Enzymol 155: 335-350.

Murphy, M., M. G. Stinnakre, et al. (1997). "Delayed early embryonic lethality following disruption of the murine cyclin A2 gene." Nat Genet 15(1): 83-86.

Musselman, C. A. and T. G. Kutateladze (2011). "Handpicking epigenetic marks with PHD fingers." Nucleic acids research 39.

Myers, K., M. E. Gagou, et al. (2009). "ATR and Chk1 suppress a caspase-3-dependent apoptotic response following DNA replication stress." PLoS Genet 5(1): e1000324.

Nakada, S., G. I. Chen, et al. (2008). "PP4 is a gamma H2AX phosphatase required for recovery from the DNA damage checkpoint." EMBO Rep 9(10): 1019-1026.

Nakano, K. and K. H. Vousden (2001). "PUMA, a novel proapoptotic gene, is induced by p53." Mol Cell 7(3): 683-694.

Nakayama, K. and K. Nakayama (2006). "Ubiquitin ligases: cell-cycle control and cancer." Nature reviews. Cancer 6(5): 369-381.

Negrini, S., V. G. Gorgoulis, et al. (2010). "Genomic instability--an evolving hallmark of cancer." Nat Rev Mol Cell Biol 11(3): 220-228.

Neutzner, A., M. Neutzner, et al. (2011). "A systematic search for endoplasmic reticulum (ER) membrane-associated RING finger proteins identifies Nixin/ZNRF4 as a regulator of calnexin stability and ER homeostasis." J Biol Chem 286(10): 8633-8643.

Nicolaou, K. C., A. L. Smith, et al. (1993). "Chemistry and biology of natural and designed enediynes." Proc Natl Acad Sci U S A 90(13): 5881-5888.

Niedernhofer, L., A. Lalai, et al. (2005). "Fanconi anemia (cross)linked to DNA repair." Cell 123(7): 1191-1198.

Nijman, S. M., T. T. Huang, et al. (2005). "The deubiquitinating enzyme USP1 regulates the Fanconi anemia pathway." Mol Cell 17(3): 331-339.

O'Brate, A. and P. Giannakakou (2003). "The importance of p53 location: nuclear or cytoplasmic zip code?" Drug Resist Updat 6(6): 313-322.

Oliver, T., E. Meylan, et al. (2011). "Caspase-2-mediated cleavage of Mdm2 creates a p53induced positive feedback loop." Molecular cell 43(1): 57-71.

Olson, D. C., V. Marechal, et al. (1993). "Identification and characterization of multiple mdm-2 proteins and mdm-2-p53 protein complexes." Oncogene 8(9): 2353-2360. 
Paulsen, R., D. Soni, et al. (2009). "A genome-wide siRNA screen reveals diverse cellular processes and pathways that mediate genome stability." Molecular cell 35(2): 228239.

Pochampally, R., B. Fodera, et al. (1999). "Activation of an MDM2-specific caspase by p53 in the absence of apoptosis." J Biol Chem 274(21): 15271-15277.

Polager, S. and D. Ginsberg (2009). "p53 and E2f: partners in life and death." Nature reviews. Cancer 9(10): 738-748.

Prelich, G., C. K. Tan, et al. (1987). "Functional identity of proliferating cell nuclear antigen and a DNA polymerase-delta auxiliary protein." Nature 326(6112): 517-520.

Qin, B., B. Gao, et al. (2013). "Ataxia Telangiectasia-mutated- and Rad3-related Protein Regulates the DNA Damage-induced G2/M Checkpoint through the Aurora A Cofactor Bora Protein." J Biol Chem 288(22): 16139-16144.

Rabik, C. A. and M. E. Dolan (2007). "Molecular mechanisms of resistance and toxicity associated with platinating agents." Cancer Treat Rev 33(1): 9-23.

Racek, T., N. Mise, et al. (2005). "C-terminal p73 isoforms repress transcriptional activity of the human telomerase reverse transcriptase (hTERT) promoter." J Biol Chem 280(49): 40402-40405.

Reinhardt, H. and M. Yaffe (2009). "Kinases that control the cell cycle in response to DNA damage: Chk1, Chk2, and MK2." Current opinion in cell biology 21(2): 245-255.

Reinhardt, H. C., A. S. Aslanian, et al. (2007). "p53-deficient cells rely on ATM- and ATRmediated checkpoint signaling through the p38MAPK/MK2 pathway for survival after DNA damage." Cancer cell 11(2): 175-189.

Renart, J., J. Reiser, et al. (1979). "Transfer of proteins from gels to diazobenzyloxymethylpaper and detection with antisera: a method for studying antibody specificity and antigen structure." Proc Natl Acad Sci U S A 76(7): 3116-3120.

Ringshausen, I., C. C. O'Shea, et al. (2006). "Mdm2 is critically and continuously required to suppress lethal p53 activity in vivo." Cancer cell 10(6): 501-514.

Rogakou, E., W. Nieves-Neira, et al. (2000). "Initiation of DNA fragmentation during apoptosis induces phosphorylation of $\mathrm{H} 2 \mathrm{AX}$ histone at serine 139." The Journal of biological chemistry 275(13): 9390-9395.

Rogakou, E. P., C. Boon, et al. (1999). "Megabase chromatin domains involved in DNA double-strand breaks in vivo." J Cell Biol 146(5): 905-916.

Rogakou, E. P., D. R. Pilch, et al. (1998). "DNA double-stranded breaks induce histone H2AX phosphorylation on serine 139." J Biol Chem 273(10): 5858-5868.

Rosenberg, B., L. VanCamp, et al. (1969). "Platinum compounds: a new class of potent antitumour agents." Nature 222(5191): 385-386.

Rotin, D. and S. Kumar (2009). "Physiological functions of the HECT family of ubiquitin ligases." Nat Rev Mol Cell Biol 10(6): 398-409.

Ruwanpura, S. M., R. I. McLachlan, et al. (2010). "Hormonal regulation of male germ cell development." J Endocrinol 205(2): 117-131.

Sadhu, K., S. I. Reed, et al. (1990). "Human homolog of fission yeast cdc25 mitotic inducer is predominantly expressed in G2." Proc Natl Acad Sci U S A 87(13): 5139-5143.

Saintigny, Y., F. Delacote, et al. (2001). "Characterization of homologous recombination induced by replication inhibition in mammalian cells." Embo J 20(14): 3861-3870.

Saito, S., A. A. Goodarzi, et al. (2002). "ATM mediates phosphorylation at multiple p53 sites, including Ser(46), in response to ionizing radiation." J Biol Chem 277(15): 1249112494.

Sanchez, Y., C. Wong, et al. (1997). "Conservation of the Chk1 checkpoint pathway in mammals: linkage of DNA damage to Cdk regulation through Cdc25." Science 277(5331): 1497-1501.

Sanger, F., S. Nicklen, et al. (1977). "DNA sequencing with chain-terminating inhibitors." Proc Natl Acad Sci U S A 74(12): 5463-5467. 
Saucedo, L. J., C. D. Myers, et al. (1999). "Multiple murine double minute gene 2 (MDM2) proteins are induced by ultraviolet light." J Biol Chem 274(12): 8161-8168.

Savitsky, K., A. Bar-Shira, et al. (1995). "A single ataxia telangiectasia gene with a product similar to PI-3 kinase." Science 268(5218): 1749-1753.

Scaglione, K. M., E. Zavodszky, et al. (2011). "Ube2w and ataxin-3 coordinately regulate the ubiquitin ligase CHIP." Mol Cell 43(4): 599-612.

Scheffner, M., J. M. Huibregtse, et al. (1993). "The HPV-16 E6 and E6-AP complex functions as a ubiquitin-protein ligase in the ubiquitination of p53." Cell 75(3): 495-505.

Scheffner, M., B. A. Werness, et al. (1990). "The E6 oncoprotein encoded by human papillomavirus types 16 and 18 promotes the degradation of p53." Cell 63(6): 11291136.

Scheuermann, J. C., A. G. de Ayala Alonso, et al. (2010). "Histone H2A deubiquitinase activity of the Polycomb repressive complex PR-DUB." Nature 465(7295): 243-247.

Schulman, B. A. and J. W. Harper (2009). "Ubiquitin-like protein activation by E1 enzymes: the apex for downstream signalling pathways." Nat Rev Mol Cell Biol 10(5): 319-331.

Sdek, P., H. Ying, et al. (2005). "MDM2 promotes proteasome-dependent ubiquitinindependent degradation of retinoblastoma protein." Mol Cell 20(5): 699-708.

Shanbhag, N. M., I. U. Rafalska-Metcalf, et al. (2010). "ATM-dependent chromatin changes silence transcription in cis to DNA double-strand breaks." Cell 141(6): 970-981.

Shao, G., D. Lilli, et al. (2009). "The Rap80-BRCC36 de-ubiquitinating enzyme complex antagonizes RNF8-Ubc13-dependent ubiquitination events at DNA double strand breaks." Proceedings of the National Academy of Sciences of the United States of America 106(9): 3166-3171.

Shapiro, A. L., E. Vinuela, et al. (1967). "Molecular weight estimation of polypeptide chains by electrophoresis in SDS-polyacrylamide gels." Biochem Biophys Res Commun 28(5): 815-820.

Sharp, D. A., S. A. Kratowicz, et al. (1999). "Stabilization of the MDM2 oncoprotein by interaction with the structurally related MDMX protein." J Biol Chem 274(53): 3818938196.

Sherr, C. (2006). "Divorcing ARF and p53: an unsettled case." Nature reviews. Cancer 6(9): 663-673.

Shi, W., A. Stampas, et al. (2003). "The pineapple eye gene is required for survival of Drosophila imaginal disc cells." Genetics 165(4): 1869-1879.

Shiotani, B. and L. Zou (2009). "Single-stranded DNA orchestrates an ATM-to-ATR switch at DNA breaks." Mol Cell 33(5): 547-558.

Shreeram, S., O. N. Demidov, et al. (2006). "Wip1 phosphatase modulates ATM-dependent signaling pathways." Mol Cell 23(5): 757-764.

Simons, A., C. Melamed-Bessudo, et al. (1997). "PACT: cloning and characterization of a cellular p53 binding protein that interacts with Rb." Oncogene 14(2): 145-155.

Smith, A. L. and K. C. Nicolaou (1996). "The enediyne antibiotics." J Med Chem 39(11): 2103-2117.

Smogorzewska, A., S. Matsuoka, et al. (2007). "Identification of the FANCl protein, a monoubiquitinated FANCD2 paralog required for DNA repair." Cell 129(2): 289-301.

Solier, S., O. Sordet, et al. (2009). "Death receptor-induced activation of the Chk2- and histone H2AX-associated DNA damage response pathways." Mol Cell Biol 29(1): 6882.

Stad, R., Y. F. Ramos, et al. (2000). "Hdmx stabilizes Mdm2 and p53." J Biol Chem 275(36): 28039-28044.

Stevenson, L. F., A. Sparks, et al. (2007). "The deubiquitinating enzyme USP2a regulates the p53 pathway by targeting Mdm2." Embo J 26(4): 976-986.

Stiff, T., M. O'Driscoll, et al. (2004). "ATM and DNA-PK function redundantly to phosphorylate H2AX after exposure to ionizing radiation." Cancer Res 64(7): 2390-2396. 
Stommel, J. and G. Wahl (2004). "Accelerated MDM2 auto-degradation induced by DNAdamage kinases is required for p53 activation." The EMBO journal 23(7): 1547-1556.

Stommel, J. M. and G. M. Wahl (2005). "A new twist in the feedback loop: stress-activated MDM2 destabilization is required for p53 activation." Cell Cycle 4(3): 411-417.

Strasser, A., A. W. Harris, et al. (1994). "DNA damage can induce apoptosis in proliferating lymphoid cells via p53-independent mechanisms inhibitable by Bcl-2." Cell 79(2): 329339.

Stucki, M., J. A. Clapperton, et al. (2005). "MDC1 directly binds phosphorylated histone H2AX to regulate cellular responses to DNA double-strand breaks." Cell 123(7): 1213-1226.

Stucki, M. and S. P. Jackson (2006). "gammaH2AX and MDC1: anchoring the DNA-damageresponse machinery to broken chromosomes." DNA Repair (Amst) 5(5): 534-543.

Suzuki, Y., Y. Nakabayashi, et al. (2001). "Ubiquitin-protein ligase activity of X-linked inhibitor of apoptosis protein promotes proteasomal degradation of caspase-3 and enhances its anti-apoptotic effect in Fas-induced cell death." Proc Natl Acad Sci U S A 98(15): 8662-8667.

Takahashi, T., T. Yamaguchi, et al. (1993). "Follow-up study of patients treated with monoclonal antibody-drug conjugate: report of 77 cases with colorectal cancer." Jpn J Cancer Res 84(9): 976-981.

Takekawa, M., M. Adachi, et al. (2000). "p53-inducible wip1 phosphatase mediates a negative feedback regulation of p38 MAPK-p53 signaling in response to UV radiation." Embo J 19(23): 6517-6526.

Tan, M., J. R. Gallegos, et al. (2006). "SAG/ROC-SCF beta-TrCP E3 ubiquitin ligase promotes pro-caspase-3 degradation as a mechanism of apoptosis protection." Neoplasia 8(12): 1042-1054.

Tanimura, S., S. Ohtsuka, et al. (1999). "MDM2 interacts with MDMX through their RING finger domains." FEBS Lett 447(1): 5-9.

Taylor, R. C., S. P. Cullen, et al. (2008). "Apoptosis: controlled demolition at the cellular level." Nat Rev Mol Cell Biol 9(3): 231-241.

Taylor, W. and G. Stark (2001). "Regulation of the G2/M transition by p53." Oncogene 20(15): 1803-1815.

Taylor, W. R. and G. R. Stark (2001). "Regulation of the G2/M transition by p53." Oncogene 20(15): 1803-1815.

Thorpe, G. H., L. J. Kricka, et al. (1985). "Phenols as enhancers of the chemiluminescent horseradish peroxidase-luminol-hydrogen peroxide reaction: application in luminescence-monitored enzyme immunoassays." Clin Chem 31(8): 1335-1341.

Tibbetts, R. S., K. M. Brumbaugh, et al. (1999). "A role for ATR in the DNA damage-induced phosphorylation of p53." Genes Dev 13(2): 152-157.

Tomita, Y., N. Marchenko, et al. (2006). "WT p53, but not tumor-derived mutants, bind to Bcl2 via the DNA binding domain and induce mitochondrial permeabilization." J Biol Chem 281(13): 8600-8606.

Tovar, C., J. Rosinski, et al. (2006). "Small-molecule MDM2 antagonists reveal aberrant p53 signaling in cancer: implications for therapy." Proc Natl Acad Sci U S A 103(6): 18881893.

Towbin, H., T. Staehelin, et al. (1979). "Electrophoretic transfer of proteins from polyacrylamide gels to nitrocellulose sheets: procedure and some applications." Proc Natl Acad Sci U S A 76(9): 4350-4354.

Tsuzuki, T., Y. Fujii, et al. (1996). "Targeted disruption of the Rad51 gene leads to lethality in embryonic mice." Proc Natl Acad Sci U S A 93(13): 6236-6240.

Tyagi, S., K. Bhui, et al. (2010). "Polo-like kinase1 (Plk1) knockdown enhances cisplatin chemosensitivity via up-regulation of p73alpha in p53 mutant human epidermoid squamous carcinoma cells." Biochem Pharmacol 80(9): 1326-1334. 
Ulrich, H. D. and H. Walden (2010). "Ubiquitin signalling in DNA replication and repair." Nat Rev Mol Cell Biol 11(7): 479-489.

Unsal-Kacmaz, K. and A. Sancar (2004). "Quaternary structure of ATR and effects of ATRIP and replication protein A on its DNA binding and kinase activities." Mol Cell Biol 24(3): 1292-1300.

Urist, M., T. Tanaka, et al. (2004). "p73 induction after DNA damage is regulated by checkpoint kinases Chk1 and Chk2." Genes Dev 18(24): 3041-3054.

Van Dilla, M. A., T. T. Trujillo, et al. (1969). "Cell microfluorometry: a method for rapid fluorescence measurement." Science 163(3872): 1213-1214.

van Leuken, R. J., M. P. Luna-Vargas, et al. (2008). "Usp39 is essential for mitotic spindle checkpoint integrity and controls mRNA-levels of aurora B." Cell Cycle 7(17): 27102719.

van Vugt, M. A., V. A. Smits, et al. (2001). "Inhibition of Polo-like kinase-1 by DNA damage occurs in an ATM- or ATR-dependent fashion." J Biol Chem 276(45): 41656-41660.

Varanasi, L., P. M. Do, et al. (2012). "Rad18 is a transcriptional target of E2F3." Cell Cycle 11(6): 1131-1141.

Vasquez, K. M. (2010). "Targeting and processing of site-specific DNA interstrand crosslinks." Environ Mol Mutagen 51(6): 527-539.

Voorhees, P. M., E. C. Dees, et al. (2003). "The proteasome as a target for cancer therapy." Clin Cancer Res 9(17): 6316-6325.

Vousden, K. H. (2006). "Outcomes of p53 activation--spoilt for choice." J Cell Sci 119(Pt 24): 5015-5020.

Vucic, D., V. Dixit, et al. (2011). "Ubiquitylation in apoptosis: a post-translational modification at the edge of life and death." Nature reviews. Molecular cell biology 12(7): 439-452.

Waldman, T., K. W. Kinzler, et al. (1995). "p21 is necessary for the p53-mediated G1 arrest in human cancer cells." Cancer Res 55(22): 5187-5190.

Wang, X. W., Q. Zhan, et al. (1999). "GADD45 induction of a G2/M cell cycle checkpoint." Proc Natl Acad Sci U S A 96(7): 3706-3711.

Ward, I. M. and J. Chen (2001). "Histone H2AX is phosphorylated in an ATR-dependent manner in response to replicational stress." J Biol Chem 276(51): 47759-47762.

Ward, I. M., K. Minn, et al. (2004). "UV-induced ataxia-telangiectasia-mutated and Rad3related (ATR) activation requires replication stress." J Biol Chem 279(11): 9677-9680.

Weber, J. D., L. J. Taylor, et al. (1999). "Nucleolar Arf sequesters Mdm2 and activates p53." Nat Cell Biol 1(1): 20-26.

Wee, L. J., T. W. Tan, et al. (2006). "SVM-based prediction of caspase substrate cleavage sites." BMC Bioinformatics 7 Suppl 5: S14.

Wee, L. J., T. W. Tan, et al. (2007). "CASVM: web server for SVM-based prediction of caspase substrates cleavage sites." Bioinformatics 23(23): 3241-3243.

Werness, B. A., A. J. Levine, et al. (1990). "Association of human papillomavirus types 16 and 18 E6 proteins with p53." Science 248(4951): 76-79.

Willis, S. N., J. I. Fletcher, et al. (2007). "Apoptosis initiated when BH3 ligands engage multiple Bcl-2 homologs, not Bax or Bak." Science 315(5813): 856-859.

Wu, X., J. H. Bayle, et al. (1993). "The p53-mdm-2 autoregulatory feedback loop." Genes Dev 7(7A): 1126-1132.

Xeros, N. (1962). "Deoxyriboside control and synchronization of mitosis." Nature 194: 682683.

Xia, Y., R. C. Padre, et al. (2009). "Phosphorylation of p53 by lkappaB kinase 2 promotes its degradation by beta-TrCP." Proc Natl Acad Sci U S A 106(8): 2629-2634.

Xiao, Z. X., J. Chen, et al. (1995). "Interaction between the retinoblastoma protein and the oncoprotein MDM2." Nature 375(6533): 694-698.

Xing, Y., I. Kurtz, et al. (2012). "Loss-of-Function Screen Reveals Novel Regulators Required for Drosophila Germline Stem Cell Self-Renewal." G3 (Bethesda, Md.) 2(3): 343-351. 
Xiong, L., F. Kou, et al. (2007). "A novel role for IGF-1R in p53-mediated apoptosis through translational modulation of the p53-Mdm2 feedback loop." J Cell Biol 178(6): 9951007.

Yang, A., M. Kaghad, et al. (1998). "p63, a p53 homolog at 3q27-29, encodes multiple products with transactivating, death-inducing, and dominant-negative activities." Mol Cell 2(3): 305-316.

Yang, J. and S. Kornbluth (1999). "All aboard the cyclin train: subcellular trafficking of cyclins and their CDK partners." Trends Cell Biol 9(6): 207-210.

Yang, J. Y., C. S. Zong, et al. (2006). "MDM2 promotes cell motility and invasiveness by regulating E-cadherin degradation." Mol Cell Biol 26(19): 7269-7282.

Yang, X. L. and A. H. Wang (1999). "Structural studies of atom-specific anticancer drugs acting on DNA." Pharmacol Ther 83(3): 181-215.

Ye, Y. and M. Rape (2009). "Building ubiquitin chains: E2 enzymes at work." Nat Rev Mol Cell Biol 10(11): 755-764.

Yuan, J., K. Luo, et al. (2010). "USP10 regulates p53 localization and stability by deubiquitinating p53." Cell 140(3): 384-396.

Zamble, D. B., D. Mu, et al. (1996). "Repair of cisplatin--DNA adducts by the mammalian excision nuclease." Biochemistry 35(31): 10004-10013.

Zhan, Q., M. J. Antinore, et al. (1999). "Association with Cdc2 and inhibition of Cdc2/Cyclin B1 kinase activity by the p53-regulated protein Gadd45." Oncogene 18(18): 28922900.

Zhang, Q., Y. Meng, et al. (2009). "RNF13: a novel RING-type ubiquitin ligase overexpressed in pancreatic cancer." Cell Res 19(3): 348-357.

Zhang, Z., H. Wang, et al. (2005). "Stabilization of E2F1 protein by MDM2 through the E2F1 ubiquitination pathway." Oncogene 24(48): 7238-7247.

Zhao, H. and H. Piwnica-Worms (2001). "ATR-mediated checkpoint pathways regulate phosphorylation and activation of human Chk1." Mol Cell Biol 21(13): 4129-4139.

Zhou, X., J. M. Liao, et al. (2012). "Scission of the p53-MDM2 Loop by Ribosomal Proteins." Genes Cancer 3(3-4): 298-310.

Zhu, H., H. O. Fearnhead, et al. (1995). "An ICE-like protease is a common mediator of apoptosis induced by diverse stimuli in human monocytic THP.1 cells." FEBS Lett 374(2): 303-308.

Zhuang, M., S. Guan, et al. (2013). "Substrates of IAP ubiquitin ligases identified with a designed orthogonal E3 ligase, the NEDDylator." Mol Cell 49(2): 273-282.

Zorbas, H. and B. K. Keppler (2005). "Cisplatin damage: are DNA repair proteins saviors or traitors to the cell?" Chembiochem 6(7): 1157-1166.

Zou, L. and S. J. Elledge (2003). "Sensing DNA damage through ATRIP recognition of RPAssDNA complexes." Science 300(5625): 1542-1548.

\section{Further references:}

Ann-Christine Loock (2012). Bachelor thesis „Associations of the oncogenic ubiquitin ligase Mdm2", University of Göttingen.

BD Pathway 800 Series User's Manual - AttoVision 1.5 (May 2006), BD Biosciences, 15010 Broschart Road, Rockville, MD 20876, USA. 